\title{
Eduardo Tomanik
}

\section{Modelamento do Desgaste por Deslizamento em Anéis de Pistão de Motores de Combustão Interna}

Tese apresentada à Escola Politécnica da Universidade de São Paulo para obtenção do título de Doutor em Engenharia.

Área de Concentração:

Engenharia Mecânica

Orientador:

Francisco Emílio Baccaro Nigro

São Paulo

julho 2000 


\section{SUMÁRIO}

\section{NOMENCLATURA \\ LISTA DE FIGURAS \\ LISTA DE TABELAS \\ RESUMO / "ABSTRACT"}

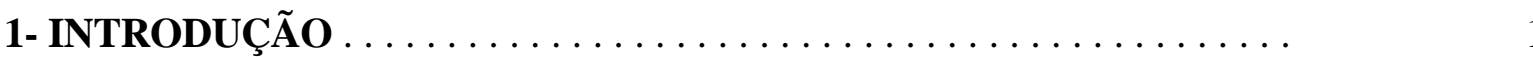

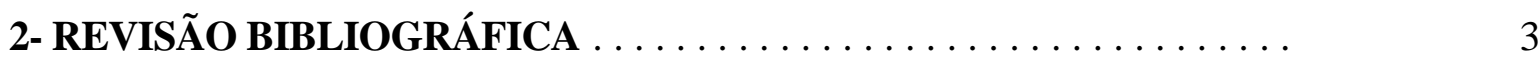

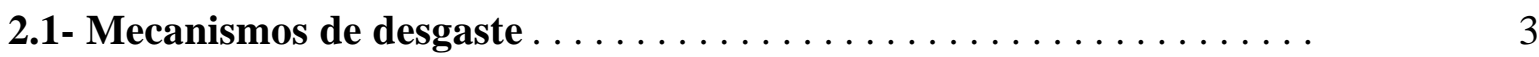

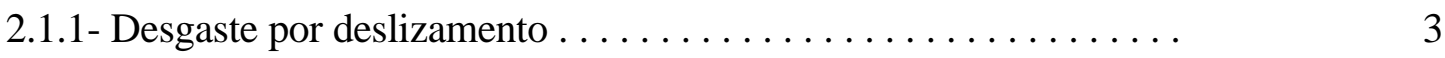

2.1.2- Desgaste abrasivo . . . . . . . . . . . . . . . . . . . . . 8

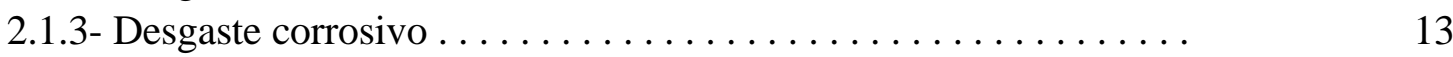

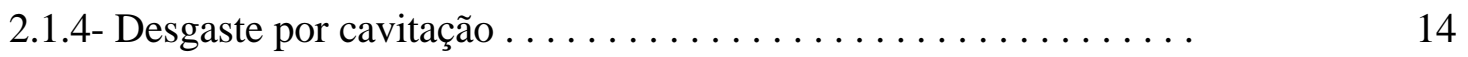

2.1.5- Desgaste por fadiga de contato . . . . . . . . . . . . . . 15

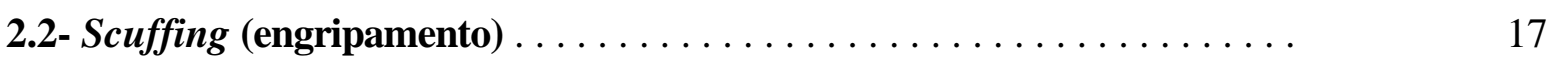

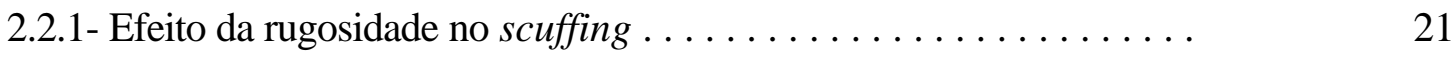

2.3- Desgaste em anéis . . . . . . . . . . . . . 23

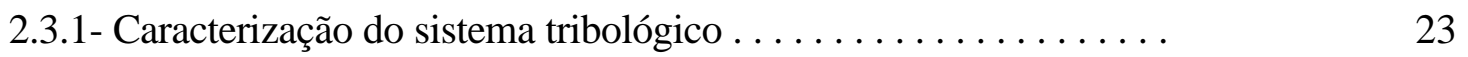

2.3.2- Métodos de medição do desgaste ................... 24

2.3.3- Desgaste do cilindro . . . . . . . . . . . . . . . . . 28

2.3.4- Taxas de desgaste e influências no desgaste de anéis ......... 30

2.4- Contato entre superfícies rugosas $\ldots \ldots \ldots \ldots \ldots \ldots \ldots \ldots \ldots \ldots$

2.4.1- Modelo de Hertz para o contato de uma esfera contra plano . . . . . 37

2.4.2- Modelo de Greenwood-Williamson . . . . . . . . . . . . 40

2.4.3- Contatos plásticos segundo o modelo de Greenwood-Williamson. $\quad 47$

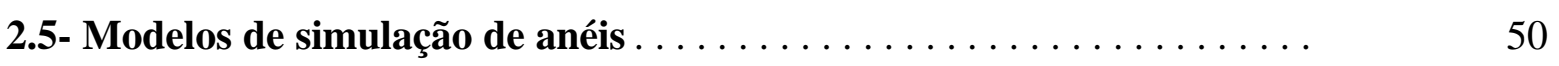

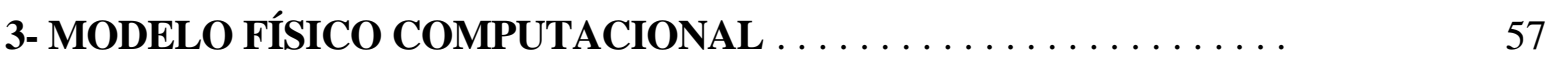

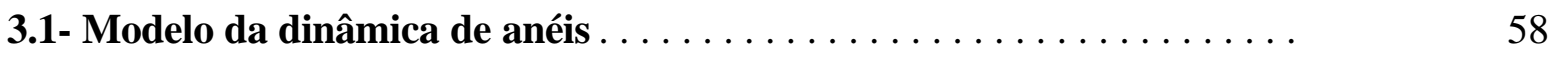

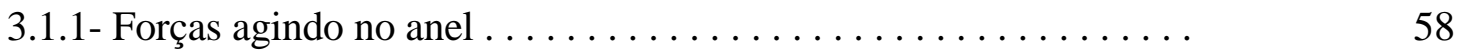

3.1.2- Movimento do anel .................... 75

3.2- Geometria instantânea do contato anel - cilindro . . . . . . . . . 78

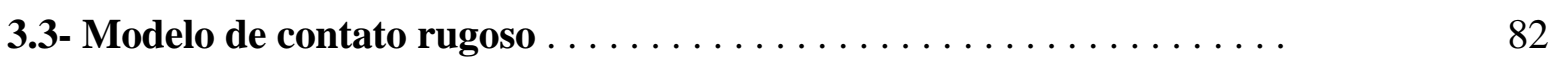

3.3.1.- Exemplo Numérico . . . . . . . . . . . . . . . . 89 


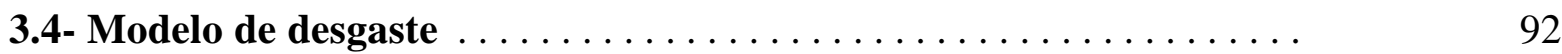

3.4.1- Mecanismo de desgaste atuante em anéis de pistão . . . . . . . 92

3.4.2- Cálculo da evolução do perfil desgastado . . . . . . . . . . 97

3.4.3- Desgaste do cilindro . . . . . . . . . . . . . . . . . . . . 103

4- PROGRAMA COMPUTACIONAL $\ldots \ldots \ldots \ldots \ldots \ldots \ldots \ldots \ldots$

4.1- Estudos de sensibilidade . . . . . . . . . . . . . . . . . . . . . 111

5- APLICAÇÃO DO MODELO PARA UM CASO EXPERIMENTAL . . . 114

5.1- Dados do motor . . . . . . . . . . . . . . . . . . . . . . 114

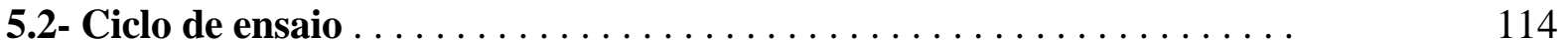

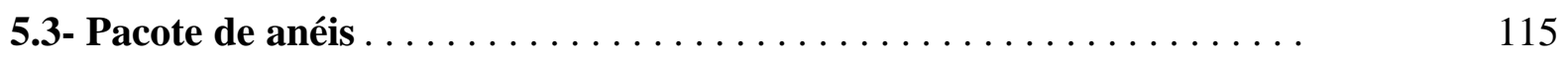

5.4- Cilindro . . . . . . . . . . . . . . . . . . . . . . . . . . . 120

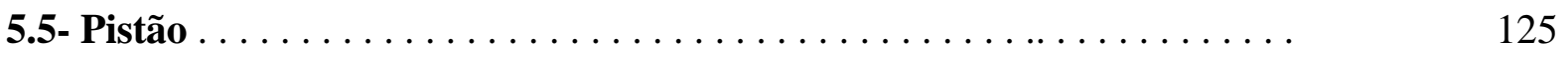

5.6- Valores medidos de desgaste . . . . . . . . . . . . . . . . 130

5.7- Resultados calculados pelo modelo . . . . . . . . . . . . . . . . . . . 140

5.7.1- Anel de $1^{\circ}$ canalete . . . . . . . . . . . . . . . . . . 141

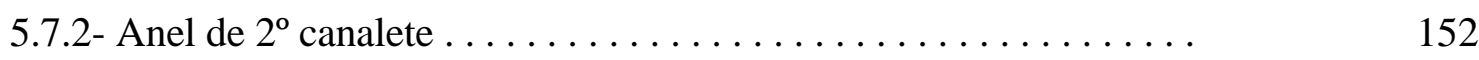

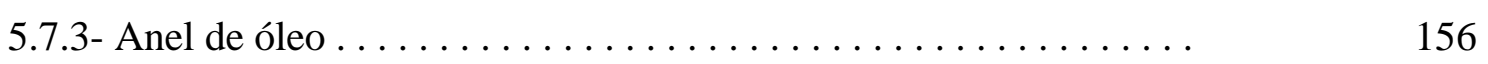

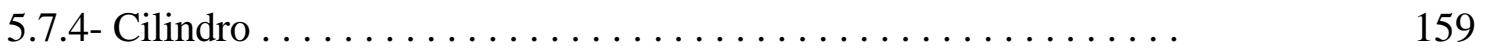

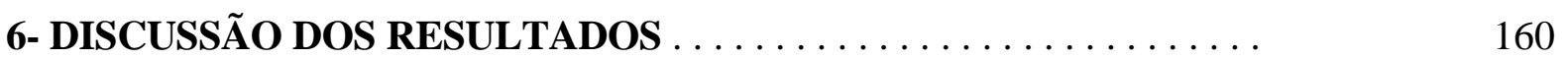

7- CONCLUSÕES E SUGESTÕES PARA TRABALHOS FUTUROS . . 169

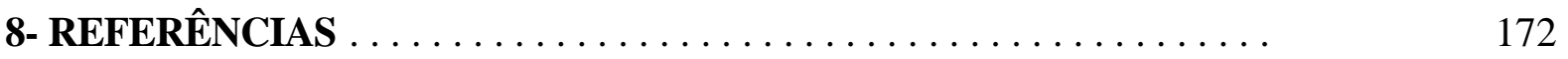

ANEXO I- COEFICIENTE DE DESGASTE

ANEXO II- DADOS DE ENTRADA PARA O MODELO DE GREENWOOD

ANEXO III- PROGRAMA FONTE PARA CÁLCULO DAS PRESSÕES RUGOSAS E SUBROTINAS DE ACUMULO DE DANO E REMOÇÃO DE MATERIAL 


\section{Nomenclatura}

$\mathrm{A}_{0}$ : área aparente de contato [m2]

$\mathrm{A}_{\mathrm{c}}$ : área real de contato [m2]

$\mathrm{A}_{\mathrm{p}}$ : área real de contato plástico [m2]

b: altura do anel [m]

Di, di: dano [adimensional]

Dn: diâmetro nominal do cilindro [m]

E: módulo de Elasticidade ou de Young [GPa]

$\mathrm{F}$ : força $[\mathrm{N}]$

$F_{0}(t), F_{1}(t), F_{3 / 2}(t), F_{5 / 2}(t)$ : integrais do modelo de Greenwood

gap: folga entre pontas do anel [m]

Hm: espessura do filme de óleo, no ponto de menor separação [m]

$\mathrm{K}$ : coeficiente adimensional de desgaste

$\mathrm{k}$ : coeficiente dimensional de desgaste [mm3 . (N.m)-1]

$\mathrm{P}$ : pressão [Pa]

$\mathrm{Ph}$ : pressão hidrodinâmica [Pa]

Pgw: pressão de contato rugoso $[\mathrm{Pa}]$

t: razão separação das superfícies / rugosidade combinada [adimensional]

Y: Limite de Escoamento uni-direcional do material (GPa)

\section{Letras Gregas:}

) : variação

: : viscosidade dinâmica [Pa.s]

8: ângulo de torção do anel [graus]

7: parâmetro de filme, razão F/espessura do filme de óleo [adimensional]

$<$ coeficiente de Poisson [adimensional, 0,0 a 1,0]

0 : densidade de asperezas por unidade de area [m-2]

\$: raio do pico das asperezas [m], admitido constante no modelo de GW

$\mathrm{F}$ : desvio padrão da distribuição combinada das alturas (z) dos picos das asperezas [m]

\section{Subscritos:}

ax: na direção axial

gas: relativo aos gases

p: pistão

\section{Abreviações}

ATS: “Anti-Thrust Side", lado oposto ao de maior pressão do pistão e lado correspondente do cilindro

GNS: "Gas Nitrided Steel”, aço nitretado a gás

G-W: Greenwood e Williamson (modelo de contato entre superfícies rugosas)

MCI: Motor (es) de Combustão Interna

MEV: Microscópio Eletrônico de Varredura

PMI: Ponto Morto Inferior

PMS: Ponto Morto Superior

PVD: "Physical Vapor Deposition"

TS: “Thrust Side", lado de maior pressão do pistão e lado correspondente do cilindro 


\section{LISTA DE FIGURAS}

Fig.2.1- Taxa de desgaste e resistência elétrica de contato para um pino de bronze deslizando contra um anel duro de stelita. HIRST apud HUTCHINGS (1992).

Fig.2.2- Mecanismos de desgaste por abrasão. ZUM GARH apud VATAVUK (1994).

Fig.2.3- Riscos de desgaste sendo interrompidos por carbonetos de Nióbio na face de contato de um anel de Ferro Fundido. VATAVUK (1994).

Fig.2.4- Taxa de desgaste em função da razão da dureza do abrasivo / dureza da superfície $\left(\mathrm{H}_{\mathrm{a}} / \mathrm{H}_{\mathrm{s}}\right)$, para abrasão a 2 corpos. MOORE apud HUTCHINGS (1992)

Fig.2.5- Superfície de um cilindro que rodou com combustível com alto teor de enxofre. VATAVUK (1994)

Fig.2.6- Teoria da deformação plástica para a ocorrência de scuffing.

Fig.2.7- Scuffing em anéis de aço provocado por micro-trincas. Motor diesel, $1500 \mathrm{~h}$ de teste. YOSHIDA et al, 1997.

Fig.2.8- Efeito da rugosidade na resistência ao "scuffing". Ensaio de bancada, anéis de aço nitretado revestidos com $\mathrm{CrN}$ atritando contra ferro fundido.

YOSHIDA, 1990.

Fig.2.9- Evolução do perfil e da área de contato ("bearing area") em função do número de horas de ensaio. TOMANIK \& GALVANO, 1998.

Fig.2.10- Perfis de rugosidade de um cilindro novo e após 200 horas de ensaio em dinamômetro. Motor a gasolina. DEMARCHI, 1994.

Fig.2.11- Influência do modo de dirigir no desgaste de anéis, motores a gasolina. THOM et al, 1995.

Fig. 2.12- Influência do óleo no desgaste de anéis e cilindro. Motor Diesel automotivo. THOM et al, 1995.

Fig.2.13- Perfis desgastados da face de contato do anel. STECHER (s.d.)

Fig.2.14- Modelo de Hertz, esfera contra um plano rígido.

Fig.2.15- Representação esquemática do contato entre uma superfície rugosa e um plano rígido. Modelo de Greenwood e Williamson.

Fig.2.16- Aspereza idealizada, ilustrando a diferença entre o topo da aspereza ("summit") e os possíveis picos ("peaks") registrados num perfil de rugosidade. 
Fig.2.17- Distribuição da altura das asperezas plotada num gráfico de probabilidade normal. WHITEHOUSE, 1994.

Fig.2.18 - Probabilidade de que um pico tenha altura maior que a distância de separação $(d)$, ou seja, que faça contato. $\left(t=d / \mathrm{F}_{\mathrm{s}}\right)$. Valores tabelados por McCOOL, 1986.

Fig.2.19- Perfil da face do anel e produto da pressão de contato rugoso pela velocidade tangencial ("Wear Load"). Anel de $2^{\circ}$ canalete, topo à direita. GULWADY, 1997.

Fig.2.20- Desgaste do anel/canalete. Anel de $1^{\circ}$ canalete, motor diesel automotivo. TIAN $(1997 \mathrm{a}, \mathrm{b})$

Fig.3.1- Modelo esquemático do fluxo de gases por orifícios.

Fig.3.2- Pressão hidrodinâmica na face de contato do anel.

Fig.3.3- Fluxograma do cálculo das pressões atuantes na face de contato do anel.

Fig.3.4- Discretização da face de contato.

Fig.3.5- Viscosidade em função da temperatura.

Fig.3.6- Exemplo de pressões hidrodinâmicas e de contato rugoso sem e com correção da viscosidade pela pressão.

Fig.3.7- Curva de Stribeck

Fig.3.8- Cinemática do pistão.

Fig.3.9- Parcelas do ângulo que a face de contato faz com a parede do cilindro.

Fig.3.10- Modelo simplificado para cálculo da torção do anel.

Fig.3.11- Máximo ângulo de torção do anel.

Fig.3.12- Esquema da determinação das propriedades do cilindro que todos os pontos i do anel "percebem" num determinado instante, onde $\mathrm{G}_{\mathrm{j}}$ é por ex. a rugosidade ou a dureza do cilindro no ponto $\mathrm{j}$.

Fig.3.13- Comparação entre as aproximações para $\mathrm{F}_{5 / 2}(\mathrm{t})$ de $\mathrm{HU}$ et al, 1994 (Hu) e de ARCOUMANIS et al, 1997 (Arc) com os valores tabelados em GREENWOOD e TRIPP, 1971 (G-T).

Fig.3.14- Comparação das pressões geradas pelo modelos de G-W e G-T. 
Fig.3.15- Cálculo das pressões rugosas e hidrodinâmicas segundos os modelos de G-W e G-T para um determinado caso de anel.

Fig.3.16- Face de contato do $1^{\circ}$ anel, cromado, motor a gasolina após 80 horas de ensaio em dinamômetro.

Fig.3.17- Anel de $1^{\circ}$ canalete, aço nitretado, após $250 \mathrm{~h}$ de ensaio em motor diesel. A área clara é a região que se desgastou, mostrada em maior aumento à direita. A região escura, com riscos verticais ainda apresenta o acabamento original.

Fig.3.18- Mesmo anel da fig. anterior, região da ponta onde o desgaste é maior.

Nesta região a área desgastada ocupa toda a altura do anel.

Fig.3.19- Foto em maior aumento do anel das figs. 3.18 e 3.19. MEV

Fig.3.20- Anel de $1^{\circ}$ canalete cromado, motor diesel, após 1000 h de ensaio. $\mathrm{MEV}$, à esquerda imagem secundária de eletrons (SEI), à direita imagem de eletrons retro-espalhados (“BEI”).

Fig.3.21- Divisão do desgaste em processos elementares. KIMURA \& SUGIMURA, 1984.

Fig.3.22- Exemplo da discretização do perfil da face de contato de um anel de $1^{\circ}$ canalete, quando novo.

Fig.3.23- Discretização do cilindro versus posições ocupadas pelos anéis em duas regiões.

Fig.4.1- Fluxograma geral do programa. 106

Fig.4.2- Fluxograma de calc. do dano acumulado, segundo a regra de ARCHARD. 108

Fig.4.3- Fluxograma da subrotina de remoção de material.

Fig.4.4- Face de contato do $1^{\mathrm{o}}$ anel prevista nos estudos de sensibilidade, após 500 interações.

Fig.5.1- Representação esquemática do pacote de anéis

Fig.5.2- Perfil medido da face de contato do $1^{\circ}$ anel quando novo, posição a $90^{\circ}$ da ponta.

Fig.5.3- Perfil adotado da face dos anéis quando novos.

Fig.5.4- Perfil típico de rugosidade da face de contato do $1^{\circ}$ anel quando novo.

$\mathrm{Ra}=0,21 ; \mathrm{Rz}=2,14 ; \mathrm{Rmax}=3,4$. (valores em : $\mathrm{m}$ ) 
Fig.5.6- Seção transversal fraturada mostrando a camada de $\mathrm{CrN}$ aplicada por PVD sobre o aço nitretado. MEV

Fig.5.7- Perfil de dureza admitido para o cilindro.

Fig.5.8- Foto por replica do acabamento superficial do cilindro.

Fig.5.9- Perfil de rugosidade do cilindro. $\mathrm{Ra}=0,83, \mathrm{Rz}=5,6, \mathrm{Rmax}=7,44$

(valores em : m)

Fig.5.10- Deformação térmica do cilindro, Dn= 150 mm. FURUHAMA et al, 1981

Fig.5.11- Deformação radial e distribuição de temperatura ao longo do cilindro.

Fig.5.12- Deformações radiais do cilindro (KOCH, 1995)

Fig.5.13- Diagrama de pressão na câmara de combustão e da velocidade do pistão.

Fig.5.14- Principais dimensões do pistão (a 2500 rpm, máxima potência).

Fig.5.15- Representação do perfil deformado do pistão.

Fig.5.16- Detalhe do perfil e inclinação do $1^{\circ}$ canalete.

Fig.5.17- Movimentação angular ("tilt") do pistão, no regime considerado.

Fig.5.18- Repres. esquemática da contribuição do pistão na inclinação do anel.

Fig.5.19- Perfil da face de contato dos anéis de $1^{\circ}$ canalete. A linha continua é o perfil quando novo, as pontilhadas são após 100, 250, 500 e 750 horas de ensaio.

Fig.5.20- Face de contato dos anéis de $1^{\circ}$ canalete, região das pontas. $5 \mathrm{X}$

Fig.5.21- Detalhe da face de contato do $1^{\circ}$ anel, após 750 h de ensaio. Região a $90^{\circ}$ da ponta. Cilindro 3. $20 \mathrm{X}$.

Fig.5.22- Detalhe da face de contato do $1^{\circ}$ anel, após $750 \mathrm{~h}$ de ensaio. Região da ponta. Cilindro 3. $20 \mathrm{X}$.

Fig.5.23- Valores medidos de aumento da folga entre pontas dos anéis de $1^{\circ}$ canalete em GNS+CrN.

Fig.5.24- Valores medidos de var. radial dos anéis de $1^{\circ}$ canalete em GNS+CrN

Fig.5.25- Valores medidos de variação radial, ao longo do perímetro, dos anéis de $1^{\circ}$ canalete, em GNS $+\mathrm{CrN}$, após 750 horas de ensaio. 
Fig.5.26- Variação radial medida pela variação do perfil da face de contato, posição a $90^{\circ}$ da ponta.

Fig.5.27- Perfil dos flancos do $1^{\circ}$ canalete, após $750 \mathrm{~h}$ de ensaio.

Fig.5.28- Exemplo da medição da área espelhada no cilindro, após $750 \mathrm{~h}$ de ensaio. Cilindro 3, lado TS.

Fig.5.29- Ex. de gráfico de perfil de rugosidade do cilindro, após 750 h de ensaio.

Fig.5.30- Pressão dos gases, agindo nos anéis, no ínicio das interações de desgaste.

Fig.5.31- Espessura mínima calculada do filme de óleo entre anéis e cilindro.

Início das interações (anéis e cilindros novos).

Fig.5.32- Espessura do filme de óleo, anel de $1^{\circ}$ canalete quando novo.

Fig.5.33- Pressões hidrodinâmicas, $1^{\circ}$ anel quando novo.

Fig.5.34- Pressões de contato rugoso, $1^{\circ}$ anel quando novo.

Fig.5.35- Perfil da face de contato e dano acumulado na $1^{\mathrm{a}}$ interação de desgaste.

Fig. 5.36- Perfil e dano acumulado durante a $10^{\mathrm{a}}$ interação.

Fig.5.37- Espessura do filme de óleo após 10 interações. Posições TS e ATS.

Fig.5.38- Evolução do perfil desgastado do $1^{\mathrm{o}}$ anel.

Fig.5.39- Espessura do filme de óleo, $1^{\circ}$ anel, após 500 interações.

Fig.5.40- Perfil calculado da face de contato do anel após 100 interações.

Fig.5.41- Filme de óleo calculado, perfil após 100 interações.

Fig.5.42- Pressões hidrodinâmicas, $1^{\circ}$ anel após 100 interações, posição TS.

Fig.5.43- Pressões de contato rugoso, $1^{\circ}$ anel após 100 interações, posição TS.

Fig.5.44- Pressões hidrodinâmicas, $2^{\circ}$ anel quando novo. Lado TS.

Fig.5.45- Pressões rugosas, anel de $2^{\circ}$ canalete quando novo. Lado TS.

Fig.5.46- Evolução do perfil desgastado do $2^{\circ}$ anel.

b- Visualizando o desgaste radial.

Fig.5.47- Pressões de contato rugoso, $2^{\circ}$ anel após 100 interações, posição TS. 
Fig.5.48- Pressões hidrodinâmicas, anel de óleo quando novo, posição TS.

Fig.5.49- Pressões de contato rugoso, anel de óleo quando novo, posição TS

Fig.5.50- Evolução do perfil desgastado do anel de óleo.

5.51- Pressões de contato rugoso, anel de óleo após 100 interações, posição TS

5.52- Evolução do desgaste radial previsto para o cilindro.

Fig.6.1- Evolução do perfil, da face de contato do $1^{\circ}$ anel, obtida experimentalmente e a prevista pelo modelo.

Fig.6.2- Comparação da taxa de desgaste radial prevista pelo modelo com a obtida experimentalmente.

Fig.6.3- Desgaste radial previsto para o pacote de anéis.

Fig.6.4- Valores previstos de desgaste radial, para o cilindro endurecido na região do PMS versus um com dureza superficial constante.

Fig.6.5- Comparação do perfil desgastado do $1^{\circ}$ anel, após 500 interações, regime constante e regime variável de operação.

Fig.6.6- Espessura de filme de óleo, entre o $1^{\circ}$ anel e a parede do cilindro, perfil desgastado no regime variável, após 500 interações.

Fig.II.1- Curva de porcentagem de material em função da profundidade ("Curva Tp") e parâmetros Rpk, Rk e Rvk de rugosidade.

Fig.II.2- Perfil de rugosidade, não filtrado, cilindro quando novo, dir. longitudinal.

Fig.II.3- Perfil de rugosidade, após filtragem numérica, cilindro quando novo, direção longitudinal.

Fig.II.4- Trecho do perfil anterior (fig. II.3), trazido agora para uma mesma ampliação nos dois eixos. 


\section{LISTA DE TABELAS}

2.1- Teorias térmicas para ocorrência de scuffing.

2.2- Principais características de camadas ou tratamentos superficiais anti-desgaste aplicadas em anéis.

2.3- Instrumentos e dispositivos de medição. DEMARCHI, 1994.

2.4- Taxa de desgaste em função da rotação. SCHENEIDER et al, 1988.

2.5- Coeficiente de desgaste, ensaio de bancada. KODALI et al, 2000.

2.6- Coeficiente de desgaste para anéis obtidos em bancada. PRIEST et al, 1999. 56

3.1- Parâmetros da equação de Vogel. 67

3.2- Valores de $\mathrm{F}_{5 / 2}(\mathrm{t})$.

3.3- Valores das funções de G-W.

4.1- Estudo de sensibilidade, desgaste radial do $1^{\circ}$ anel. 113

5.1- Ciclo de ensaio. 114

5.2- Dados dos anéis. 116

5.3- Composição do material do cilindro (\% peso). 120

5.4- Ângulo formado na face de contato do $1^{\circ}$ anel. 135

5.5- Área espelhada no cilindro, após 750 h de ensaio. 137

5.6- Desgaste medido no restante do pacote de anéis. 139

6.1- Desgaste radial (: m) dos anéis após 750 horas. 163

I.1- Valores típicos do coeficiente de desgaste. RABINOWICZ, 1984.

II.1- Parâmetros de entrada para o modelo de G-W 181

$\begin{array}{ll}\text { II.2- Rugosidade medida no cilindro } & 185\end{array}$

II.3- Rugosidade medida no $1^{\circ}$ anel em GNS + CrN 186

$\begin{array}{ll}\text { II.4- Valores Calculados a partir do perfil de rugosidade. } & 189\end{array}$ 


\section{RESUMO}

O desgaste de anéis de pistão e cilindro foi modelado através de um programa computacional que calcula as pressões hidrodinâmicas e de contato rugoso agindo nas superfícies deslizantes de contato. Ambas pressões foram completa e acopladamente calculadas através de, respectivamente, a equação de Reynolds e o modelo de Greenwood-Williamson. O movimento secundário do pistão e as deformações de origem térmica no canalete foram consideradas, essa última foi verificada ser fundamental na definição do perfil desgastado do anel de primeiro canalete. O modelo prevê a remoção de material (desgaste), tanto nos anéis quanto no cilindro, em virtude das pressões de contato rugoso através da lei de Archard e então recalcula o sistema, desse modo a evolução do perfil das superfícies deslizantes pode ser previsto.

Os valores previstos de desgaste para o anel e cilindro são comparados com um ensaio em dinamômetro de um motor diesel. Embora nenhuma tentativa seja feita para prever a exata taxa de desgaste, os perfis desgastados foram previstos com razoável precisão. É sabido que o perfil da face de contato, em especial do primeiro anel, afeta o consumo de óleo lubrificante, o atrito e a resistência ao scuffing. Prevendo-se a evolução do perfil desgastado do anel, pode-se otimizar o projeto do sistema através de simulação numérica, reduzindo-se o número dos usuais longos ensaios de durabilidade. 


\section{"ABSTRACT"}

Wear of piston ring and cylinder was modelled through a computer code that calculates the hydrodynamic and roughness contact pressures acting in the contact surfaces. Both pressures are fully and coupled solved through, respectively, Reynolds equation and Greenwood-Williamson model. Piston secondary motion and piston groove thermal deformation are considered. The latter was discovered to be fundamental in defining the top ring worn profile. Due to the rough contact pressures, the model predicts material removal in both the piston ring and the cylinder surfaces and recalculates the system, hence predicting the evolution of the worn sliding surface of both parts.

The predicted wear of the piston ring pack and cylinder model is compared with a 750 hours medium duty diesel engine dynamometer test. No attempt was made to correlate the exact wear rate, but the worn running profiles were predicted with reasonable precision. It is known that this running profile, specially for the top ring, affects oil consumption, friction and scuffing resistance. By predicting the evolution of the worn profile, one can be able to optimize piston ring system by numerical simulation, reducing the number of long durability tests. 


\title{
AGRADECIMENTOS
}

Ao meu orientador, Francisco Nigro, por me mostrar escadas quando eu só via muros.

\author{
A Marcia, Victor e Luiza. O amor e alegria deles não me deixaram \\ esquecer que a realidade é muito mais complexa, rica e gratificante \\ do que qualquer modelo computacional.
}

Aos meus colegas do grupo Mahle-Cofap, pelas eventuais ajudas, mas principalmente pelo companheirismo. 


\section{1- INTRODUÇÃO}

O sistema tribológico do anel de pistão é dos mais complexos: envolve superfícies não conformes / cargas e velocidades variáveis / atrito hidrodinâmico e misto / presença de partículas abrasivas / substâncias corrosivas resultantes da combustão / paradas e partidas do motor. Todos estes fatores afetam o desgaste do anel. A geometria e a rugosidade das superfícies atritantes modificam-se com o desgaste e estas modificações por sua vez alteram a taxa e eventualmente os mecanismos de desgaste.

Embora seja objeto de muitos estudos científicos, o modelamento e equacionamento do desgaste é ainda uma prática incomum na engenharia. MENG \& LUDEMA (1995) dizem que "... engineers and designers should have equations to predict wear rates. Unfortunately the available equations are so confusing that few designers can use any of them to predict product life with confidence. The desire for equations is particularly urgent in "automated" design where most every other topic is more quantified than is the topic of wear.”

Na indústria automobilística, além dos ganhos advindos de um sistema tribológico otimizado, o desenvolvimento de técnicas de modelamento do desgaste se faz necessário para minimizar o tempo e o custo de desenvolvimento de novos produtos. Este desenvolvimento, em geral, é feito com longos testes de dinamômetro. O objetivo da tese é modelar o desgaste que ocorre em anéis de pistão de $1^{\circ}$ canalete de motores de combustão interna. 
Este é o anel que está sujeito às condições mais severas de funcionamento. A tese pretende:

- equacionar o contato entre o anel e cilindro;

- estimar as pressões decorrentes deste contato;

- estimar, a partir de parâmetros levantados empiricamente, a taxa de desgaste;

- predizer as alterações da geometria da face de contato do anel com a parede do

cilindro, como essa geometria evolui ao longo da vida do motor e como essas

alterações afetam o desempenho do pacote de anéis.

O modelo será comparado com resultados experimentais obtidos em ensaio em

dinamômetro. A complexidade de um modelo como o proposto deve ser enfatizada: a

tribologia é ainda uma ciência mais fenomenológica que teórica. Pequenas alterações no

sistema são capazes de produzir taxas de desgaste com ordens de diferença; por este motivo,

o principal enfoque será na capacidade do modelo prever o perfil desgastado do $1^{\circ}$ anel e o

comportamento tribológico deste perfil. Com a predição de perfis de anéis tribólogicamente

otimizados para uma determinada aplicação se espera reduzir o número de testes necessários

para esta otimização, bem como entender melhor as variáveis envolvidas. Isto geralmente é

impraticável num teste complexo e de difícil acesso como o de anéis de pistão num motor em funcionamento. 


\section{2- REVISÃO BIBLIOGRÁFICA}

\section{1- MECANISMOS DE DESGASTE}

Existem diversas classificações para os mecanismos de desgaste e a nomenclatura ainda está por ser melhor definida. Dependendo do autor, o desgaste verificado em anéis de pistão é descrito como "adesivo" (PINT \& SCHOCK, 2000), "adesão durante o amaciamento seguido de abrasão e corrosão durante o uso" (BARBER \& LUDEMA, 1987), “micropolimento"(HILL et al, 1996); termos como “desgaste por deslizamento" e “desgaste oxidativo" são também comuns na literatura. Isso de certa forma reflete a controvérsia existente sobre os reais fundamentos físicos do desgaste. LUDEMA (1996) relaciona 34 termos diferentes ao discutir a nomenclatura para descrever o desgaste. Para efeito de classificação, podemos grosseiramente dividir os principais mecanismos de desgaste em: desgaste por deslizamento / por abrasão / por corrosão / por cavitação / por fadiga de contato / por erosão.

\subsection{1- DESGASTE POR DESLIZAMENTO}

Em geral, quando 2 corpos lubrificados deslizam entre si, o óleo existente na região de contato desenvolve pressões hidrodinâmicas que mantém as superfícies separadas. Sob certas condições (baixas velocidades, por ex.), essas pressões não são suficientes para manter essa separação e parte da carga é suportada pelo contato das asperezas existentes nas superfícies. As asperezas em contato se deformam e se desgastam por um processo de fadiga ou por arrancamento. O desgaste das asperezas geralmente produz uma superfície 
polida, o que melhora as condições hidrodinâmicas.

O desgaste por deslizamento é também chamado por alguns autores de desgaste por adesão. Neste trabalho preferiu-se adotar a nomenclatura defendida por 2 livros-texto recentes: HUTCHINGS (1992) e LUDEMA (1996): desgaste por deslizamento. Embora a adesão exerça um papel importante, existem outros processos físicos e químicos agindo no desgaste, quando 2 corpos deslizam entre si. Na área automotiva, o termo "desgaste adesivo" também é associado à transferência macroscópica de material entre o anel e o cilindro (DEMARCHI, 1994), ou seja, a um desgaste bastante severo também denominado por "engripamento" ou "scuffing", que será discutido no item 2.2.

O desgaste por deslizamento é comumente modelado pela equação de Archard ${ }^{1}$ :

$$
Q=\frac{K \cdot W}{H} \quad\left[\mathrm{~mm}^{3} / \mathrm{m}\right]
$$

onde $Q$ : volume desgastado do material mais mole, por unidade de distância percorrida.

$K$ : coeficiente adimensional de desgaste [0..1]

$W$ : carga normal $[\mathrm{N}]$

$H$ : dureza do corpo mais mole [N.m $\left.{ }^{-2}\right]$

${ }^{1}$ Vide desenvolvimento no anexo I. 
A equação de Archard é largamente utilizada pela sua simplicidade e também por permitir quantificar a severidade do desgaste, em diferentes sistemas, pelo coeficiente $K$. O parâmetro $k=K / H\left[\mathrm{~mm}^{3}(\mathrm{~N} \cdot \mathrm{m})^{-1}\right]$ é mais comum em aplicações de engenharia, e é denominado de coeficiente dimensional de desgaste. $k$ representa o volume $\left[\mathrm{mm}^{3}\right]$ de material removido por desgaste por unidade de distância percorrida [m] por unidade de carga normal no contato $[\mathrm{N}]$.

HUTCHINGS (1992, p.84) analisa as relações embutidas na equação de Archard: - o desgaste é proporcional à constante $K$. Entretanto, $K$ não é uma característica dos materiais e sim do sistema tribológico. A princípio, cada sistema teria que ser investigado para determinação dessa constante.

- o desgaste é inversamente proporcional à dureza do corpo mais mole. Isso é geralmente válido: aumentar a dureza da superfície é uma das práticas mais comuns para redução do desgaste. Mas mesmo isso não é uma lei universal: sob determinadas condições o aço inoxidável tem taxa de desgaste similar ao bronze, muito mais mole.

- o desgaste aumenta com a carga. Embora isso seja em geral verdadeiro, a linearidade implícita na equação vale em intervalos relativamente pequenos. A fig.2.1 (HIRST apud HUTCHINGS, 1992) mostra resultados de ensaio de pino de bronze contra um anel duro de stelita. 


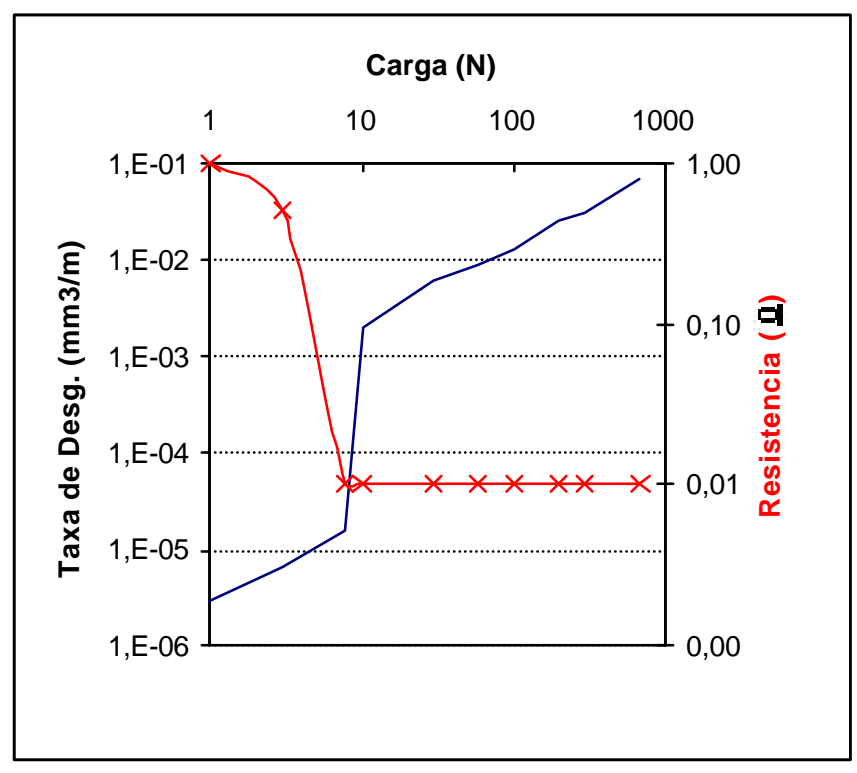

Fig.2.1- Taxa de desgaste e resistência elétrica de contato para um pino de bronze deslizando contra um anel duro de stelita. HIRST apud HUTCHINGS (1992).

Na fig. 2.1, a taxa de desgaste aumenta linearmente com a carga, o coeficiente de desgaste dimensional $(k)$ vale aproximadamente $2 \mathrm{E}-6 \mathrm{~mm}^{3} .(\mathrm{N} . \mathrm{m})^{-1}$ para cargas baixas. Nesta fase, a resistência elétrica entre os corpos é relativamente alta, significando que o contato está ocorrendo entre os filmes de óxido superficiais. Com uma carga entre 5 e $10 \mathrm{~N}$ ocorre um brusco aumento na taxa de desgaste, da ordem de $100 \mathrm{X}$ maior que anteriormente. Ao mesmo tempo a resistência elétrica entre os 2 corpos cai rapidamente. O regime de desgaste abaixo da transição é comumente chamado de desgaste moderado ("mild wear"), enquanto o alto desgaste após a transição é chamado de desgaste severo. O desgaste moderado é caracterizado por debris formado por pequenas partículas (tipicamente de 0,01 a $1: \mathrm{m}$ ), predominantemente constituídas de óxidos. Esse tipo de desgaste é também chamado de desgaste oxidativo (“oxidative wear"), sendo a taxa de desgaste dependente das velocidades 
de formação e arrancamento do óxido superficial; mas, ao contrário do que o nome pode sugerir, a oxidação em geral reduz a taxa de desgaste, ao formar um filme duro e geralmente com baixo coeficiente de atrito. A superfície desgastada geralmente apresenta aspecto polido. Já o desgaste severo produz partículas metálicas muito maiores (20 a $200:$ m) e, conseqüentemente, a superfície tem aspecto rugoso. Por sua alta taxa de desgaste, sua ocorrência é inaceitável na maioria dos sistemas mecânicos.

Apesar dessas limitações, a equação de Archard talvez seja a única sobre desgaste que tem larga aceitação. Em resumo, pode-se dizer que ela é válida para um dado sistema (carga, geometria, lubrificação etc.), desde que os regimes envolvidos não se alterem.

A equação de Archard prevê a taxa de desgaste do material mais mole, já sobre a taxa de desgaste do material mais duro, a única citação encontrada foi a de BOOSER 1984 (p. 206), que diz que uma boa estimativa pode ser obtida pela relação entre a dureza do corpo mais duro e a do mais mole $(\mathrm{Hd} / \mathrm{Hm})$

\begin{tabular}{|c|c|}
\hline$(\mathrm{Hd} / \mathrm{Hm})$ & desgaste do mais duro/ do mais mole (em volume) \\
\hline$<3$ & $(\mathrm{Hm} / \mathrm{Hd})^{2}$ \\
\hline$>3$ & $3(\mathrm{Hm} / \mathrm{Hd})$ \\
\hline
\end{tabular}




\subsection{2- DESGASTE ABRASIVO}

O desgaste abrasivo ocorre pela ação de partículas duras pressionadas e deslizando sobre a ou as superfícies. O desgaste abrasivo é denominado de 2 corpos quando uma das superfícies tem partículas duras protuberantes, e de 3 corpos quando as partículas duras são livres para rolar e deslizar entre as 2 superfícies. A taxa de desgaste é normalmente menor nesse último caso. Eventualmente um processo de 3 corpos pode se transformar num de 2, se a partícula dura penetrar e ficar impregnada numa das superfícies (usualmente a mais mole). Neste caso, a maior taxa de desgaste geralmente ocorre na superfície mais dura e não na mais mole.

O desgaste produzido por uma partícula abrasiva pode ser provocado por um processo de microcorte, por um processo de fadiga causado pelo microsulcamento, ou por microlascamentos se a superfície for frágil. A fig. 2.2 ilustra esses mecanismos.

A abrasão pode ser reduzida pela adição de partículas duras na matriz. Essas partículas podem interromper os riscos (microcorte, microsulcamento), dependendo da distribuição e tamanho relativos dessas em relação ao abrasivo. A fig.2.3 mostra um exemplo dessa interrupção pela presença de carbonetos de Nióbio na face de contato de um anel de ferro fundido nodular. 

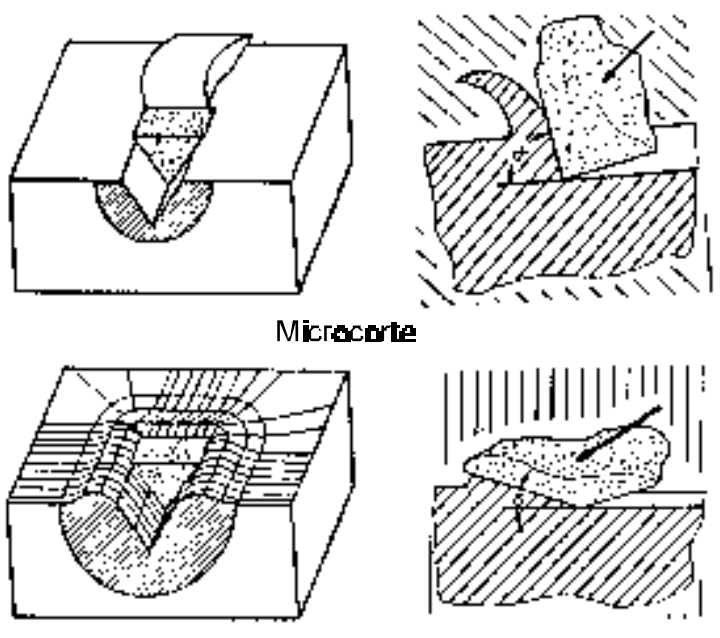

Microsul camento

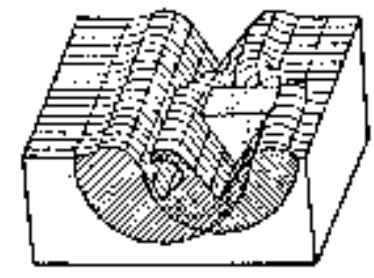

Microladiga

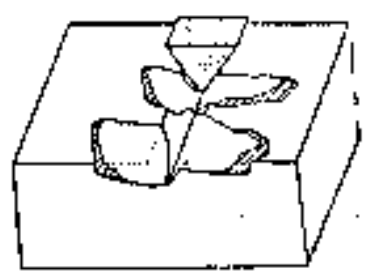

Micrd sscesmento

Fig.2.2- Mecanismos de desgaste por abrasão. ZUM GAHR apud VATAVUK (1994).

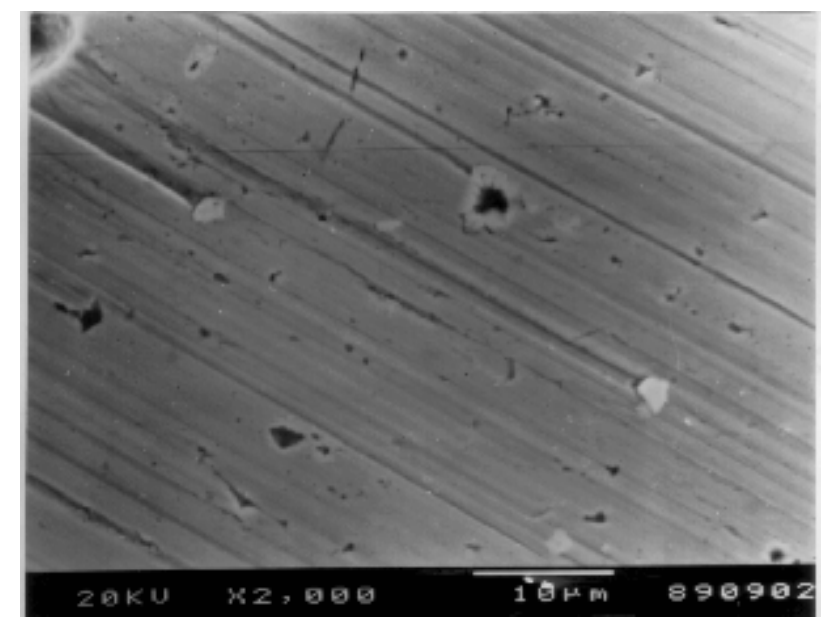

Fig.2.3- Riscos de desgaste sendo interrompidos por carbonetos de Nióbio na face de contato de um anel de Ferro Fundido. VATAVUK (1994). 
A dureza relativa das partículas é de fundamental importância: partículas com durezas menores que a da superfície causam muito menos desgaste que partículas duras. Para partículas significativamente mais duras, o valor exato dessa dureza tem menor influência. A taxa de desgaste é muito sensível se a razão entre a dureza do abrasivo e a da superfície é próxima de 1. Vide fig. 2.4 .

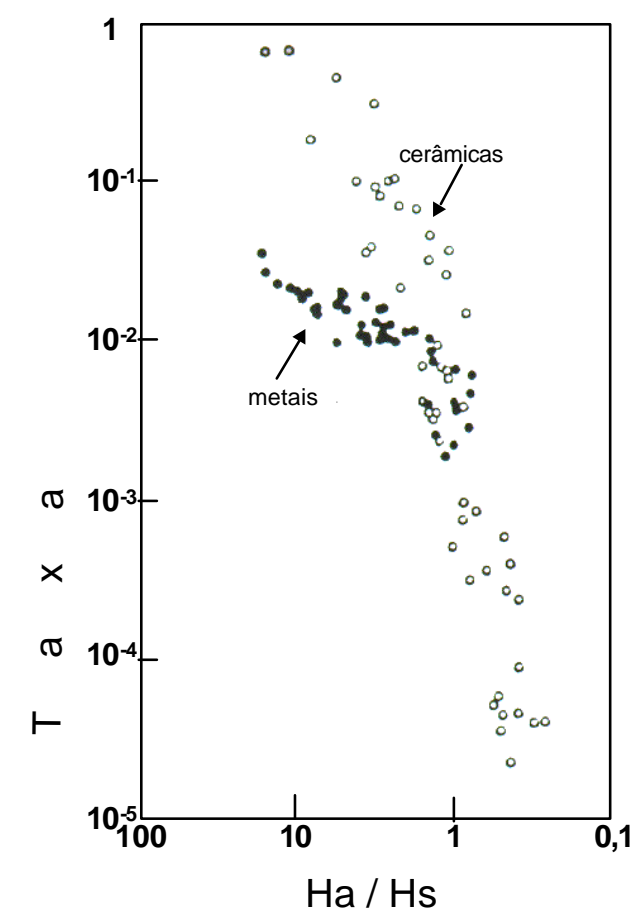

Fig.2.4- Taxa de desgaste em função da razão da dureza do abrasivo / dureza da superfície $\left(\mathrm{H}_{\mathrm{a}} / \mathrm{H}_{\mathrm{s}}\right)$, para abrasão a 2 corpos. MOORE apud HUTCHINGS (1992)

Em M.C.I., as partículas que podem provocar o desgaste abrasivo podem ter diversas origens. As principais são: 
- cinzas e material carbonizado, resíduos sólidos da combustão. Mesmo que inicialmente pequenas e moles, essas partículas podem se aglomerar e endurecer pela compactação provocada pelo movimento secundário do pistão.

- partículas metálicas e óxidos provenientes do desgaste.

- poeira admitida junto com o ar e não bloqueada pelo sistema de filtragem.

- partículas metálicas oriundas dos processos de fabricação, que permanecem no motor por limpeza deficiente.

- resíduos de areia utilizada na fundição do bloco e cabeçote, que permanecem no motor por limpeza deficiente.

Segundo GAUTAM et al (1998) as espécies mais significativas do material particulado em Diesel são: carbono elementar (53,4\%), carbono orgânico (29,6\%), sulfatos $(9,2 \%)$, amônia $(0,31 \%)$, nitratos $(0,09 \%)$ e silicatos $(0,008 \%)$. A maior parte desse material resulta da combustão incompleta do combustível e lubrificante e é constituída de agregados de partículas pequenas e esféricas. Individualmente, as partículas têm aproximadamente 0,02: m de diâmetro e os agregados até $0,5: \mathrm{m}$. A fuligem encontrada em motores Diesel contém hidrogênio, oxigênio e enxofre, bem como componentes provenientes de aditivos do lubrificante, como fósforo, zinco e cálcio. Gautam testa diversos óleos lubrificantes com 0 e 3\% (em peso) de contaminação de fuligem e observa que o desgaste aumenta de 10 a $100 \%$, dependendo do óleo utilizado. A presença de altos níveis de fósforo e de aditivos neutralizadores de acidez minimizam, em parte, os efeitos nocivos da fuligem. 
Em MCI, a fuligem age não só como abrasivo. O depósito compactado no topo do pistão e no fundo do canalete endurece, diminui a folga daquele com o cilindro e aumenta a força que o pistão exerce contra o cilindro, aumentando o desgaste. O depósito no fundo do canalete pode eliminar a folga radial anel/pistão e aumentar a pressão que o anel exerce contra o cilindro. URABE et al (1998) examinam o efeito do uso de EGR ("Exhaust Gas Recirculation", Recirculação do gás de escape) em motores Diesel e verificam que o desgaste do anel foi 4 vezes maior do que sem o uso do EGR. Mesmo com o uso de filtros para eliminar o material particulado, o uso do EGR dobrou o desgaste. Há que se destacar que no trabalho de Urabe foram usados anéis de primeiro canalete sem revestimento. Em anéis usuais, com revestimento resistente ao desgaste, a diferença deve ser, provavelmente, menor. Urabe et al verificam que o atrito aumenta com o uso do EGR, mas que este aumento deve-se principalmente ao depósito de carvão no fundo do canalete. Com o movimento angular do pistão, o anel encosta nesse depósito e aumenta a força contra a parede do cilindro. Mais recentemente, o mesmo Urabe, em co-autoria com ISHIKI et al (2000), defende que mesmo sem o uso de EGR, o desgaste de anéis é provocado pela ação abrasiva da esteadita presente no cilindro. O uso do EGR apenas tornaria o óleo lubrificante mais propício para essa ação de corte (o que explicaria o aumento de desgaste nos anéis), entretanto esta hipótese é no mínimo, polêmica.

BARBER \& LUDEMA (1987), HAYNES apud MICHALSKI \& PAWLUS (1994), entre outros, sugerem que partículas abrasivas podem ser aprisionadas nos vales de brunimento e nos veios de grafita existentes na parede do cilindro, o que diminuiria o desgaste abrasivo 
provocado por essas partículas. Com o desaparecimento desses vales pelo desgaste, aumentaria o desgaste abrasivo.

\subsection{3- DESGASTE CORROSIVO}

Em M.C.I., o desgaste corrosivo deve-se a reações químicas (devido a misturas óleo / combustível) na face de contato anel/cilindro. A presença de enxofre no combustível aumenta o desgaste corrosivo. $\mathrm{O}$ enxofre no combustível se oxida em $\mathrm{SO}_{2}$ ou $\mathrm{SO}_{3}$ que então reage com água para formar $\mathrm{H}_{2} \mathrm{SO}_{3}$ ou $\mathrm{H}_{2} \mathrm{SO}_{4}$. Mesmo com baixos teores de enxofre, outros ácidos se formam, como por exemplo o ácido nítrico (FURUHAMA, 1991). A presença de detergentes alcalinos no lubrificante $\left(\mathrm{CaCO}_{3}\right.$, sulfonatos, etc.) neutraliza os ácidos, formando sulfato de Cálcio $\left(\mathrm{CaSO}_{4}\right)$, água e dióxido de carbono. O desgaste corrosivo que pode ser controlado pela presença de detergentes alcalinos no lubrificante. A alcalinidade dos lubrificantes é designada pelo TBN ("Total Base Number", Número de Basicidade Total). Acredita-se que o desgaste corrosivo seja o mecanismo dominante quando o motor opera ou muito frio ou muito quente (BECKER, 1998). Em particular, nota-se um grande aumento no desgaste do cilindro quando a temperatura do parede do cilindro cai abaixo do ponto de condensação dos produtos de combustão (BEHRENS, 1988). A corrosão pode ser significativa em MCI que rodem com combustível com alto teor de enxofre, como em motores marítimos, por exemplo. VATAVUK (1994) estuda o efeito de altos índices de enxofre no combustível e adição de partículas duras tanto no anel como no cilindro. A fig.2.5 mostra a superfície de um cilindro que rodou com combustível com alto teor de enxofre; a 
corrosão fez com que a steadita ficasse em alto relevo. O posterior arrancamento dessa steadita provoca um maior desgaste por abrasão. SHUSTER (1999) encontra traços de enxofre em anéis desgastados, mas conclui que a corrosão é um efeito de $2^{\mathrm{a}}$ ordem, sendo a fadiga de contato o principal mecanismo de desgaste atuante.

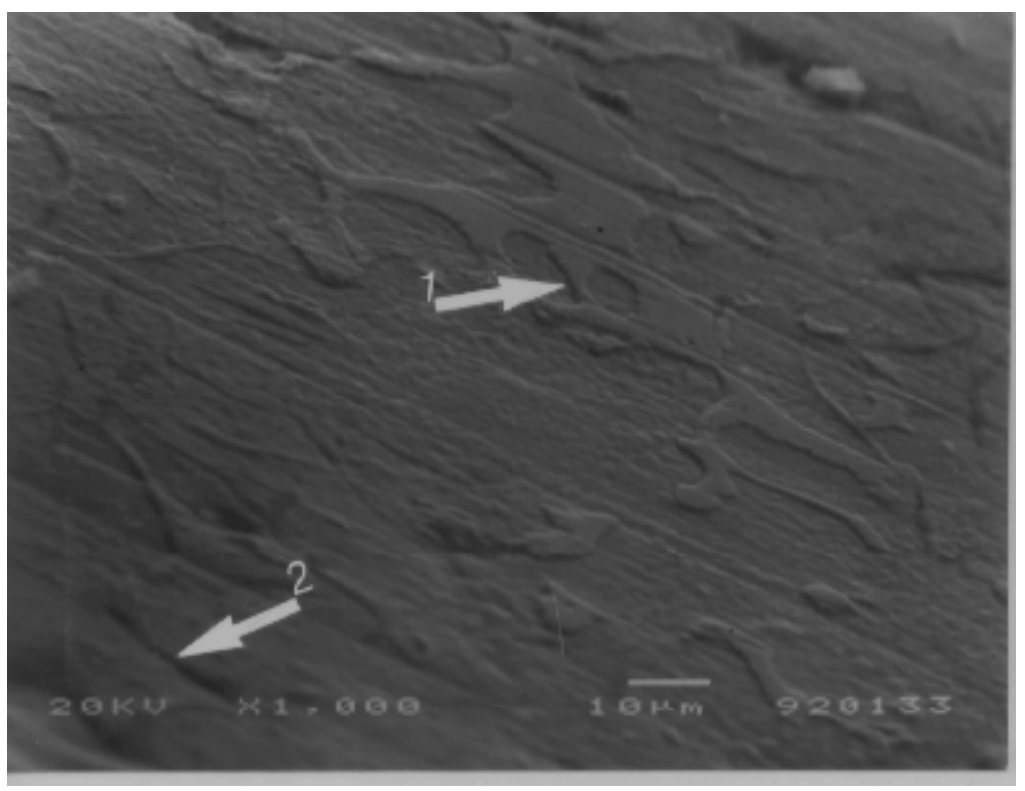

Fig.2.5- Superfície de um cilindro que rodou com combustível com alto teor de enxofre. A seta 1 indica a fase steadita em alto relevo. A seta 2, grafita. Imagem de elétrons secundários, M.E.V. VATAVUK (1994)

\subsection{4- DESGASTE POR CAVITAÇÃO}

No contato anel/cilindro ocorre apenas a deaeração gasosa: bolhas de gases são formadas quando a pressão do filme de óleo cai abaixo da pressão de saturação dos gases dissolvidos. 
A formação e colapso dessas bolhas é muita mais lenta do que na cavitação (bolhas de vapor do líquido) e o decorrente dano / desgaste é desprezível.

\subsection{5- DESGASTE POR FADIGA DE CONTATO}

Vários autores consideram o desgaste provocado pela fratura das asperezas ou do filme superficial sob ação de cargas alternadas como um mecanismo independente. Outros preferem incluir esse fenômeno como um dos que compõem o desgaste por deslizamento. Outros ainda só caracterizam como desgaste por fadiga se as macro-tensões envolvidas forem altas. VATAVUK (1994) diz ser difícil a caracterização de fadiga na superfície de anéis porque as macro-tensões são muito baixas. Entretanto, como será visto no item 2.4, as tensões atuantes nas asperezas em contato são bastante altas. É geralmente aceito que os assim chamados mecanismos de desgaste adesivo e oxidativo ocorram como resultado de fraturas ao longo dos pontos microscópicos de contato (KIMURA \& SUGIMURA, 1984). Já em 1975, HALLING propõe que o desgaste originado do contato deslizante de 2 superfícies rugosas (o então chamado “desgaste adesivo”) pode ser descrito por uma lei que contempla a probabilidade das asperezas se contatarem (o tratamento estatístico dado por Greenwood-Williamson, que será visto mais a frente) e o número de ciclos para ruptura por fadiga (a lei de Manson-Coffin para fadiga de baixo ciclo). Essa abordagem foi posteriormente refinada por FINKIN (1978) que considerou que apenas os contatos plásticos entre asperezas contribuem para o desgaste. Ambos concluem que o modelo de Archard pode ser entendido como um caso particular de suas equações mais gerais.

HALLING \& ARNELL (1984) propõem uma lei genérica para o desgaste em função das 
micro-tensões e do expoente $r$ de fadiga do material, definido pela lei de Wöhler:

$$
\text { Nímero de ciolor para falha }=\left(\frac{\epsilon_{1}}{\epsilon_{\max }}\right)^{r}
$$

onde , 1 é a deformação para falha em 1 ciclo e , max é a máxima deformação ocorrendo no contato em um ciclo de carregamento. $\mathrm{O}$ expoente de fadiga pode ser alternativamente definido pelas tensões envolvidas. BULATOV \& VEDERNIKOVO (1993) verificam, em testes de bancada, que a resistência ao desgaste de anéis de pistão varia com o número de deformações cíclicas que o anel sofreu anteriormente. KARKAMAR et al (1996) modelam o desgaste ocorrendo por rolamento ou deslizamento usando o modelo de Greenwood-Williamson para cálculo das tensões atuantes nos pontos de contato e a citada relação de Wöhler para determinar o número de ciclos de contato para a remoção de uma camada de material. USHIJIMA et al (1999) usam abordagem semelhante para estimar o desgaste ocorrendo em bronzinas de MCI.

No clássico trabalho de SUH (1973), este propõe que o desgaste no deslizamento é causado pela formação de vazios e trincas sub-superficiais provocadas pelas deformações plásticas causadas pelas tensões atuantes, e que os então chamados desgastes "adesivo", por fretting e por fadiga, seriam todos provocados pelo mecanismo proposto. Suh propõe uma equação para o volume desgastado total de um corpo duro deslizando sobre outro mais mole, mas a equação depende de parâmetros empíricos relacionados com a topografia da superfície, bem como de propriedades metalúrgicas relativamente complexas. 


\section{2- SCUFFING (ENGRIPAMENTO)}

$\mathrm{Na}$ área automotiva scuffing significa um desgaste, em geral catastrófico, com transferência de material entre os pares atritantes e nítido aumento da rugosidade. Em português, é geralmente denominado de "engripamento", porque, em ocorrências no campo, o pistão não consegue mais se mover e o motor trava. Em dinamômetro, em geral, consegue-se interromper o ensaio antes do travamento total. Na literatura em inglês sobre tribologia, scuffing tem significado ligeiramente diferente do descrito acima, bem como seu significado difere entre os Estados Unidos e a Inglaterra. (HUTCHINGS, 1992).

Muitos pesquisadores observam que uma camada dura e branca (após "etching") se forma na maioria dos materiais ferrosos em testes de scuffing, lubrificados ou secos. Essa camada branca é geralmente aceita como uma mistura de austenita, martensita e carbetos, ou mesmo ferro fundido branco. ROGERS apud BARBER \& LUDEMA (1987) defende que o scuffing é causado pela contínua produção e fragmentação dessa camada branca, formando partículas abrasivas e provocando maior desgaste. Em geral, acredita-se que essa camada branca seja resultado e não causa do scuffing. A presença desta camada transformada, freqüentemente separada do material original por uma camada revenida, sugere que as superfícies que sofreram scuffing passaram por uma transformação de fase: formação de martensita, devido a uma temperatura local muito alta provocada pelo atrito, e então um rápido esfriamento pelo material do corpo. Supõe-se que a temperatura na superfície é de, pelo menos, 720 C ( SHUSTER et al, 1999a), já que essa é a temperatura necessária para a 
transformação austenítica. Pressões altas podem causar uma redução desconhecida nessa temperatura crítica.

A ocorrência de scuffing em MCI pode ser caracterizada por (SHUSTER, 1999):

- aumento da rugosidade da face de contato do anel e do cilindro;

- transferência de ferro do cilindro para a face do anel;

- redução da dureza da camada de cromo do anel na região que sofreu scuffing;

- transformação martensítica em cilindros endurecidos ou na superfície do anel abaixo da camada de cromo.

A tabela 2.1, baseada na revisão de BIN (1998), resume as teorias com ênfase nos aspectos térmicos para explicar a ocorrência de scuffing:

\begin{tabular}{|l|l|}
\hline \multicolumn{2}{|c|}{ Tabela 2.1- Teorias térmicas para ocorrência de scuffing } \\
\hline Potência Específica & $\begin{array}{l}\text { Scuffing é função da pressão média Hertziana vezes a } \\
\text { velocidade de deslizamento. Esse produto, multiplicado pelo } \\
\text { coeficiente de atrito, pode ser entendido como a razão de } \\
\text { dissipação da energia de atrito por unidade de área nominal } \\
\text { de contato. }\end{array}$ \\
\hline $\begin{array}{l}\text { Incremento de } \\
\text { ("Femperatura local }\end{array}$ & $\begin{array}{l}\text { Existe uma temperatura característica de scuffing para cada } \\
\text { combinação lubrificante/superfícies atritantes. O Scuffing } \\
\text { ocorre quando a máx. T no contato atingir um certo valor } \\
\text { crítico. }\end{array}$ \\
\hline $\begin{array}{l}\text { Amolecimento Térmico } \\
\text { (AUE, 50s) }\end{array}$ & $\begin{array}{l}\text { O calor gerado num determinado ponto de contato ("spot") } \\
\text { provoca aquecimento e expansão, produzindo uma } \\
\text { "protuberância térmica". Essa, por sua vez, gera mais atrito, } \\
\text { o que aumenta a temperatura e a expansão local. } \\
\text { Eventualmente, o filme de óleo é destruído, ocorrendo uma } \\
\text { micro-solda e o "scuffing". }\end{array}$ \\
\hline $\begin{array}{l}\text { Instabilidade termoelástica } \\
\text { (DOWN, BURTON, 70s) }\end{array}$ & $\begin{array}{l}\text { Propõe equações para velocidade e carga críticas } \\
\text { para ocorrência de scuffing, sob condições de alta } \\
\text { velocidade de deslizamento . }\end{array}$ \\
\hline
\end{tabular}


Outros teorias priorizam os aspectos mecânicos, mais especificamente o aumento de rugosidade provocado por deformação plástica. LUDEMA (1984) considera ser a fadiga de baixo ciclo (regime plástico) a mais provável explicação para ocorrência de scuffing: algumas asperezas se romperiam por fadiga de baixo ciclo após algumas dezenas ou centenas de ciclos de deformação plástica. As partículas removidas se aglomerariam em partículas maiores, que seriam repetidamente deformadas e encruadas ao passar pela região de contato. Eventualmente, um desses aglomerados seria grande o suficiente para suportar toda a carga de contato, produzindo tensões excessivas e aumentando, significativamente, a temperatura local e alterando tanto o filme lubrificante quanto os filmes superficiais protetivos; isso realimentaria o processo e propagaria o dano até um estágio catastrófico. Vide fig. 2.6.

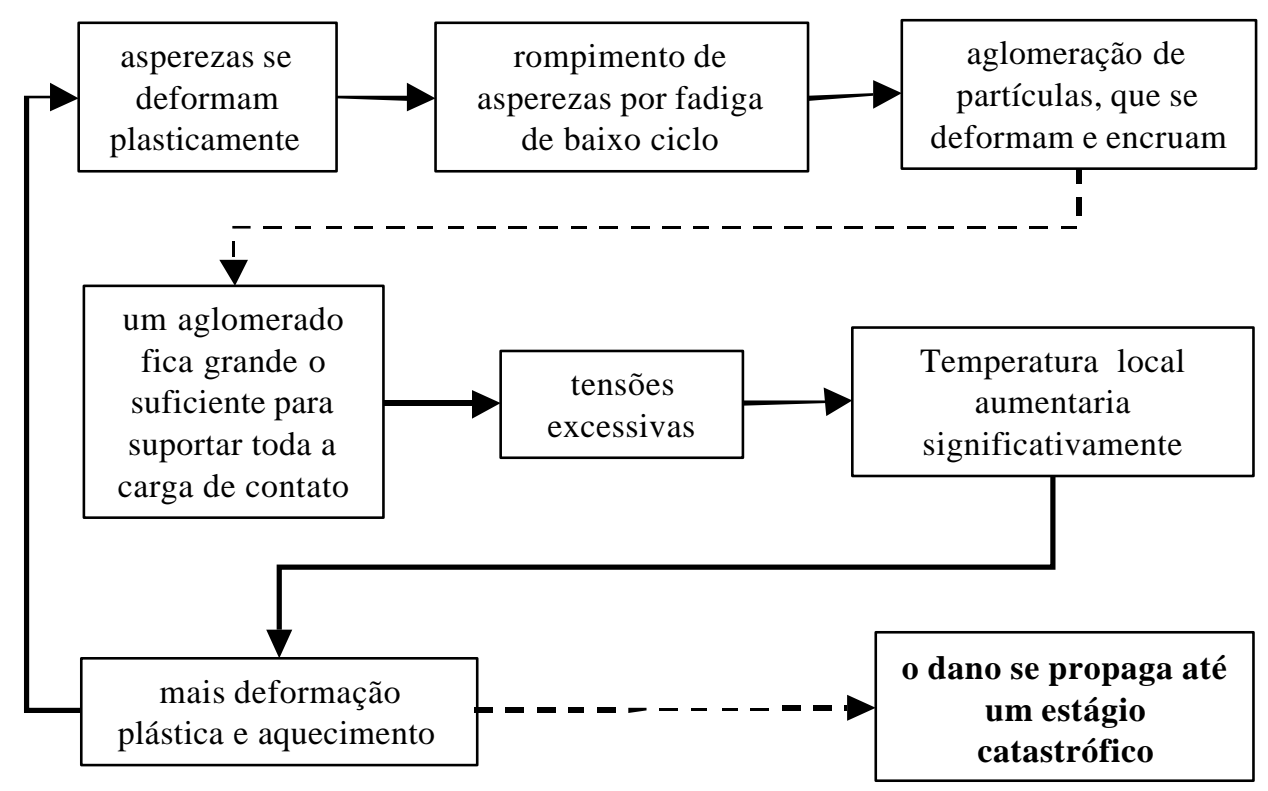

Fig.2.6- Teoria da deformação plástica para a ocorrência de scuffing. 
Os critérios térmicos e o defendido por Ludema não parecem ser excludentes, e sim estágios diferentes de um mesmo processo, iniciando com a deformação plástica, e num determinado momento, evoluindo de um desgaste moderado para um catastrófico, onde os aspectos térmicos seriam dominantes. Recentemente, vale citar o trabalho de KIM \& LUDEMA (1995), que conseguiram uma correlação muito boa entre ensaios de scuffing e as propriedades de fadiga de baixo ciclo para aços SAE 4340.

YOSHIDA et al (1997) estudam a ocorrência de scuffing em anéis de aço nitretados a gás. Após 1500 h de teste, os anéis falharam com destacamento de material, vide fig.2.7.

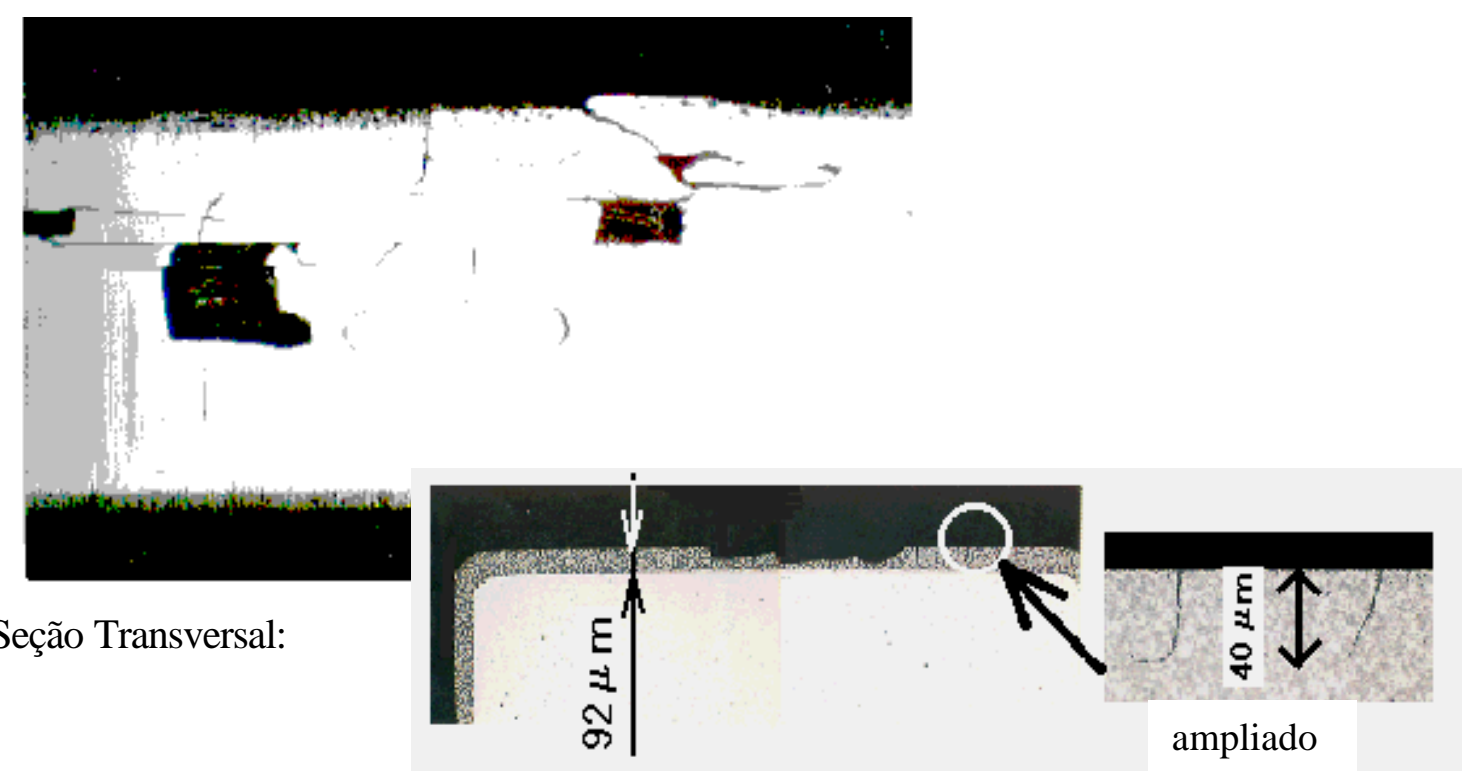

Fig.2.7- Scuffing em anéis de aço nitretado provocado por micro-trincas. Motor diesel, $1500 \mathrm{~h}$ de ensaio. YOSHIDA et al (1997).

Trincas perpendiculares à superfície nuclearam-se e propagaram, até que, a uma determinada profundidade, mudaram de direção, eventualmente se conectando e causando destacamento 
macroscópico. O problema foi resolvido com a adoção de uma sobre-camada mais dura que reduziu o desgaste, o que permitiu a manutenção de um perfil hidrodinâmico na face do anel e conseqüente diminuição das tensões de contato.

\subsection{1- Efeitos da rugosidade no scuffing}

O efeito da rugosidade é complexo. Em geral, um acabamento mais fino implica numa pequena deformação do filme de óxido e numa maior temperatura crítica. Entretanto, se a superfície é demasiadamente lisa, qualquer pequena partícula de debris pode causar um dano pequeno, que progride com o deslizamento entre as superfícies e pode chegar a um grande dano. Para uma superfície polida, verificou-se que a temperatura crítica foi tão baixa quanto para uma muito rugosa, BIN (1998).

A rugosidade superficial influencia fortemente 2 grandezas mensuráveis: coeficiente de atrito e carga de scuffing. STAPH apud BIN (1998) verificou que um aumento da rugosidade superficial reduz grandemente a carga necessária para scuffing e aumenta o coeficiente de atrito no scuffing. Já a temperatura crítica, mencionada na hipótese de Blok, permaneceu praticamente constante para diferentes rugosidades. 
YOSHIDA (1990) testa, em bancada, anéis de aço nitretados com cobertura adicional de CrN e verifica que, enquanto com rugosidade Rz 0,2 : m não ocorre scuffing, com rugosidades crescentes a carga necessária para scuffing diminui. Vide fig. 2.8.

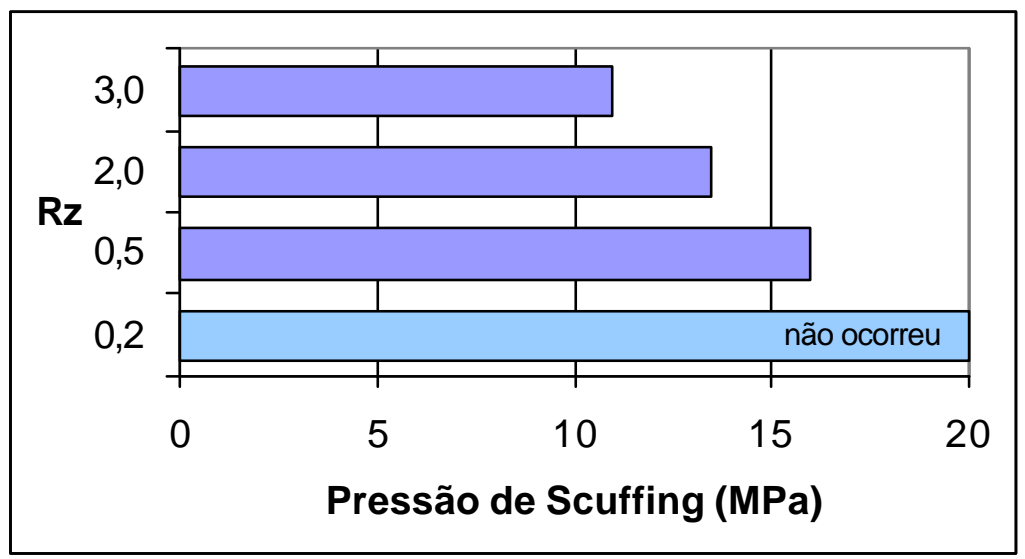

Fig.2.8- Efeito da rugosidade na resistência ao scuffing. Ensaio de bancada, anéis de aço nitretado revestidos com CrN atritando contra ferro fundido. YOSHIDA, 1990.

O ensaio descrito por Yoshida é peculiar por apresentar scuffing ocorrendo com coeficientes de atrito bastante baixos $(0,025$ a 0,035$)$ e por apresentar o molibdênio e o aço nitretado com desempenho semelhante. O molibdênio é considerado como a melhor cobertura antiscuffing para anéis de pistão. BIN (1998) realizou uma série de testes de bancada com anéis de pistão e pedaços de camisas de cilindro, principalmente de compósitos com matriz de alumínio, e concluiu que a resistência ao scuffing diminui com o aumento da rugosidade do cilindro, exceto para acabamentos muito finos, como por exemplo de $90 \mathrm{MPa}(\mathrm{Ra}=0,10$ : m) para $20 \mathrm{MPa}(\mathrm{Ra}=0,45: \mathrm{m})$. Já com $\mathrm{Ra}=0,05:$ m, a pressão de scuffing é $80 \mathrm{MPa}$, mesmo valor que para $\mathrm{Ra}=0,20: \mathrm{m}$. 


\section{3- DESGASTE EM ANÉIS}

\subsection{1- CARACTERIZAÇÃO DO SISTEMA TRIBOLÓGICO}

Os anéis de pistão, em especial o do $1^{\circ}$ canalete, estão sujeitos a complexas e severas condições tribológicas:

- velocidades médias de até $20 \mathrm{~m} / \mathrm{s}$. Como o movimento é alternado, a velocidade é variável, sendo zero nos pontos de reversão e máxima aproximadamente no meio do curso. - pressões de até 20 MPa (200 bar) em alguns motores Diesel de última geração. Novamente, essa pressão varia ao longo dos 4 tempos do motor.

- a parede do cilindro é em geral de ferro fundido, com um típico acabamento superficial denominado "brunimento". A rugosidade superficial é da ordem de $\mathrm{Rz}=6: \mathrm{m}(\mathrm{Ra}$ aproximadamente 1,0), quando nova.

- a temperatura da parede do cilindro é em torno do $100 \mathrm{C}$, enquanto a do $1^{\circ}$ anel é da ordem de $250 \mathrm{C}$.

- como conseqüência, o filme de óleo é da ordem de alguns poucos micrometros no meio do curso, mas da ordem de apenas décimos de micrometro nos pontos de reversão - ou seja: da mesma ordem que a altura das asperezas e portanto o regime de lubrificação é limite.

- o $1^{\circ}$ anel, para motores Diesel, é em aço ou ferro fundido nodular, com um revestimento anti-desgaste. Este revestimento é geralmente molibdênio, mais especificamente uma liga a base de molibdênio, níquel e cromo aplicada por plasma, ou cromo duro depositado eletroliticamente. Mais recentemente, têm-se desenvolvido também camadas de Nitreto de 
Cromo (CrN) aplicadas por PVD ("Physical Vapor Deposition”) sobre aço inoxidável. A tabela abaixo indica as principais características destes revestimentos.

Tabela 2.2- Principais características de camadas ou tratamentos superficiais anti-desgaste aplicadas em anéis.

\begin{tabular}{|l|c|c|c|}
\hline & dureza & espessura & $\mathbf{R z}^{*}$ \\
& $\mathbf{( H V )}$ & $\mathbf{( : ~ m )}$ & $\mathbf{( : ~ m )}$ \\
\hline Molibdênio & $325 \mathrm{~min}$. & 150 & 1 \\
\hline Cromo & $800 \mathrm{~min}$. & 150 & 0,57 \\
\hline Aço nitretado & $900 \mathrm{~min}$. & 100 & 0,35 \\
\hline CrN (sobre aço nitretado) & $\sim 2000$ & 10 a 30 & 0,60 \\
\hline
\end{tabular}

*quando nova

\subsection{2- MÉTODOS DE MEDIÇÃO DO DESGASTE}

O método mais comum de medição de desgaste de anéis é o aumento da folga entre pontas (“gap”): monta-se o anel num padrão com diâmetro de furo conhecido e mede-se a folga entre pontas do anel com uma lâmina cônica graduada, com resolução de $0,05 \mathrm{~mm}$. Comparando com o valor inicial, tem-se o aumento da folga entre pontas. Esse valor pode ser entendido como a média de desgaste radial multiplicado por $2 \mathrm{~B}$, uma vez que o que é medido é a diferença entre um perímetro conhecido (do padrão) e o do anel. É comum caracterizar a taxa de desgaste, medida pelo aumento da folga entre pontas, em unidades como $: \mathrm{m} / 100 \mathrm{~h}$ ou $: \mathrm{m} / 1000 \mathrm{~km}$. Como essa taxa costuma diminuir com testes mais longos 
(maior desgaste ocorre durante o amaciamento), é preciso cuidado ao comparar valores advindos de ensaios com diferentes durações.

Outro método bastante comum de medição do desgaste em anéis é a variação da espessura radial. Deve-se notar que, em geral, o desgaste não é uniforme ao longo do anel, sendo maior nas pontas. TRUHAN \& COVINGTON (1993), por exemplo, verificam desgaste $150 \%$ maior nas pontas do que a média ao longo do restante do anel. O maior desgaste usualmente verificado nas pontas faz com que a medição do desgaste radial não possa ser substituída pela do aumento da folga entre pontas. Mesmo que apenas numa determinada região o desgaste radial seja excessivo, isso pode ser suficiente para inutilizar o anel, seja por acabar com o revestimento anti-desgaste, seja porque essa região pode não contatar o cilindro em momentos de pouca pressão dos gases, acarretando consumo de óleo e/ou "blow-by" excessivo. O desgaste radial também pode ser avaliado pela variação do perfil da face de contato.

Em trabalhos de desenvolvimento costuma-se também indicar o desgaste por perda de massa. Mesmo que obtida através de uma balança microanalítica com resolução de $0,1 \mathrm{mg}$, essa medida deve ser avaliada com cuidado: o baixo desgaste verificado em anéis (da ordem de $\sim 10 \mathrm{mg} / 100 \mathrm{~h}$ ) pode induzir a conclusões equivocadas em decorrência de qualquer transferência de material para o anel. Especialmente para revestimentos com porosidade (molibdênio, por ex.) a medição por perda de massa é contra-indicada: é comum anéis apresentarem ganho de massa, mesmo após longos ensaios. 
Para anéis de óleo, a medição da perda de força tangencial é bastante útil. Estes anéis não contam com a pressão dos gases para auxiliar a vedação de modo que a perda de força tangencial, seja por desgaste na radial, seja no contato mola/corpo do anel, ou mesmo por perda de eficiência por efeito térmico da mola (sem remoção de material), afetando diretamente o desempenho do anel de óleo.

Para uma avaliação rápida, usualmente não numérica, usa-se também a porcentagem da altura da face de contato já "desgastada” ("bearing area”). Dado seu perfil abaulado, o anel faz contato, inicialmente, contra o cilindro numa faixa estreita, que vai aumentando com o aumento do desgaste. A fig. 2.9 mostra uma evolução típica da área de contato em função da duração do ensaio. Essa figura também ilustra como o desgaste depende fortemente do perfil inicial. Abaulados maiores (raios menores de curvatura) na face de contato provocam menores áreas de contato mas maiores desgastes radiais e consequentemente, maior variação na folga entre pontas, para um mesmo volume de material removido. Um bom compromisso desse abaulado inicial e de sua evolução ao longo da vida do anel é um dos desafios de um bom projeto de anéis.

O anel também se desgasta em sua altura axial, mas, pelas baixas velocidades relativas envolvidas, esse desgaste costuma ser da ordem de alguns poucos micrometros. Em motores de automóvel, o desgaste que o anel provoca no canalete de pistão pode ser significativo, mas motores diesel mais solicitados têm um porta-anel de material resistente ao desgaste, sendo o desgaste do canalete desprezível nesses casos. 


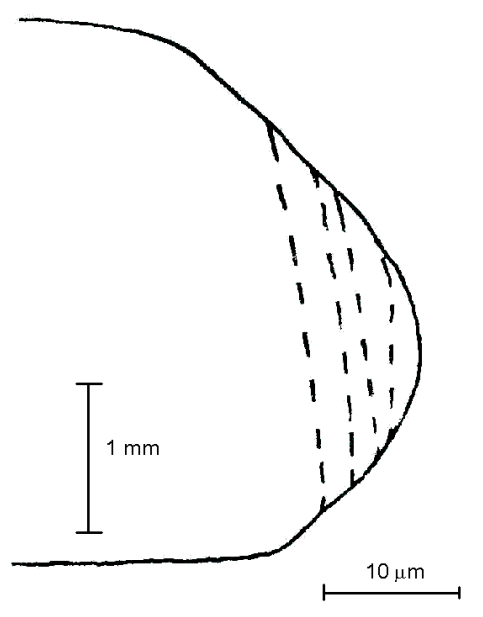

Fig.2.9- Evolução do perfil e da área de contato ("bearing area") em função do número de horas de ensaio. O perfil contínuo é o anel quando novo e as linhas pontilhadas são após 100, 250, 500 e 750 h de ensaio. TOMANIK \& GALVANO (1998).

DEMARCHI (1994) lista a resolução e a incerteza da medição das principais características de anéis, vide tabela 2.3 .

\begin{tabular}{|c|l|c|c|}
\hline \multicolumn{2}{|c|}{ Tabela 2.3 - Instrumentos e dispositivos de medição } & \multicolumn{1}{c|}{ DEMARCHI (1994) } \\
\hline Característica & \multicolumn{1}{|c|}{$\begin{array}{c}\text { Instrumento ou } \\
\text { dispositivo }\end{array}$} & Resolução & $\begin{array}{r}\text { Incerteza do processo } \\
\text { de medição ( } \pm \text { ) }\end{array}$ \\
\hline $\begin{array}{c}\text { Folga entre pontas } \\
(\mathrm{mm})\end{array}$ & Lâmina cônica & 0,05 & 0,10 \\
\hline $\begin{array}{c}\text { Espessura Radial } \\
(\mathrm{mm})\end{array}$ & Dispositivo com relógio & 0,001 & 0,002 \\
\hline $\begin{array}{c}\text { Massa } \\
(\mathrm{mg})\end{array}$ & Balança eletrônica & 0,01 & 0,6 \\
\hline
\end{tabular}




\subsection{3- DESGASTE DO CILINDRO}

A medição do desgaste no cilindro traz ainda maiores dificuldades. Medidas da variação diametral confundem-se com deformações geométricas que o cilindro sofre e são, em geral, de pouca utilidade, exceto no caso de desgastes muito grandes (da ordem de várias dezenas de micrometros). Vale lembrar que um aumento de $100:$ m no diâmetro do cilindro implica diretamente num aumento da folga funcional entre pontas do anel $\mathrm{B}$ vezes maior $(\sim 300: \mathrm{m})$. Assim, uma medida usual na "prática de oficina" é a medição da folga entre pontas do anel quando montado no cilindro. Durante a montagem de um motor novo, essa medida é importante para verificar a adequação das peças. Na desmontagem, ela é uma medida do desgaste combinado anel + cilindro.

O cilindro apresenta desgaste diferenciado ao longo de seu comprimento: maior no PMS do $1^{\circ}$ anel (TING, 1980; ISHIZUKI et al, 1981; BARBER \& LUDEMA, 1987), já que essa região, como vimos, sofre as condições tribológicas mais severas. Esse desgaste, se excessivo, provoca um pronunciado aumento localizado no diâmetro, que pode ser medido através de um perfilômetro ou um rugosímetro usando um curso longo. Como o desgaste do cilindro é bastante pequeno, uma medida usual, mas de difícil interpretação, é a variação da rugosidade, vide a extensa discussão em PAWLUS, 1998. A fig.2.10 mostra perfis de rugosidade de um cilindro, de motor gasolina, quando novo e após 200 horas de teste, DEMARCHI (1994). Pawlus propõe o uso de parâmetros de amplitude de rugosidade para medição de pequenos valores de desgaste no cilindro. Pawlus, entretanto, obtém valores de 
correlação dos valores de desgaste alcançados pelo método proposto e os com um "calibre padrão" entre 0,41 e 0,62, mesmo na situação estudada pelo autor, provavelmente com cuidados maiores que os usuais.

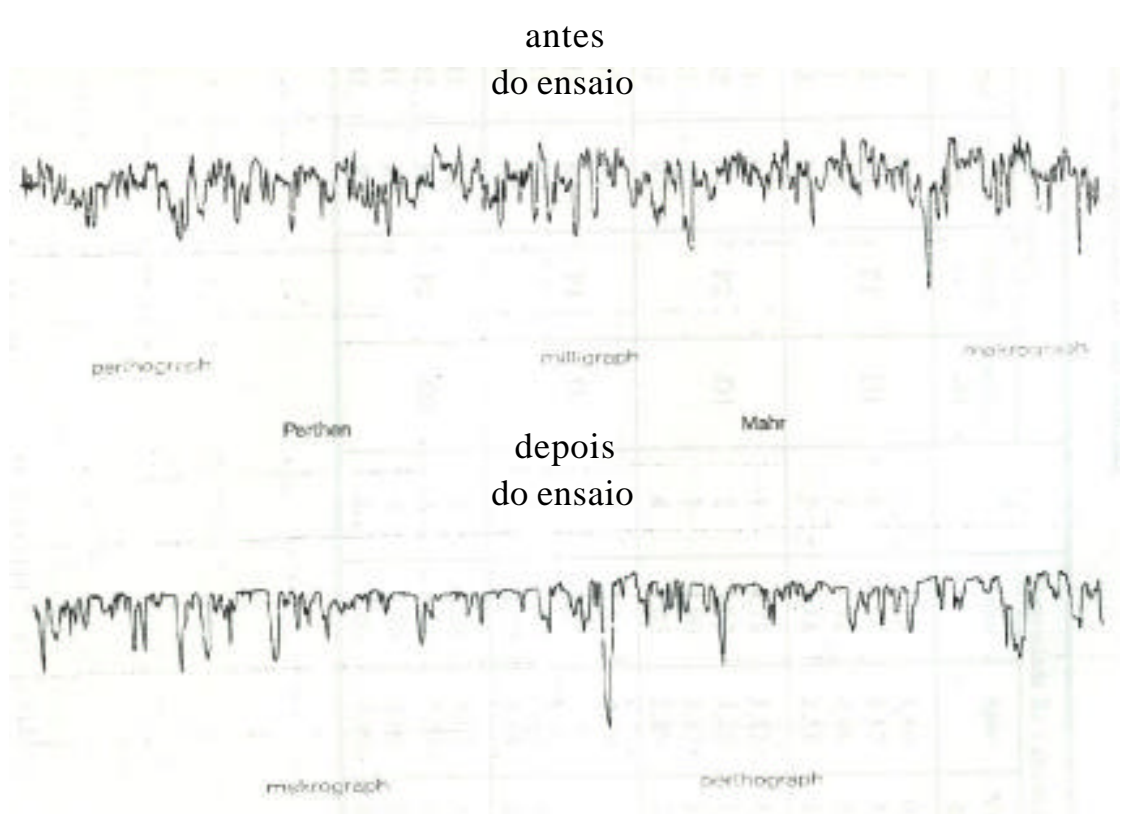

Fig.2.10- Perfis de rugosidade de um cilindro novo e após 200 horas de ensaio em dinamômetro. Motor a gasolina. DEMARCHI, 1994

Uma outra medida de desgaste, em geral restrita a ensaios de desenvolvimento, é a medição da área espelhada do cilindro. Como área espelhada ou polida se entende regiões onde os riscos de brunimento desapareceram completamente. Embora existam equipamentos capazes de fazer a medição dessa área por meios ópticos, eles não são de uso comum. Usualmente, a medida da área polida é feita cortando o cilindro ao meio e demarcando a região onde os riscos de brunimento sumiram e comparando com a área total do cilindro ou com a área 
percorrida pelos anéis. Assim, a área espelhada é usualmente dada como porcentagem de uma dessas duas áreas, DEMARCHI (1994).

\subsection{4- TAXAS DE DESGASTE E INFLUÊNCIAS NO DESGASTE DE ANÉIS}

O desgaste dos anéis depende fortemente do ciclo de ensaio ou do modo de dirigir. A fig.2.11 (THOM et al, 1995), mostra o desgaste verificado em motores de veículos com diferentes utilizações.

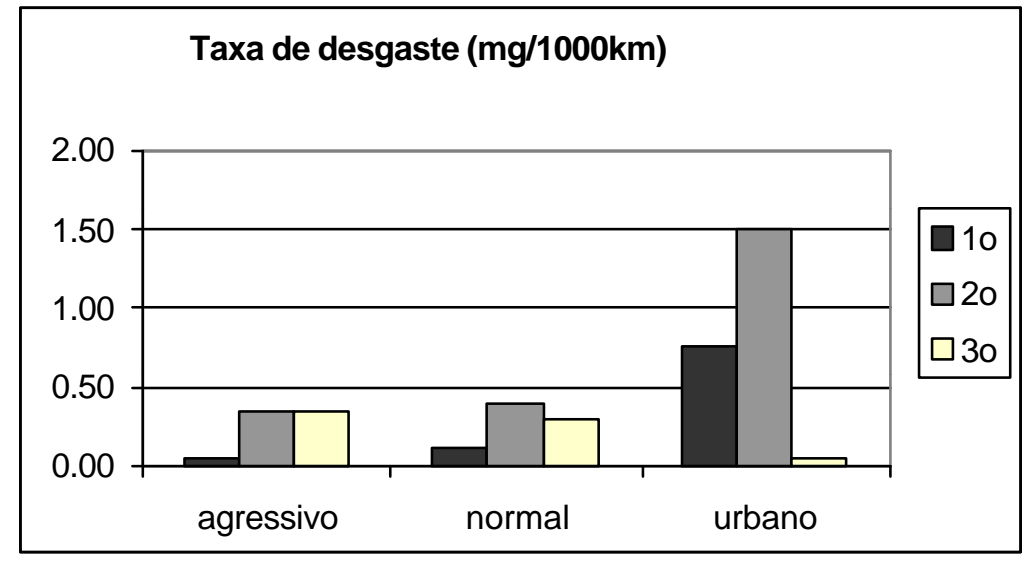

Fig.2.11- Influência do modo de dirigir no desgaste de anéis, motores a gasolina. THOM et al (1995).

O desgaste depende também da qualidade e do estado do óleo. A fig. 2.12, também de THOM, mostra que o desgaste verificado com um óleo no final do intervalo de troca foi o dobro que com o mesmo óleo no início de vida. 


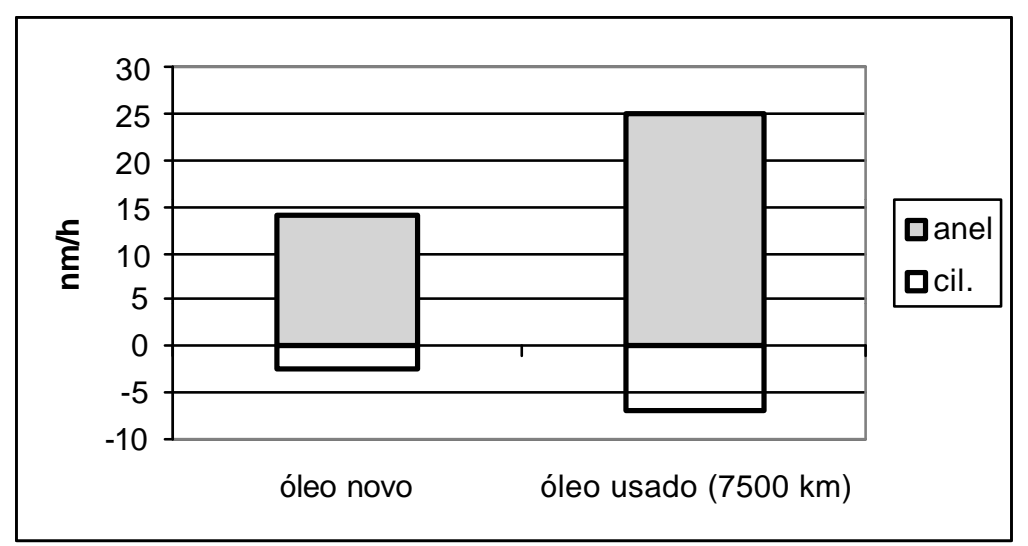

Fig.2.12- Influência do óleo no desgaste de anéis e cilindro. Motor Diesel automotivo. THOM et al (1995).

A literatura apresenta valores de desgaste em anéis em variação de peso, de radial, de aumento da folga entre pontas etc. As condições de teste são também as mais diversas: plena carga, cíclica tentando reproduzir as condições de uso, cíclica (por ex. quente/frio) tentando acelerar o desgaste etc. Essa abordagem, se por um lado é compreensível, por se tratar de um componente industrial, muitas vezes em uma aplicação específica, por outro lado dificulta o intercâmbio de experiências.

O desgaste de anéis e cilindro pode degradar o desempenho do motor; ISHIZUKI et al (1981) verificaram experimentalmente num motor Diesel que a maior influência no consumo de óleo (C.O.) foi o desgaste do cilindro. 
Schneider et al (1988) estudaram o desgaste de anéis cromados de $1^{\circ}$ canalete em motores

Diesel através da medição contínua da radiotividade da face de contato dos anéis,

previamente dopados por rádio isótopos. A partir dos valores medidos, o autor propôs uma equação empírica para a taxa de desgaste:

$$
W[\mathrm{~nm} / \mathrm{h}]=a \cdot \mathrm{e}^{b T}+c
$$

onde $\quad T$ : tempo em horas de utilização do motor

$a$ : taxa de desgaste com 0 horas, devido ao amaciamento

$b$ : constante de tempo do amaciamento

$c$ : taxa de desgaste após o amaciamento estar completo

Os autores observam que a taxa de desgaste diminui com o aumento da rotação do motor, tanto durante o amaciamento quanto após. Isso fica mais claro se calcularmos a taxa de desgaste após o amaciamento pelo numero de ciclos de potência (vide última coluna da tabela).

\begin{tabular}{|c|c|c|c|c|}
\hline \multicolumn{3}{|c|}{ 2.4- Taxa de desgaste em função da rotação } & (SCHNEIDER et al, 1988) \\
\hline \multirow{2}{*}{$\mathrm{rpm}$} & \multicolumn{2}{|c|}{ taxa de desgaste } & $\mathrm{b}$ & \\
& \multicolumn{2}{|c|}{$[\mathrm{nm} / \mathrm{h}]$} & {$\left[\mathrm{h}^{-1}\right]$} & \\
\cline { 2 - 3 } & $\mathrm{a}$ & $\mathrm{c}$ & & \\
\hline 1200 & 145 & 30,3 & $-0,012$ & 0,84 \\
\hline 1500 & 124 & 26,9 & $-0,018$ & 0,60 \\
\hline 1800 & 73 & 20,2 & $-0,011$ & 0,37 \\
\hline 2100 & 58 & 13,8 & $-0,02$ & 0,22 \\
\hline
\end{tabular}


Os autores também verificam o esperado aumento da taxa de desgaste com a Pressão Média Efetiva e que apenas $10 \%$ do cromo removido da face de contato é retirado do sistema pelo filtro de óleo, sendo que os $90 \%$ restantes recirculam com o óleo. Essas partículas de cromo, pequenas demais para serem removidas pelo filtro, podem causar desgaste abrasivo. Apenas com a drenagem e troca de óleo essas partículas foram removidas.

FRITZ (1990) mede continuamente o desgaste de anel de $1^{\circ}$ canalete num motor Diesel (500 h de ensaio, Pressão Média Indicada = 2,3 MPa, pressão máxima de combustão de 14,5 MPa, máximo de 1200 rpm) e obtém valores de 45 a 60 nm/h. DEMARCHI (1994) estuda a influência de diversas variáveis como revestimento, matéria-prima, perfil da face de contato e ovalização do anel em MCI à gasolina. MICHALSKI \& PAWLUS (1994) testam diferentes materiais e acabamento superficiais de cilindro sob condições abrasivas, e verificam que o ranqueamento de desgaste é invertido ao se passar de testes em bancada para testes em motor, pelo menos neste caso, inviabilizando o uso de testes de bancada. Em cilindros de ferro fundido, o mecanismo de desgaste predominante parece ser polimento (HILL, 1996), onde os riscos de desgaste são em pequeno número e o desgaste parece ocorrer gradual e uniformemente. BUDINSKI apud HILL (1996) define polimento como a "remoção progressiva, não intencional, de material da superfície pela ação atritante de outro corpo sob condições que o material é removido sem visível riscamento, fratura ou deformação plástica. 
KNOWLAND \& RUSSELL (1996) propuseram uma equação empírica para estimar o desgaste acelerado que ocorre durante amaciamento. Segundo os autores, a taxa instantânea de remoção do material pode ser estimada por:

$$
\frac{8 W}{B t}=\left[\alpha \cdot e^{\left(-t \cdot V_{b} \cdot\right)}+\gamma\right] \frac{F_{b} V_{p}}{\pi D_{n} \cdot b}
$$

onde $\quad "=\left(\right.$ B. $\left.A_{l} \cdot D_{n} \cdot b\right) /\left(F_{b} \cdot V_{p}\right)$

$$
\begin{aligned}
& \$=A_{2} / V_{p} \\
& \left(=\mathrm{B} \cdot A_{3} \cdot D_{n} \cdot b / F_{b} \cdot V_{p}\right. \\
& V_{p}: \text { velocidade do pistão } \\
& b \text { : altura do anel } \\
& W: \text { altura gasta do anel } \\
& F_{b}: \text { força de atrito devido ao contato das asperezas } \\
& A_{1}, A_{2}, A_{3} \text { constantes empíricas }
\end{aligned}
$$

Uma análise dos termos da equação mostra sua desnecessária complicação e utilidade discutível: $\left(F_{b} . V_{p}\right) /\left(\right.$ B. $\left.D_{n} . b\right)$ pode ser entendido como uma potência de desgaste por unidade de área do anel. Chamando esse termo de $w l$, a equação (2.4) pode ser reescrita:

$$
\frac{8 W}{\delta t}=\left(\frac{A_{1}}{w l} \cdot e^{\left(-A_{2} t\right)}+\frac{A_{3}}{w l}\right) w l \quad \rightarrow \quad \frac{8 W}{8 t}=A_{1} \cdot e^{\left(-\Delta_{2} \cdot t\right)}+A_{3}
$$

ou seja, bastante similar a (2.3): 
- para tempos longos, a taxa de desgaste tende à $A_{3}$, constante.

- no início da vida $(t Y 0)$ a taxa de desgaste vale $A_{1}+A_{3}$.

- para tempos intermediários, o incremento da taxa decresce exponencialmente, com

expoente $A_{2}$.

Os autores apresentam, sem maiores detalhes, gráficos de taxa de desgaste ao longo do ângulo do virabrequim (da ordem de $2 \mathrm{E}-11 \mathrm{~mm} / \mathrm{s}$ nos pontos de reversão do movimento, por grau do virabrequim), bem como estimativas do perfil desgastado do anel, inclusive para diferentes regiões do anel, mas igualmente sem fornecer detalhes.

FROLUND \& SCHRAMM (1997) compilam da literatura os valores experimentais, que variam de 0,6 a 3,4 : m, de filme de óleo remanescente na parede de cilindros de $\mathrm{MCI}$ em funcionamento. KODALI et al (2000) ensaiam diferentes materiais de cilindro em bancada contra anel cromado, sendo seus resultados resumidos na tabela 2.5.

\begin{tabular}{|c|c|c|}
\hline Tabela 2.5- Coef. de desgaste, ensaio de bancada & \multicolumn{2}{c|}{ KODALI et al (2000) } \\
\hline Material do cilindro & \multicolumn{2}{|c|}{ Coef. de desgaste, $k$} \\
& \multicolumn{2}{|c|}{$\left[\mathrm{mm}^{3} / \mathrm{N} . \mathrm{m}\right]$} \\
\cline { 2 - 3 } & óleo novo & usado* \\
\hline Ferro fundido (FoFo) & $9,80.10^{-11}$ & $3,05.10^{-10}$ \\
\hline FoFo cinzento, endurecido por indução & $1,90.10^{-11}$ & $1,73.10^{-10}$ \\
\hline FoFo cinzento, especialmente ligado & $3,96 \cdot 10^{-11}$ & $5,85.10^{-11}$ \\
\hline
\end{tabular}

* contendo 350 ppm de ferro, 4,5\% fuligem e TBN 3,5 (quando novo: 7,0) 
O perfil da face de contato, que se modifica durante a vida do motor devido o desgaste, tem forte influência no desempenho do anel. Vários estudos, teóricos ou experimentais, abordam esse assunto. FURUHAMA \& HIRUMA (1975) estudam a formação do perfil abaulado do anel em funcionamento e supõem que scuffing ocorre se esse perfil provocado pelo desgaste for inadequado; STECHER (s.d.) chega à conclusões semelhantes, vide fig.2.13. YOSHIDA et al (1991) estudam o consumo de óleo num motor Diesel em função do valor do abaulado e do ângulo da face de contato do $1^{\circ}$ anel. MIHARA \& INOUE (1995) estudam a influência do perfil desgastado no consumo de óleo e concluem que o típico perfil abaulado assimétrico resulta principalmente da inclinação do anel dentro do canalete e propõem um perfil ótimo quanto ao consumo de óleo. Como já citado, YOSHIDA et al (1997) estudam falhas em anéis de $1^{\circ}$ canalete em aço nitretado e concluem que essas foram causadas por pressões de contato excessivas provocadas pela formação de um perfil hidrodinamicamente inadequado.

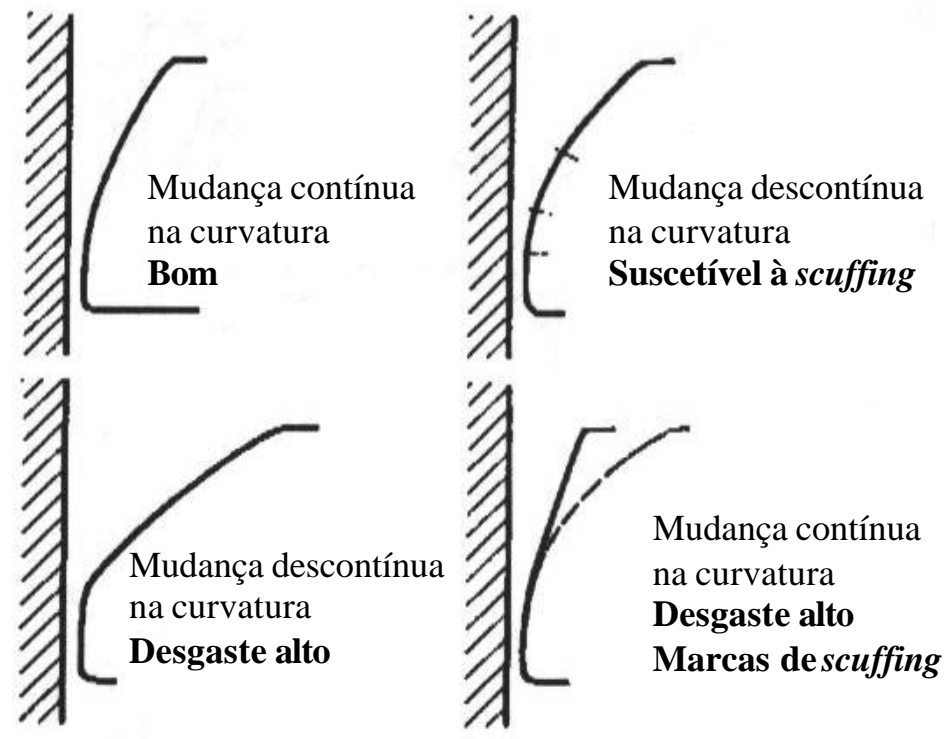

Fig.2.13- Perfis desgastados da face de contato do anel. STECHER (s.d.). 


\section{4- CONTATO ENTRE SUPERFÍCIES RUGOSAS}

\subsection{1- Modelo de Hertz para o contato de uma esfera contra plano}

Quando 2 superfícies são pressionadas, o contato ocorre, inicialmente, em poucos pontos, nos picos das asperezas mais altas. Com o aumento da pressão, mais asperezas vão progressivamente entrando em contato e as mais altas vão se deformando, permitindo o contato das menores. A área real de contato é, em geral, muito menor que a área aparente. Para efeito de análise, o contato entre 2 superfícies rugosas é usualmente modelado como o contato entre uma superfície suposta lisa, rígida e plana e uma outra com rugosidade igual à rugosidade combinada das 2 superfícies originais.

As asperezas individuais são bastante "suaves". Inclinações maiores que 10 graus são bastante raras e a maioria das asperezas têm inclinação muito menor (HUTCHINGS, 1992). Estudando o comportamento de asperezas individuais, é conveniente modelá-las como protuberâncias perfeitamente lisas, de formato esférico. Quando uma esfera de material elástico é pressionada contra um plano com uma carga normal $W$ (fig.2.14), o contato entre os 2 corpos se dará numa área circular de raio $a$ [m], dado pela equação de Hertz (1881):

$$
\alpha=\left(\frac{3 W r}{4 E^{\prime}}\right)^{1 / \beta}
$$

onde $W$ : carga normal $[\mathrm{N}]$

$r$ : raio da esfera $[\mathrm{m}]$ 
$E^{\prime}$ : um módulo de Elasticidade $\left[\mathrm{N} / \mathrm{m}^{2}\right]$ que depende dos módulos de Elasticidade, $E_{1}$ e $E_{2}$ e dos coeficientes de Poisson, $<_{1} \mathrm{e}<_{2}$, dos materiais da esfera e do plano:

$$
\frac{1}{E^{\prime}}=\frac{\left(1-v_{1}^{2}\right)}{E_{1}}+\frac{\left(1-v_{2}^{2}\right)}{E_{2}}
$$

A área de contato entre a esfera e o plano é dada então por:

$$
\text { Área de contato }=\mathbf{B} \cdot a^{2} \tilde{\mathbf{n}} 0.83 \mathrm{~B} \cdot\left(W r / E^{\prime}\right)^{2 / 3}
$$

A pressão média é dada por $P_{\mathrm{m}}=W /$ área de contato, mas não é uniforme, sendo que a pressão máxima ocorre no centro, caindo para zero nas bordas do contato (vide fig. 2.14). A pressão máxima $\left(\mathrm{P}_{\max }\right)$ vale aproximadamente $1,5 P_{\mathrm{m}}$. Hertz também estudou as tensões de cisalhamento ao longo da profundidade do plano. A máxima tensão de cisalhamento ocorre a uma profundidade de $\sim 0,48 a$ e vale $\sim 0,47 P_{\mathrm{m}}$ (ou 0,31 $P_{\text {max }}$ ). Admitindo que a deformação plástica ocorra quando a tensão de cisalhamento, $\mathrm{J}_{\max }$, atinja metade da tensão de escoamento unidimensional $Y$ (critério de Tresca), temos que nesse momento $P_{\mathrm{m}}$ vale $1,1 Y$. Se a carga continua sendo aumentada, a região plastificada cresce em direção à superfície. Tanto teórica quanto experimentalmente se levantou que a pressão média também aumenta (assintóticamente) até atingir um máximo de 2,8 Y, WILLIAMS, 1994, item 3.5.1. 


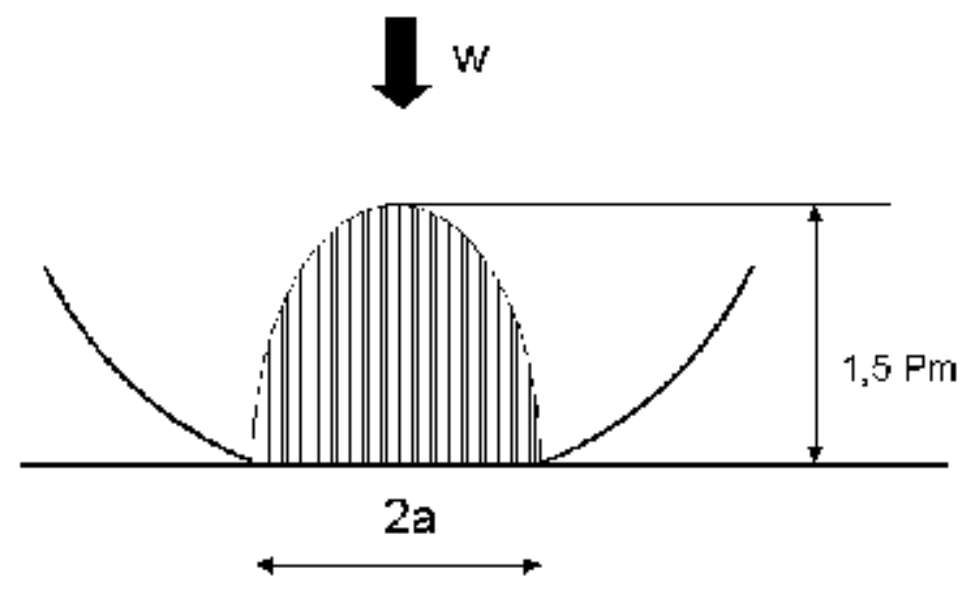

Fig.2.14- Modelo de Hertz, esfera contra um plano rígido.

Com a ocorrência de deformações plásticas, a distribuição elíptica assumida por Hertz não é mais válida, o que significa também que $\mathrm{P}_{\max }$ é diferente de $1,5 P_{\mathrm{m}}$. Veremos a frente que diversas verificações mostram que o contato é plástico na maioria dos acabamentos de engenharia. Mesmo assim, as equações de Hertz ainda são usadas por duas razões:

- a imprecisão cometida é da mesma ordem que a dos demais parâmetros envolvidos, por ex. do valor do módulo de Elasticidade dos materiais.

- Após um primeiro contato onde ocorra a deformação plástica, os demais contatos se comportam elasticamente ("shakedown mechanism").

Hertz também admitiu que não existe atrito entre os corpos em contato, o que, em princípio, impediria seu uso no modelamento de corpos deslizando com contato rugoso.

Tal limitação também é desprezada. Se o coeficiente de atrito é menor que 0,3 , os erros são pequenos. (WILLIAMS, 1994). 
A deformação normal ( $)$ z) que a esfera sofre pode ser calculada por:

$$
\begin{gathered}
W=\frac{4}{3} \cdot E^{\prime} \cdot \sqrt{r} \cdot \Delta z^{3 / 2} \\
\Delta z=\left(\frac{3 W}{4 E^{\prime} \sqrt{r}}\right)^{\frac{2}{3}}=\frac{a^{2}}{r}
\end{gathered}
$$

\subsection{2- Modelo de Greenwood-Williamson}

O modelo mais utilizado de contato entre superfícies rugosas foi apresentado por GREENWOOD e WILLIAMSON (G-W) em 1966. O modelo de G-W admite que a superfície rugosa tem picos com formato esférico de raio $\$$, que se distribuem uniformemente sobre a superfície, com densidade por unidade de área $=0$. A outra superfície é admitida rígida, lisa e plana. Os picos da superfície rugosa têm altura aleatória e se deformarão elasticamente quando carregados de acordo com as equações de Hertz; a fig. 2.15 mostra o contato entre a superfície rugosa e um plano rígido.

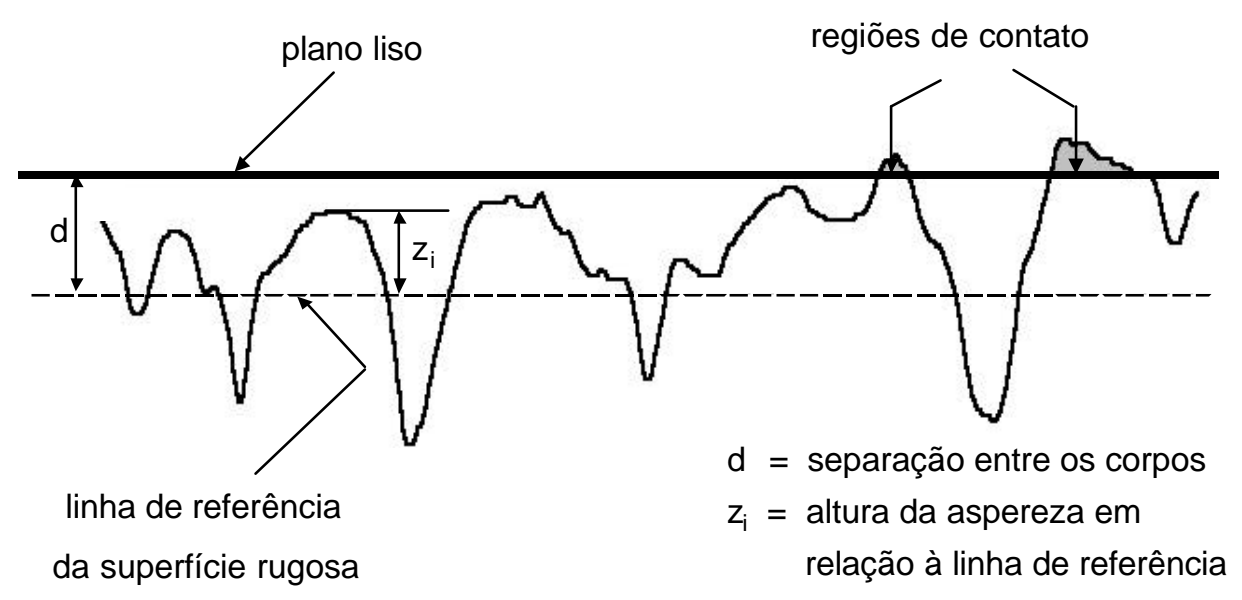

Fig. 2.15- Representação esquemática do contato entre uma superfície rugosa e um plano rígido e liso. Modelo de Greenwood e Williamson. 
A altura dos picos individuais acima do plano de referência é $z$. É importante ressaltar que as medidas usuais de rugosidade não registram necessariamente (e em geral não o fazem) a ocorrência da máxima altura de uma aspereza. A distribuição de altura e a densidade dos "topos" ("summits") que farão inicialmente contato não é a mesma dos picos registrados nas medidas de rugosidade. Imaginemos a ponta de um rugosímetro passando pela aspereza idealizada da fig. 2.16; apenas o percurso que passasse pelo topo seria capaz de medir a altura real da aspereza, embora todos os outros registrassem a ocorrência de um pico (“peak”). Por ser mais usual, será mantida a terminologia “pico”, mas o leitor deve estar atento ao fato de que o modelo de G-W contempla, na verdade, os topos das asperezas.

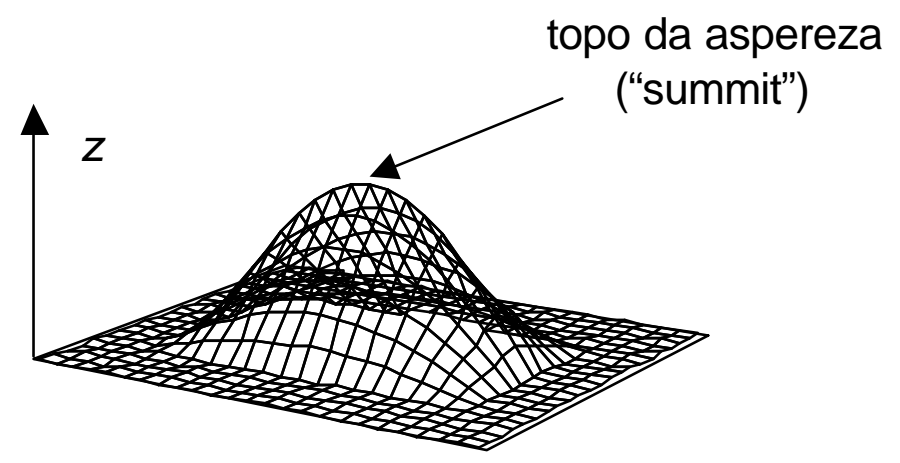

Fig. 2.16- Aspereza idealizada, ilustrando a diferença entre o topo da aspereza ("summit") e os possíveis picos (“"peaks") registrados num perfil de rugosidade.

Admite-se que a altura dos picos tenha uma certa distribuição estatística. Essa distribuição pode ser descrita pela função densidade de probabilidade $\mathrm{N}(z)$, tal que:

$$
\int_{-\infty}^{+\infty} \phi(z) \delta z=1
$$


de forma que todos os picos sejam incluídos. A probabilidade de que uma aspereza faça contato com a superfície plana é a probabilidade de que a altura $(z)$ dessa aspereza seja maior do que a separação $(d)$ entre os planos referência:

$$
P(z>0)=\int_{d} \phi(z) \delta z
$$

e o número de contatos entre asperezas e o plano liso (por unidade de área)

$$
n=n \cdot \int_{d} \phi(z) \delta z
$$

Uma dada aspereza, inicialmente com altura $z_{s}$, terá então sido comprimida de um montante $*_{s}$ dado por: $*_{s}=z_{s}-d$. A área de contato entre a aspereza e a superfície lisa será uma pequena região circular, digamos de área $A_{i}$ e raio $a_{i}$, tal que: $A_{i}=\mathrm{B} \cdot a_{i}{ }^{2}$

Se esse contato permanecer no campo elástico e se as tensões de um contato não afetarem os contatos vizinhos (ou seja, se a distância entre as asperezas em contato for grande se comparada com a área de contato), podemos tratar cada contato de aspereza como um contato Hertziano entre uma esfera e um plano. A relação entre a área de contato e a deformação é dada pela eq. (5), substituindo ) $z$ por ${ }_{s}=\left(z_{s}-d\right)$ :

$$
A_{i}=\mathrm{B} \cdot a_{i}{ }^{2}=\mathrm{B} \cdot \$ \cdot\left(z_{s}-d\right)
$$


A área total de contato A é a soma de todos os contatos entre asperezas:

$$
A=\sum A_{i}=n \cdot A_{t} \cdot \Pi \cdot \beta \cdot \int_{d} \phi(z)(z-\phi) \delta z
$$

onde $A_{0}$ é a área aparente de contato; 0.A é o número total de asperezas.

Do mesmo modo, a carga $w_{i}$ suportada nesse típico contato, é dada pela eq. (2.9):

$$
w_{i}=\frac{4}{3} \cdot E^{\prime} \cdot \sqrt{\beta} \cdot \Delta z^{3 / 2}
$$

e a carga total W é a soma de todos os contatos, de modo que:

$$
W=\frac{4}{3} \cdot n \cdot A_{\mathrm{b}} \cdot E^{\prime} \cdot \sqrt{\beta} \cdot \int_{d} \phi(z)(z-\phi)^{3 / 2} \delta z
$$

O número total de contatos $n$, a área $A$ e a carga de contato $W$, dados respectivamente pelas equações (2.13), (2.15) e (2.17), dependem claramente da distribuição $N(z)$ adotada. Se a altura da aspereza segue uma distribuição exponencial, as integrais podem ser resolvidas analiticamente e tanto o número de contatos quanto a área real de contato são linearmente proporcionais à carga total $W$. Com o aumento de carga, o tamanho de cada ponto de contato aumenta, mas mais asperezas entram em contato, de modo que o tamanho médio dos pontos de contato permanece o mesmo. Se o contato é plástico, a pressão é constante e já atingiu seu máximo, novamente a área real de contato também é linearmente proporcional à carga aplicada. 
Greenwood e Williamson definiram um índice de plasticidade do contato, R:

$$
\Psi=\frac{E^{\prime}}{H} \sqrt{\frac{\sigma_{\varepsilon}}{\beta}}
$$

onde, $H$ : dureza de indentação da superfície rugosa

$\mathrm{F}_{\mathrm{S}}$ : desvio padrão da distribuição de altura das asperezas $(\mathrm{Rq})$

$\left(F_{S} / \$\right)^{1 / 2}$ é aproximadamente igual à inclinação média das asperezas. A ocorrência de deformação plástica nos contatos é determinada pelo valor de $R$. Para valores de $R<0,6$, a deformação plástica nas asperezas só ocorre com pressões nominais de contato muito altas; já para valores de $\mathrm{R}>1$, a maioria das asperezas se deforma plasticamente, mesmo sob pressões nominais muito baixas. Para metais, com acabamentos usuais de engenharia, $\mathrm{R}$ tem valor entre 0,1 e 100 . Mesmo metais polidos tem $R$ maior que 1,0 e o contato entre asperezas será majoritariamente plástico (HUTCHINGS, 1992). A carga suportada por cada aspereza será proporcional à sua área de contato, a área total de contato será proporcional à carga normal aplicada e independente da exata distribuição estatística da alturas. Já para cerâmicas e polímeros, que têm menor razão $E^{\prime} / H$, o contato é mais provavelmente elástico. Embora existam índices ligeiramente diferentes (por ex. vide WHITEHOUSE, 1994, p. 769 ), o índice de plasticidade R de Greenwood é um marco na caracterização do comportamento elástico/plástico do contato, em função da rugosidade das superfícies. Suas implicações no estudo de atrito, desgaste e lubrificação são inúmeras. 
Embora a distribuição exponencial descreva razoavelmente o decil das maiores asperezas em muitas superfícies reais, foi verificado experimentalmente que a distribuição Gaussiana descreve melhor a distribuição das alturas. Os gráficos da fig. 2.17 mostram uma superfície com distribuição normal e uma que teve seus picos removidos; os picos remanescentes mais altos podem continuar sendo considerados como uma distribuição normal.
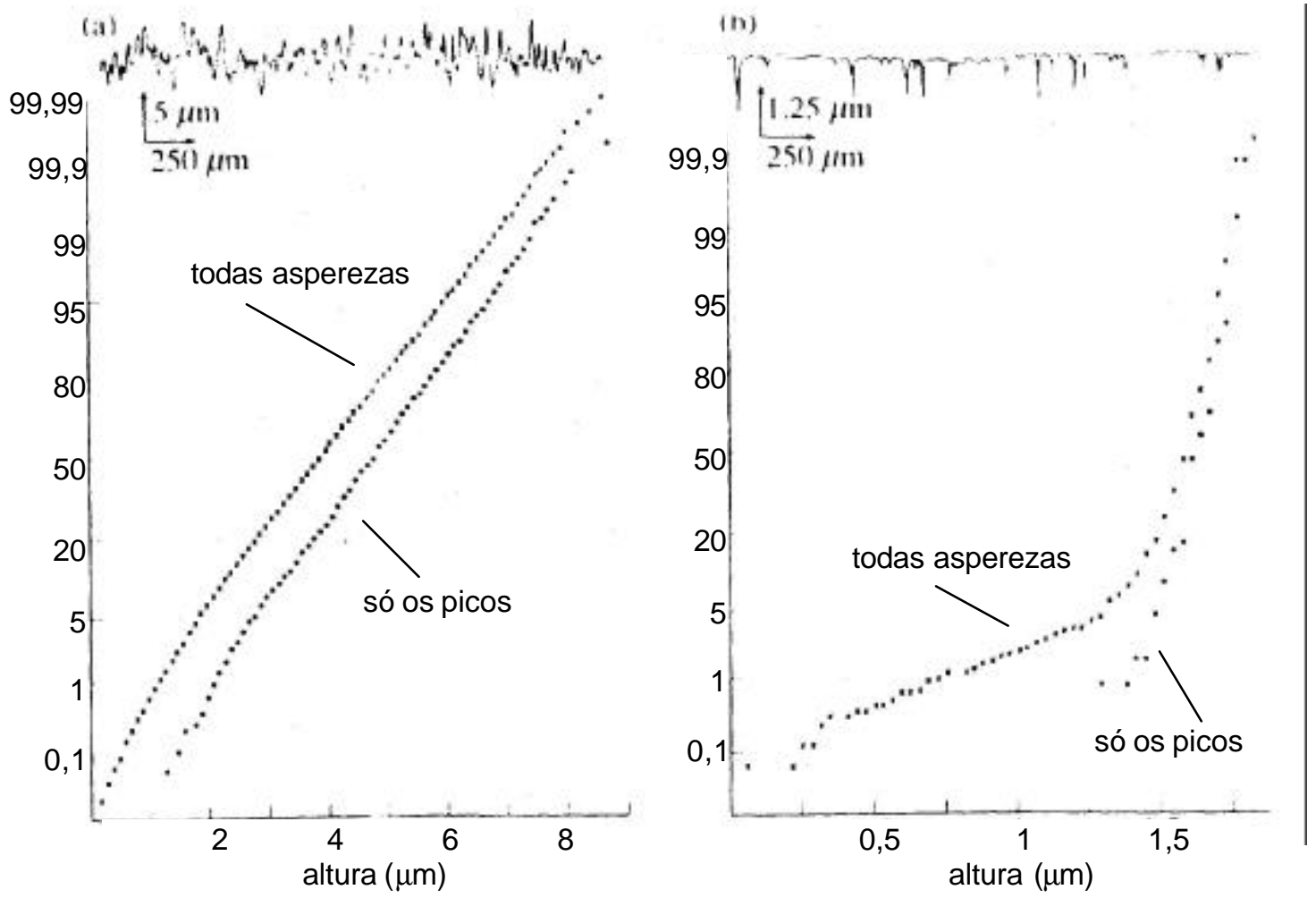

Fig.2.17- Distribuição da altura das asperezas, plotada num gráfico de probabilidade normal. WHITEHOUSE (1994)

Para uma distribuição Gaussiana, as equações (2.13), (2.15) e (2.17) precisam ser integradas numericamente mas, para quantidades fisicamente razoáveis, os resultados não são muito diferentes dos obtidos com a distribuição exponencial. Os valores das integrais podem ser 
calculados com auxílio da curva normal, de média 0 e desvio padrão 1 . Usando a função probabilidade de densidade normal $\mathrm{N}(x)$, a probabilidade de que um pico tenha altura, acima do plano de referência, maior que $d$ é:

$$
P\left(z_{2}>0\right)=\int_{d \sigma_{s}}^{\infty} \phi(t) d t=F_{D}(t)
$$

onde $\mathrm{F}_{\mathrm{s}}$ é o desvio padrão das alturas das asperezas, $F_{0}(t)$ é a área sob a curva normal à direita do valor $t=\left(d / \mathrm{F}_{\mathrm{S}}\right)^{1}$. A fig. 2.18 mostra os valores calculados de $F_{0}(t)$, a partir dos valores tabelados por McCOOL (1986) ${ }^{2}$.

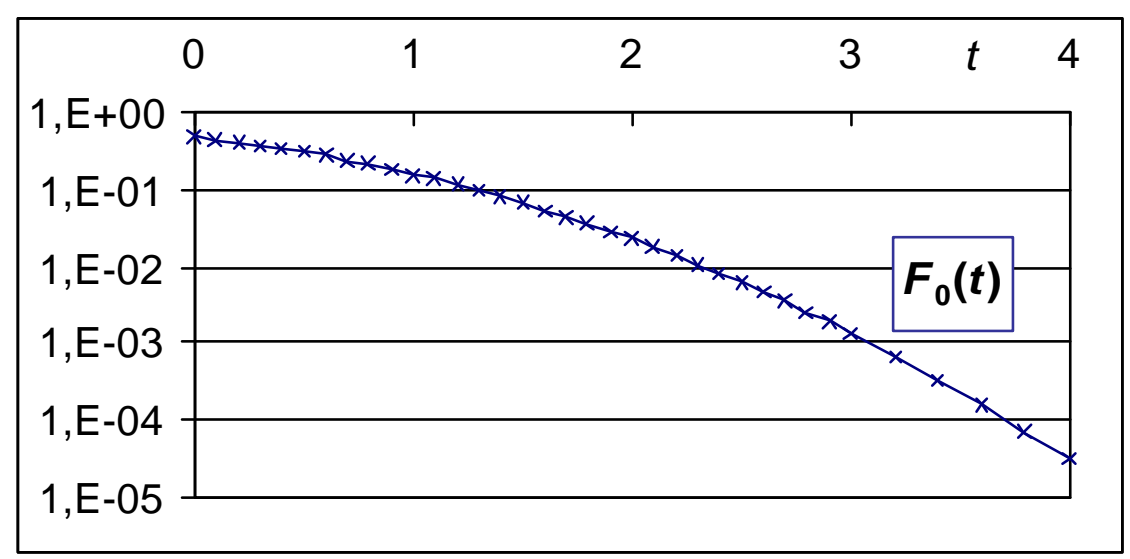

Fig. 2.18- Probabilidade de que um pico tenha altura maior que a distância de separação $(d)$, ou seja, que faça contato $\left(t=d / \mathrm{F}_{\mathrm{S}}\right)$. Valores tabelados por McCOOL, 1986.

${ }^{1}$ Em hidrodinâmica, $\mathbf{t}=\left(d / \mathrm{F}_{\mathrm{s}}\right)$ é conhecido por 7 , parâmetro de filme.

${ }^{2}$ Corrigindo-se o claro erro de tipografia nos valores de $t=2,1$ a 2,3 
De modo similar, a área de contato e a carga total podem ser calculadas com ajuda das funções $F_{1}(t)$ e $F_{3 / 2}(t)$ :

$$
A_{c}=n \cdot A_{\mathrm{d}} \cdot \Pi \cdot \beta \cdot \sigma_{\mathrm{s}} \cdot F_{1}(t)
$$

onde:

$$
\begin{aligned}
& W=\frac{4}{3} \cdot n \cdot A_{\mathbf{b}} \cdot E^{\prime} \cdot \sqrt{\beta} \cdot \sigma_{2}^{3 / 2} \cdot F_{3 / 2}(t) \\
& F_{1}(t)=\int_{d \neq \sigma_{s}}^{\infty} \phi(t) \cdot t \cdot d t \\
& F_{3 / 2}(t)=\int_{0 / 1 / \sigma_{s}} \phi(t) \cdot t^{3 / 2} \cdot d t
\end{aligned}
$$

$\mathrm{F}_{0}(\mathrm{t}), \mathrm{F}_{1}(\mathrm{t})$ e $\mathrm{F}_{3 / 2}(\mathrm{t})$ podem ser calculados por métodos numéricos ou encontrados em tabelas, por ex. em GREENWOOD \& TRIPP (1971) e McCOOL (1986).

\subsection{3- Contatos plásticos segundo o modelo de Greenwood-Williamson}

Uma determinada aspereza começará a se deformar plasticamente quando a máxima tensão de cisalhamento atingir metade da tensão de escoamento unidimensional. Vimos que, para uma esfera contra um plano, isso significa:

$$
\boldsymbol{J}_{\max }=0,31 P_{\text {max }}>Y / 2
$$

lembrando que $P_{\max }=1,5 P_{m}$ e usando as equações (3), (4) e (5), obtemos que o inicio da 
deformação plástica ocorre quando:

$$
0,31 \frac{2 E^{\prime} \sqrt{\Delta z}}{\pi \sqrt{\beta}}>\frac{Y}{2}
$$

$\mathrm{ou}$

$$
\begin{aligned}
& \Delta z=\left(z_{c}-d\right)>6,4 \beta\left(\frac{Y}{E^{\prime}}\right)^{2}=w_{p} \\
& z_{s}>d+w_{p}
\end{aligned}
$$

então todo pico cuja altura exceder $\left(d+w_{p}\right)$ sofrerá alguma deformação plástica. A densidade de contatos plásticos pode ser estimada então por:

$$
\eta_{p}=\eta_{0} \cdot F_{D}\left(t+w_{p} / \sigma_{s}\right)
$$

de modo semelhante à (2.20), a área de contatos plásticos é dada por:

$$
A_{p}=\eta \cdot A_{D} \cdot \Pi \cdot \beta \cdot \sigma_{s} \cdot F_{1}\left(t+w_{p} / \sigma_{s}\right)
$$

e a razão entre a área de contato plástica e a área total de contato por:

$$
\frac{\mathbf{A}_{p}}{\mathbf{A}_{c}}=\frac{F_{1}\left(t+w_{p} / \sigma_{s}\right)}{F_{1}(t)}
$$

Quanto maior $\left(w_{p} / \mathrm{F}_{s}\right)$, menor o número de contatos plásticos. Note-se que, exceto por uma constante, $w_{p}$ é o inverso de $\mathrm{R}^{2}$ (índice de plastificação definido em (2.18)). 
McCOOL, 1986 compara os valores numéricos obtidos com modelos posteriores e mais complexos que os do modelo de Greenwood-Williamson e verifica que as pressões e áreas de contato obtidas são da mesma ordem.

A hipótese do modelo de G-W de que o pico das asperezas é circular foi relaxada num modelo posterior (GREENWOOD \& TRIPP, 1971). O modelo de Greenwood-Tripp considera a solução de Hertz para o contato de 2 parabolóides (o que inclui esferas e elipsóides radialmente simétricos). A solução de Hertz aplica-se apenas aproximadamente já que, dificilmente, as 2 asperezas estarão alinhadas. Devido ao desalinhamento entre as asperezas, a força normal suportada se decomporá numa vertical e numa tangencial. Entretanto, a inclinação das asperezas é tão pequena que o erro cometido pode ser ignorado.

Para o caso de 2 parabolóides a carga total por unidade de comprimento é dada por:

$$
\left.w=\frac{16 \sqrt{2}}{15} \pi(n \beta)^{2} E \cdot \sqrt{\frac{1}{\beta}} \int_{\alpha}(z-\alpha)^{5 / 2} \phi(z) \alpha z\right)
$$

ou usando a mesma metodologia da eq. (2.20)

$$
w=\frac{16 \sqrt{2}}{15} \pi(n \beta)^{2} E \cdot \sqrt{\frac{1}{\beta}} \sigma_{s}^{5 / 2} F_{5 / 2}(t)
$$

$\mathrm{F}_{5 / 2}$ podendo ser calculado de maneira similar a $\mathrm{F}_{0}, \mathrm{~F}_{1}$ e $\mathrm{F}_{3 / 2}$. 


\section{5- MODELOS DE SIMULAÇÃO DE ANÉIS}

A bibliografia sobre modelos de simulação do comportamento dos anéis é extensa. $\mathrm{Na}$ década de 90, podem ser destacados, por exemplo, os trabalhos de KERIBAR et al (1993), TIAN et al (1997a), ARCOUMANIS et al (1997) e KNOPF et al (1998). No Brasil, 2 dissertações de mestrado sobre o assunto foram apresentadas: ZOTTIN (1992) e TOMANIK (1993). Entre os programas de simulação de anéis disponíveis no mercado, podem ser citados: CASE (Southwest Research Institute), RINGPAK (Ricardo Software) e GLIDE (AVL). A maioria dos trabalhos na área considera um modelo bidimensional (axi-simétrico), no qual o pacote de anéis é modelado como um "labirinto de orifícios". As principais grandezas calculadas são o fluxo de gases da câmara de combustão para o carter do motor ("blow- by") e mais recentemente, o consumo de óleo lubrificante. O contato entre as superfícies (comumente) e o desgaste (eventualmente) são, em geral, modelados utilizando respectivamente os modelos de Greenwood e o de Archard. O modelo de Greenwood tem sido usado pelo menos desde a década de 80 (RUDDY, 1982) e ainda hoje é o mais utilizado.

Entretanto, embora a previsão do blow-by e mesmo a do consumo de óleo lubrificante já estejam se tornando prática de engenharia, a estimativa do desgaste ainda é feita ou por ensaios de bancada de validade por vezes discutível ou por longos e custosos ensaios em motor. Com durabilidade requerida de centenas de milhares de quilômetros, torna-se evidente a necessidade de métodos preditivos para uso na fase de projeto do motor. A seguir, serão abordados os trabalhos na área de modelamento do desgaste de anéis: 
TING (1980) descreve os passos básicos para cálculo do desgaste de cilindros:

1- Obter a curva da pressão de combustão para o motor e o regime em estudo.

2- Admite-se que a pressão agindo atrás do $1^{\circ}$ anel é igual à pressão de combustão. Calcular a pressão agindo nos demais anéis do pacote.

3- Calcular o filme de óleo na face de contato do anel a cada ângulo do virabrequim.

Determinar as regiões onde o filme de óleo é menor que o limite para lubrificação hidrodinâmica.

4- Determinar a pressão nominal de contato entre os anéis e o cilindro ao longo dos 4 tempos do motor.

5- Calcular as forças laterais do pistão atuando nos lados de maior e de menor pressão.

Convertê-las em pressão nominal de contato dos anéis ${ }^{1}$.

6- Somar as pressões calculadas nos passos 4 e 5 para cada um dos anéis.

7- A cada altura do cilindro determinar a somatória das pressões nominais de contato.

8- Estimar o desgaste no cilindro através da equação de Archard.

Os passos de 1 a 4 são hoje calculados pelos programas de simulação de anéis, o 5 pode ser feito com a simulação do movimento secundário do pistão. Os passos 6 e 7 são apenas uma somatória de valores calculados nos passos anteriores. Finalmente, o passo 8 seria o cálculo do desgaste ocorrendo no cilindro. Ting não prevê o cálculo das pressões devido ao contato rugoso, provavelmente por limitações computacionais da época. Outro aspecto não considerado é a variação das superfícies ao longo da vida do motor.

1 TING adota este procedimento para explicar o desgaste diferenciado circunferencial do cilindro, maior no lado de maior pressão. 
Os trabalhos seguintes ao de Ting procuraram melhorar o modelamento, tanto das condições atuantes nos anéis (pressões, lubrificação etc.), como do contato entre superfícies rugosas. HANNOSCHOCK (1985) usa a equação de Archard e o modelo de Greenwood \& Williamson num programa de simulação de anéis, para estudar o desgaste do anel e cilindro. O programa RINGPAK calcula o produto da pressão de contato rugoso ao longo do perfil, pela velocidade instantânea do anel. Esse produto é denominado de "Wear Load". Mas os valores calculados, em geral, não concordam com o desgaste verificado experimentalmente. A fig. 2.19,

reproduzida de GULWADY (1997) mostra os valores calculados para o $2^{\circ}$ anel. Pelos valores mostrados, o desgaste deveria se concentrar na região inferior da face de contato, enquanto que em geral acontece o contrário (vide por ex. a fig, 2.20). Gráficos semelhantes de "Wear Load" são obtidos para anéis de $1^{\circ}$ canalete. A partir do "wear load", a taxa de desgaste poderia ser calculada pela equação:

$$
\text { taxa de desgaste }\left[\mathrm{m}^{3} / \mathrm{s}\right]=\frac{K \int_{\Delta}(\text { wear lood })\left[\mathrm{Pam} \cdot \mathrm{s}^{-1}\right] \delta A\left[\mathrm{~m}^{2}\right]}{H\left[\mathrm{~kg} / \mathrm{mm}^{2}\right] \cdot 9,81.10^{6}}
$$

onde $A$ é a área do anel, ou seja também seguindo a lei de Archard. Um dos problemas em se usar a lei de Archard é que não existem valores confiáveis para o coeficiente de desgaste. 

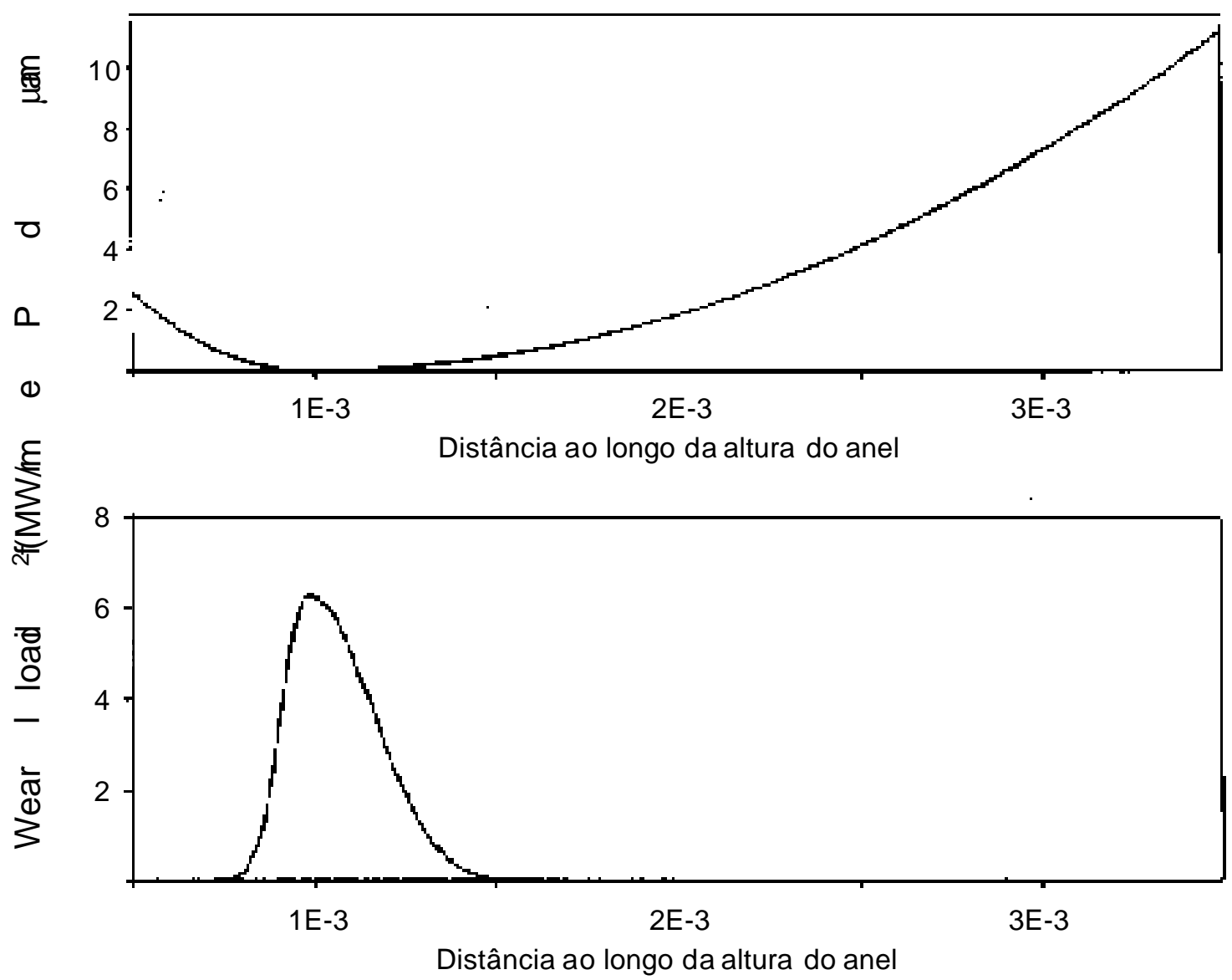

Fig. 2.19- Perfil da face do anel e produto da pressão de contato rugoso pela velocidade tangencial ("Wear Load"). Anel de $2^{\text {o }}$ canalete, topo à direita. GULWADY et al (1997).

TIAN et al (1997 a), concluem que o maior desgaste na parte superior da face de contato do anel de $1^{\circ}$ canalete é devido ao desgaste do flanco inferior do canalete. Essa conclusão não parece concordar com as próprias medições apresentadas. Vide reprodução na fig. 2.20. É nítido o resultante perfil cônico do $1^{\circ}$ anel, bem como o desgaste na lateral inferior do anel. Mas o desgaste no flanco inferior do canalete parece muito pequeno para explicar tanto o perfil cônico da face de contato, como o desgaste na lateral inferior do anel. O mesmo autor num outro trabalho (TIAN, 1997b) conclui que o desgaste anel/canalete tende a criar um ângulo 
constante de desgaste. Analisando a fig. 2.9 é possível perceber que o ângulo da face de contato parece assumir um valor constante já com 250 h e que não continua a aumentar, o que seria esperado se esse ângulo fosse provocado pelo desgaste do canalete.

RICHARDSON \& KRAUSE (1998) utilizam o programa RINGPAK para estudar a influência de valores admitidos de desgaste, na face de contato e na altura de anéis e do cilindro no consumo de óleo e blow-by de 2 motores Diesel. Concluem que a influência depende do motor e que o desgaste da face do anel tem maior peso do que o desgaste da parede do cilindro, bem como que o desgaste da altura do anel tem pouca influência. Se por um lado este trabalho procura prever a influência do desgaste, por outro não prevê de quanto seria esse desgaste. A modelagem dos perfis desgastados é também bastante simplista.

KNOPF (1998) utiliza o modelo de Patir e Cheng para calcular a lubrificação mista; considera diferentes orientações da rugosidade e a possibilidade de deformações plásticas no contato rugoso, mas ainda não considera a deformação do canalete, nem tão pouco tenta prever a evolução do desgaste. 


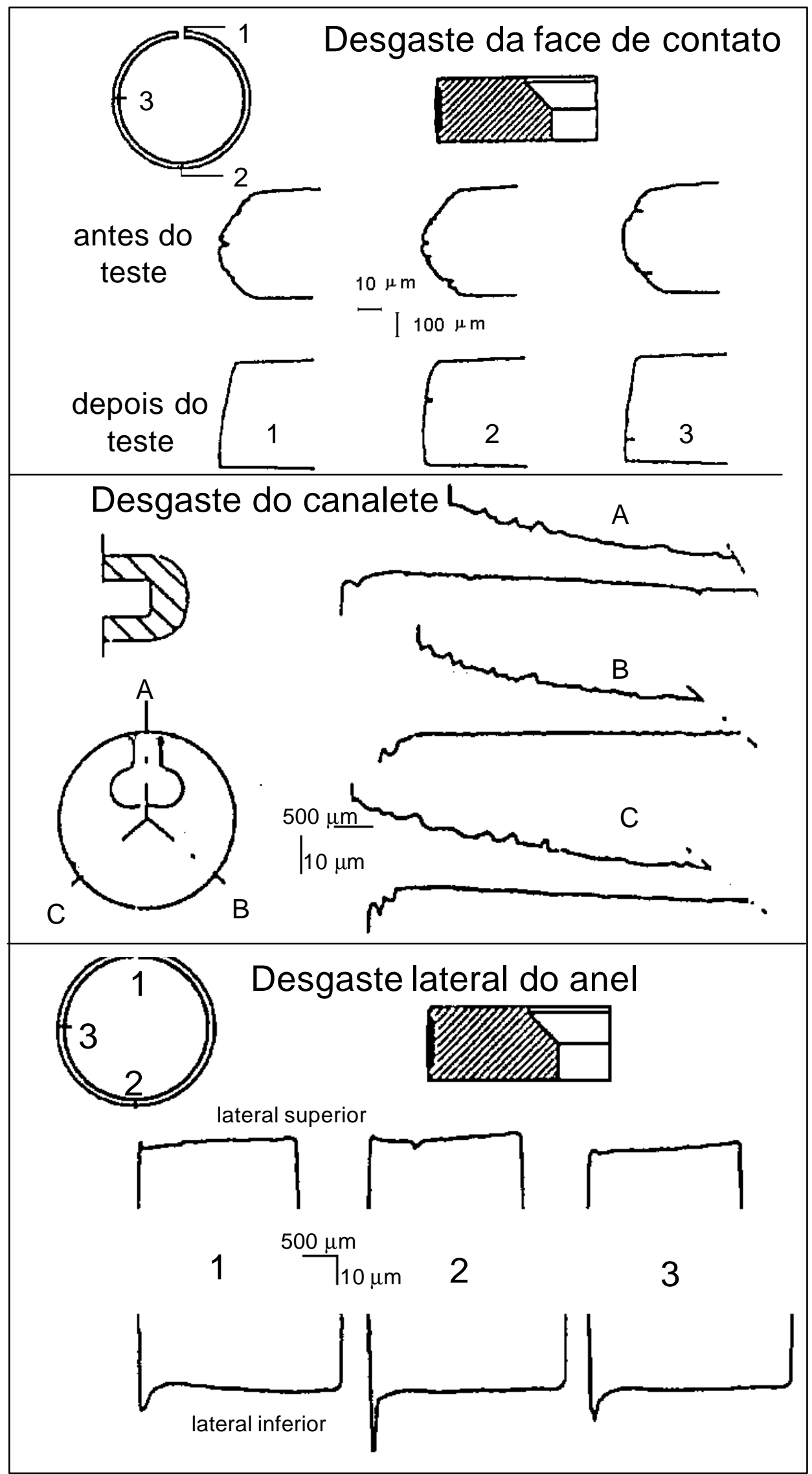

Fig. 2.20- Desgaste do anel/canalete. Anel de $1^{\circ}$ canalete, motor Diesel automotivo. TIAN (1997a, b) 
Muito recentemente foram publicados 2 trabalhos sobre o modelamento do desgaste de anéis de pistão: PRIEST et al (1999) utilizam um modelo de simulação do pacote de anéis e valores experimentais do coeficiente de desgaste, obtidos em bancada, para prever o desgaste dos anéis. Os autores correlacionam a espessura do filme de óleo com um determinado valor de taxa de desgaste, se aquela for menor que 4 vezes a rugosidade combinada; também limitam o valor mínimo para a espessura em metade dessa rugosidade. Aparentemente não resolvem de forma acoplada as pressões hidrodinâmicas e as de contato rugoso. A tabela abaixo reproduz os valores experimentais de taxa de desgaste obtidos pelos autores.

\begin{tabular}{|c|c|c|}
\hline \multicolumn{2}{|c|}{ Tabela 2.6- Coef. de desgaste para anéis obtidos em bancada } \\
\hline $\begin{array}{c}\text { Temperatura } \\
\text { ( C })\end{array}$ & $\begin{array}{c}\text { condição do } \\
\text { lubrificante }\end{array}$ & $\begin{array}{c}\mathbf{k}_{\mathbf{0}} \\
\left(\mathbf{m m}^{\mathbf{3}} \mathbf{m m}^{-1} \mathbf{N}^{-1}\right)\end{array}$ \\
\hline 200 & novo & $2 \cdot 10^{-13}$ \\
\hline 300 & novo & $4 \cdot 10^{-12}$ \\
\hline 300 & degradado & $5 \cdot 10^{-11}$ \\
\hline
\end{tabular}

PINT \& SCHOCK (2000) partem de um modelo comercial de simulação de anéis para prever o desgaste de anéis; ao contrário do usual na literatura, os autores utilizam Rz (e não Rq) como descritor da distribuição da altura das rugosidades; admitem também como limite para contato rugoso 1 e não 3 ou 4 vezes a rugosidade combinada. Consideram que se a espessura do filme de óleo for menor que a rugosidade combinada, toda carga é suportada pelas asperezas. Concluem que o perfil desgastado do anel é definido pelo seu movimento angular dentro do canalete. 


\section{3- MODELO FÍSICO COMPUTACIONAL}

Para modelamento da evolução do perfil da face deslizante do anel ao se desgastar é necessário um equacionamento detalhado das forças atuantes no anel, o que é bastante complexo dada a característica transitória dos fenômenos que ocorrem num MCI: num motor a 2500 rpm, a pressão atuante no $1^{\circ}$ anel varia de atmosférica a mais de $15 \mathrm{MPa}$ e a velocidade de 0 a mais de $15 \mathrm{~m} / \mathrm{s}$ num intervalo de tempo de 48 milisegundos. Para equacionamento das forças atuantes no anel partiu-se do programa de computador descrito em TOMANIK (1993) e foram feitos os seguintes melhoramentos:

- cálculo da posição axial contínua do anel dentro do canalete;

- inclusão da torção do anel e do canalete;

- melhor descrição do perfil da face de contato;

- cálculo das pressões de contato rugoso.

Além disso, como contribuição fundamental para o desenvolvimento do tema, foram criados algoritmos de:

- cálculo da taxa de desgaste;

- cálculo da evolução do perfil desgastado e de sua influência no sistema.

Nos itens a seguir, apresentaremos as principais características do modelo físicocomputacional desenvolvido. Vale mencionar que como primeira aproximação optou-se por desconsiderar os efeitos das deformações elásticas dos anéis e cilindro na geometria de contato. 


\section{1- MODELO DA DINÂMICA DE ANÉIS}

\subsection{1- Forças agindo no anel}

Força própria - O anel de pistão em seu estado livre, fora do cilindro, não possui raio de curvatura constante. Sua forma livre é projetada para que, quando montado no cilindro, o anel exerça uma pressão, em geral não uniforme, ao longo de seu perímetro. Já o anel de óleo tem uma seção transversal relativamente esbelta e depende da ação de molas ou expansores para conseguir as pressões próprias relativamente altas (até 2,5 MPa). A força própria do anel é denominada força tangencial e é um dado importante de projeto e controle de produto. Quando em funcionamento, a pressão própria sofre a influência do gradiente de temperatura existente entre a face interna e externa do anel, bem como das deformações do cilindro. No modelo se admitiu que a pressão seja uniforme ao longo do perímetro do anel, calculada pela equação 3.1, e que não se altere com o desgaste.

$$
P_{t}=\frac{2 . F t}{D_{n} \cdot b}
$$

Força dos gases - O fluxo de gases pelo pacote de anéis gera pressões variáveis ao longo dos 4 tempos do motor e em cada sub-volume da região dos anéis. O fluxo de gases é calculado admitindo um modelo bi-dimensional onde cada canalete e intercanalete é um subvolume conectado por orifícios. Esses orifícios são a folga entre pontas do anel e a folga axial entre o anel e o canalete. A fig. 3.1 mostra esquematicamente esse modelo, que é aplicado na 
grande maioria dos programas de simulação de anéis, sendo que as áreas de passagem entre anel e canalete variam conforme a posição axial do anel. Basicamente admite-se que: - A pressão acima do $1^{\circ}$ anel, a cada instante, é igual à da câmara de combustão. Essa pressão da câmara é um dado de entrada, podendo ser obtida experimentalmente ou calculada por programas de simulação de combustão.

- A pressão abaixo do anel de óleo é igual à do cárter e constante ao longo dos 4 tempos do motor, sendo facilmente medida. Em geral, é pouco maior que a pressão atmosférica.

- O fluxo de gases é um regime transiente, adiabático, satisfazendo a lei dos gases perfeitos.

- A temperatura do gás é igual a média das paredes que o circundam a cada instante.

- A perda de carga pelo fluxo circunferencial é desprezível.

- A vazão em massa dos gases por um orifício, enquanto o escoamento não estiver blocado, pode ser calculada por:

$$
m=\frac{C_{\Sigma} \cdot A \cdot P_{0}}{\sqrt{R . T_{0}}} \cdot \sqrt{2 \frac{k}{k-1}\left[\left(\frac{P_{k}}{P_{0}}\right)^{2 / k}-\left(\frac{P_{k}}{P_{0}}\right)^{\frac{k+1}{k}}\right]}
$$

onde $C_{d}$ : coeficiente de descarga, admitido $=0,86$

$A$ : área de passagem pelo orifício

$P_{0}, T_{0}$ : pressão e temperatura à juzante

$P_{e}$ : pressão à montante

k: razão entre os calores específicos à pressão e a volume constante

Para um determinado valor de $P_{0}$ e $T_{0}$, à medida que $P_{e}$ é reduzida, a vazão mássica cresce até quando a velocidade no orifício atinge a sônica; qualquer redução maior de pressão não 
provoca aumento de vazão mássica (escoamento blocado); a equação anterior se resume à de vazão crítica:

$$
\dot{m}=\frac{C_{\Sigma} \cdot A \cdot P_{0}}{\sqrt{R \cdot T_{0}}} \cdot 0,685
$$
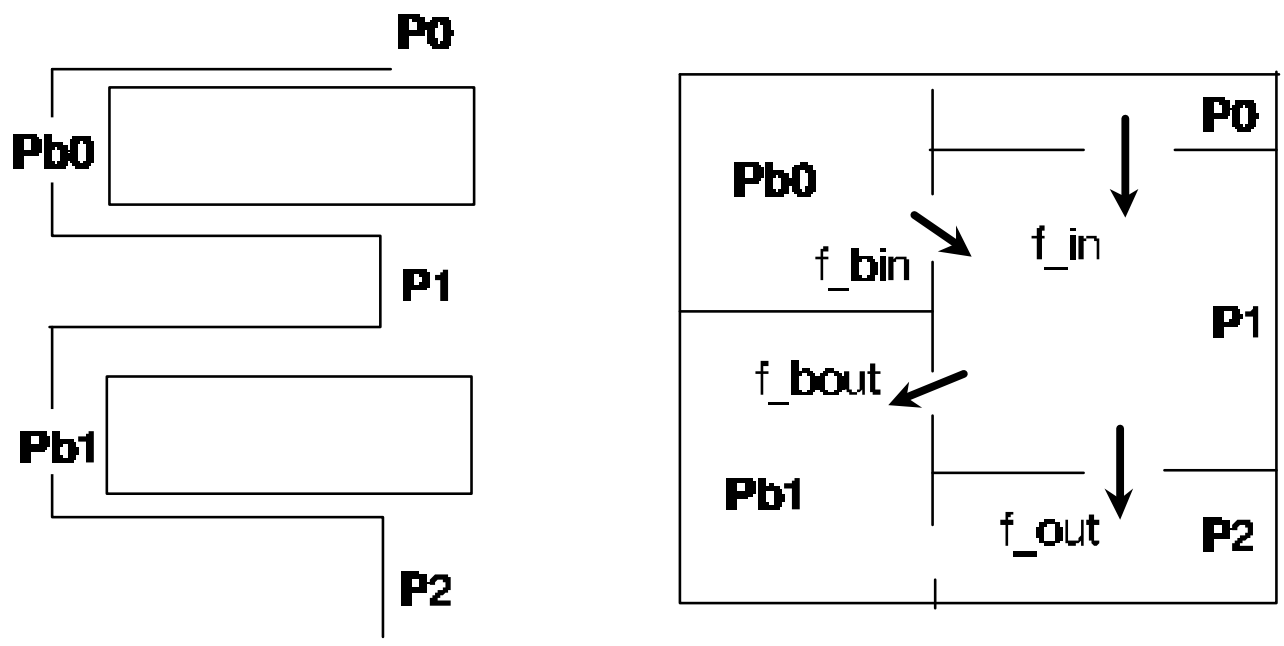

Fig. 3.1- Modelo esquemático do fluxo de gases por orifícios.

Pressões:

- P0: do land do anel anterior

- P1: do land do anel sendo calculado

- P2: do land do anel posterior

- $\mathrm{Pb} 0$ : do volume atrás do anel anterior

- Pb1: do volume atrás do anel sendo calculado

Fluxos (em massa):

- f_in: entrando no intercanalete, através da folga entre pontas do anel anterior

- f_out: saindo do intercanalete, através da folga entre pontas do anel

- f_bin: entrando no intercanalete, através da eventual folga axial do anel anterior

- f_bout: saindo do intercanalete, através da eventual folga axial do anel

É feita uma estimativa inicial para a pressão em cada volume e, assim, a vazão em massa instantânea em cada orifício e a resultante variação de pressão em cada volume podem ser calculadas. O processo é repetido para cada grau do virabrequim, até que as pressões resultantes tenham convergido dentro de uma certa precisão. 
A variação de pressão em cada volume, resultante da vazão dos gases é:

$$
d P=\frac{R \cdot T \cdot \dot{m} \cdot d t}{V}
$$

e o fluxo total ao longo do ciclo ("blow-by"):

$$
\text { Blow }- \text { by }=\sum_{0}^{719}(\min \cdot \Delta t) \cdot \frac{\text { ppm }}{2}
$$

Com o desgaste radial, a folga entre pontas do anel aumenta e consequentemente a área do orifício. Despreza-se o desgaste axial, que em geral é da ordem de poucos micrometros, muito menor que a folga axial anel/canalete.

Força hidrodinâmica - $\mathrm{O}$ anel de pistão é modelado como um mancal de deslizamento, com velocidade e carregamento variáveis. A cada instante, a velocidade é definida pela cinemática primária do pistão (vide eq. 3.27) e o carregamento é dado pela somatória da força dos gases e própria do anel. A partir da equação de Navier-Stokes para escoamentos, chega-se à equação geral de Reynolds, a partir das hipóteses habituais, listadas a seguir:

a) fluxo laminar;

b) forças de campo =0;

c) forças de inércia desprezíveis;

d) espessura do filme pequena quando comparada com as outras dimensões;

e) em cada posição $(x, z)$ a pressão, densidade e viscosidade são constantes ao longo do filme;

f) nas superfícies de contato a velocidade do lubrificante é igual à do corpo; 
g) comparados com $\mathrm{d} u / \mathrm{d} y$ e $\mathrm{d} v / \mathrm{d} y$, todos os outros gradientes de velocidade são desprezíveis;

fica:

$$
\frac{\partial}{\partial x}\left(\frac{p h^{3}}{\mu} \frac{\partial p}{\partial x}\right)+\frac{\partial}{\partial z}\left(\frac{p h^{3} \frac{\partial p}{\mu}}{\partial z}\right)=6\left(U_{1}-U_{2}\right) \frac{\partial(\rho h)}{\partial x}+12 p\left(W_{1}-W_{2}\right)
$$

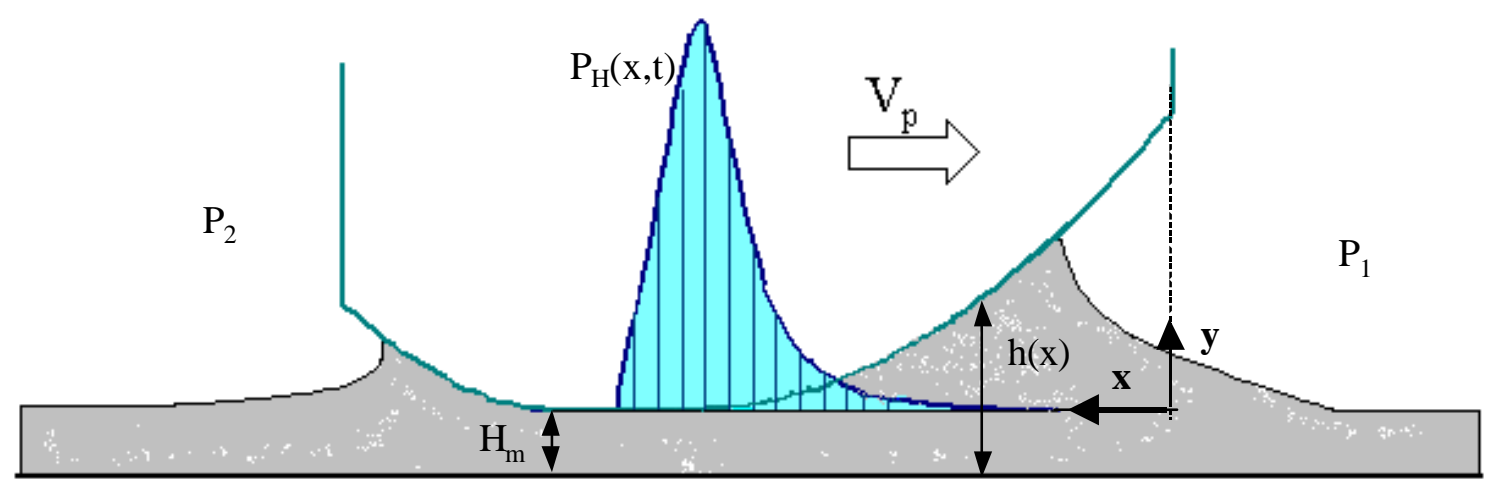

Fig. 3.2 - Pressão hidrodinâmica na face de contato do anel

Assumindo ainda que:

h) o lubrificante é incompressível e portanto Dconstante;

i) a viscosidade é constante no filme de óleo: $M 1 /$ : ) / $M=0$;

obtemos:

$$
\frac{\partial}{\partial x}\left(h^{3} \frac{\partial p}{\partial x}\right)+\frac{\partial}{\partial z}\left(h^{3} \frac{\partial p}{\partial z}\right)=6 \mu\left(U_{1}-U_{2}\right) \frac{\partial h}{\partial x}+12 \mu\left(W_{1}-W_{2}\right)
$$


Considerando a parede do cilindro estacionária $\left(U_{2}=V_{2}=0\right)$, sendo $V_{1}=\mathrm{d} h / \mathrm{d} t \mathrm{e}$ desprezando a variação da pressão no eixo $z$, obtemos finalmente a equação unidimensional de Reynolds:

$$
\frac{d}{d x}\left(h^{3} \frac{d p}{d x}\right)=6 \mu U \frac{\partial h}{\partial x}+12 \mu \frac{\partial h}{\partial t}
$$

Integrando duplamente em relação à x:

$$
P_{H}(x)=6 \mu U \frac{d x}{f_{h^{2}}}+12 \mu \frac{\partial h}{\partial t} \frac{x}{h^{3}} d x+C_{1} \frac{d x}{h^{3}}+C_{2}
$$

onde $P_{H}(\mathrm{x})$ é a pressão hidrodinâmica no ponto x e $C_{1}$ e $C_{2}$ são constantes de integração determinadas pelas condições de contorno:

- $P_{H}(0)=$ pressão na borda de ataque do anel $=P_{1}$

- $P_{H}(\mathrm{~b})=$ pressão na borda de saída do anel $=P_{2}$

Além disso, impõe-se a condição de contorno usualmente aplicada à equação de Reynolds: zerar todas as pressões que pelo cálculo resultarem negativas (fisicamente o fluído não resiste à tração):

$$
\text { se } P_{H}(\mathrm{x})<0 \text { então } P_{H}(\mathrm{x})=0, d P_{H} / d x=0
$$

Para cálculo da distribuição da pressão hidrodinâmica é necessária também, a descrição do perfil do anel. O perfil da face de contato de cada anel é um dado de entrada do modelo, que vai modificando-se com o desgaste. O perfil hidrodinâmico instantâneo depende da inclinação relativa entre o anel e a parede do cilindro. O cálculo dessa inclinação é detalhado mais a 
frente. No modelo, o perfil é fornecido discretizado em 100 pontos ao longo da altura do anel (coordenada x na fig. 3.2). Uma vez determinadas as constantes $C_{1}$ e $C_{2}$, a solução da equação 3.8 pode ser obtida a partir do necessário equilíbrio: a pressão do filme de óleo deve equilibrar a carga radial aplicada pelo anel em cada instante (a aceleração radial do anel é considerada nula).

$$
\sum_{1}^{100} P_{H}(x, t)+b\left(p_{t}+p_{B}\right)=0
$$

onde $p_{b}$ é a pressão dos gases agindo no diâmetro interno do anel.

A solução numérica deste problema é obtida de maneira iterativa: adota-se inicialmente uma espessura mínima de filme de óleo $\mathrm{H}_{\mathrm{m}}$; calcula-se a carga suportada por este filme; se a força for maior que a necessária para o equilíbrio, uma nova estimativa (espessura maior que a anterior) é feita, procedendo-se o contrário se a força for menor; assim sucessivamente até que o equilíbrio em cada instante seja satisfeito dentro de uma tolerância pré-definida. Se a separação definida pelo filme de óleo for menor que um certo limite num determinado ponto do perfil do anel, começam a agir forças de contato rugoso, as quais serão descritas no item 3.3. Uma visão geral do algoritmo das forças atuantes no perfil da face de contato do anel é dada na fig. 3.3. 


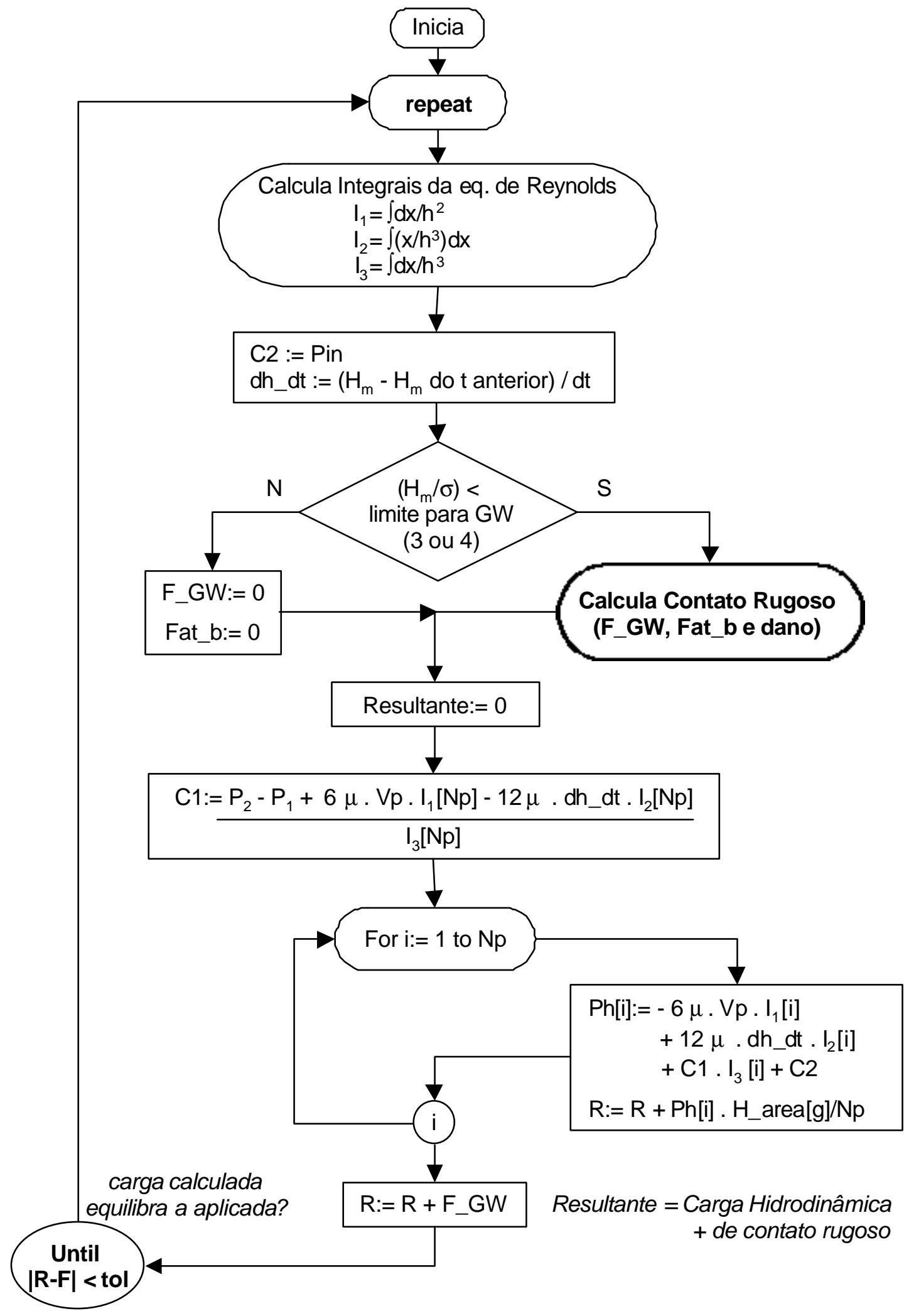

Fig.3.3- Fluxograma do cálculo das pressões atuantes na face de contato do anel. 
Para diminuir a carga computacional, as integrais da equação de Reynolds (3.9) são calculadas pela simples somatória dos termos dependentes de h:

$$
\begin{aligned}
& I_{1}(i)=\sum_{j=2}^{i}\left(\frac{\Delta x}{h^{2}}\right) \\
& I_{2}(i)=\sum_{j=2}^{i}\left(\frac{\Delta x \cdot x_{j}}{h^{3}}\right) \\
& I_{3}(\hat{z})=\sum_{j=2}^{i}\left(\frac{\Delta x}{h^{3}}\right)
\end{aligned}
$$

onde: $j$ : índice da fatia ao longo da face de contato, $(\mathrm{j}=1 . .100)$

) $x=b / 100 \quad$ (altura do anel dividida pelo número de pontos da discretização)

$h_{m}=H m+\left(h_{j-1}+h_{j}\right) / 2$, separação da fatia à parede do cilindro

$H m$ = espessura do filme de óleo, no ponto de menor separação

$h_{j}=$ "altura"do ponto $x_{j}$ a partir do ponto mais proeminente do perfil (considerando a inclinação do anel em relação ao cilindro), vide fig. 3.4

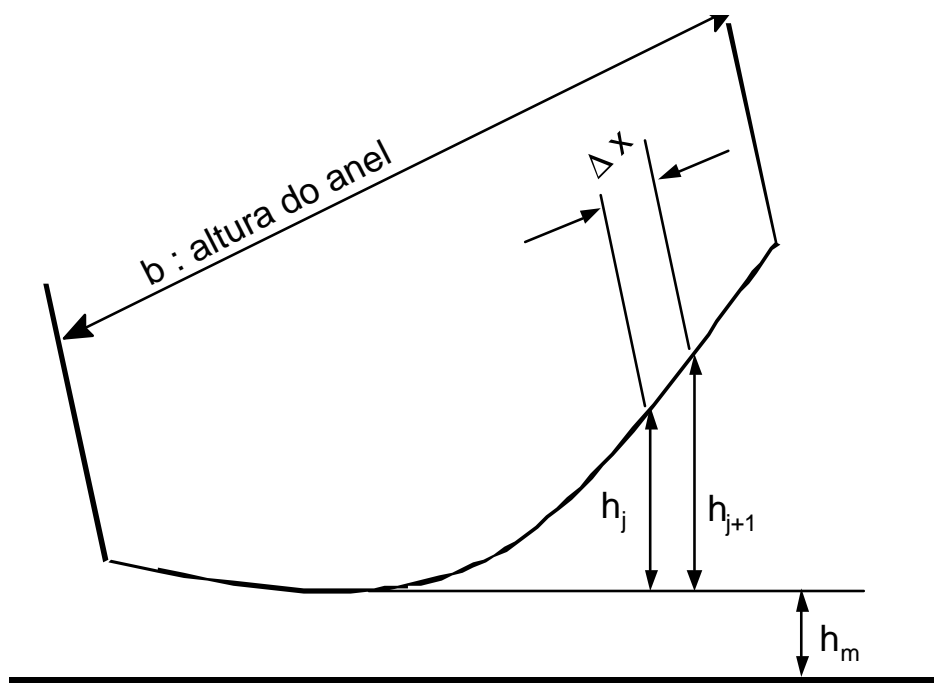

Fig.3.4- Discretização da face de contato. 
Admite-se que a viscosidade do óleo, em função da temperatura, segue a equação de Vogel:

$$
\mu=a \cdot e^{\mid \frac{b}{T+c \mid}}
$$

Onde $T$ é a temperatura em Celsius, e $a, b, c$ são constantes de acordo com a classificação

SAE do óleo, vide tabela 3.1. Os valores calculados são mostrados na fig. 3.5.

\begin{tabular}{|l|c|c|c|}
\hline \multicolumn{4}{|c|}{ Tabela 3.1- Parâmetros da equação de Vogel } \\
\hline $\begin{array}{c}\text { classificação } \\
\text { SAE }\end{array}$ & $\begin{array}{c}\text { a } \\
\left(10^{-3} \text { Pa.s }\right)\end{array}$ & $\begin{array}{c}\text { b } \\
\text { (Celsius) }\end{array}$ & $\begin{array}{c}\text { c } \\
\text { (Celsius) }\end{array}$ \\
\hline $5 \mathrm{~W}$ & 0,05567 & 900 & 110,8 \\
\hline $10 \mathrm{~W}$ & 0,04082 & 1066 & 116,5 \\
\hline $15 \mathrm{~W}$ & 0,06681 & 902 & 100,2 \\
\hline $20 \mathrm{~W}$ & 0,02370 & 1361 & 123,3 \\
\hline 20 & 0,04987 & 1028 & 108,0 \\
\hline 30 & 0,02370 & 1361 & 123,3 \\
\hline 40 & 0,07227 & 1396 & 121,7 \\
\hline 50 & 0,01963 & 1518 & 122,6 \\
\hline
\end{tabular}

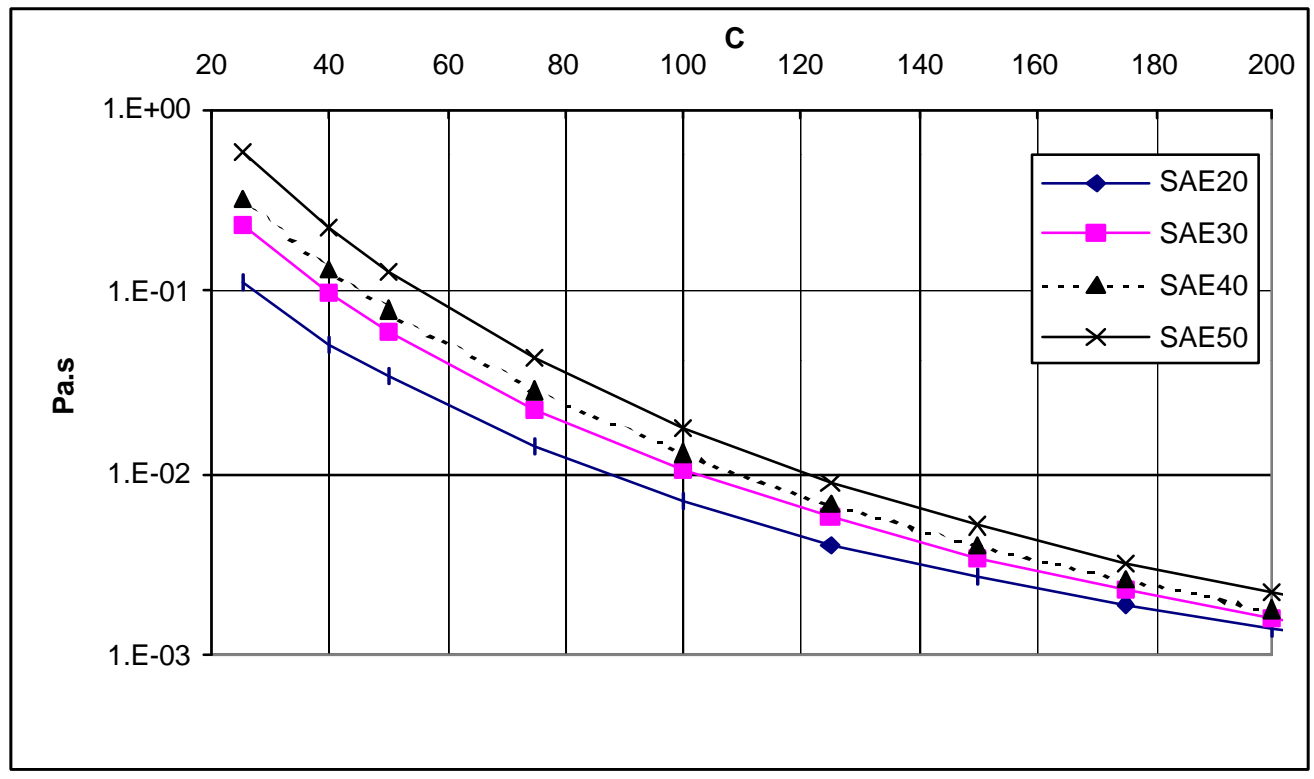

Fig. 3.5- Viscosidade em função da temperatura. 
A viscosidade do óleo também varia com a pressão, se esta é alta o suficiente ( $5 \mathrm{MPa}$ ). Esse fato, em geral, não é considerado nos programas de simulação em virtude das dificuldades computacionais que envolve. No presente modelo, a seguinte abordagem foi adotada:

- a dependência da viscosidade com a pressão é descrita por:

$$
\mu=\mu_{0} \cdot e^{(2 \cdot P)}
$$

onde $\quad P$ : pressão efetiva no fluido $(\mathrm{Pa})$

$:_{0}$ : viscosidade à pressão atmosférica

" é um índice da variação da viscosidade com a pressão, que para óleos minerais pode ser aproximada por (HUTCHINGS, p.62, 1992):

$$
x=, 0,6+0,965 \cdot \log _{10}\left(\mu_{0} \cdot 10^{3}\right), 10^{-8} \quad\left[\mathrm{~Pa}^{-1}\right]
$$

A princípio, como a pressão hidrodinâmica varia a cada posição $\mathrm{x}$, cada posição teria um valor de correção da viscosidade. Para diminuir a carga computacional, a seguinte simplificação foi adotada: a cada instante, um fator médio de correção é adotado para todo filme. Esse fator é calculado com a pressão média do filme de óleo no instante anterior. Para cálculo dessa pressão média, desprezam-se os pontos com pressões hidrodinâmicas iguais a zero. Embora simplista e provavelmente sub-dimensionada, essa abordagem já trouxe aumentos de até $40 \%$ na viscosidade, com conseqüente aumento do filme de óleo e redução das pressões de contato rugoso (cujo cálculo será detalhado no item 3.3). A fig. 3.6 compara as pressões calculadas com e sem correção da viscosidade, para um caso específico de anel. 

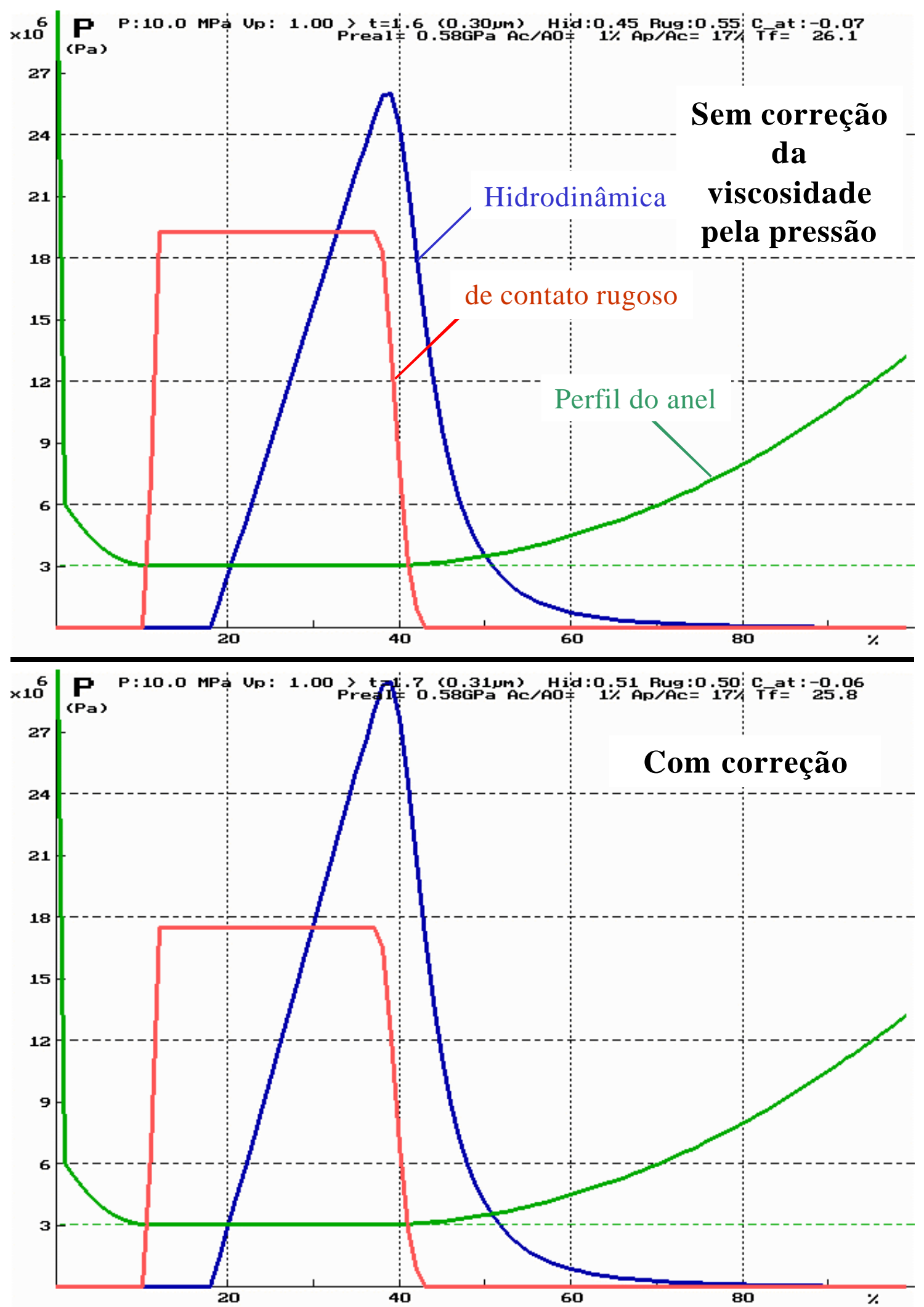

Fig. 3.6- Exemplo de pressões hidrodinâmicas e de contato rugoso sem e com correção da viscosidade pela pressão. Pressão atuante de $10 \mathrm{MPa}$, velocidade de $1 \mathrm{~m} / \mathrm{s}$. 
As seguintes hipóteses simplificadoras foram também admitidas:

1- A cada instante, a temperatura do óleo é a média da temperatura dos 2 corpos em contato: do anel e a do cilindro, na posição em que o anel se encontra.

2- Para óleos multiviscosos, o modelo usa a classificação SAE maior, já que se pretende simular as condições do motor em regime. Assim, para um óleo SAE 15W40, a viscosidade do SAE 40 é adotada.

3- A cada instante, existe tanto óleo quanto necessário para o equilíbrio radial. Essa hipótese é denominada de "fully flooded" na literatura sobre simulação de anéis. Embora menos realista que a abordagem "starved", onde a quantidade de óleo pode não ser suficiente para preencher todo o anel, reduzindo sua capacidade de carga e, portanto, reduzindo a espessura mínima do filme. O erro na evolução do perfil desgastado pela abordagem "fully flooded" pode ser considerado pequeno, pois o efeito "starved" ocorre principalmente quando o filme de óleo tende a ser espesso, e nessa condição não ocorre desgaste.

4- A viscosidade não depende da velocidade de cisalhamento ("shear thinning"). TAYLOR (1994) estuda tanto o efeito da abordagem "starved" quanto do cisalhamento no calculo da espessura do filme e verifica diferenças significativas apenas no meio do curso, mas pouca nos pontos de reversão (onde tanto a velocidade quanto a espessura são baixas). Desse modo, o efeito dessas 2 simplificações no cálculo do desgaste pode ser admitido pequeno.

5- A viscosidade foi também admitida não variar com o passar do tempo. O óleo lubrificante costuma ter sua viscosidade aumentada com o número de horas em funcionamento, mas essa variação não costuma ser significativa. Mais complexa é a questão da real viscosidade do óleo na zona de anéis, onde efeitos de diluição de combustível e a presença de fuligem e 
outros contaminantes podem alterar o comportamento do óleo lubrificante. Esses efeitos não foram considerados no presente modelo.

6- Não foram considerados efeitos elasto-hidrodinâmicos.

Força de contato rugoso - Se a separação entre o anel e a parede do cilindro é menor que a rugosidade combinada das 2 superfícies, começam a existir interações entre as asperezas. Grandes pressões de contato, como as da fig. 3.6, aparecem. Pela sua complexidade, o equacionamento dessas pressões será detalhado no item 3.3.

Força de inércia - Dada pelas acelerações causadas pelo movimento primário (alternativo) e secundário ("tilt”) do pistão (aceleração de arrastamento), multiplicadas pela massa do anel. A aceleração da gravidade foi desprezada por ser muito menor que as demais. Assim a força de inércia axial é dada por:

$$
I=a_{p}+a_{a d t} \cdot r_{p p} \cdot M_{a}
$$

onde $a_{p}$ : aceleração primária do pistão

$a_{\text {tilt }}$ : aceleração angular do pistão

$r_{p}$ : distância do ponto circunferencial do anel ao plano definido pelo eixo do pino e o eixo do cilindro. No modelo axi-simétrico adotado, esse efeito (aceleração angular) será desprezado, uma vez que ocorre em sentidos opostos para cada metade do anel. 
Forças de atrito - $\mathrm{O}$ atrito entre superfícies lubrificadas pode ser classificado em 3 regimes de lubrificação, segundo a curva de Stribeck (fig. 3.7).

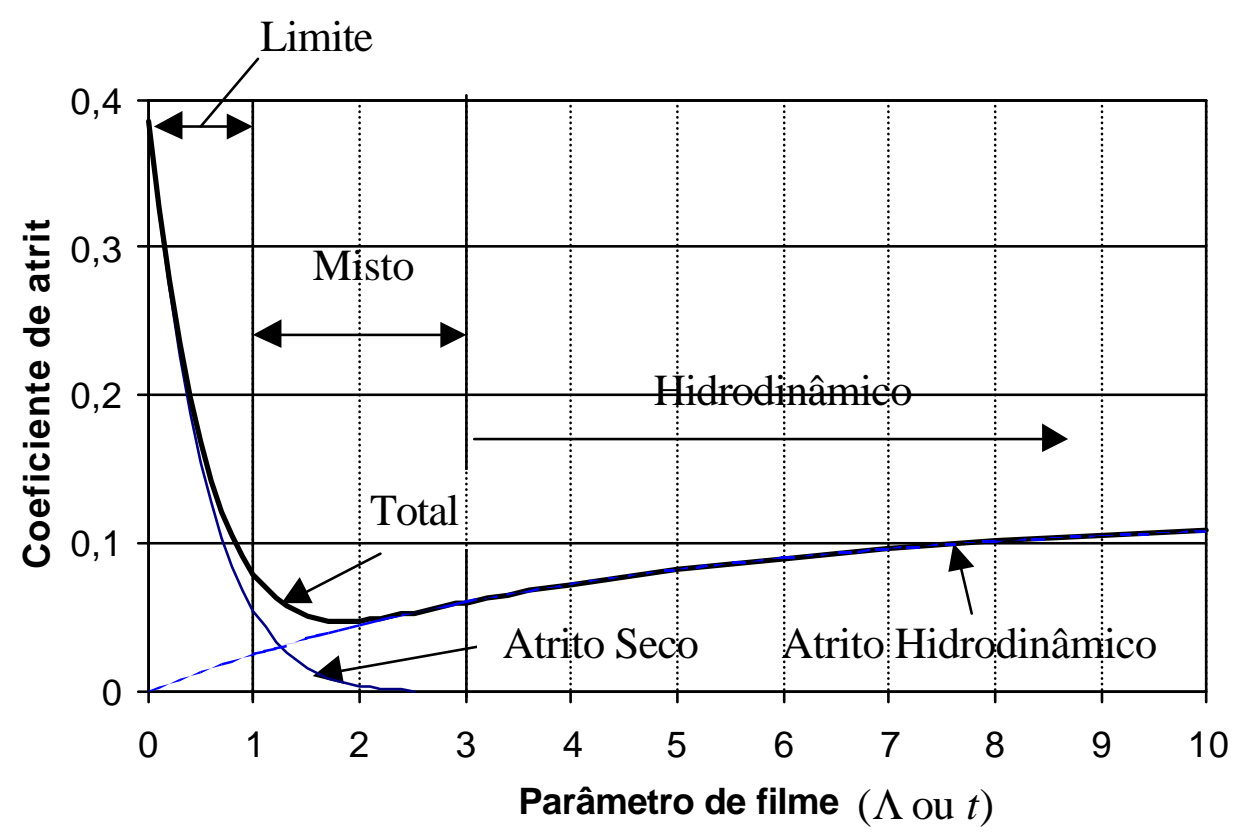

Fig. 3.7 - Curva de Stribeck.

O coeficiente de atrito $f$ pode ser expresso por:

$$
f=a f_{t}+11-a_{k}
$$

onde $f_{\mathrm{s}}$ é o coeficiente de atrito seco, $f_{h}$ o de atrito hidrodinâmico e " a fração que a força de contato metal a metal representa da força total, variando de 0 a 1.

Quando " $\mathrm{Y} 0, f \mathrm{Y} f_{\mathrm{h}}$ e o atrito é classificado como hidrodinâmico. No modelo, a força de atrito hidrodinâmico entre o anel e a parede do cilindro é calculada explicitamente pela equação (3.22) para cada grau do virabrequim. O atrito por unidade de perímetro é dado pela integral da tensão de cisalhamento do fluido ao longo da face do anel. Assim a força hidrodinâmica de atrito pode ser calculada por: 


$$
\begin{aligned}
& F_{x_{H}}=\text { (perimetro do amel) } \cdot \mu \cdot \int_{0}^{b}\left(\frac{d u}{d y}\right)_{y-k} d x \\
& \left(\frac{d u}{d y}\right)_{y=k}=\frac{-U}{h}+\frac{h \cdot d p}{2 \cdot \mu \cdot d x} \\
& F_{\text {at }}=\text { (perimetro do amel) } \int_{0}^{b}\left(\frac{h . d p}{2 . d x}-\frac{\mu . U}{h}\right) d x
\end{aligned}
$$

Como em 3.12 a 3.14, o cálculo da integral é feito por somatória:

$$
F_{A_{H}}=\text { (permetro do amel) } \sum_{t=2}^{100}\left(\frac{h_{i} \cdot \Delta p}{2}-\frac{\mu . U}{h_{t}} \Delta x\right)
$$

onde $\quad$ ) $p=\mathrm{P}_{\mathrm{H}}[\mathrm{i}]-\mathrm{P}_{\mathrm{H}}[\mathrm{i}-1]$

Quando " $\mathrm{Y} 1, f \mathrm{Y} f_{\mathrm{s}}$ e o atrito é classificado como limite ("boundary"): a espessura do filme é muito menor que a necessária para separar as rugosidades das duas superfícies e praticamente o total da força normal é proveniente do contato metal-metal. O coeficiente de atrito seco, $f_{\mathrm{s}}$, depende do par de materiais em contato e é um dado de entrada para o modelo. A força de atrito seco é dada pela carga eventualmente suportada pelo contato $\operatorname{rugoso}\left(\mathrm{F}_{\mathrm{GW}}\right)$ multiplicada por $f_{\mathrm{s}}$

$$
F_{\text {ats }}=f_{t} \cdot F_{\mathrm{EW}}
$$

A força de atrito total, a cada instante, é dada pela soma das parcelas hidrodinâmica e seca. 
Força de Atrito Radial - Na face lateral do anel os deslocamentos e as velocidades radiais são muito pequenos (da ordem de : $\mathrm{m}$ e de $\mathrm{cm} / \mathrm{s}$ ), função principalmente do movimento secundário do pistão; assim, o atrito é seco ou misto. Como o enfoque neste trabalho é o desgaste na face de contato do anel com a parede do cilindro, a força de atrito radial não será considerada. Pode-se admitir, também, que o eventual efeito dessa força radial se anula ao longo do anel, já que, se ela aumenta a pressão de contato numa metade do anel, ela reduz na outra.

Força de amortecimento axial - Quando o anel se move axialmente no canalete, descolando de um flanco e se aproximando do flanco oposto do canalete, aparece uma força de amortecimento, devido ao óleo que precisa ser afastado (efeito "squeeze"). Esta força (por unidade de comprimento) será calculada pela equação proposta por KORNPROBST et al (1989):

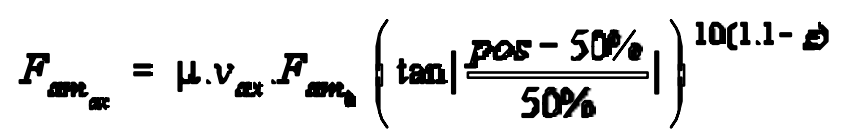

onde $v_{a x}$ : velocidade axial relativa do anel (em relação ao canalete) pos: posição do anel no canalete em \% $F_{a m 0}:$ coeficiente de amortecimento específico $\left(10^{4} . .10^{8}\right)$, admitido $=10^{7}$ $g$ : grau de preenchimento de óleo (0...1), admitido = 0,6. 


\subsection{2- Movimento do anel}

O anel se move conjuntamente com o pistão; desse modo, numa primeira abordagem, sua velocidade e posição ao longo do cilindro são ditadas pela cinemática do pistão. Além disso, devido às necessárias folgas de funcionamento, o anel apresenta em relação ao pistão, os seguintes movimentos:

- axial, dentro do canalete;

- torcional, (também chamado de "twist") assumindo a forma de um prato (positivo se virado para cima, negativo se o oposto);

- radial, função da variação da espessura do filme de óleo, da deformação do cilindro e do movimento secundário do pistão;

- de rotação, aleatório e que não será considerado neste modelo.

Os itens a seguir descrevem o equacionamento desses movimentos.

Cinemática do Pistão - Como já mencionado, o pistão de MCI apresenta dois movimentos, vide fig. 3.8:

- primário, que constitue o seu movimento alternativo devido o mecanismo de biela-manivela. Seu equacionamento é mostrado a frente;

- secundário (também chamado de "tilt") de inclinação em torno de seu pino, cujo cálculo complexo é normalmente feito através de programas dedicados. No caso foi usado o programa PISDYN da RICARDO SOFTWARE (vide NIGRO, 1999). 


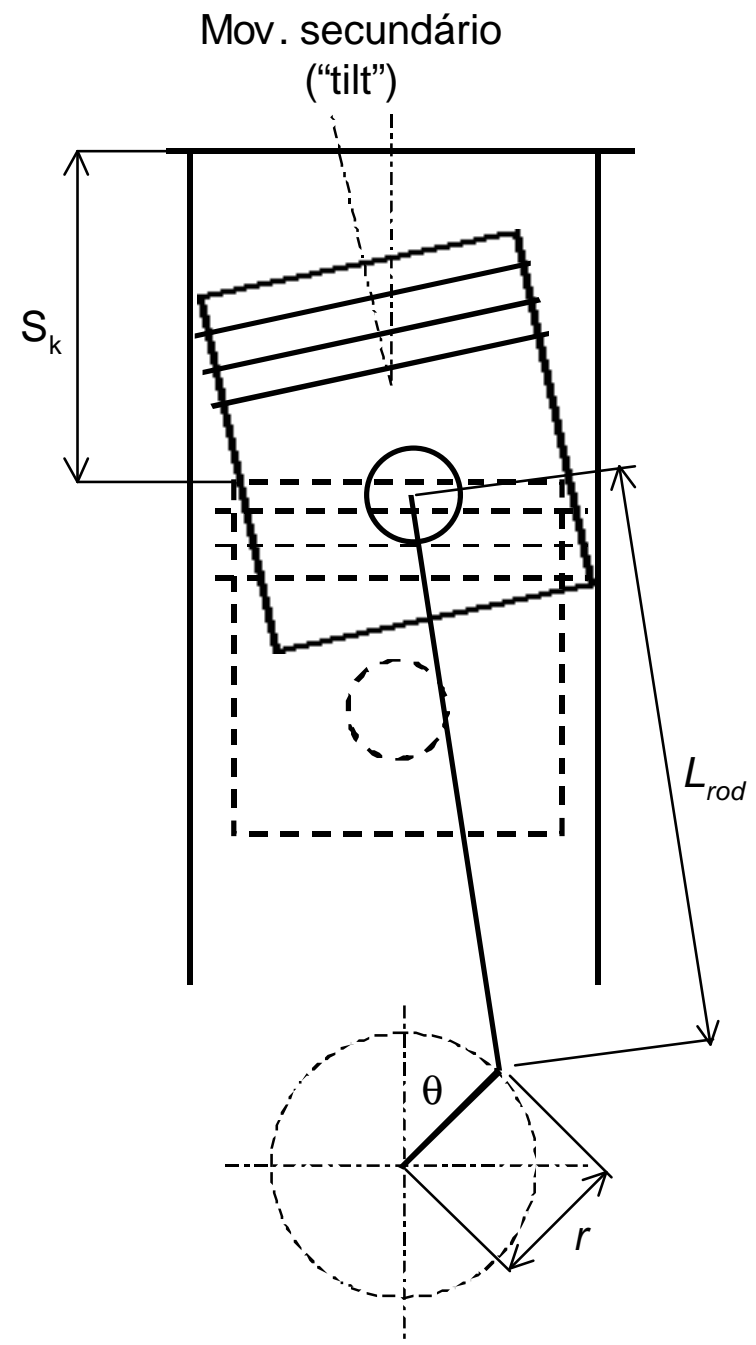

Fig.3.8- Cinemática do pistão.

A aceleração primária do pistão pode ser calculada com boa aproximação por ${ }^{1}$ :

$$
\xi_{p}=r \cdot w^{2} \cdot\left(\cos \theta+\frac{r}{L_{\operatorname{rod}}} \cdot \cos 2 \theta\right) \quad\left[\mathrm{m} / \mathrm{s}^{2}\right]
$$

onde $\quad r:$ raio do virabrequim $=$ curso $/ 2$

${ }^{1}$ BOSCH - Automotive Handbook (3rd edition) p. 399. 
$w:$ velocidade angular $=2$. B $. r p m / 60$

2 : ângulo do virabrequim, 0 no PMS durante a combustão

$L_{\text {rod }}:$ comprimento da biela

A velocidade do pistão é aproximadamente:

$$
v_{p}=v \cdot r \cdot\left(\operatorname{sen} \theta+\frac{r}{2 \cdot L_{\mathrm{rod}}} \cdot \operatorname{sen} 2 \theta\right)
$$

e a distância ao Ponto Morto Superior:

$$
S_{k}=r\left(1+\frac{L_{\text {rod }}}{r}-\cos \theta-\sqrt{\left(\frac{L_{\text {rod }}}{r}\right)^{2}-\operatorname{sen}^{2} \theta}\right)
$$

Movimento axial dentro do canalete - A aceleração axial do anel dentro do canalete é calculada pela $2^{\mathrm{a}}$ lei de Newton:

$$
\Sigma^{F}-m_{a} \cdot \alpha c_{a x}=0
$$

onde:

$$
3 F_{\text {ax }}=F_{\text {gas }}-I+F_{\text {am_ax }}+F_{\text {at } \_ \text {ax }}
$$

Mas a força de amortecimento, $F_{\text {am_ax }}$, depende da velocidade relativa anel/canalete e torna essas 2 equações acopladas, o que impede sua solução analítica. A solução é obtida por meio de um método numérico interativo, similar ao descrito para determinação da espessura do filme de óleo. 


\section{2- GEOMETRIA INSTANTÂNEA DO CONTATO ANEL - CILINDRO}

O ângulo que a face de contato do anel faz com a parede do cilindro é determinante para seu comportamento hidrodinâmico e tribológico; este ângulo é a soma de várias parcelas conforme apresentado na fig. 3.9:

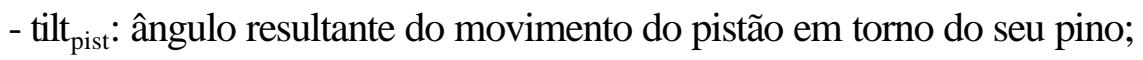

- $8_{\text {can }}$ ângulo que o canalete faz com o plano horizontal do pistão;

- $8_{\text {cil }}$ ângulo devido à deformação longitudinal do cilindro;

- $8_{\text {anel }}$ : ângulo causado pela torção do anel dentro do canalete.

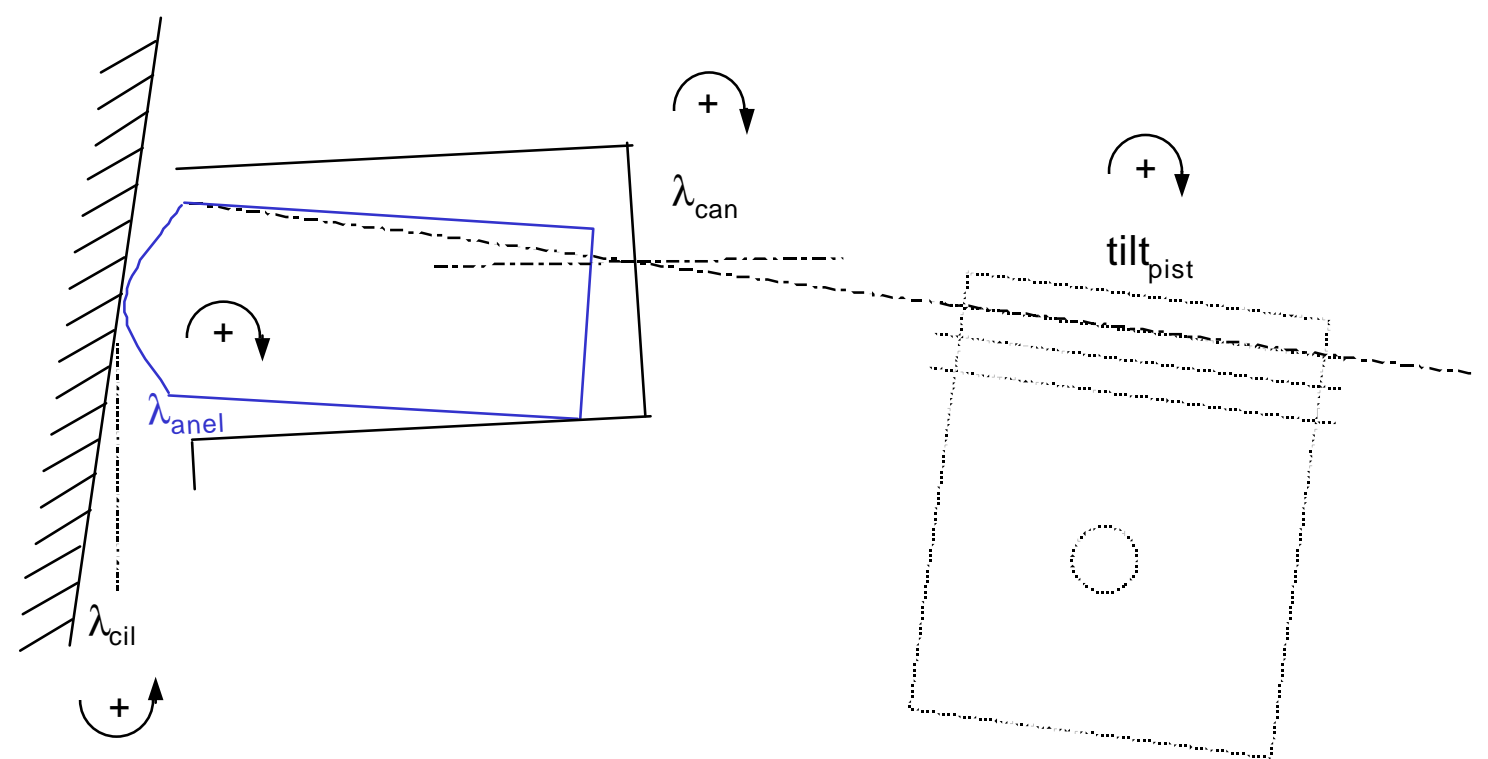

Fig.3.9- Parcelas do ângulo que a face de contato faz com a parede do cilindro.

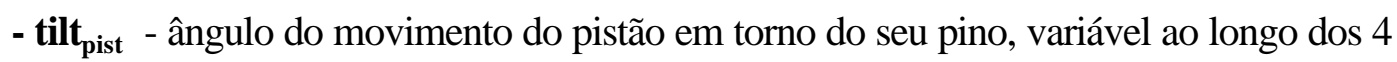
tempos do motor, e é um dado de entrada opcional, mas importante do programa. Sua 
influência no anel depende da posição angular deste em relação ao pino do pistão. O modelo considera apenas o plano perpendicular ao pino do pistão, mas calcula a inclinação total do anel no lado de maior e menor pressão, ou seja, as pressões atuantes na face de contato do anel são calculadas para as duas situações extremas. Se não fornecido o modelo admite tilt $_{\text {pist }}=0$.

- $\boldsymbol{8}_{\text {can }}$ : ângulo que o canalete faz com o plano horizontal do pistão. Dado de entrada, calculado com o auxílio de um programa de Elementos Finitos, que considera as deformações elásticas e térmicas do pistão.

- $\mathbf{8}_{\text {cil }}$ ângulo devido à deformações radiais ao longo do cilindro, essas são fornecidas inicialmente como dado de entrada mas modificam-se com o desgaste do cilindro.

- $\boldsymbol{8}_{\text {anel}}$ : ângulo causado pela torção do anel dentro do canalete. A torção total é soma da torção própria do anel mais a provocada pelos momentos atuantes, sendo seu cálculo complexo $^{2}$ porque é acoplado com o cálculo das demais forças. No modelo, para diminuir a carga computacional, as seguintes simplificações foram adotadas:

- para cálculo dos momentos atuantes foram consideradas as seguintes forças mostradas na fig.3.10.

- força dos gases agindo nas laterais do anel;

${ }^{2}$ PRIEST (1999) por ex. prefere adotar uma função senoidal para descrever a torção do anel ao longo do ciclo do motor. 
- forca de atrito axial na face de contato. Essa força, para cálculo do momento, é admitida como um décimo da força dos gases atuando no diâmetro interno do anel; - resultante das forças radiais (hidrodinâmicas e de contato rugoso) agindo na face de contato.

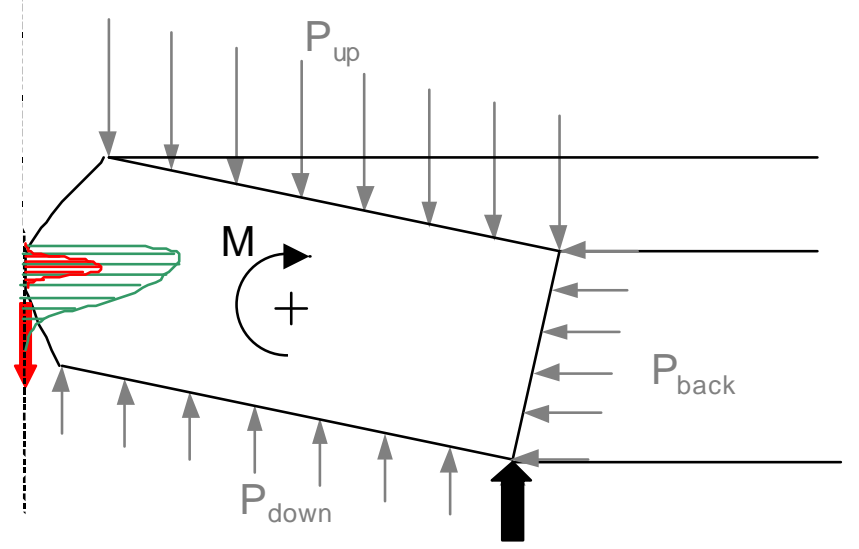

Fig.3.10- Modelo simplificado para cálculo da torção do anel.

As forças citadas provocam, com seus respectivos braços de alavanca, um momento M que deforma o anel como um prato. A este opõe-se o momento elástico ${ }^{3}$ da eq. 3.31:

$$
M_{\text {dia }}=\frac{E \cdot b^{3} \cdot \operatorname{m}\left(\frac{D_{n}}{D_{i}}\right)}{3\left(D_{i}+D_{i}\right)} \cdot u \cdot \lambda_{\text {and }}
$$

Onde $b$ : altura do anel

$D_{n}$ : diâmetro nominal

${ }^{3}$ Vide RUDDY (1979) e KORNPROBST (1989) 
$D_{i}$ : diâmetro interno $=D_{n}-2 . a$

$a$ : radial do anel

$u$ : perímetro do anel

$8_{\text {anel }}$ : ângulo de torção do anel (radianos)

A torção do anel pode ser calculada pelo equilíbrio de momentos:

$$
\lambda_{\text {and }}=\operatorname{aratan}\left(\frac{M}{M_{\text {ele }}}\right)
$$

Este ângulo é limitado pela folga axial anel/canalete. Vide fig. 3.11. Assim:

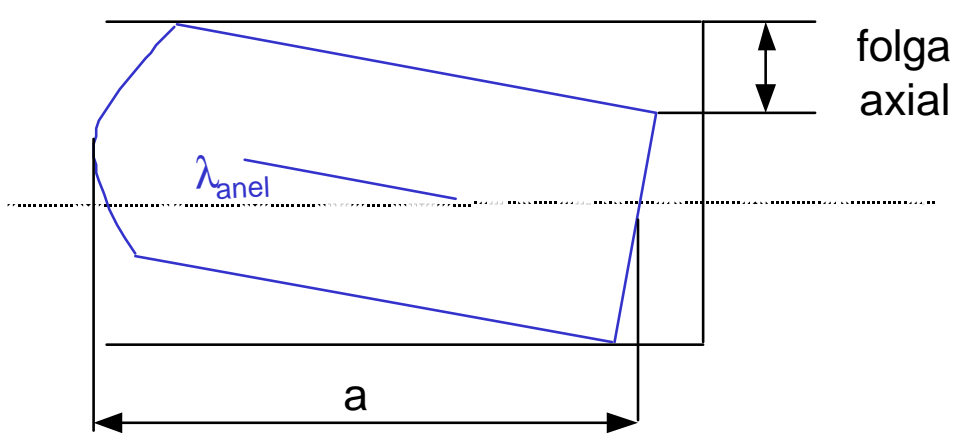

$$
\operatorname{Max}\left|\lambda_{\text {acel }}\right|=\operatorname{aratan}\left(\frac{\text { folga arial }}{a}\right)
$$

Fig.3.11- Máximo ângulo de torção do anel. 


\section{3- MODELO DE CONTATO RUGOSO}

As forças que surgem na face de contato do anel devido ao contato rugoso são modeladas pelo modelo de Greenwood-Williamson (discutido no item 2.4). Se a espessura do filme lubrificante entre um determinado ponto da face de contato do anel e a parede do cilindro for menor que 3 vezes a rugosidade local combinada anel/cilindro, começam a ocorrer interações entre as asperezas e surge naquele ponto uma pressão $\mathrm{P}_{\mathrm{gw}}$. Essa pressão depende das propriedades (rugosidade por ex.) combinadas naquele local. No modelo, a face da seção do anel é dividida em 99 fatias de mesma altura, assim como o cilindro. Como o anel se move, os pontos do cilindro que o anel percebe em um determinado intervalo de tempo mudam ao longo do curso. No modelo, a título de redução da carga computacional, foi adotado que as propriedades do cilindro, que todos os pontos do anel "percebem" num determinado instante, são dadas pela média ponderada dos pontos vizinhos ao centro do anel ${ }^{4}$ (vide fig. 3.12)

${ }^{4}$ Já que a discretização é tal que a máxima distância percorrida pelo anel, no intervalo de 1 grau do virabrequim, é menor que o espaçamento entre pontos do cilindro. 


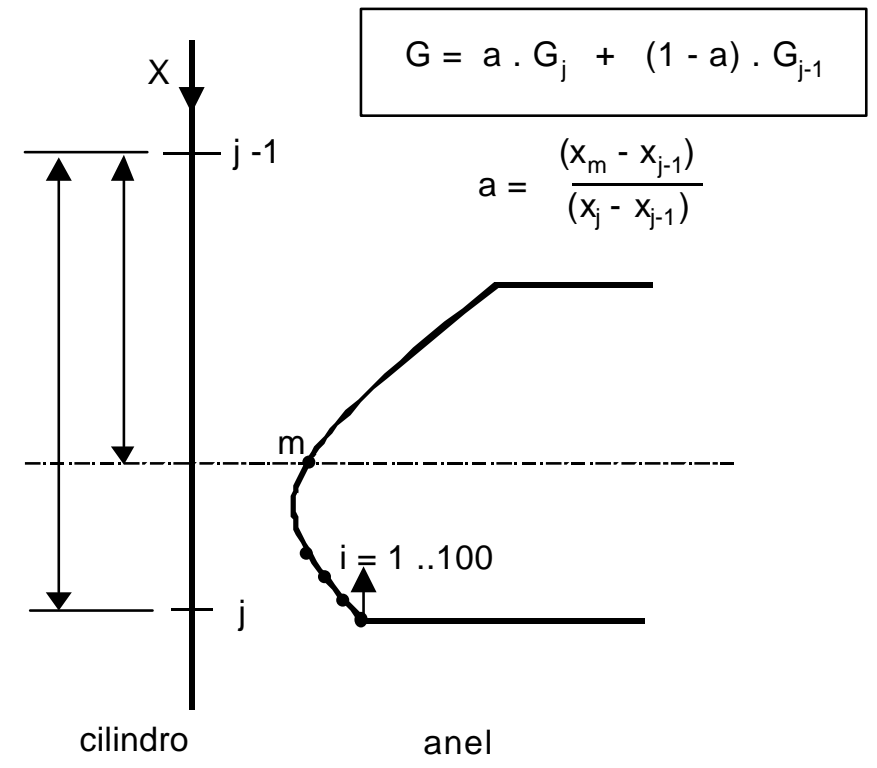

Fig.3.12- Esquema da determinação das propriedades do cilindro que todos os pontos i do anel "percebem" num determinado instante, onde $\mathrm{G}_{\mathrm{j}}$ é por ex. a rugosidade ou a dureza do cilindro no ponto $\mathrm{j}$.

A pressão de contato rugoso, no ponto i, é dado pela equação

$$
\begin{aligned}
P_{\text {ow }}[i] & =\frac{4}{3} \cdot \eta \cdot E_{i} \cdot \sqrt{\beta} \cdot \sigma_{i}^{3 / 2} \cdot F_{3 / 2}(t) & \text { se } P_{\mathrm{gw}}[\mathrm{i}] \# 3 . Y[\mathrm{i}] \\
& =\mathbf{3 , 0} \cdot Y[\mathrm{i}] & \text { se } P_{\mathrm{gw}}[\mathrm{i}]>3 . Y[\mathrm{i}]
\end{aligned}
$$

onde $\quad 0$ : densidade de picos $\left(\mathrm{m}^{-2}\right)$, admitida constante

\$: raio médio das asperezas, admitido constante

$\mathrm{F}_{\mathrm{i}}$ : rugosidade combinada no ponto $\mathrm{i}=\left(\mathrm{R}_{\mathrm{qi}}{ }^{2}+\mathrm{R}_{\mathrm{qc}}{ }^{2}\right)^{1 / 2}$

$E_{\mathrm{i}}$ : Módulo de elasticidade combinada:

$$
\frac{1}{E_{i}}=\frac{1-v_{\text {edel }}^{2}}{E_{\text {end }}}+\frac{1-v_{e d}^{2}}{E_{e d}}
$$


$b$ : altura do anel $[\mathrm{m}]$

$N p$ : número de trechos na face de contato do anel

$\mathrm{F}_{3 / 2}(\mathrm{t})$ : integral do modelo de G-W

A razão entre a área real de contato $\left(A_{\mathrm{c}}\right)$ e a área aparente $\left(A_{0}\right)$ :

$$
\frac{A_{c}}{A_{b}}=\eta \cdot \pi \cdot \beta \cdot \sigma_{c} \cdot F_{1}(t)
$$

e a razão entre a área de contato plástico $\left(A_{\mathrm{p}}\right)$ e a área de contato $\left(A_{\mathrm{c}}\right)$ :

$$
\frac{\mathbf{A}_{p}}{\mathbf{A}_{c}}=\frac{F_{1}\left(t+w_{p} / 0_{2}\right)}{F_{1}(t)}
$$

Embora o modelo de Grenwood-Tripps (G-T), e não o de G-W, seja mais usado nos programas de simulação de anéis, em particular com a aproximação de HU et al (1994) para cálculo de $\mathrm{F}_{5 / 2}(\mathrm{t})$, optou-se pelo modelo de $\mathrm{G}-\mathrm{W}$ pelas seguintes razões:

- o modelo de G-W é melhor documentado na literatura, tendo sido encontradas tabelas mais detalhadas de valores das integrais desse modelo do que das do modelo de G-T.

- tanto a aproximação de Hu et al (1994), quanto a de ARCOUMANIS et al (1997) apresentam fortes desvios em relação aos valores tabelados no trabalho de G-T (vide fig. 3.13 e tabela 3.2). Para o intervalo de maior interesse para cálculo das pressões rugosas ( $t$ entre 1,5 e 2,5), os erros não são grandes, mas para o cálculo da porcentagem de deformação plástica é necessário calcular $\mathrm{F}_{1}(\mathrm{t})$ para valores maiores que o $t$ local, o que torna os erros excessivos.

- pretende-se, no futuro, explorar a abordagem estatística de McCOOL (1988) para cálculo 
das pressões extremas de contato rugoso, que usa o modelo de G-W.

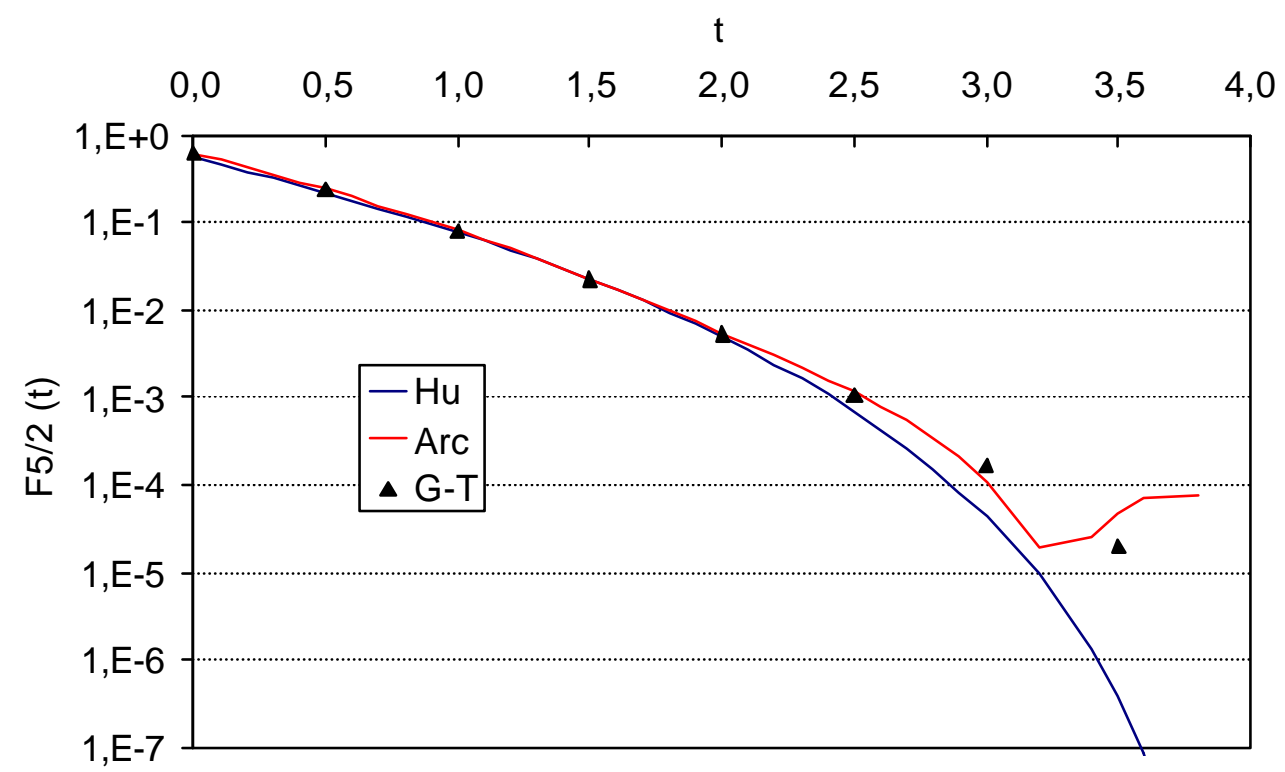

Fig.3.13- Comparação entre as aproximações para $\mathrm{F}_{5 / 2}(\mathrm{t})$ de $\mathrm{HU}$ et al, $1994(\mathrm{Hu})$ e de ARCOUMANIS et al, 1997 (Arc) com os valores tabelados em GREENWOOD e TRIPP, $1971(\mathrm{G}-\mathrm{T})$

A fig.3.14 mostra as pressões geradas pelos dois modelos para diferentes valores de $t$. O modelo de G-W gera pressões rugosas maiores para um mesmo distanciamento $t$. Em média, as pressões calculadas por G-W são cerca de $30 \%$ maiores no intervalo $t=3$ a $2,50 \%$ no intervalo $t=2$ a 1 , que as calculadas por G-T. 


\begin{tabular}{|c|c|c|c|}
\hline \multicolumn{4}{|c|}{ Tabela 3.2 - Valores de $\mathbf{F}_{\mathbf{5} / 2}(\boldsymbol{t})$} \\
\hline $\boldsymbol{t}$ & $\mathbf{G - T}$ & $\mathbf{H u}$ & Arcoumanis \\
\hline 0,0 & 0,61664 & 0,55022 & 0,61670 \\
\hline 0,5 & 0,24040 & 0,22180 & 0,24041 \\
\hline 1,0 & 0,08056 & 0,07771 & 0,08071 \\
\hline 1,5 & 0,02286 & 0,02248 & 0,02279 \\
\hline 2,0 & 0,00542 & 0,00492 & 0,00549 \\
\hline 2,5 & 0,00106 & 0,00070 & 0,00115 \\
\hline 3,0 & 0,00017 & 0,00004 & 0,00011 \\
\hline 3,5 & 0,00002 & 0,00000 & 0,00005 \\
\hline 4,0 & 0,00000 & 0,00000 & 0,00000 \\
\hline
\end{tabular}

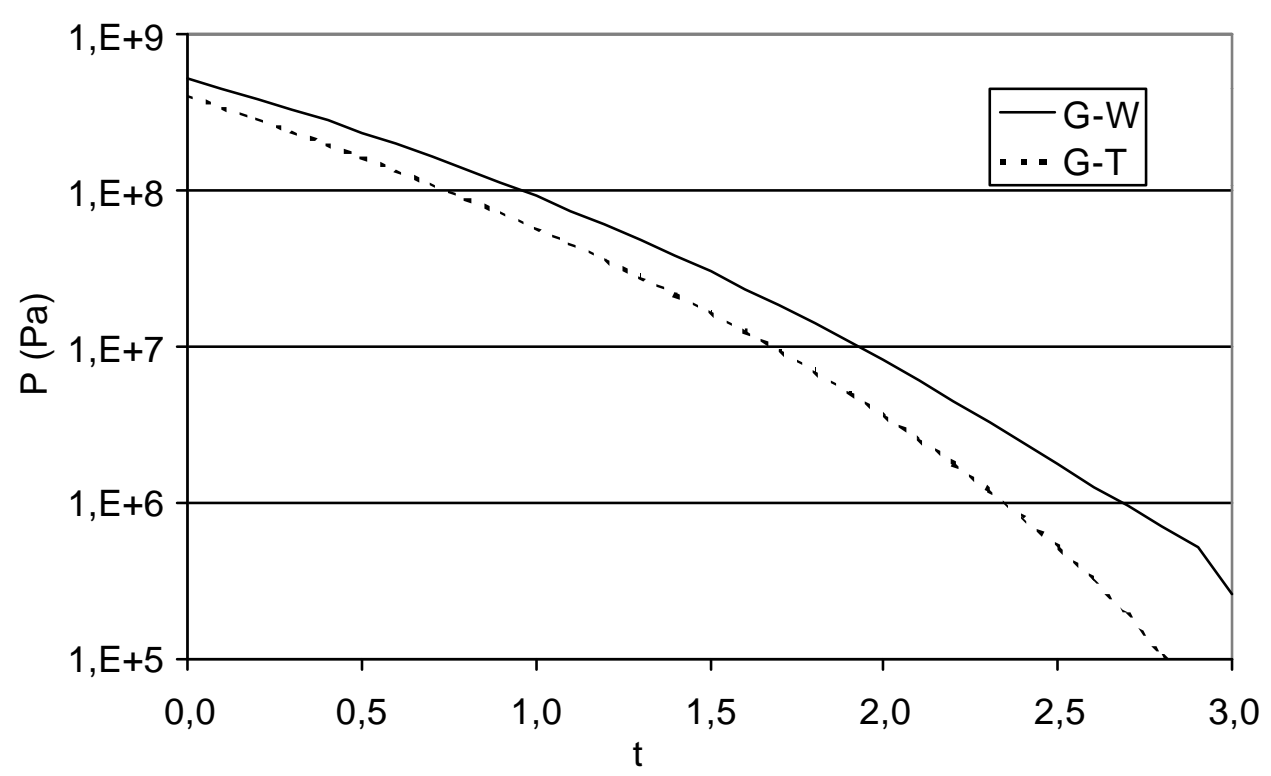

Fig.3.14- Comparação das pressões geradas pelos modelos de G-W e G-T.

$0=3,19.10^{9} \mathrm{~m}^{-2}, \$=275: \mathrm{m}, \mathrm{F}=0,18: \mathrm{m}, \mathrm{E}^{\prime}=200 \mathrm{GPa}$. 
A fig. 3.15 compara os dois modelos para um caso de anéis: o modelo de G-W produz um filme de óleo mais espesso porque as pressões rugosas são maiores, reduzindo, em contrapartida, as pressões hidrodinâmicas. Ou seja, o modelo de G-W é mais severo em termos de desgaste. Nada impede que no futuro se implemente o modelo de G-T, que é considerado mais realista por levar em conta o contato de duas superfícies rugosas. É possível calcular os valores de $\mathrm{F}_{5 / 2}(t)$ por métodos numéricos mais complexos, como aparece no próprio apêndice 2 do trabalho de GREENWOOD, TRIPP (1971).

$Z(\mu \mathrm{m})$

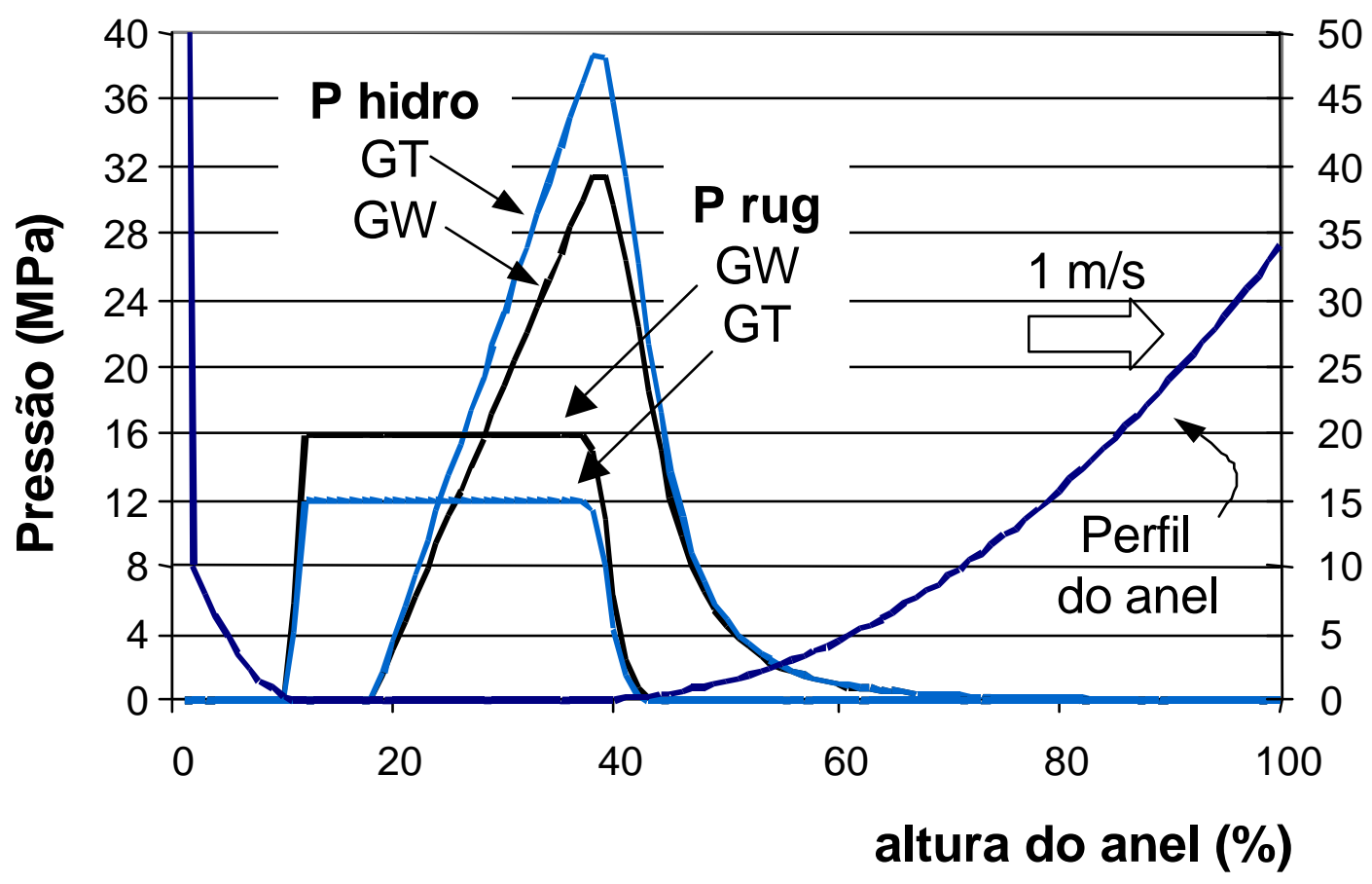

Fig.3.15- Cálculo das pressões rugosas e hidrodinâmicas segundo os modelos de G-W e G-

T para o um determinado caso de anel. Pressão aplicada no anel= $10 \mathrm{MPa}$, demais dados como na fig. 3.6. Viscosidade $=0,013$ Pa.s ${ }^{-1}$, desprezado efeito "squeeze". 
As integrais $\mathrm{F}_{0}(t), \mathrm{F}_{1}(t)$ e $\mathrm{F}_{3 / 2}(t)$ foram aproximadas por polinômios interpoladores, a partir das tabelas de McCOOL, 1986.

$$
\begin{aligned}
& \mathbf{F}_{\mathbf{0}}(\boldsymbol{t})=-7,97644 \mathrm{E}-5 . t^{6}+4,70151 \mathrm{E}-3 . t^{5}-3,9394 \cdot \mathrm{E}-2 . t^{4}+0,110974 . t^{3}+ \\
&-2,26998 \mathrm{E}-2 . t^{2}-0,394608 . t+0,499873, \text { se } \boldsymbol{t} \text { \#3.0 } \\
&=111,24 . \mathrm{e}^{-3,7522 t}, \text { se } \boldsymbol{t}>\mathbf{3 . 0}
\end{aligned}
$$

$\mathbf{F}_{1}(\boldsymbol{t})=-7,163 \mathrm{E}-4 . t^{6}+7,8643 \mathrm{E}-3 . t^{5}-2,8394 \mathrm{E}-2 . t^{4}+9,211055 \mathrm{E}-3 . t^{3}+$

$$
+0,195747 . t^{2}-0,499283 . t+0,39889 \quad, \text { se } t \text { \#3.0 }
$$

$$
=\quad 62,041 \cdot \mathrm{e}^{-3,9792 t} \quad, \text { se } t>\mathbf{3 . 0}
$$

$$
\begin{array}{rlr}
\mathbf{F}_{3 / 2}(t)= & -6,85507 \mathrm{E}-4 . t^{6}+6,22034 \mathrm{E}-3 . t^{5}-1,25047 \mathrm{E}-2 . t^{4}-5,59306 \mathrm{E}-2 . t^{3}+ \\
& +0,32596 \cdot t^{2}-0,617398 . t+0,429964 & , \text { se } \boldsymbol{t} \# \mathbf{3 . 0} \\
& =58,788 . \mathrm{e}^{-4,085 t} & , \text { se } \boldsymbol{t}>\mathbf{3 . 0}
\end{array}
$$

A tabela 3.3 compara valores calculados pelas aproximações acima com alguns dos tabelados em McCOOL, 1986:

\begin{tabular}{|c|c|c|c|c|c|c|}
\hline \multicolumn{7}{|c|}{ Tabela 3.3 - Valores das funções de G-W } \\
\hline $\boldsymbol{t}$ & \multicolumn{2}{|c|}{$\mathbf{F}_{\mathbf{0}}(\boldsymbol{t})$} & \multicolumn{2}{|c|}{$\mathbf{F}_{\mathbf{1}}(\boldsymbol{t})$} & \multicolumn{2}{c|}{$\mathbf{F}_{3 / 2}(\boldsymbol{t})$} \\
\hline & McCOOL & eq. $(26)$ & McCOOL & eq. $(27)$ & McCOOL & eq. $(28)$ \\
\hline 0,0 & 0,5000 & 0,5000 & 0,3989 & 0,3989 & 0,4299 & 0,4300 \\
\hline 0,5 & 0,3085 & 0,3084 & 0,1978 & 0,1978 & 0,1951 & 0,1952 \\
\hline 1,0 & 0,1587 & 0,1587 & 0,0833 & 0,0833 & 0,0757 & 0,0756 \\
\hline 1,5 & 0,0668 & 0,0668 & 0,0293 & 0,0293 & 0,0246 & 0,0246 \\
\hline 2,0 & 0,0228 & 0,0228 & $8,49.10^{-3}$ & $8,51.10^{-3}$ & $6,66.10^{-3}$ & $6,67.10^{-3}$ \\
\hline 2,5 & 0,0062 & 0,0062 & $2,00.10^{-3}$ & $2,00.10^{-3}$ & $1,47.10^{-3}$ & $1,43.10^{-3}$ \\
\hline 3,0 & 0,0135 & 0,0135 & $3,82.10^{-4}$ & $3,72 \cdot 10^{-4}$ & $2,64.10^{-4}$ & $2,11.10^{-4}$ \\
\hline 3,6 & $1,59 \mathrm{E}-4$ & $1,59 \mathrm{E}-4$ & $3,91.10^{-5}$ & $3,82.10^{-5}$ & $2,53.10^{-5}$ & $2,41.10^{-5}$ \\
\hline 4,0 & $3,17 \mathrm{E}-5$ & $3,37 \mathrm{E}-5$ & $7,14.10^{-6}$ & $7,81.10^{-6}$ & $4,44.10^{-6}$ & $4,71 \cdot 10^{-6}$ \\
\hline
\end{tabular}




\subsection{1- EXEMPLO NUMÉRICO}

Para efeito de ilustração e validação do procedimento de cálculo, o exemplo numérico de McCOOL, 1986 foi repetido, detalhando alguns passos e utilizando os polinômios interpoladores desenvolvidos. McCOOL considera dois corpos planos e fornece os valores combinados, sendo detalhadas algumas das propriedades dos dois corpos:

- módulo de Elasticidade, $E=210 \mathrm{GPa}$

o módulo de Elasticidade equivalente é dado pela eq. (3.35)

$$
\begin{aligned}
& \frac{1}{E^{\prime}}=\frac{\left(1-v_{1}{ }^{2}\right)}{E_{1}}+\frac{\left(1-v_{2}{ }^{2}\right)}{E_{2}} \\
& E^{\prime}=115 \mathrm{GPa}
\end{aligned}
$$

- coeficiente de Poisson, $\leftarrow 0,3$

- tensão de escoamento uni-direcional, $Y=2 \mathrm{GPa}$

- desvio padrão da altura média dos picos, dado por $\mathrm{R}_{\mathrm{q}} \quad \mathrm{R}_{\mathrm{q} 1}=0,10: \mathrm{m}$

$$
\mathrm{R}_{\mathrm{q} 2}=0,22: \mathrm{m}
$$

o desvio padrão composto da altura dos picos, $F_{s}$ :

$$
\sigma_{z}=\sqrt{R_{y 1}^{2}+R_{s i}^{2}}=\sqrt{0,10^{2}+0,22^{2}}=0,24 \mu \mathrm{m}
$$

- densidade de picos, $0=3,9 \cdot \mathrm{E}^{9} / \mathrm{m}^{2}$

- raio médio do pico das asperezas, $\$=66: \mathrm{m}$

supondo que esses dois corpos sejam aproximados até uma distância, $d=0,60: \mathrm{m}$

O número de contatos por unidade de área, $N$, pode ser calculado pela probabilidade de um 
pico ser maior do que a distância $d$, multiplicado pela densidade de picos

$$
\begin{array}{lr}
t=d / \mathrm{F}_{\mathrm{s}}=0,60 / 0,24=2,5 & \\
\text { de (26): } \mathrm{F}_{0}(2,5)=6,21 \cdot 10^{-3} & N=6,21 \mathrm{E}-3 \cdot 3,9 \cdot 10^{9} \\
\text { a densidade de picos, } 0=3,9 \cdot 10^{9} / \mathrm{m}^{2} & =24,2 \text { contatos } / \mathrm{mm}^{2}
\end{array}
$$

A pressão de contato nominal, $W / A_{0}$, pode ser calculada pela eq. (2.21):

$$
W=\frac{4}{3} \cdot \eta \cdot A_{0} \cdot E^{\prime} \cdot \sqrt{\beta} \cdot a_{s}^{3 / 2} \cdot F_{3 / 2}(t)
$$

de (3.40): $\quad \mathrm{F}_{3 / 2}(t=2,5)=1,43 \cdot 10^{-3}$

$$
\begin{aligned}
W / A_{0}=4 / 3 \cdot 3 & , 9 \cdot 10^{9} \cdot 115 \cdot 10^{9} \cdot\left(66 \cdot 10^{-6}\right)^{1 / 2} \cdot\left(0,24 \cdot 10^{-6}\right)^{3 / 2} \cdot 1,43 \cdot 10^{-3} \\
& =817.000 \mathrm{~N} / \mathrm{m} 2=817 \mathrm{MPa} \quad(\mathrm{McCool} \text { obteve } 811 \mathrm{MPa})
\end{aligned}
$$

A fração de área em contato $\left(A_{\mathrm{C}} / A_{0}\right)$ pode ser calculada pela eq. (3.36)

$$
A_{t}=\eta \cdot A_{t} \cdot \Pi \cdot B \cdot \sigma_{t} \cdot F_{1}(t)
$$

de (3.39): $F_{1}(2,5)=2,00 \cdot 10^{-3}$

$$
\begin{aligned}
A_{\mathrm{c}} / A_{0} & =3,9 \cdot 10^{-9} \cdot 3,14 \cdot 66 \cdot 10^{-6} \cdot 0,24 \cdot 10^{-6} \cdot 2,00 \cdot 10^{-3} \\
& =3,88 \cdot 10^{-4}=0,039 \%
\end{aligned}
$$


ou seja, a pressão real atuando nos contatos vale

$W / A_{\mathrm{c}}=\left(W / A_{0}\right) /\left(A_{\mathrm{c}} / A_{0}\right)=817.10^{3} / 3,88.10^{-4}=2,1 \mathrm{GPa}$

portanto o material escoou plasticamente nos pontos de contato. Nesses pontos a pressão de contato pode assumir valores de até aproximadamente 3 vezes o limite de escoamento uni-direcional. Para cálculo do número de asperezas com contato plástico, utiliza-se o parâmetro de limite plástico normalizado $\left(w_{\mathrm{p}}, \mathrm{F}_{\mathrm{s}}\right)$

$w_{p} / \mathrm{F}_{\mathrm{s}}=6,4 \cdot 66 \cdot 10^{-6} \cdot(2 / 115)^{2} / 0,24 \cdot 10^{-6}$

$=0,53($ McCool obteve 0,58)

A razão entre a área de contatos plásticos em relação à total de contato é dado pela eq.

$$
\frac{\mathbf{A}_{p}}{\mathbf{A}_{t}}=\frac{F_{1}\left(t+W_{p} / \sigma_{\Delta}\right)}{F_{1}(t)}=\frac{F_{1}(2,5+0,53)}{F_{1}(2,5)}=\frac{F_{1}(3,03)}{F_{1}(2,5)}=\frac{3,41 \cdot 10^{-4}}{2,00 \cdot 10^{-3}}=0,17
$$

$A_{\mathrm{p}} / A_{\mathrm{c}} \quad=17 \% \quad($ McCool obteve $15,1 \%)$

Estendendo esse exemplo vamos agora admitir que nesses $17 \%$ de área de contato a pressão tenha atingido o valor de 2,8.Y=5,6 GPa, pode-se calcular a pressão $P^{\prime}$ atuante no restante da área de contato:

$$
\frac{W}{A_{c}}=\frac{A_{p}}{A_{c}} \cdot P_{p}+\left(1-\frac{A_{p}}{A_{c}}\right) \cdot P^{\prime}
$$

$P^{\prime} \quad=(2,1 \mathrm{GPa}-0,17 \cdot 5,6 \mathrm{GPa}) / 0,83=1,4 \mathrm{GPa}$

ou seja, um valor também bastante alto (70\% do limite de escoamento). 


\section{4- MODELO DE DESGASTE}

\subsection{1- Mecanismo de desgaste atuante em anéis de pistão}

Baseando-se na observação de peças ensaiadas, admitiu-se o seguinte modelo para o desgaste em anéis de pistão de MCI:

- inicialmente existe uma alta taxa de desgaste porque as superfícies ainda são não conformes e as rugosidades são relativamente altas. As partículas removidas (debris) agem como abrasivo e provocam riscos na face de contato do anel e cilindro. A fig. 3.16 mostra a face de contato do $1^{\circ}$ anel, cromado, motor a gasolina, após 80 horas de ensaio em dinamômetro.

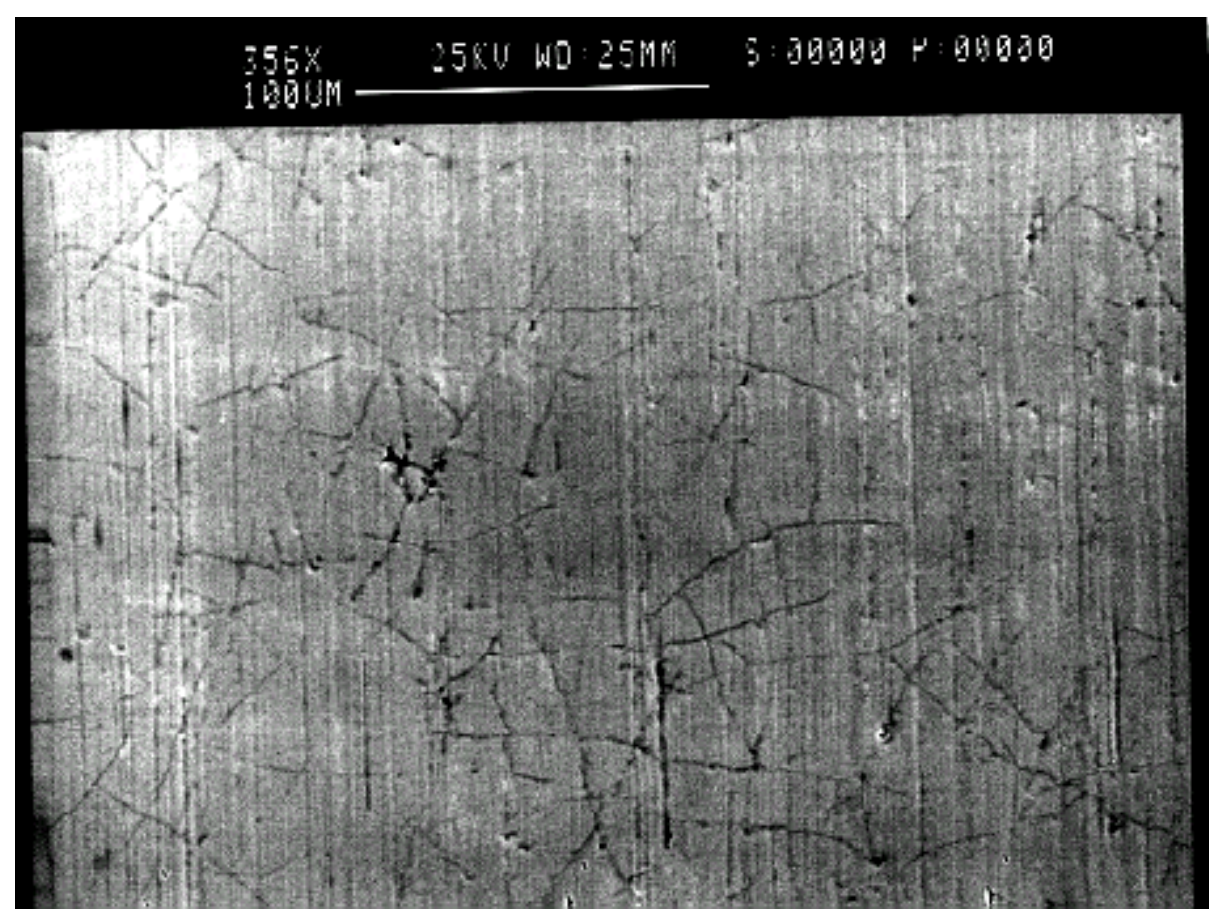

Fig.3.16- Face de contato do $1^{\circ}$ anel, cromado, motor a gasolina após 80 horas de ensaio em dinamômetro. 
Esses riscos tem poucos micrometros de largura e profundidade (vide ISHIKI et al, 2000).

Onde o filme de óleo entre o anel e o cilindro é maior, existe pouca interação e o acabamento superficial do anel é preservado, como veremos nas fotografias seguintes. O desgaste radial é, em geral, ainda muito pequeno.

Passada essa fase inicial, as partículas maiores tendo sido removidas do sistema por filtragem do óleo, bem como as tensões de contato reduzidas porque as superfícies se tornaram mais lisas e mais conformes, o mecanismo de desgaste passa a ser outro. A fig. 3.17 mostra o aspecto típico da superfície de anéis testados em motor, a região que se desgasta tem aspecto brilhante e liso, sua rugosidade vale cerca de Ra $0,10: \mathrm{m}$. Alguns riscos ainda são visíveis, mas eles tendem a desaparecer com durações maiores do ensaio, bem como em posições do anel onde o desgaste é maior (em geral nas pontas, vide fig. 3.18). Com maior aumento, fig. 3.19, são visíveis pequenas crateras ("pittings"), sugerindo que o mecanismo preponderante de desgaste é a fadiga de contato. 


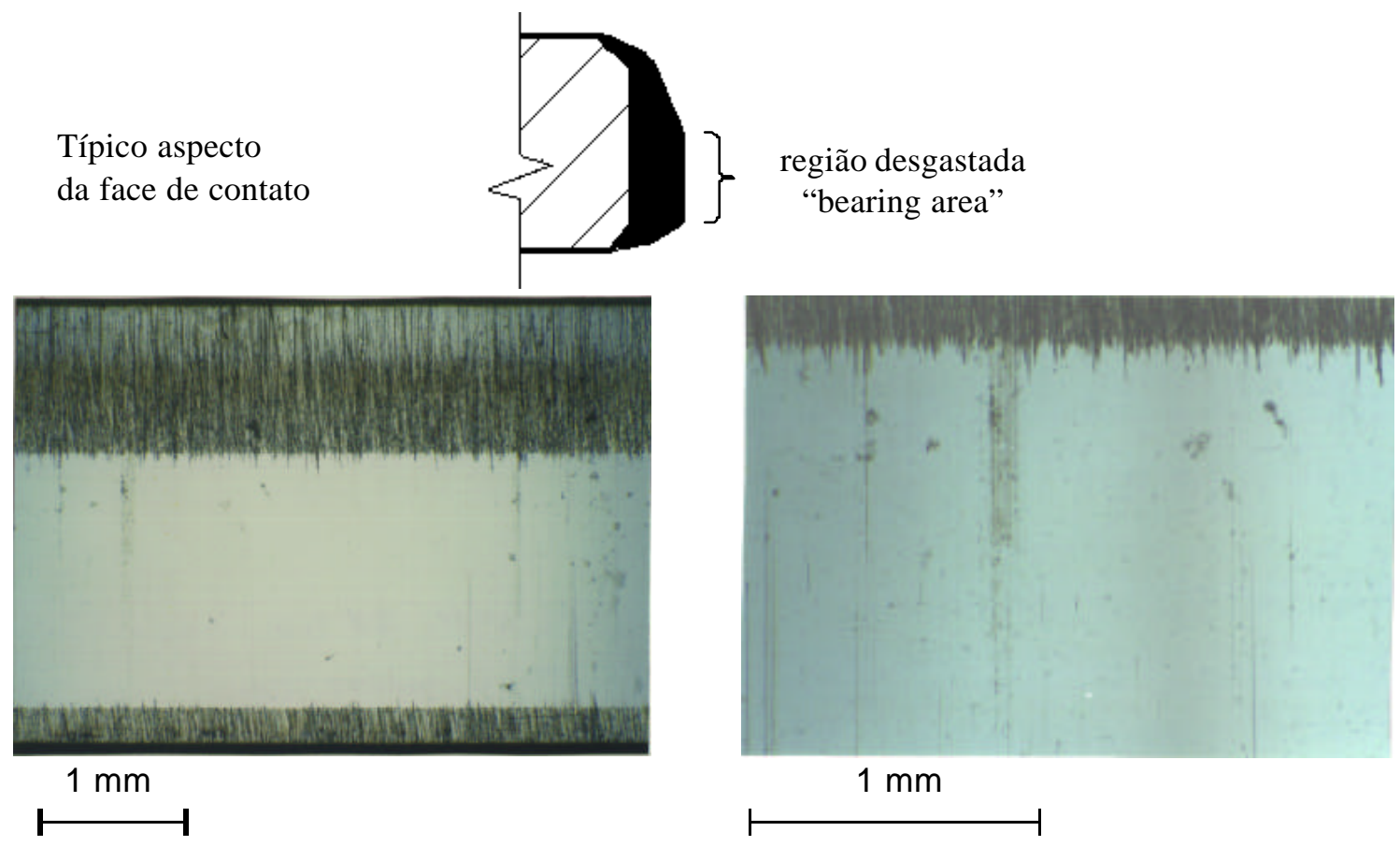

Fig.3.17- Anel de $1^{\circ}$ canalete, aço nitretado, após 250 h de ensaio em motor diesel. A área clara é a região que se desgastou, mostrada em maior aumento à direita. A região escura, com riscos verticais ainda apresenta o acabamento original.

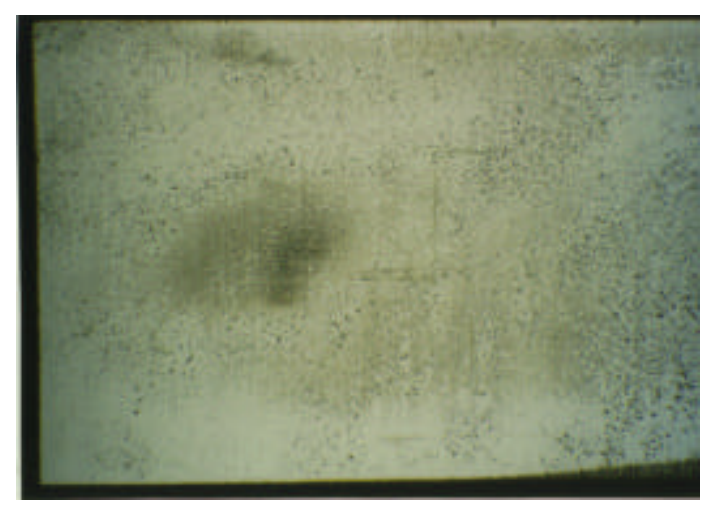

$1 \mathrm{~mm}$

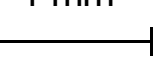

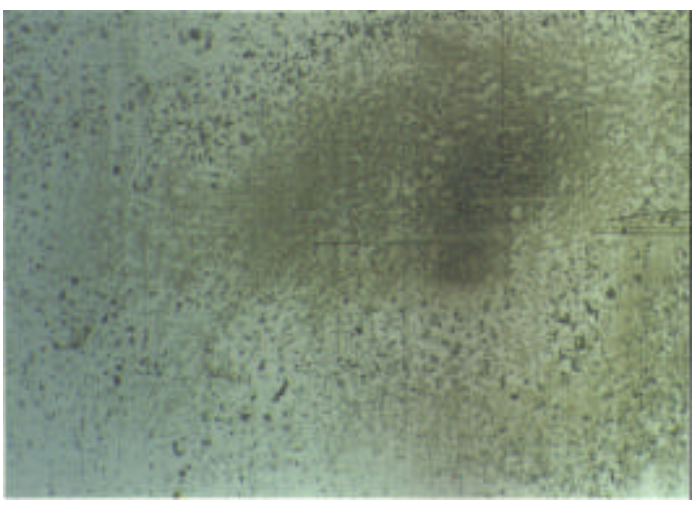

$1 \mathrm{~mm}$

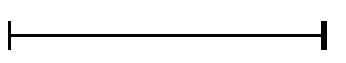

Fig.3.18- Mesmo anel da fig. anterior, região da ponta onde o desgaste é maior. Nesta região a área desgastada ocupa toda a altura do anel. 


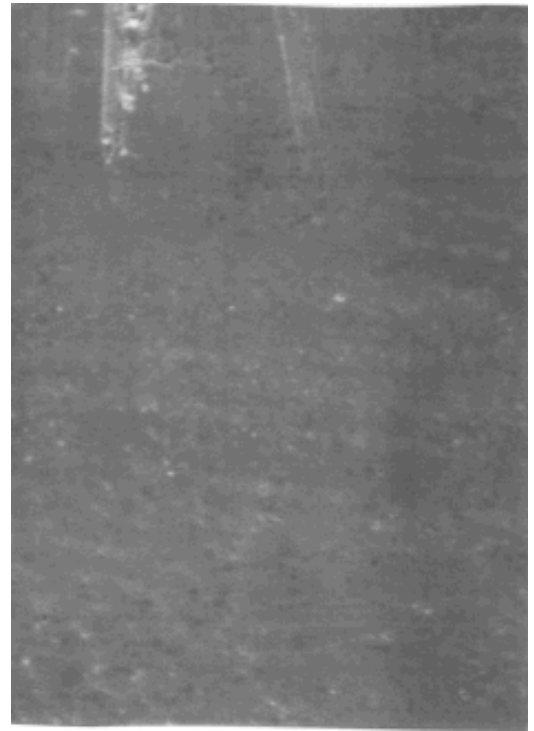

$350 x$

Posição oposta às pontas, $250 \mathrm{~h}$

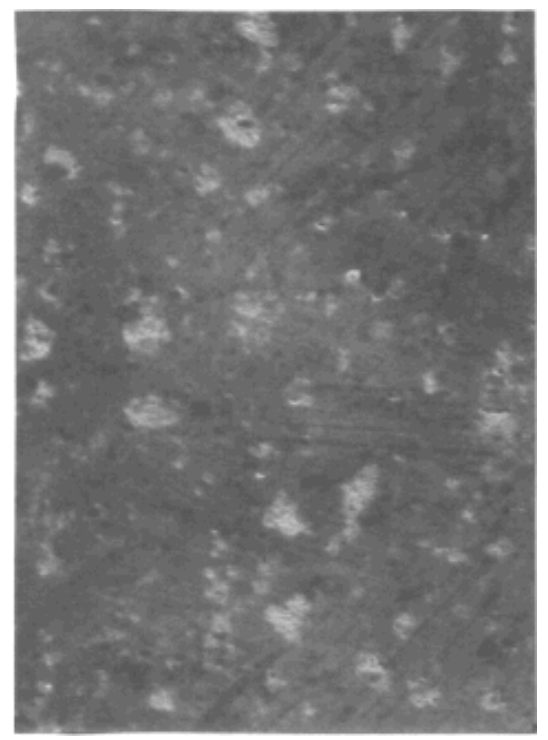

$350 x$

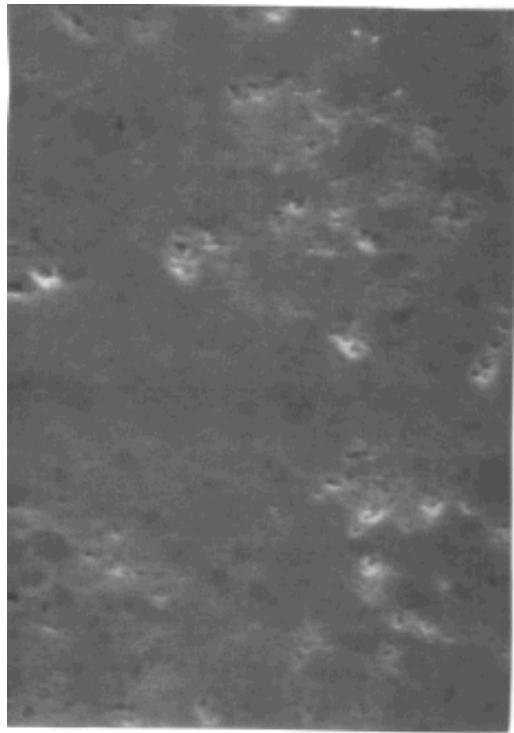

$1.000 \mathrm{x}$

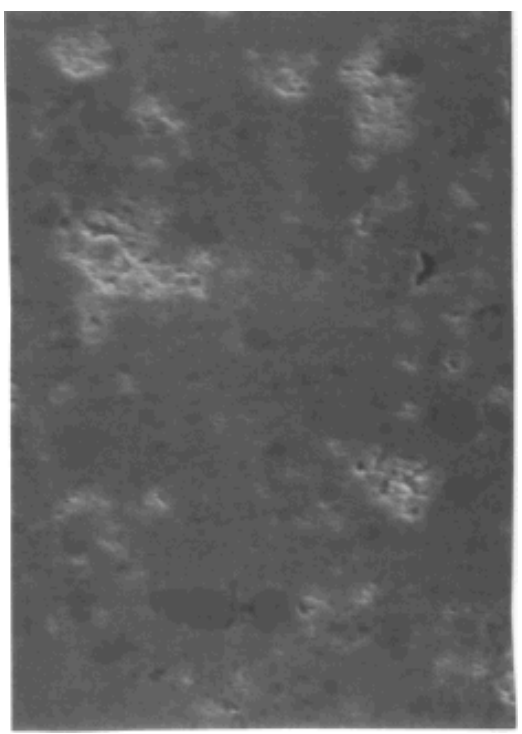

$1.000 \mathrm{x}$

Posição próxima às pontas, $250 \mathrm{~h}$

Fig.3.19- Foto em maior aumento do anel das figs. 3.17 e 3.18. MEV 
A fig.3.20 mostra um anel cromado, motor diesel, após 1000 h de ensaio. Os "pittings"se concentram nas bordas das fissuras existentes do cromo. As fissuras funcionam como concentradoras de tensão e micro trincas surgem devido à ação de repetidas deformações plásticas causadas pelas pressões de contato. Mecanismo similar para o desgaste normal de anéis cromados é descrito por SHUSTER et al (1999b).

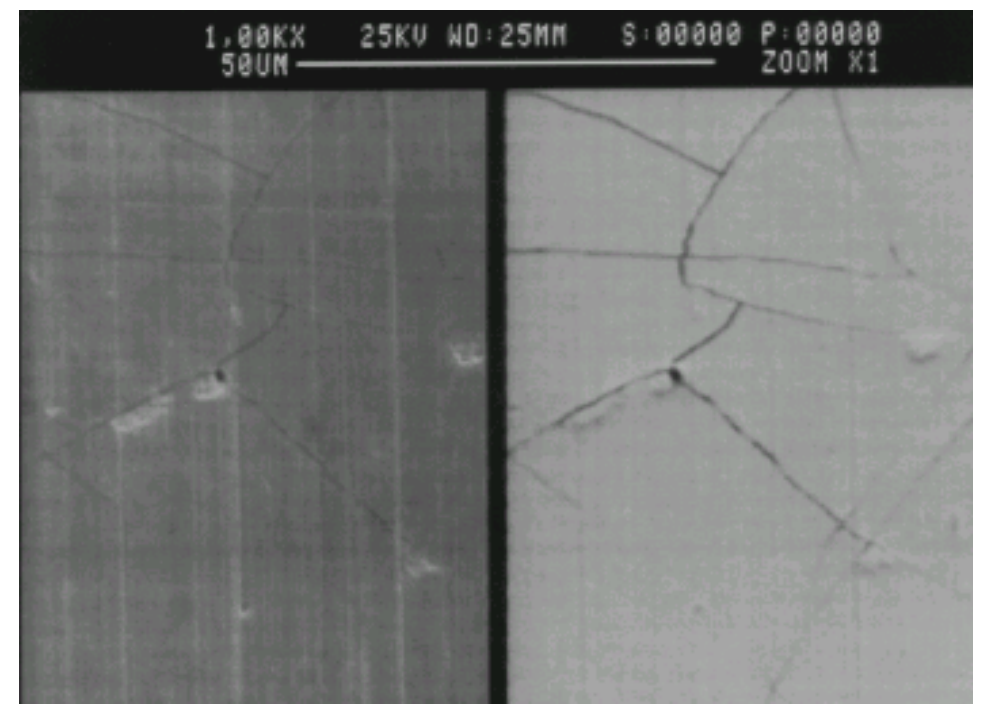

Fig.3.20- Anel de $1^{\circ}$ canalete cromado, motor diesel, após 1000 h de ensaio. MEV, À esquerda, imagem de elétrons secundários (SEI). À direita, imagem de elétrons retroespalhados (“BEI”). 


\subsection{2- Cálculo da evolução do perfil desgastado.}

Para calcular a evolução do perfil do anel em função do desgaste foi admitido que:

- O desgaste é uniforme ao longo do perímetro do anel.

- O desgaste é proporcional à intensidade e frequiência do contato entre as asperezas das duas superfícies. O contato entre asperezas ocorre quando o filme de óleo lubrificante é menor que um determinado valor, o qual depende da rugosidade combinada das superfícies deslizantes. O contato rugoso é modelado conforme o modelo de Greenwood-Williamson. Após um determinado intervalo de tempo, o desgaste modifica a rugosidade e o perfil das superfícies deslizantes. Com a mudança do perfil e da carga suportada pelas asperezas, a espessura de filme de óleo também se modifica, o que pode alterar a intensidade do contato das asperezas e a taxa de desgaste. Mecanismos similares de desgaste tem sido propostos por diversos autores, por ex. KIMURA \& SUGIMURA (1984) de onde foi reproduzida a fig. 3.21. A iniciação e crescimento de trincas não são calculados no modelo proposto, já que isso exigiria uma carga computacional muito grande; de maneira simplificada admite-se que ocorre remoção de material num ponto quando o dano acumulado nesse ponto atinja um valor crítico. Esse valor crítico e a quantidade de material removido foram arbitrariamente definidos, de modo a compatibilizar a velocidade de execução do programa com um passo de remoção pequeno o suficiente para garantir a convergência e uma "suave" evolução do perfil desgastado. Vale lembrar que o modelo se propõe a prever a evolução do perfil desgastado e não a taxa de desgaste propriamente dita. 


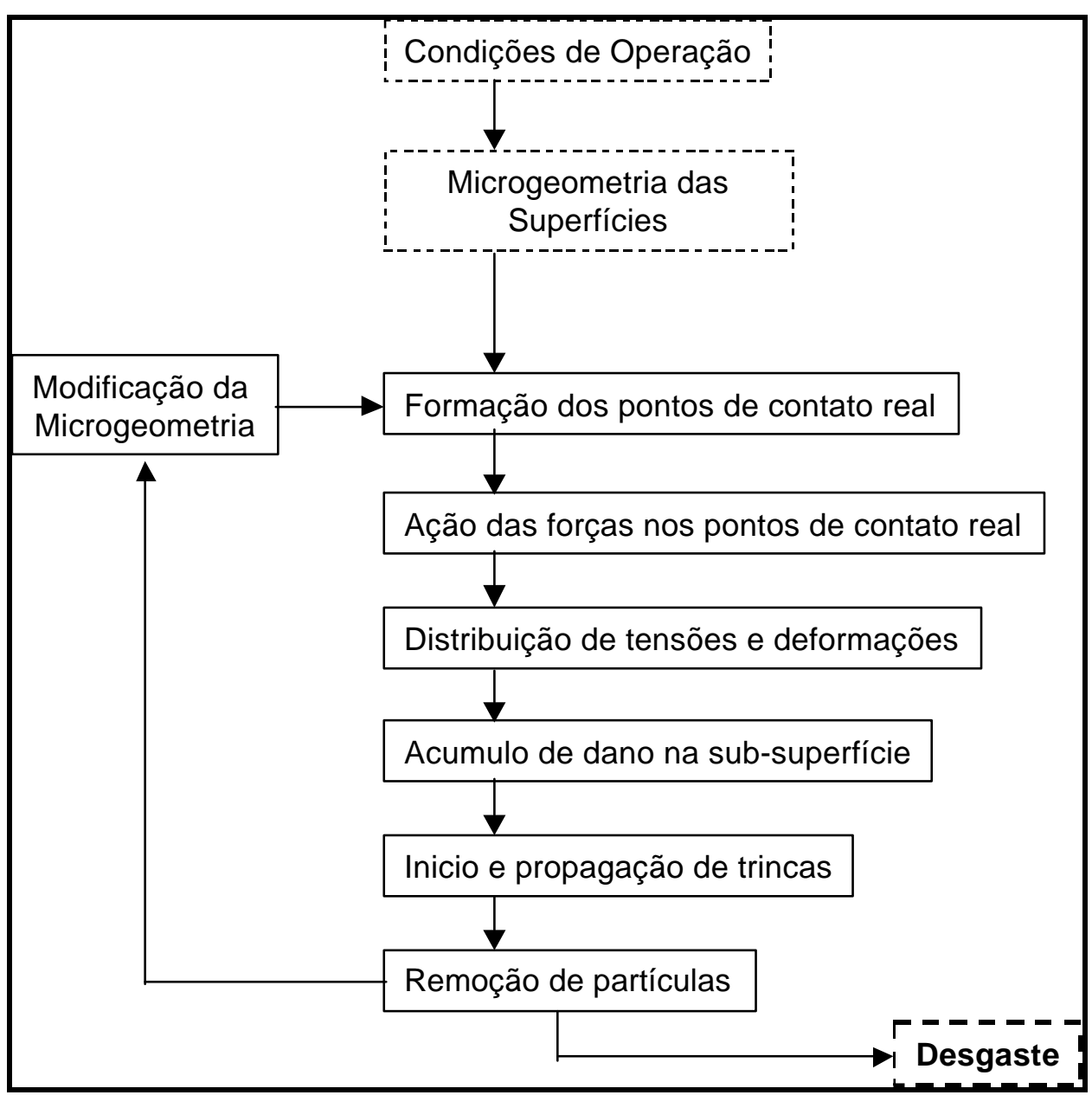

Fig.3.21- Divisão do desgaste em processos elementares. KIMURA \&

SUGIMURA, 1984

A remoção de material a cada interação é suficientemente pequena para que as condições de operação e tribológicas atuantes no sistema possam ser consideradas constantes. O modelo alerta se a remoção por interação é maior que um determinado valor.

O perfil da face de contato do anel pode ser discretizado por 100 pontos $^{5}$. Vide fig.3.22.

${ }^{5}$ Fisicamente cada ponto representa uma fatia axial do anel. 
Cada ponto da face de contato pode ser caracterizado por:

- sua posição relativa X em relação à altura do anel, topo: i= 100;

- seu perfil $\left(\mathrm{z}_{\mathrm{i}}\right)$ em relação ao ponto mais proeminente;

- sua rugosidade, definida pelo desvio padrão da altura $\left(F_{S}\right)$, densidade e raio médio dos picos;

- propriedades do material: módulo de Elasticidade $(E)$ e tensão limite de escoamento $(Y)$

- dano acumulado, função da tensão que atuou no ponto, dividida pelo limite de escoamento.

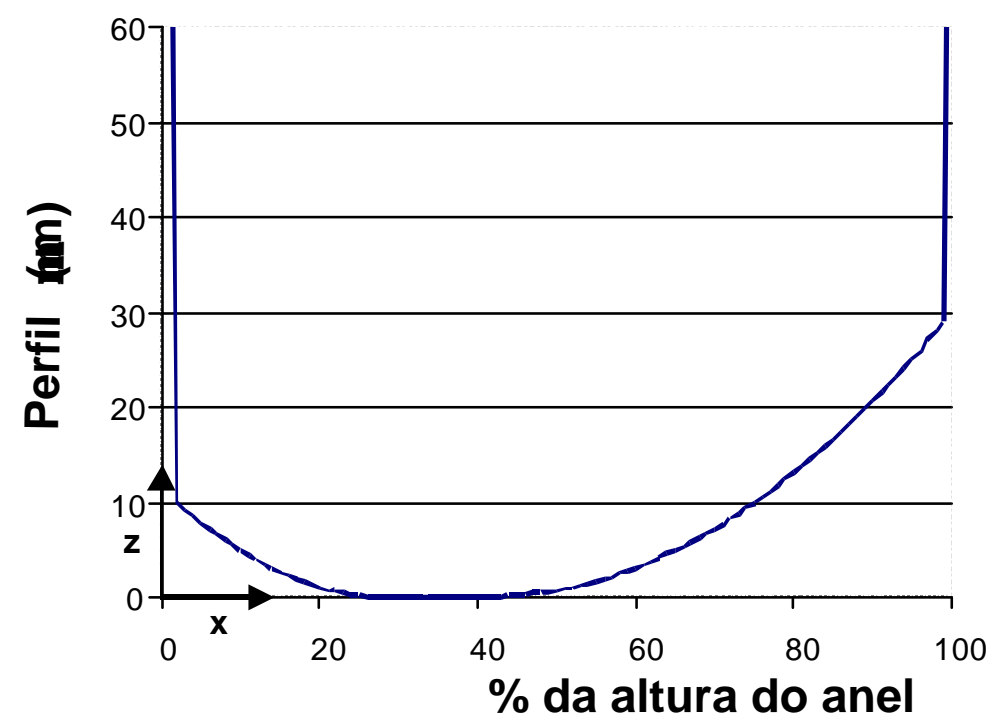

Fig. 3.22- Exemplo da discretização do perfil da face de contato de um anel de $1^{\circ}$ canalete, quando novo.

Em função das tensões atuantes, é atribuído um certo dano a cada ponto do anel e do cilindro. É adotado um multiplicador para diminuir o número de interações necessárias para 
simulação de um determinado valor de desgaste. Esse multiplicador pode ser ajustado arbitrariamente, mas não pode ser muito grande para garantir que a evolução do perfil desgastado seja suave. O incremento de dano () $D[\mathrm{i}, \mathrm{t}])$ no ponto $\mathrm{i}$, a cada instante é dado por uma das diferentes "regras" descritas a seguir, que são parâmetros de entrada do programa computacional:

- Lei de Archard - Como vimos no capítulo 2, o volume de material removido por distância percorrida pode ser modelada pela eq. (2.1):

$$
\frac{Q}{\Delta s}=\frac{K \cdot W}{H}
$$

lembrando que o coeficiente de desgaste $K$, é em geral desconhecido e que a velocidade de remoção admitida pelo modelo é arbitrada, o incremento de dano a cada interação pode ser definida como:

$$
\Delta D[i, t]=\left(\frac{P_{\alpha^{*}}[i, t]}{Y[\dot{i}]}\right) \cdot \Delta s
$$

onde $P_{g w}$ : Pressão de contato rugoso no ponto $i$

$Y$ : tensão de escoamento unidimensional do material, $Y=\mathrm{HV} / 2,83$, sendo $\mathrm{HV}$ a dureza em Vickers (WILLIAMS, 1994 eq. 3.93)

) s: distância percorrida no intervalo de tempo correspondente a um intervalo angular do virabrequim. O modelo utiliza 1 grau de virabrequim como intervalo. 
Fadiga - Tentou-se também uma expressão que considerasse, ainda que aproximadamente, a ação da fadiga nos pontos em contato. Definiu-se o dano por fadiga como:

$$
\Delta D[i, t]=A_{p} / A_{e} \cdot\left(\frac{P_{e w}[i, t] /\left(A_{e} / A_{Q}\right)}{Y[i]}\right)^{m} . \Delta s
$$

onde $P_{\mathrm{gw}}[\mathrm{i}, \mathrm{t}] /\left(A_{\mathrm{d}} / A_{0}\right)$ : a pressão real, de contato rugoso, atuante no ponto num dado instante. $m$ : expoente de Wöller de fadiga, admitido igual a 2, $A_{\mathrm{p}} / A_{\mathrm{c}}$ : fração, em área, de contatos que estão com deformação plástica.

Não foram modelados os desgastes abrasivo nem corrosivo, que com certeza devem participar do processo. Essa simplificação é também admitida nos demais modelos recentes de desgaste de anéis (PRIEST et al, 1999; PINT \& SCHOCK, 2000), considerando apenas a operação de motores em condições especiais de ensaio em dinamômetro.

- quando o dano acumulado num certo ponto atinge um certo valor crítico $^{6}$, a rugosidade neste ponto diminui. Mas o perfil ainda não se altera.

- quando o dano acumulado num certo ponto atinge um outro valor crítico, maior que o anterior, ocorre remoção local de material ( $\mathrm{Zi}$ diminui). A rugosidade local cresce. O dano local acumulado é reduzido, mas não zerado.

- a cada interação, o processo se repete com os perfis do anel e do cilindro calculado na interação anterior.

${ }^{6}$ arbitrado de modo a garantir um tempo razoável de computação. 
- a folga entre pontas do anel aumenta de acordo com a remoção de material na face de contato.

- a superfície quando nova pode ter e geralmente tem um certo nível de dano prévio, provocado pelas operações de usinagem.

- as interações de cálculo são repetidas até que ocorra um dos seguintes:

- um determinado número de ciclos tenha sido calculado (500 por exemplo)

- o fluxo de gases (blow-by) pela folga entre pontas do anel atinja valores muito altos - o desgaste do canalete do pistão é desprezado, o que é bastante razoável para pistões de motores diesel com porta-anel em material resistente ao desgaste. 


\subsection{3- Desgaste do cilindro}

- O desgaste do cilindro é calculado de maneira similar ao dos anéis, mas para o cilindro apenas o a regra de Archard foi implementada. Como o cilindro é, em geral, mais mole que o anel e como a pressão é igual nas duas superfícies num dado instante e posição, o cilindro acumula mais dano. Vale mencionar entretanto, que sendo a superfície do cilindro significativamente maior que a do anel, a profundidade de desgaste no cilindro é menor. - Como o sistema de referência para cálculo das pressões de contato rugoso acompanha cada anel, a discretização dos pontos ao longo do cilindro não corresponde à discretização da face de contato do anel a cada posição deste. Para diminuir o esforço computacional foi feita a simplificação que para o cilindro as pressões de contato rugoso se concentram no centro da face de contato do anel e são distribuídas proporcionalmente nos pontos vizinhos do cilindro ao centro do meio do anel; metodologia similar à descrita em 3.3 para cálculo das propriedades do cilindro. A fig.3.23 mostra a posição do centro dos anéis em relação às posições do cilindro para o caso que vai ser descrito no item 5. Observar também que o espaçamento entre os pontos no cilindro é menor que o espaçamento percorrido pelos anéis em 1 grau do virabrequim, mesmo na região de máxima velocidade do pistão. 


\section{Região próxima ao topo}

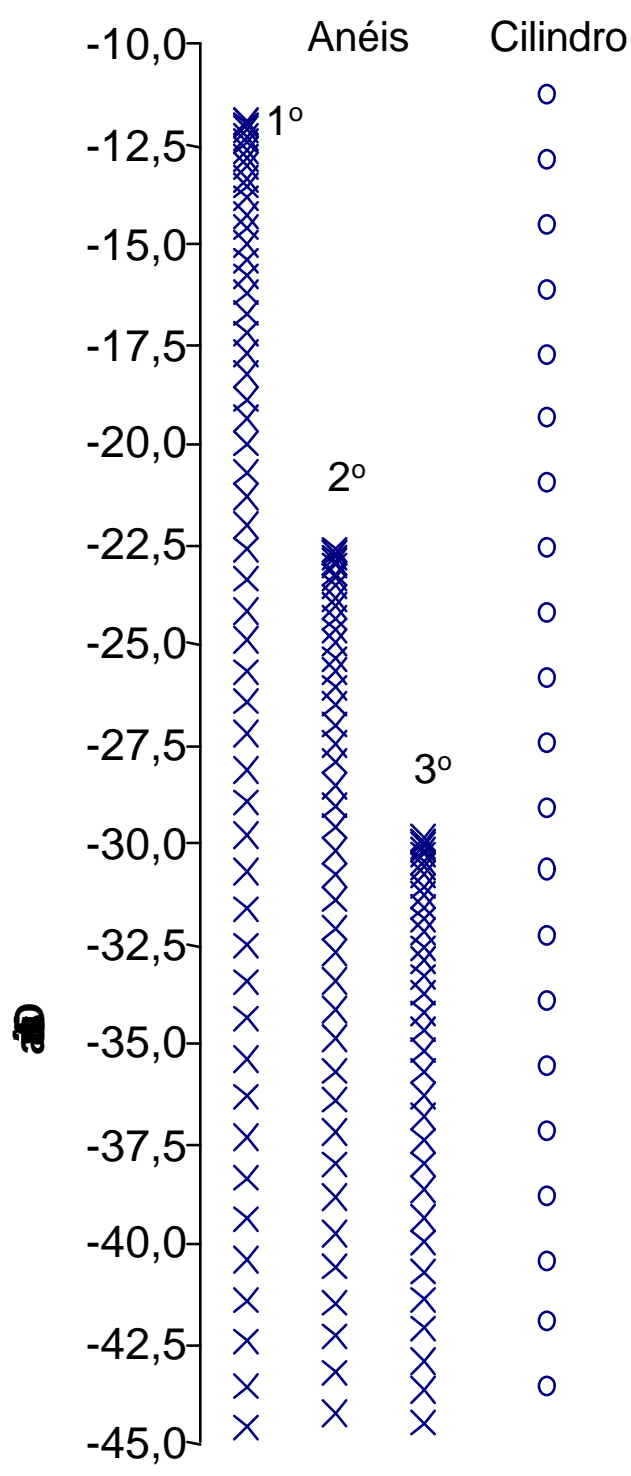

\section{Região próxima ao meio do curso}

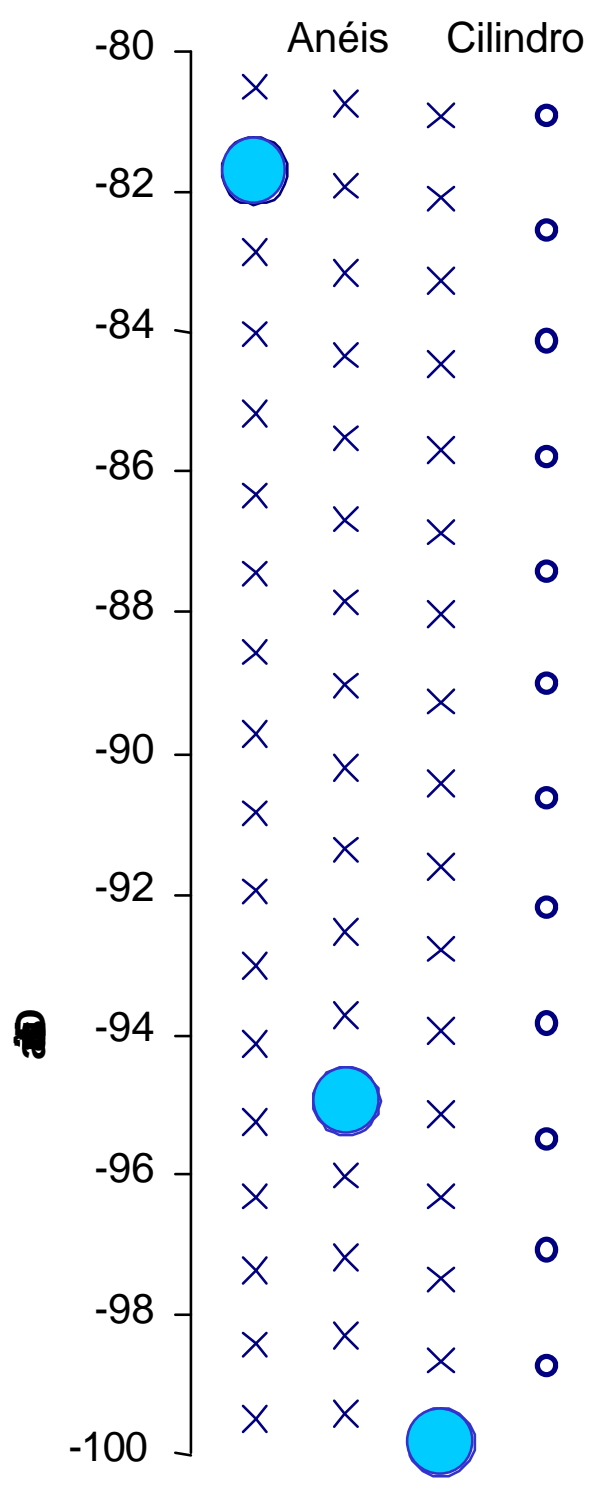

Posições no ângulo 85

Fig. 3.23- Discretização do cilindro versus posições ocupadas pelos anéis em 2 regiões: próximo do topo do cilindro e no meio do curso. Note-se que as posições no cilindro são eqüidistantes, enquanto que a dos anéis dependem da distância percorrida em 1 grau do virabrequim. 


\section{4- PROGRAMA COMPUTACIONAL}

O modelo foi implementado através de um código computacional em "Turbo Pascal V7.0". Embora o programa fonte tenha mais de 1600 linhas, os requisitos de memória e o tamanho do código executável são bastante baixos (respectivamente, 1 Mb e 40 kb). Necessita-se, entretanto, de uma alta velocidade de processador; a execução de 500 interações de desgaste demora cerca de 6 horas num Pentium III de $600 \mathrm{MHz}$. A fig. 4.1 mostra o fluxograma geral do código.

Dado o tamanho do programa completo, no anexo III é reproduzido o programa fonte de uma versão simplificada do modelo. Essa versão calcula o filme de óleo, as pressões hidrodinâmicas e de contato rugoso, e as frações de área em contato $\left(A_{\mathrm{c}} / A_{0}\right)$ e de contatos plásticos $\left(A_{\mathrm{p}} / A_{\mathrm{c}}\right)$, que surgem num perfil carregado quando esse desliza sobre outra superfície. Esta versão foi utilizada, por exemplo, para gerar os resultados das fig.3.6 e 3.15. As subrotinas de cálculo de dano e remoção de material, não presentes nessa versão simplificada, são listadas à parte, também no anexo III e são comentadas mais à frente (vide fig. 4.2 e 4.3). Detalhes do cálculo das forças atuando nos anéis podem ser encontrados em TOMANIK,1993. 


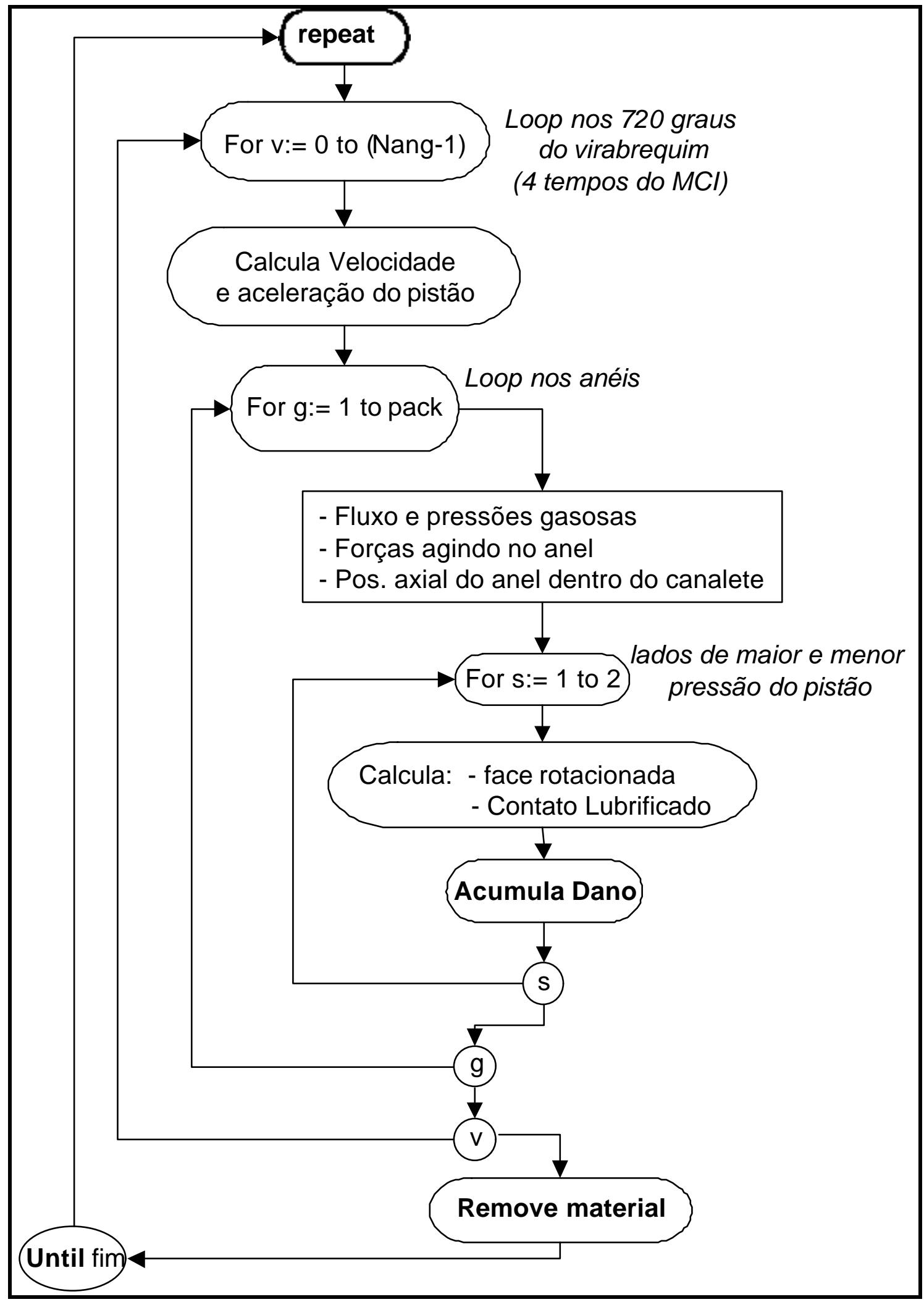

Fig.4.1 - Fluxograma geral do programa. Cada "loop" principal (do "repeat" até o "Until fim”) é uma interação de desgaste. 
A pressão de contato rugoso, segundo o modelo de Greenwood-Williamson, atuando em cada fatia $i$ do anel é expresso por $P g w[i]$; enquanto $Y[i]$ representa o limite de escoamento uni-direcional do material (que pode ser entendido como uma medida de sua dureza superficial) nessa fatia. A fig.4.2 mostra o fluxograma da subrotina de cálculo do dano acumulado, segundo a lei de Archard (eq.3.42); o cálculo pela lei de fadiga é semelhante, apenas utilizando-se a eq.3.43 para o dano no anel. A constante multiplicadora, $\boldsymbol{a c}$, representa o número de ciclos idênticos do motor (sem remoção de material e conseqüente alteração das condições no anel) a cada interação do programa, multiplicada pelo coeficiente adimensional de desgaste admitido internamente no programa. Nos casos apresentados no capítulo 5 utilizou-se $a c=$ velocidade angular do motor [rpm] dividido por 10. A variável $a[i]$ distribui a pressão atuando no ponto $i$ do anel para os dois pontos vizinhos do cilindro, segundo a "regra da alavanca" (vide item 3.4.3 e fig. 3.12). 


\section{Para cada anel, a cada grau do virabrequim}

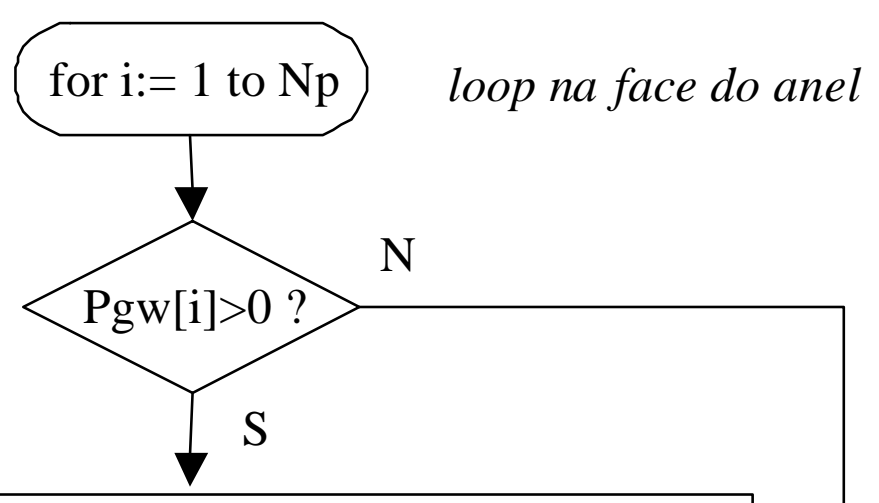

no anel:

$\mathrm{D}[\mathrm{i}]:=\mathrm{D}[\mathrm{i}]+\mathrm{ac} .(\mathrm{Pgw}[\mathrm{i}] / \mathrm{Y}[\mathrm{i}]) . \Delta \mathrm{s}$ no cilindro:

$\operatorname{Dc}[\mathrm{j}-1]:=\operatorname{Dc}[\mathrm{j}-1]+\mathrm{ac} .(\mathrm{a}[\mathrm{i}] . \operatorname{Pgw}[\mathrm{i}] / \mathrm{Y}[\mathrm{j}-1]) . \Delta \mathrm{s}$

$\operatorname{Dc}[\mathrm{j}]:=\operatorname{Dc}[\mathrm{j}]+\mathrm{ac} \cdot((1-\mathrm{a}[\mathrm{i}]) \cdot \operatorname{Pgw}[\mathrm{i}] / \mathrm{Y}[\mathrm{j}]) . \Delta \mathrm{s}$

Fig.4.2- Fluxograma de cálculo do dano acumulado, segundo a regra de Archard.

A fig.4.3 mostra o fluxograma da subrotina de remoção de material para o anel. Note-se que z[i] aumenta com a remoção de material, ou seja, afastando o perfil do anel da parede do cilindro. Ao final dessa subrotina o código verifica qual é o mínimo afastamento z[i] do perfil do anel, e subtrai esse valor de todos os pontos do perfil, "fazendo" novamente o ponto mais proeminente do perfil do anel retornar à mesma distância da parede do cilindro que ocupava antes da remoção de material. 
Para cada anel, ao fim de uma interação (720 graus do virabrequim)

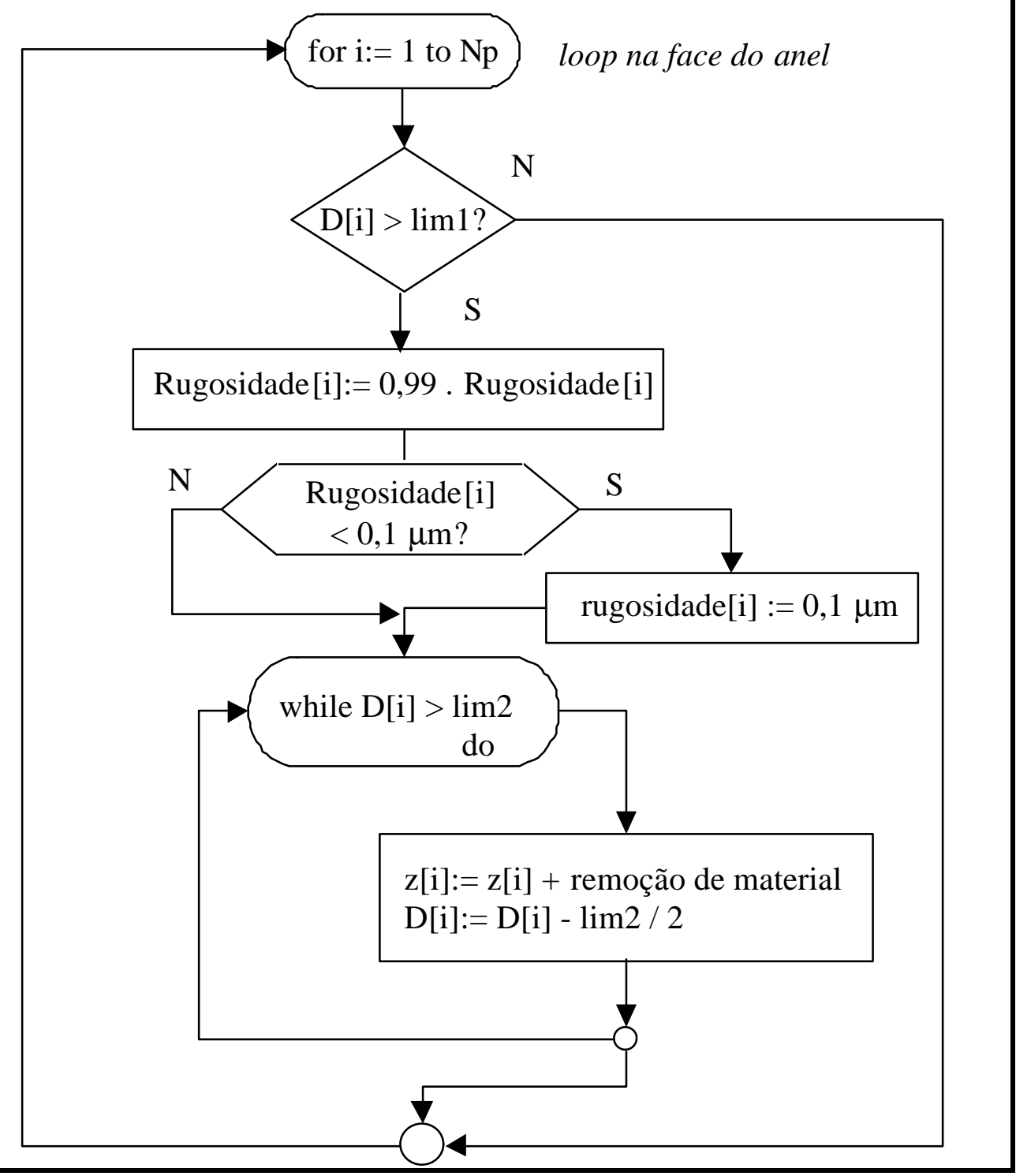

Fig.4.3- Fluxograma da subrotina de remoção do material.

O fator de redução da rugosidade por interação foi escolhido, após algumas tentativas, de modo a permitir uma boa convergência ao modelo computacional. O mesmo aconteceu com as constantes $\lim 1$ e $\lim 2$, que definem os limites de dano acumulado para ocorrer, respectivamente, redução da rugosidade e remoção de material. No caso apresentado no capítulo 5, usou-se $\lim 1=0,1, \lim 2=0,5$ e remoção de material $=0,1: \mathrm{m}$. Para os valores 
de densidade (0) e raio (\$) dos picos das asperezas, foram adotados os valores citados em ARCOUMANIS et al (1997): $0=3,10.10^{9}, \$=275,4: \mathrm{m}$ (vide discussão no anexo II). Observe-se ainda que somente após um certo acúmulo de dano, eventualmente um certo número de interações, é que ocorre alteração de rugosidade e remoção de material.

Para o cilindro, a subrotina é similar, sendo que o valor da remoção de material, a cada ponto do cilindro, é adicionado ao valor, já existente, da deformação radial naquele ponto, não existindo a necessidade de subtrair o valor mínimo.

Os resultados do programa são fornecidos através de arquivos no formato texto, sendo os seguintes os principais arquivos:

- R_i.j: Grandezas, como espessura do filme de óleo, forças, posição axial etc, do anel i, na interação j, a cada grau do virabrequim;

- CD_i.j : arquivo com o perfil (desgastado) do anel i, na interação j;

- PH_i.j: pressões hidrodinâmicas, atuando em cada fatia da face do anel i, na interação j, a cada grau do virabrequim;

- PGW_i.j: pressões de contato rugoso, atuando em cada fatia da face do anel i, na interação j, a cada grau do virabrequim;

- CDB.j: dano acumulado e desgaste ao longo do cilindro na interação j. 


\section{1- Estudos de sensibilidade}

A sensibilidade do modelo a variações de alguns dos dados de entrada, e de algumas das hipóteses foi testada, calculando-se um caso específico com diferentes dados de entrada (vide tabela 4.1).

Em $1^{\circ}$ lugar foi verificada a sensibilidade de se alterar o limite de contato rugoso de 3 para 4 vezes a rugosidade combinada. Para o $1^{\circ}$ anel a diferença, no desgaste radial, foi de $4 \%$ após 100 interações, $2 \%$ após 500 interações. A seguir, investigou-se também um maior refinamento da discretização da face de contato, que passou de 100 para 200 pontos. Novamente a diferença observada de desgaste foi muito pequena, 6\% após 100 interações, 4\% após 500.

Para verificar o efeito da rotação do anel no perfil desgastado da face de contato, simulou-se um caso onde a cada interação o anel era "girado" de $20^{\circ} \mathrm{em} 20^{\circ}$. Houve um ligeiro arredondamento da face de contato desgastada quando comparada ao caso do anel fixo (vide fig.4.4), mas optou-se por permanecer calculando apenas as posições de maior pressão pistão/cilindro (TS) e o lado oposto (ATS). Para explorar outras possibilidades, foram estudados dois outros casos adicionais: um com um pistão com movimento secundário diferente (fruto de diferentes folgas pistão/cilindro) e outro sem deformações térmicas do canalete (pistão frio, por exemplo). A tabela 4.1 resume os valores obtidos e a fig.4.4, o perfil previsto para o $1^{\circ}$ anel após 500 interações de desgaste. Observou-se que a deformação 
térmica do canalete é de longe a causa de maior alteração do perfil desgastado do anel, seguida da alteração de folgas pistão/cilindro, que também está relacionado às deformações térmicas do pistão.

A abordagem de fadiga (eq.3.43) não foi extensivamente explorada, ao se verificar que o perfil desgastado, previsto por este modelo, era bastante similar ao previsto pela lei de Archard (eq.3.42). Embora a distribuição das pressões e a velocidade de remoção de material fossem diferentes, o que se verificou é que, com o desgaste, as duas formulações geram um perfil do anel que adapta-se às condições geométricas impostas pelo movimento do anel e pistão. Ou seja, mesmo com uma distribuição inicial diferente de pressão, as duas abordagens ajustavam o perfil do anel para a geometria imposta, assim como aconteceu com os casos citados no estudo de sensibilidade. 


\begin{tabular}{|l|l|c|c|c|c|}
\hline \multicolumn{2}{|c}{ Tabela 4.1- Estudo de sensibilidade, desgaste radial do $\mathbf{1}^{\circ}$ anel } \\
\hline \multirow{2}{*}{} & & \multicolumn{4}{c|}{ desgaste radial } \\
\cline { 3 - 6 } & & 100 interações & \multicolumn{2}{c|}{500 interações } \\
\cline { 3 - 6 } & & $: \mathrm{m}$ & ) & $: \mathrm{m}$ & ) \\
\hline gw3 & referência, caso descrito no cap. 5 & 1,10 & - & 8,07 & - \\
\hline gw4 & limite para contato rugoso: $t=4 \mathrm{~F}$ & 1,14 & $4 \%$ & 8,21 & $2 \%$ \\
\hline rw200 & maior discretização na face de contato & 1,16 & $6 \%$ & 8,38 & $4 \%$ \\
\hline gir & anel girando & 1,11 & $1 \%$ & 9,03 & $12 \%$ \\
\hline bl & diferente mov. secundário do pistão & 1,00 & $-9 \%$ & 7,28 & $-10 \%$ \\
\hline atp_0 & sem deformação térmica no $1^{\circ}$ canalete & 2,72 & $47 \%$ & 11,69 & $45 \%$ \\
\hline
\end{tabular}

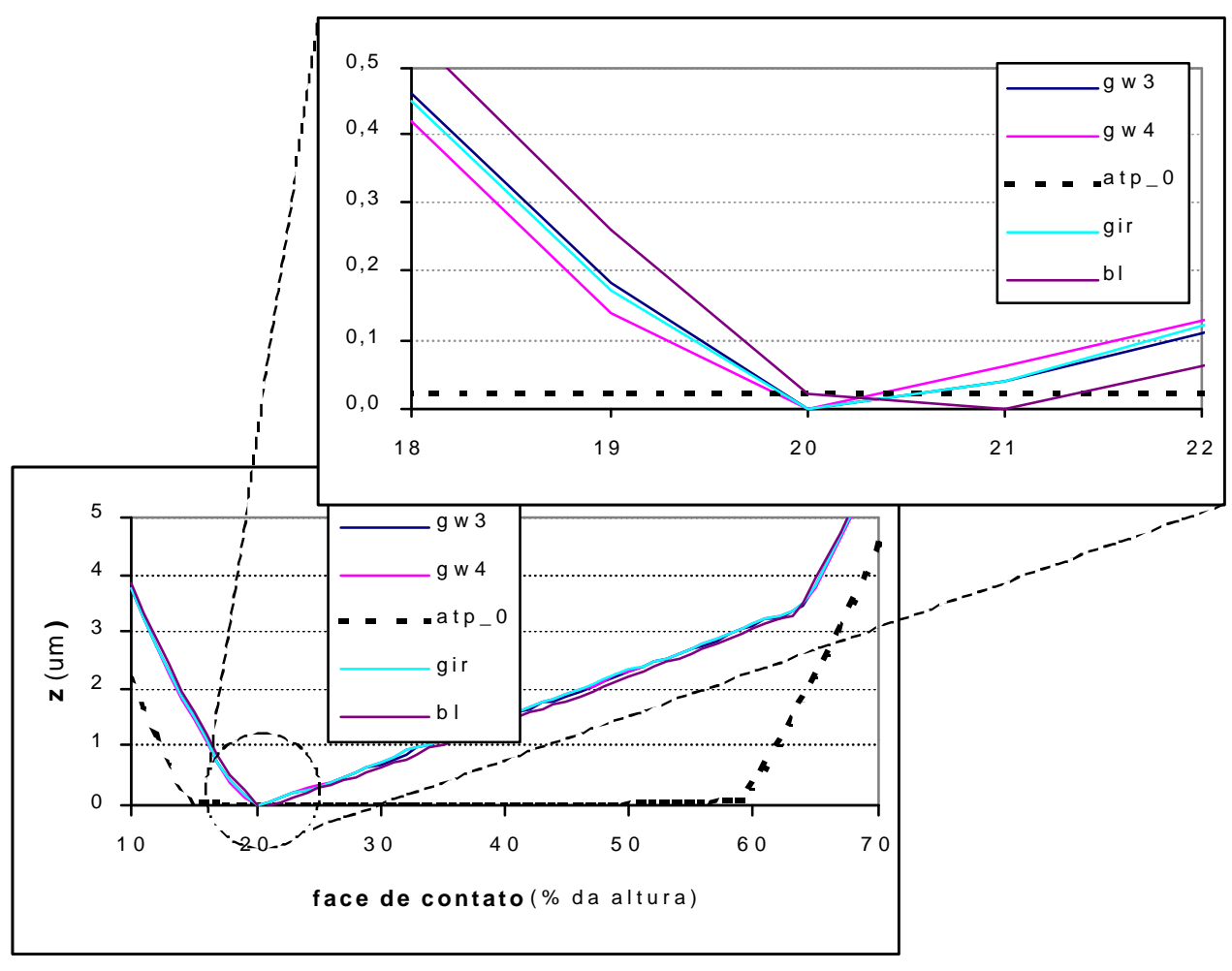

Fig.4.4- Face de contato do $1^{\circ}$ anel prevista nos estudos de sensibilidade, após 500 interações. 


\section{5- APLICAÇÃO DO MODELO PARA UM CASO EXPERIMENTAL}

Para avaliar a aplicabilidade do modelo foi feita uma comparação entre os valores calculados do perfil desgastado dos anéis e cilindro versus os valores experimentais obtidos em um motor diesel após $750 \mathrm{~h}$ de ensaio em dinamômetro.

\section{1- DADOS DO MOTOR}

Diesel, injeção direta, turbo-comprimido com pós resfriamento, 6 cilindros em linha, potência máxima de $210 \mathrm{~kW}$ a 2500 rpm, diâmetro $102 \mathrm{~mm}$, curso de $130 \mathrm{~mm}$, Lrod= $215 \mathrm{~mm}$.

\section{2- CICLO DE ENSAIO}

O motor foi ensaiado conforme ciclo abaixo:

\begin{tabular}{|c|c|c|c|c|}
\hline \multicolumn{5}{|c|}{ Tabela 5.1 - Ciclo de ensaio } \\
\hline passo & duração & rpm & carga & T água de resfriamento \\
& $(\mathbf{m i n})$ & & & $(\mathbf{C})$ \\
\hline 1 & 13 & 2500 & $100 \%$ & $85 / 92$ \\
\hline 2 & 3 & 800 & residual & ambiente \\
\hline
\end{tabular}

Óleo lubrificante: SAE 15W40 - API CE. Troca a cada 250 h, complementação quando necessário. Motor foi desmontado com 100, 250, 500 e 750 h, quando os anéis e cilindros eram medidos. 


\section{3- PACOTE DE ANÉIS}

Em 4 cilindros foram montados anéis experimentais de $1^{\circ}$ canalete em aço nitretado com uma cobertura adicional de CrN depositado por PVD (“Physical Vapor Deposition”) com espessura de $10: \mathrm{m}$, enquanto nos dois cilindros restantes foram montados anéis de série, em ferro fundido com cobertura de cromo e partículas de cerâmica. $\mathrm{O} 2^{\circ}$ anel é em ferro fundido nodular com revestimento de cromo duro depositado eletroliticamente. $\mathrm{O}$ anel de óleo utilizado é um duas peças em ferro fundido cinzento também revestido em cromo. A fig. 5.1 mostra esquematicamente a geometria do pacote de anéis, sendo os demais dados do pacote apresentados na tabela 5.2.

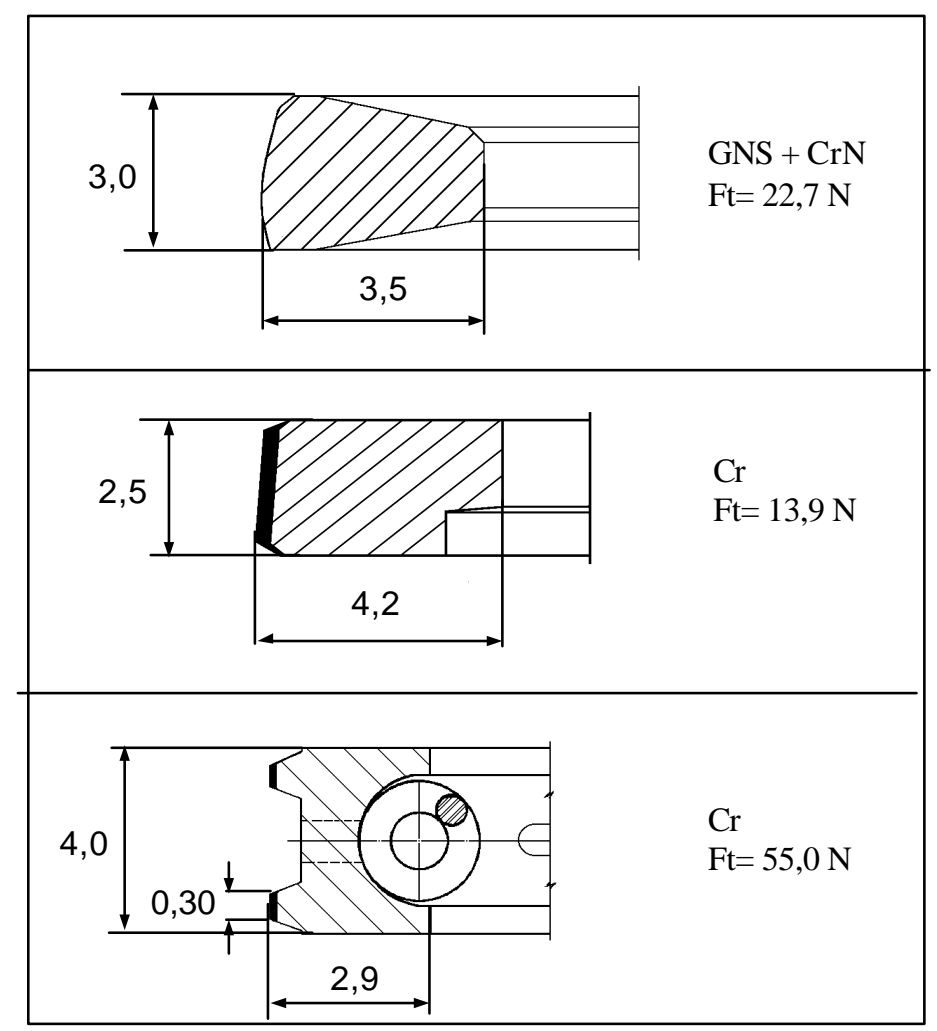

Fig.5.1- Representação esquemática do pacote de anéis. 


\begin{tabular}{|c|c|c|c|}
\hline \multicolumn{4}{|c|}{ Tabela 5.2- Dados dos anéis } \\
\hline característica & $1^{\circ}$ anel & $2^{\circ}$ anel & anel de óleo \\
\hline tipo & trapezoidal & retangular & 2 peças \\
\hline folga entre pontas (mm) & 0,40 & 0,80 & 0,80 \\
\hline massa $(\mathrm{g})$ & 22,8 & 20,6 & 20,2 \\
\hline revestimento & $\mathrm{CrN}$ & Cr duro & Cr duro \\
\hline rugosidade $\mathrm{Ra}(: \mathrm{m})$ & $\sim 0,20$ & $\sim 0,20$ & $\sim 0,20$ \\
\hline espessura $(: m)$ & 10 & 150 & 150 \\
\hline $\mathrm{E}(\mathrm{GPa})$ & 210 & 100 & 100 \\
\hline micro-dureza (HV) & 1500 & 900 & 900 \\
\hline
\end{tabular}

O modelo contempla todo o pacote de anéis, bem como o cilindro, mas a análise se concentrará principalmente no anel de $1^{\circ}$ canalete que é o que sofre as condições tribológicas mais severas, sendo em particular modelado o anel em aço nitretado com $\mathrm{CrN}$. Os demais anéis e o cilindro serão discutidos resumidamente mais a frente.

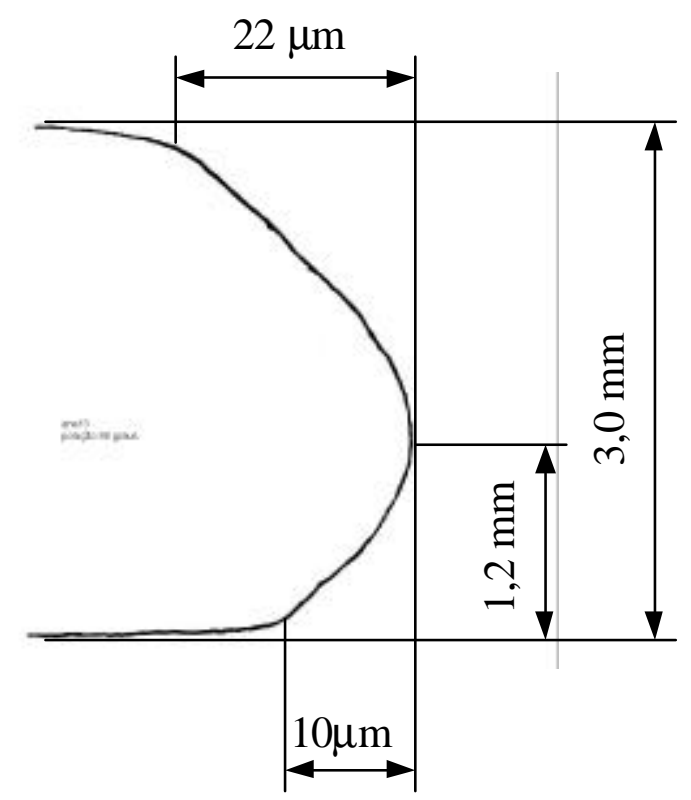

Fig. 5.2- Perfil medido da face de contato do $1^{\circ}$ anel, quando novo, posição a $90^{\circ}$ da ponta. 
A fig. 5.2 mostra um perfil medido da face de contato do $1^{\mathrm{o}}$ anel quando novo. Fruto das dispersões de produção, este perfil sofre ligeiros desvios tanto de anel para anel quanto ao longo de um mesmo anel. A fig. 5.3 mostra os perfis adotados como dado de entrada no modelo e a fig.5.4 mostra um gráfico típico de rugosidade da face de contato do anel.

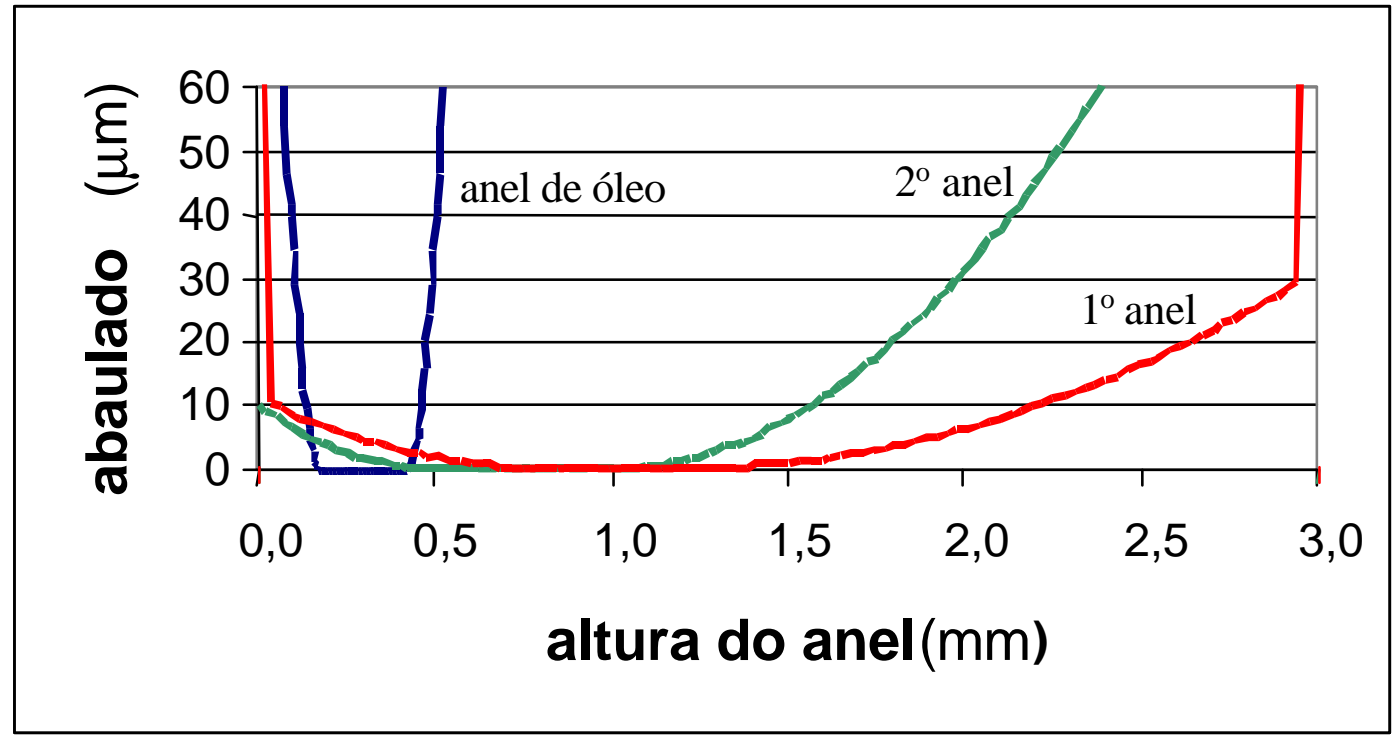

Fig.5.3- Perfil adotado da face dos anéis, quando novos.

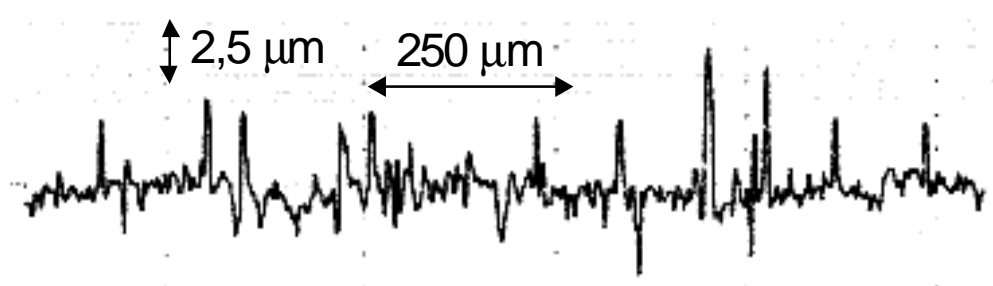

Fig.5.4- Perfil típico de rugosidade da face de contato do $1^{\circ}$ anel quando novo. $\mathrm{Ra}=0,21$; $\mathrm{Rz}=2,14 ; \mathrm{Rmax}=3,4 .($ valores em : m) 
A fig. 5.5 mostra o aspecto superficial da camada de $\mathrm{CrN}$; embora aparentemente bastante lisa e homogênea, essa camada, quando analisada com grande aumento, apresenta pequenos nódulos de cromo (“droplets”) decorrentes do processo de deposição por PVD. O modelo não considera tal não homogeneidade. A fig. 5.6 mostra uma seção fraturada mostrando a camada de $\mathrm{CrN}$ ( 10 : m de espessura) sobre o aço nitretado. Na versão atual, o modelo não considera que atingido um certo desgaste radial as propriedades da face de contato podem mudar, mas isso pode ser implementado, sem grandes dificuldades.

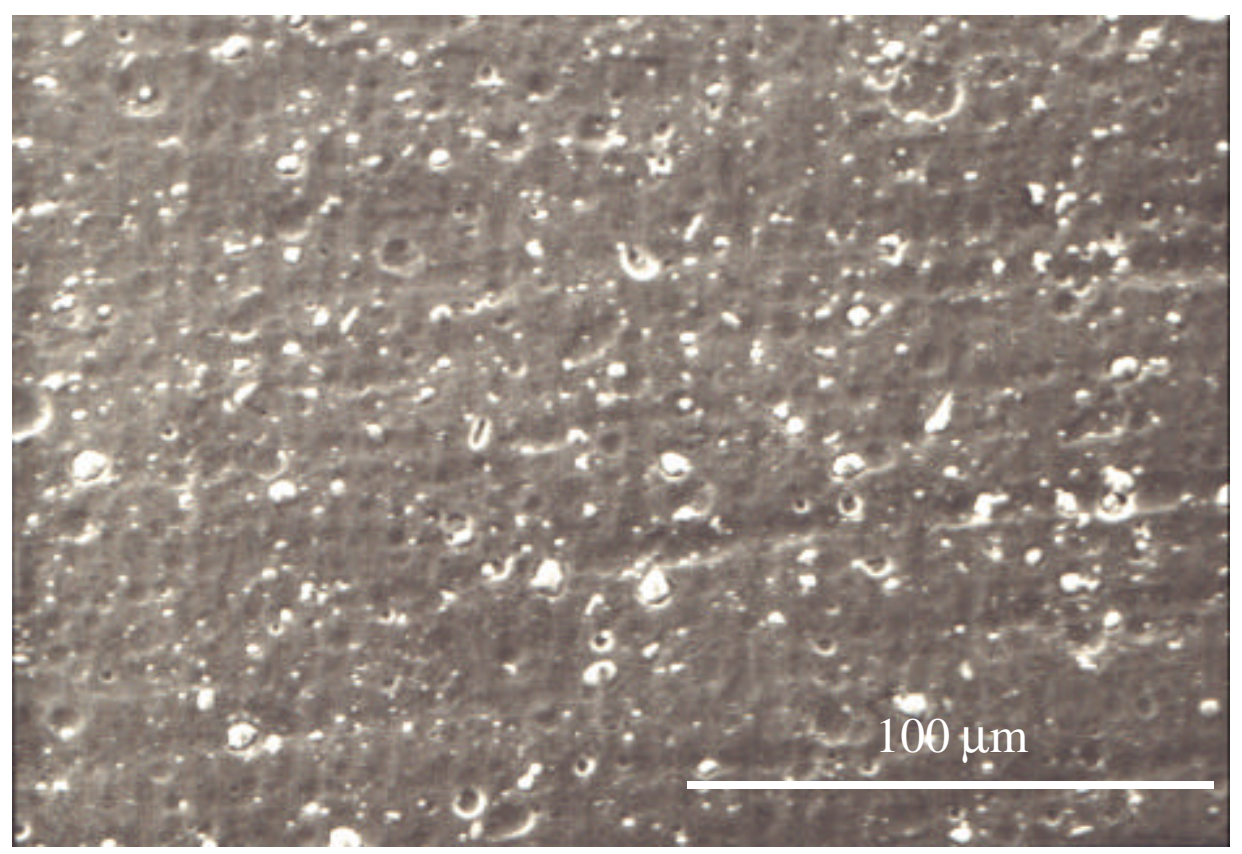

Fig.5.5- Aspecto da face de contato do $1^{\circ}$ anel em CrN aplicado por PVD. MEV. 


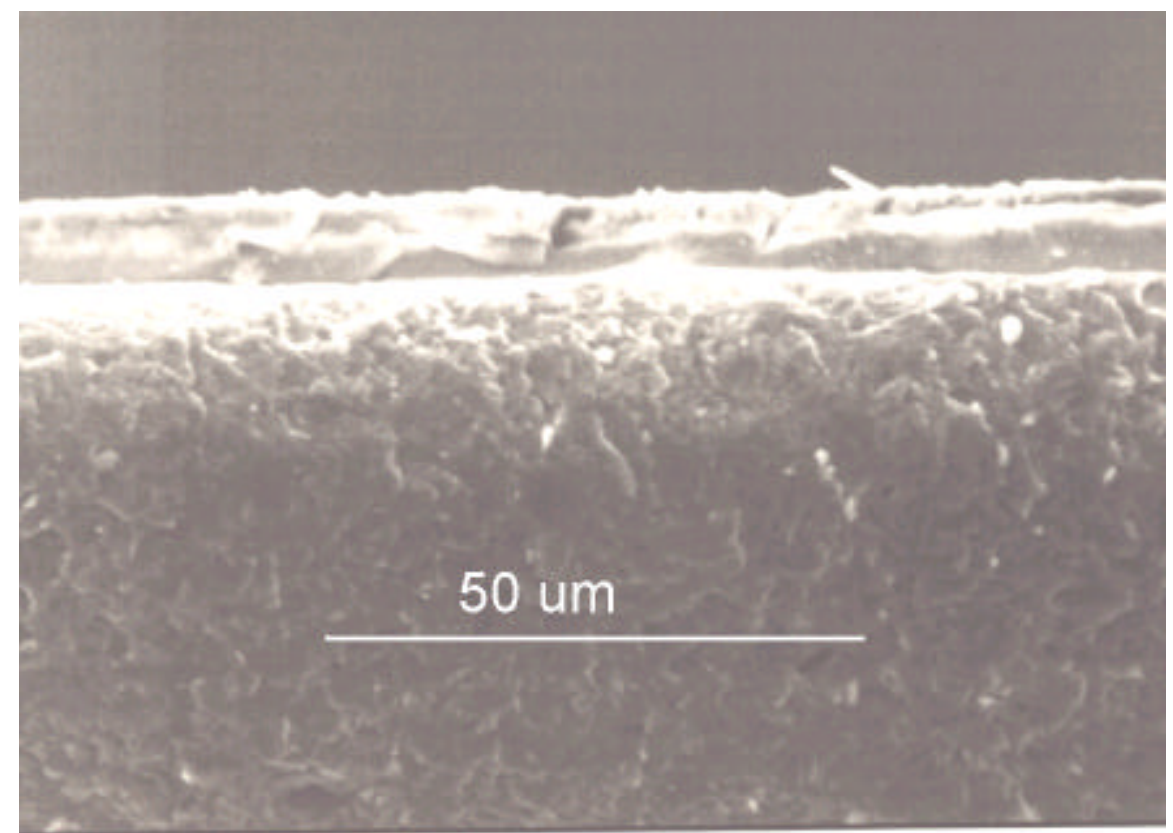

Fig.5.6- Seção transversal fraturada mostrando a camada de CrN aplicada por PVD sobre o aço nitretado. MEV 


\section{4- CILINDRO}

O cilindro é de ferro fundido cinzento, com a composição dada abaixo:

\begin{tabular}{|c|c|c|c|c|c|c|c|c|}
\hline \multicolumn{7}{|c|}{ Tabela 5.3 - Composição do material do cilindro (\% peso) } \\
\hline $\mathbf{C}$ & $\mathbf{S i}$ & $\mathbf{M n}$ & $\mathbf{P}$ & $\mathbf{S}$ & $\mathbf{C r}$ & $\mathbf{N i}$ & $\mathbf{C u}$ & $\mathbf{M o}$ \\
\hline 3,65 & 1,93 & 0,77 & 0,03 & 0,176 & 0,139 & 0,058 & 0,549 & 0,044 \\
\hline
\end{tabular}

O Cilindro é endurecido por indução na região do PMS do $1^{\circ}$ anel ( 15 a $50 \mathrm{~mm}$ do topo), onde a micro-dureza é bastante alta $(\sim 800 \mathrm{HV})$; no restante do cilindro a micro-dureza superficial é cerca de 400 HV. Para o modelo foi admitido o perfil de dureza mostrado na fig. 5.7.

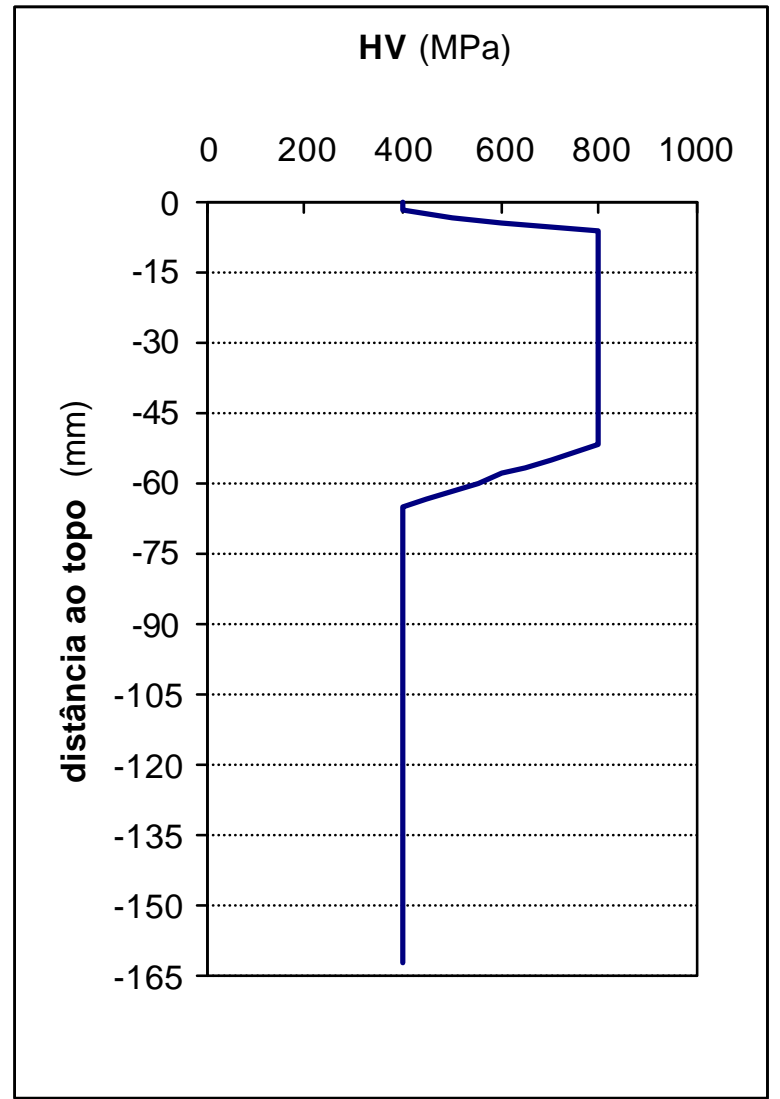

Fig.5.7- Perfil de dureza admitido para o cilindro. 
$\mathrm{O}$ cilindro tem o típico acabamento de brunimento, vide fig.5.8. A rugosidade é cerca de $\mathrm{Ra}=$ 0,8: m, mas composta de vales relativamente profundos (vide fig. 5.9) que não interferem no contato rugoso, sendo assim necessária uma correção nos valores de rugosidade medidos para sua entrada no modelo de G-W. PRIEST et al (1999) adotam, por exemplo, um valor $50 \%$ menor que o medido para o cilindro novo e $32 \%$ menor que o medido para o cilindro após uso, mas não tentam predizer o desgaste do cilindro. Como o atual modelo incorpora o cálculo do desgaste do cilindro, optou-se por adotar um valor inicial de $F=0,20: \mathrm{m}$; valores maiores exigiam uma queda muito rápida no valor da rugosidade ou então provocavam pressões de contato excessiva e convergência muito demorada. Este tópico carece de maior aprofundamento, sendo um assunto que ainda gera polêmicas na literatura, inclusive quanto ao aspecto da medição usando rugosímetros mecânicos ser incapaz de caracterizar a rugosidade do brunimento (ROSÉN et al, 1996).

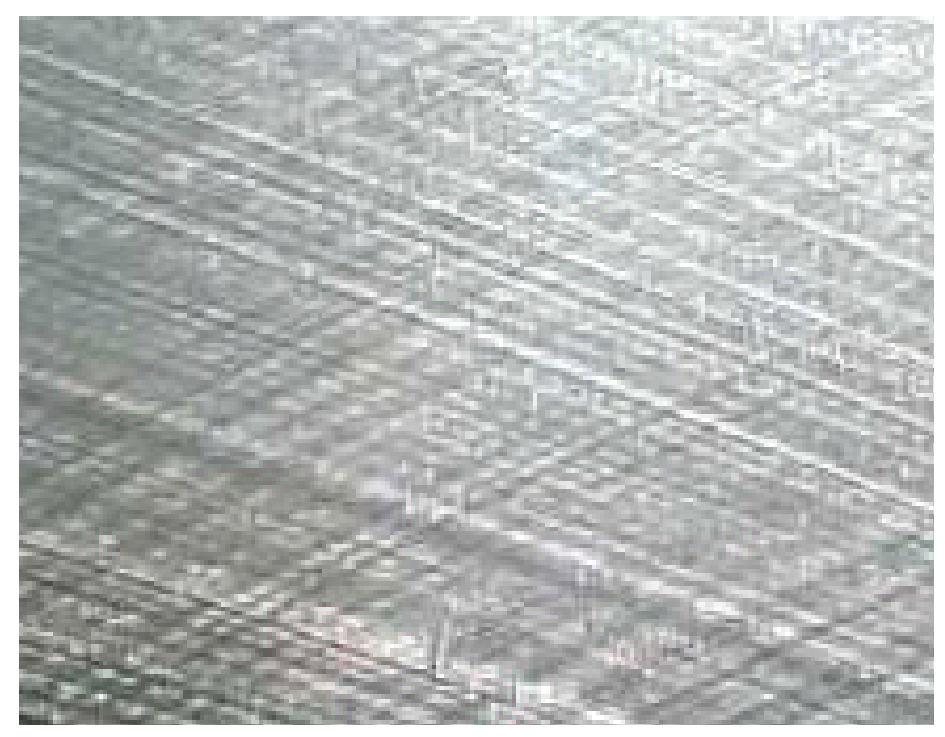

Fig.5.8- Foto por replica do acabamento superficial do cilindro. 


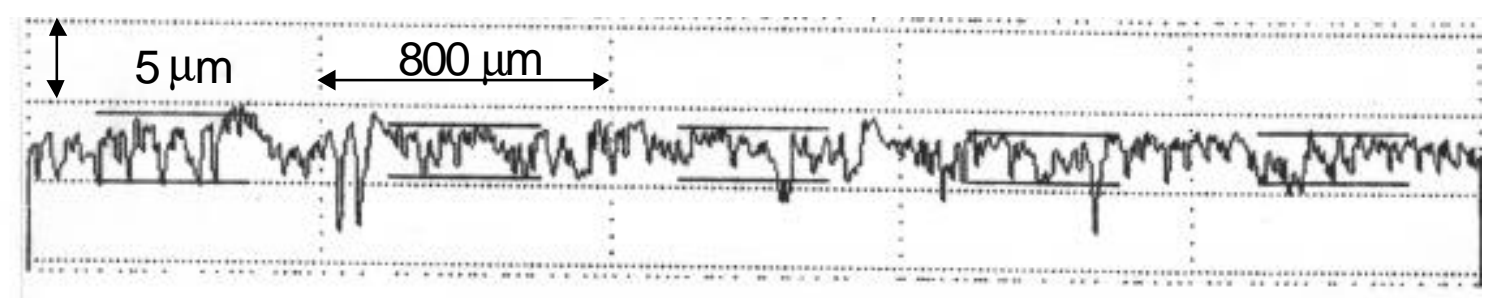

Fig.5.9- Perfil de rugosidade do cilindro. $\mathrm{Ra}=0,83, \mathrm{Rz}=5,6, \mathrm{Rmax}=7,44, \mathrm{Rpk}^{1}=0,22$, $\mathrm{Rk}=1,54, \mathrm{Rvk}=1,28$ (valores em : $\mathrm{m}$ ).

Em operação, o cilindro apresenta ao longo de seu comprimento um típico perfil com deformações radiais de origem térmica, cujo máximo ocorre um pouco abaixo do PMS do $1^{\circ}$ anel. A fig. 5.10 reproduz valores medidos por FURUHAMA et al (1981). No caso em estudo se adotou a distribuição mostrada na fig. 5.11. Além da deformação ao longo do cilindro, este também apresenta deformações no plano horizontal, assumindo forma tridimensional bastante complexa. A fig. 5.12 mostra os valores obtidos por KOCH, 1995. As deformações radiais numa mesma seção não são consideradas no presente modelo. 


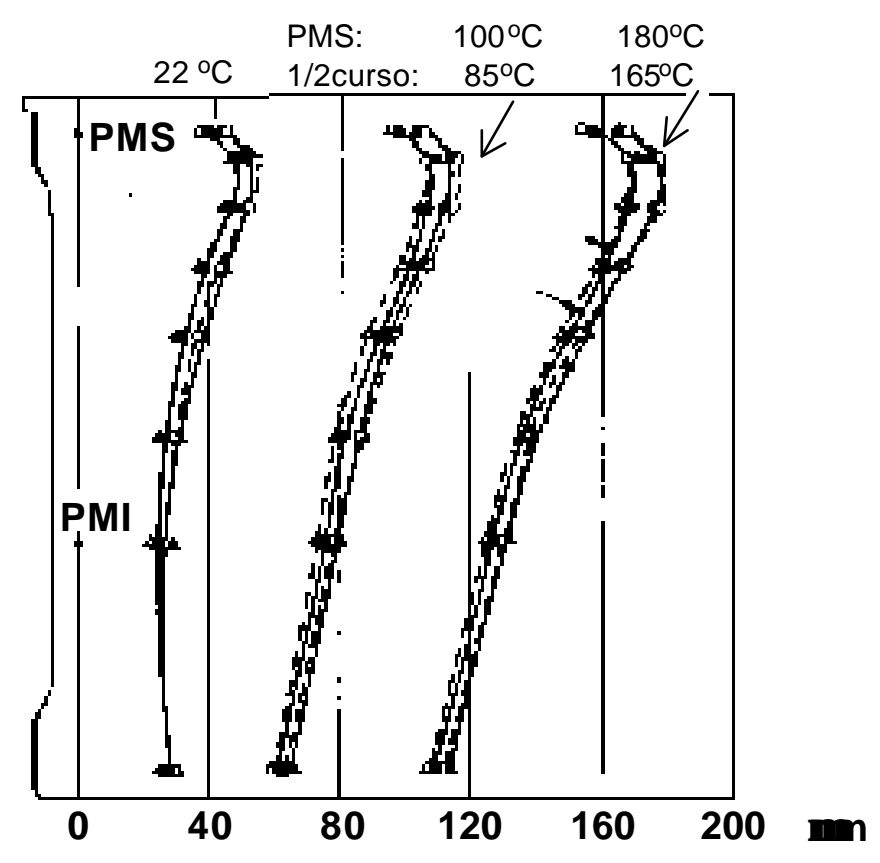

Fig.5.10- Deformação térmica do cilindro, $\mathrm{D}_{\mathrm{n}}=150 \mathrm{~mm}$. FURUHAMA et al, 1981.

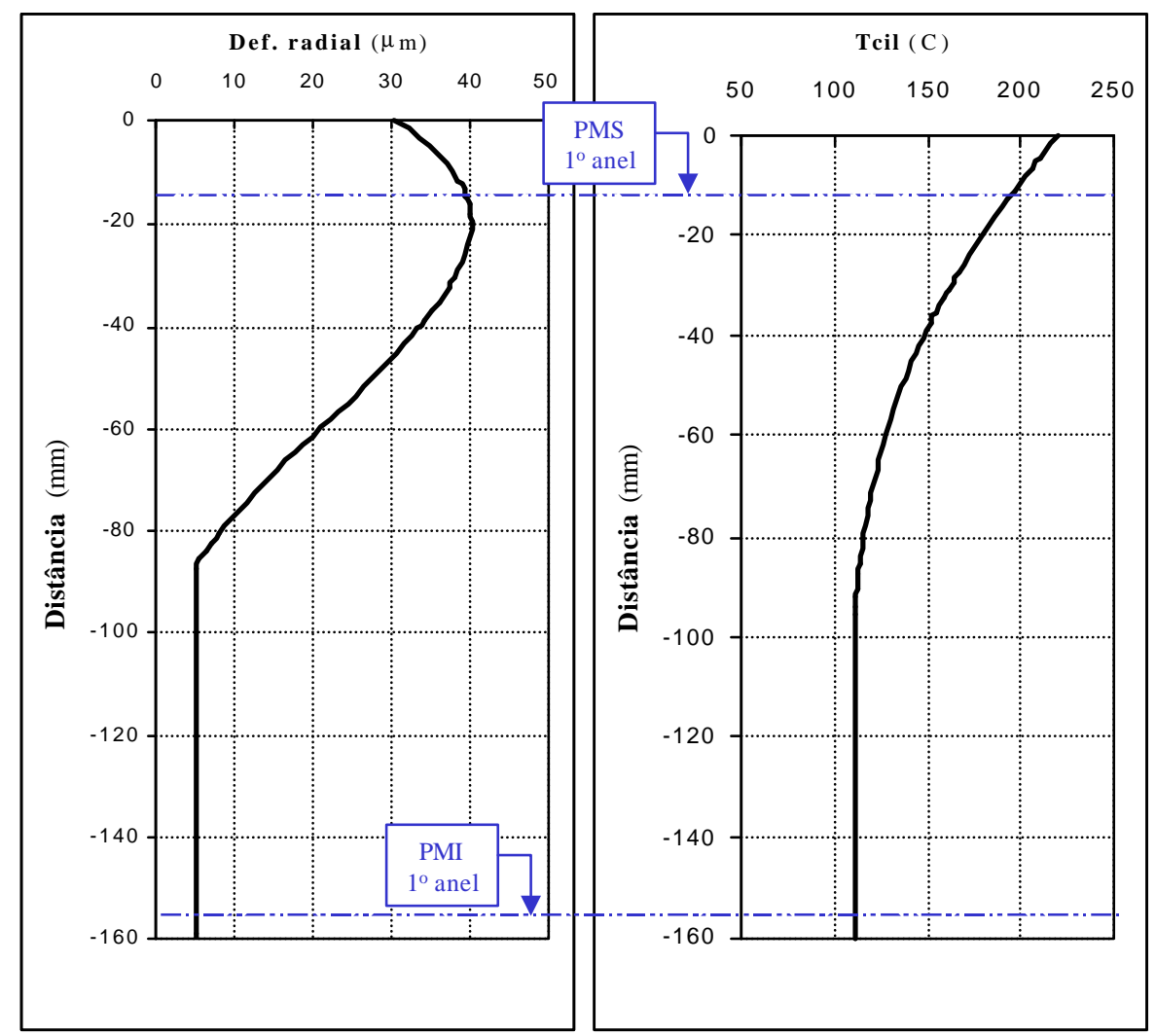

Fig.5.11- Deformação radial e distribuição de temperatura adotados ao longo do cilindro. 


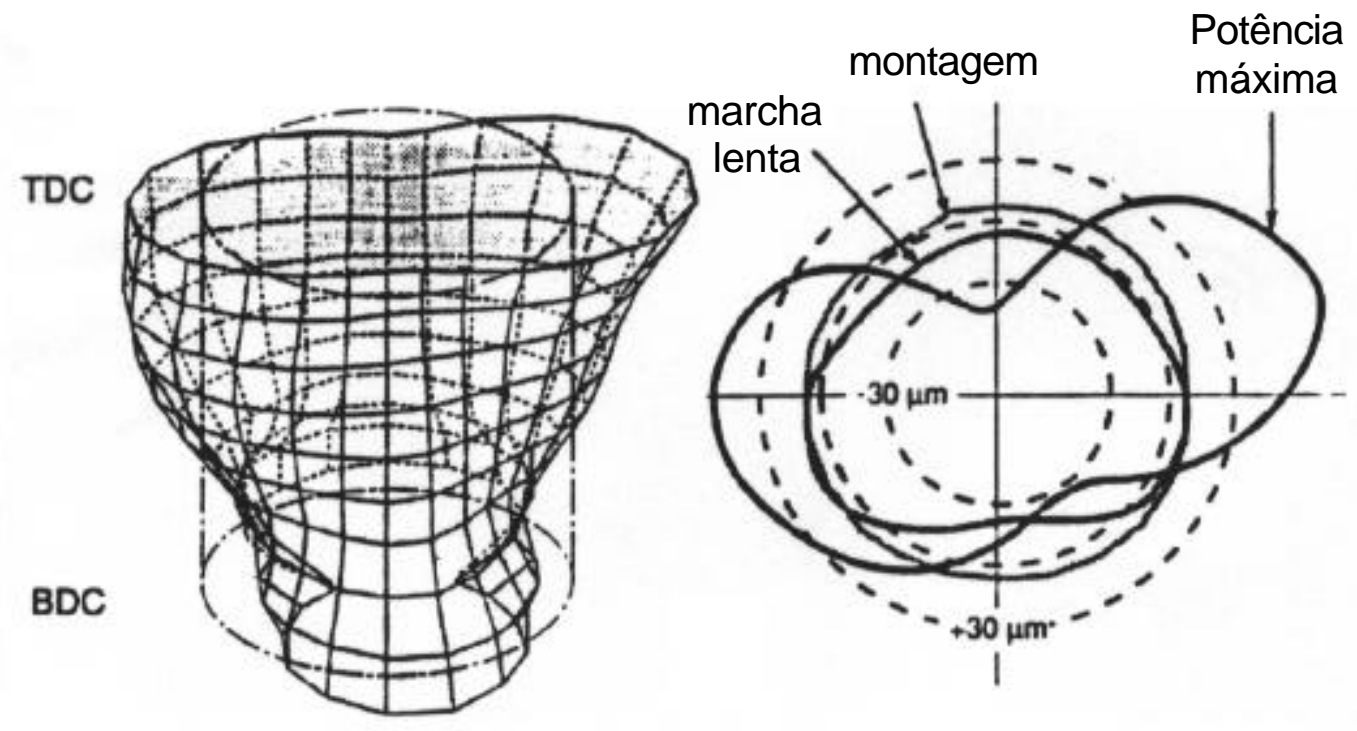

Fig.5.12- Deformações radiais do cilindro (KOCH, 1995). 


\section{5- PISTÃO}

O pistão é em liga de alumínio, com porta anel em "Ni-resist" no $1^{\circ}$ canalete. Em funcionamento, o pistão tem suas dimensões alteradas pela sua deformação térmica e mecânica, que variam em função do regime de operação. Para a simulação do desgaste apenas o regime de $2500 \mathrm{rpm}$ a plena carga foi considerado. Isto corresponde a:

- $81 \%$ (13/16) do tempo de ensaio,

- 93\% (13 . 2500/ (13.2500 + 3. 800)) da distância percorrida pelos anéis.

A máxima pressão de combustão é de $16 \mathrm{MPa}$, sendo o restante do diagrama de pressão ao longo dos 4 tempos do motor estimado por um programa de simulação do ciclo de combustão, desenvolvido internamente no grupo Mahle. A fig. 5.13 mostra a pressão na câmara de combustão e a velocidade do pistão (calculada pela eq. 3.27).

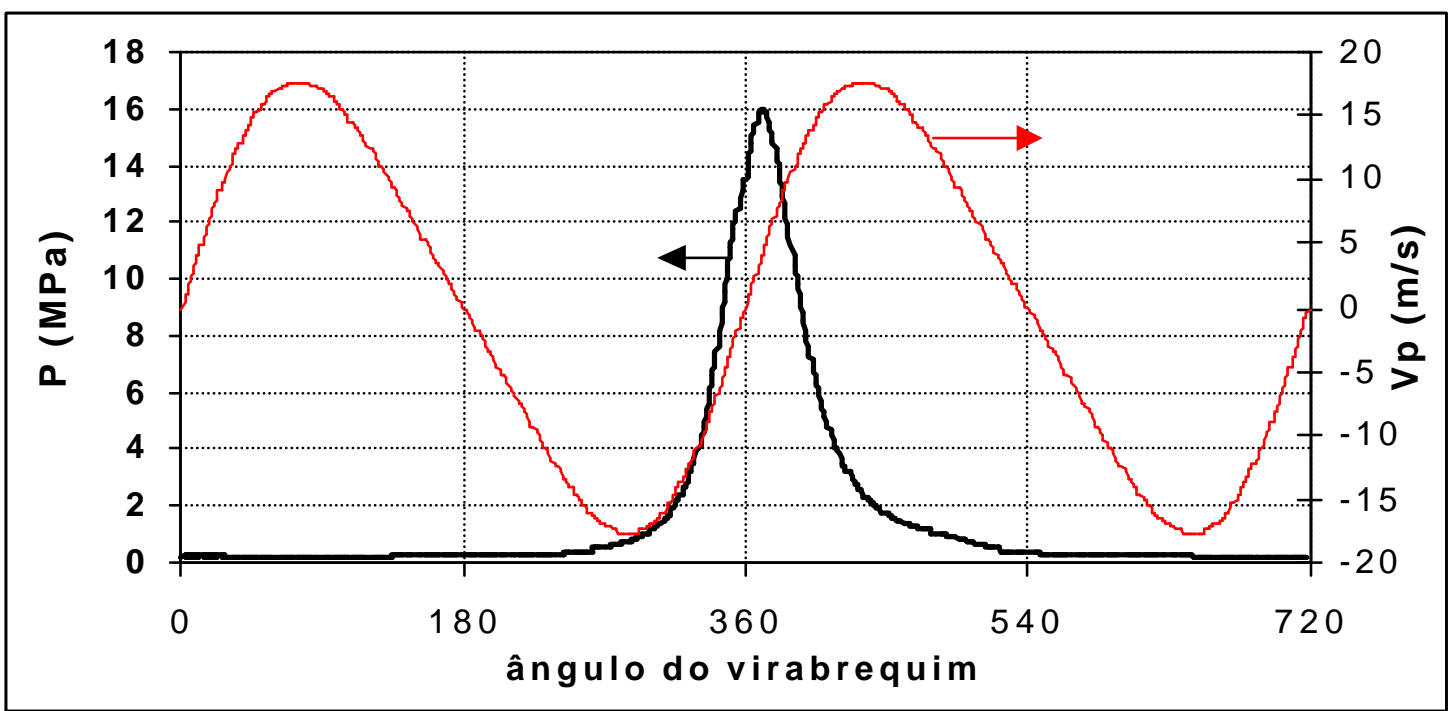

Fig. 5.13 - Diagrama de pressão na câmara de combustão e da velocidade do pistão. 
O perfil do pistão em funcionamento (2500 rpm, plena carga) foi calculado por elementos

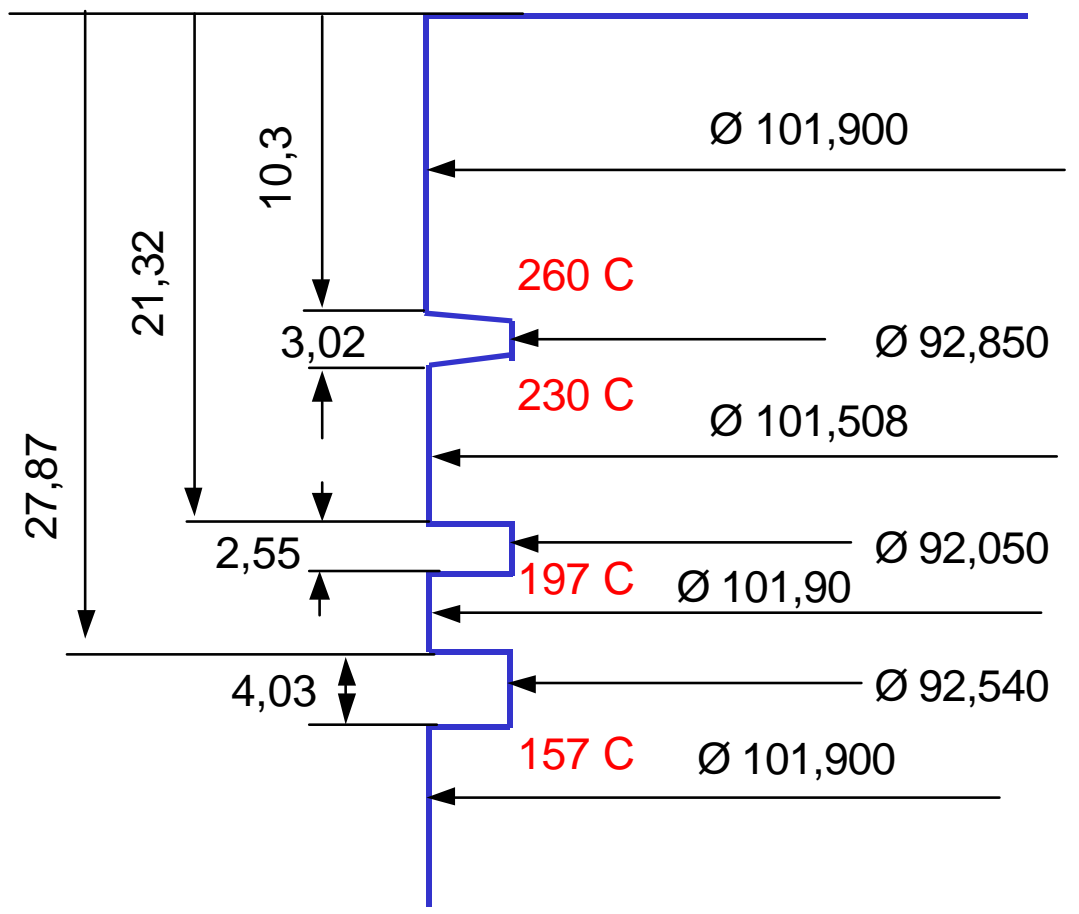

finitos. A fig.5.14 mostra as principais dimensões, a quente, do pistão.

Fig.5.14- Principais dimensões do pistão (a 2500 rpm, máxima potência).

Em particular foi calculada a deformação do $1^{\circ}$ canalete, já que esta interfere significativamente na inclinação do anel em relação à parede do cilindro. A fig. 5.15 mostra o perfil deformado do pistão e a 5.16 um detalhe do $1^{\circ}$ canalete. Como o pistão tem considerável inércia térmica, sua temperatura permanece praticamente constante ao longo dos 4 tempos do motor. Além da deformação provocada pela temperatura existe a provocada pela pressão de combustão, que só ocorre durante alguns graus do virabrequim, mesmo assim ela pode ser significativa já que ocorre no momento de maior desgaste do anel/cilindro (próximo ao PMS). No caso estudado, a diferença entre a deformação térmica e a térmica 
mais mecânica foi pequena e por simplicidade apenas a $1^{\mathrm{a}}$ foi utilizada. Devido à deformação diferente entre o flanco superior e o inferior, o $1^{\circ}$ canalete torce negativamente 0,30 graus.

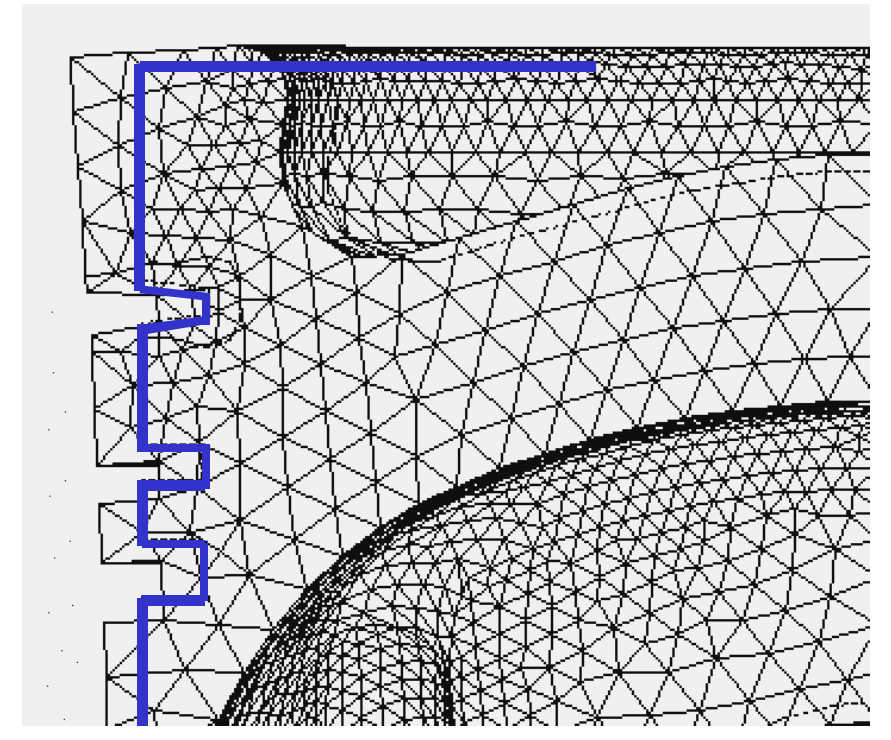

Fig.5.15- Representação do perfil deformado do pistão.

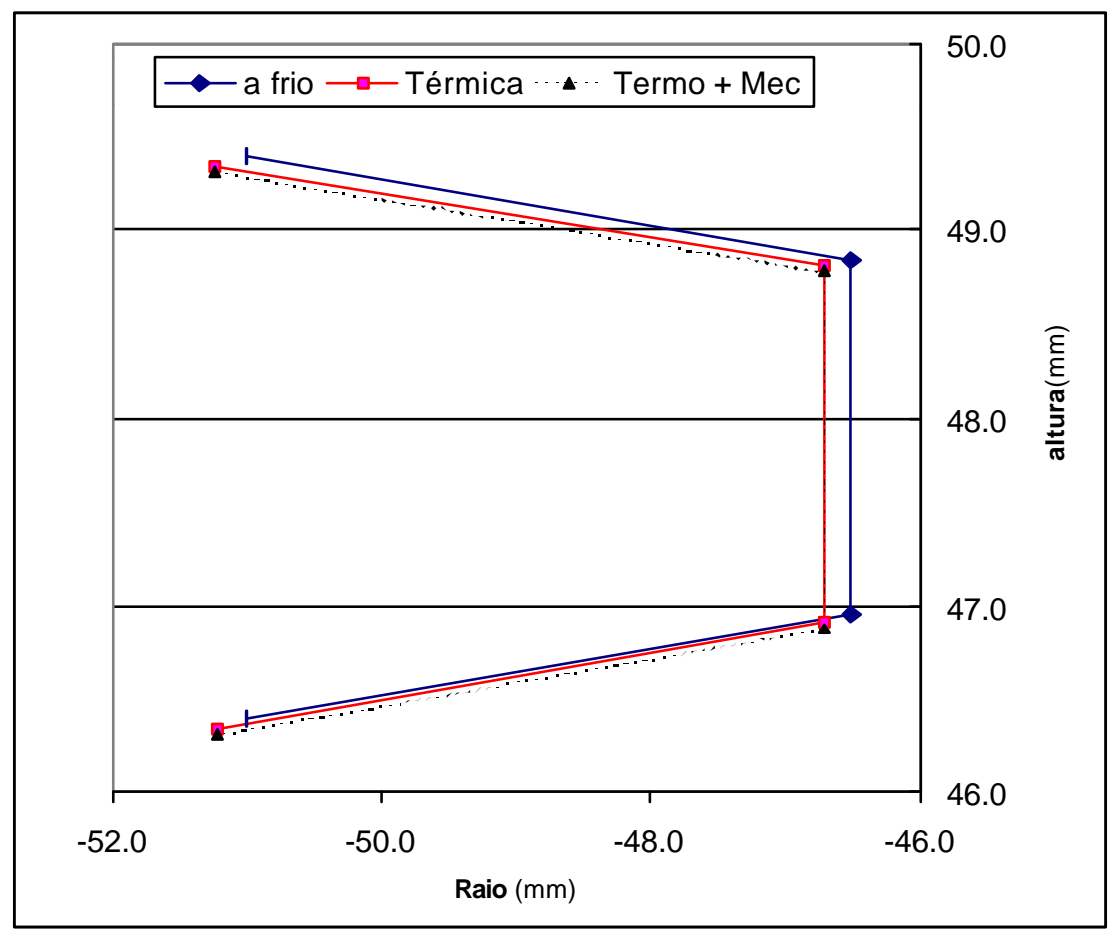

Fig.5.16- Detalhe do perfil e inclinação do $1^{\circ}$ canalete. 
Como vimos, o perfil hidrodinâmico que o anel oferece à parede do cilindro depende também da inclinação instantânea do pistão como um todo, que teve seu movimento secundário calculado por um programa dedicado ${ }^{2}$; a fig. 5.17 mostra a inclinação do pistão ao longo dos 4 tempos do motor.

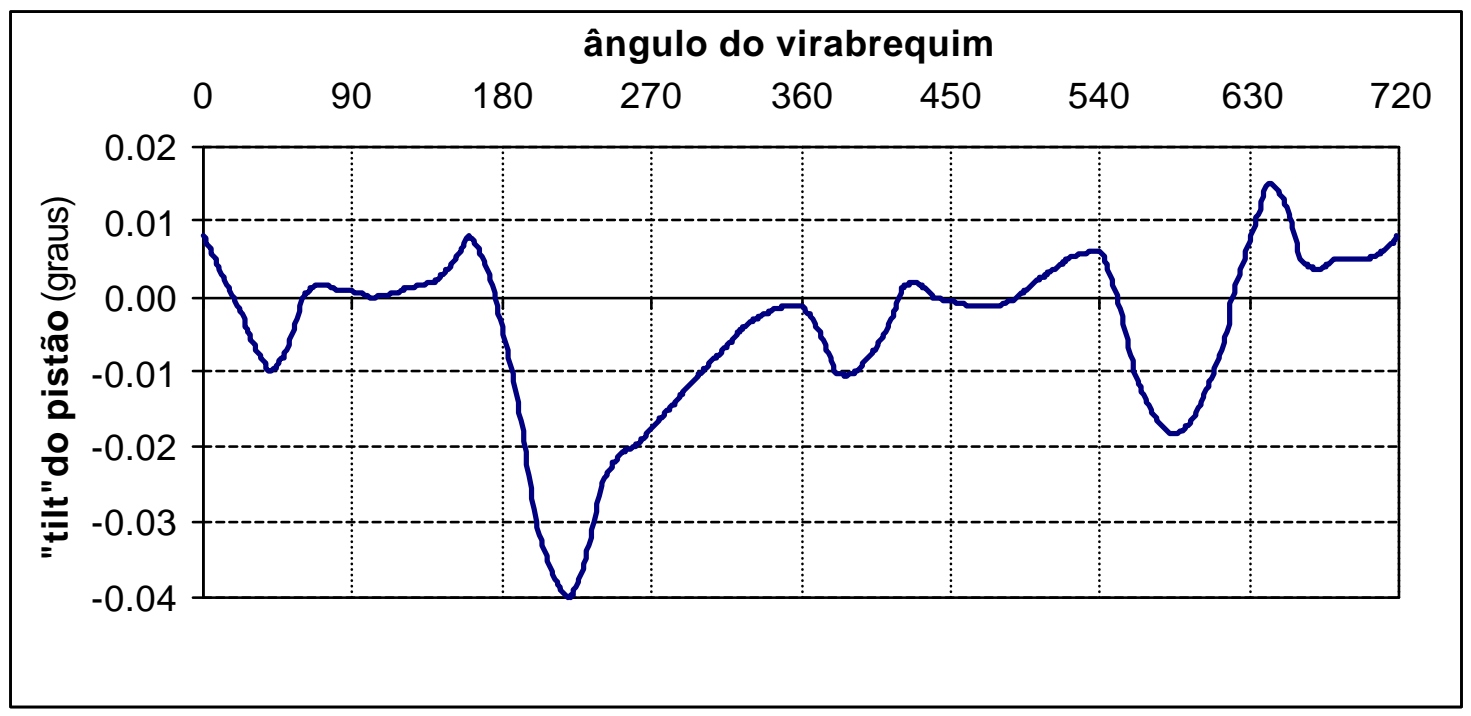

Fig. 5.17- Movimentação angular (“tilt") do pistão, no regime considerado.

A contribuição do movimento secundário do pistão na inclinação do anel depende da posição relativa da seção transversal do anel em relação ao pino do pistão. Vide fig. 5.18. A contribuição é máxima no plano perpendicular ao pino, no qual define-se os lados de maior pressão (“TS") e lado oposto ao de maior pressão (“ATS”) e nula no plano que passa pelo eixo do pino. Como já discutido no item 4.1 pode-se obter o desgaste do anel considerandose apenas as posições de TS e ATS, calculou-se as pressões hidrodinâmicas e de contato rugoso para esses dois lados diametralmente opostos e fazendo-se a média dos danos em 
cada lado, ao invés de calcular-se o dano ao longo de toda a circunferência do anel (admitindo-se rotação uniforme do anel). Os resultados apresentados neste capítulo foram calculados desta maneira.

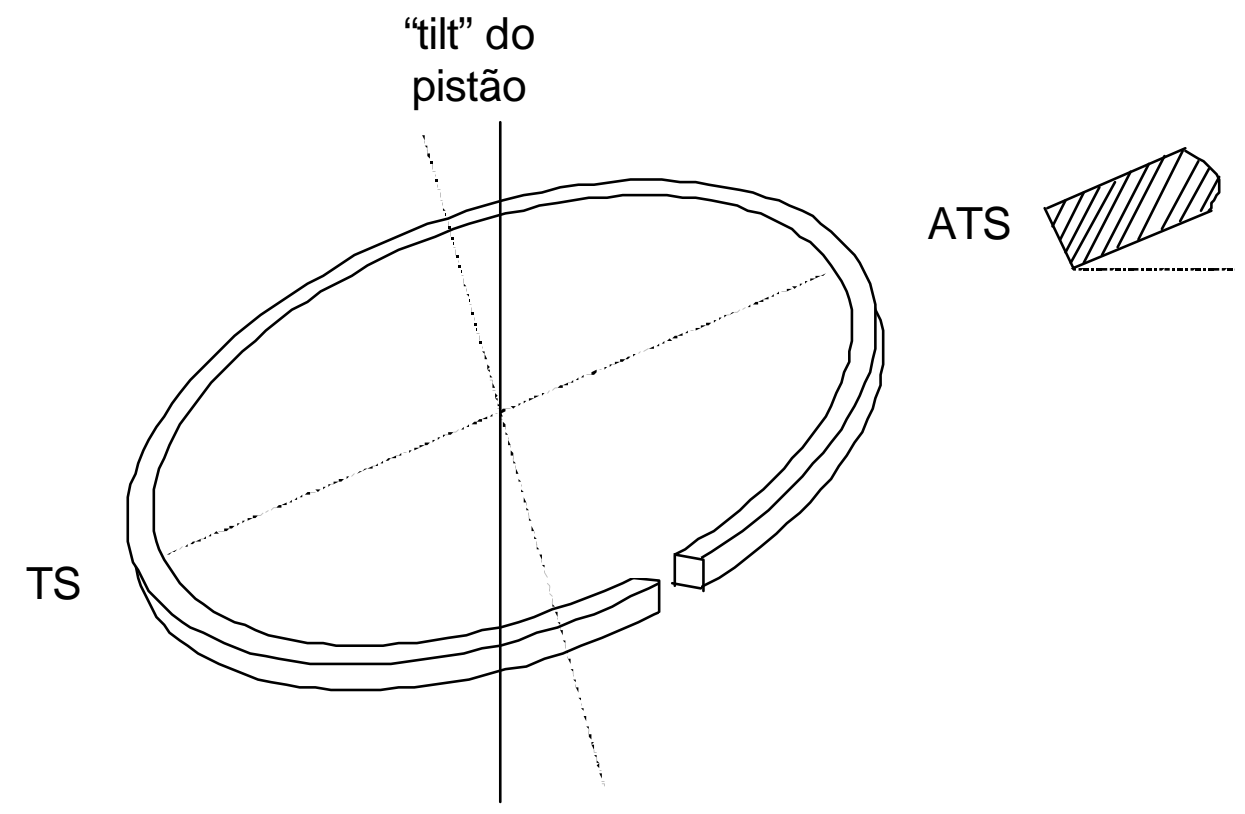

Fig.5.18- Representação esquemática da contribuição da inclinação do pistão na inclinação do anel. 


\section{6- VALORES MEDIDOS DE DESGASTE}

A fig. 5.19 mostra o perfil medido do anel de $1^{\circ}$ canalete, posição a $90^{\circ}$ da ponta. Nos anéis em GNS com nitreto de cromo (CrN) depositado por PVD (cilindros 2, 3,5 e 6), o desgaste radial foi em torno de $8:$ m após 750 horas de ensaio. Nota-se que a porção desgastada ainda não atingiu toda a altura do anel, o que praticamente já aconteceu por exemplo no anel cromado do cilindro 1. O abaulado inicial se transformou com o desgaste num perfil levemente cônico.
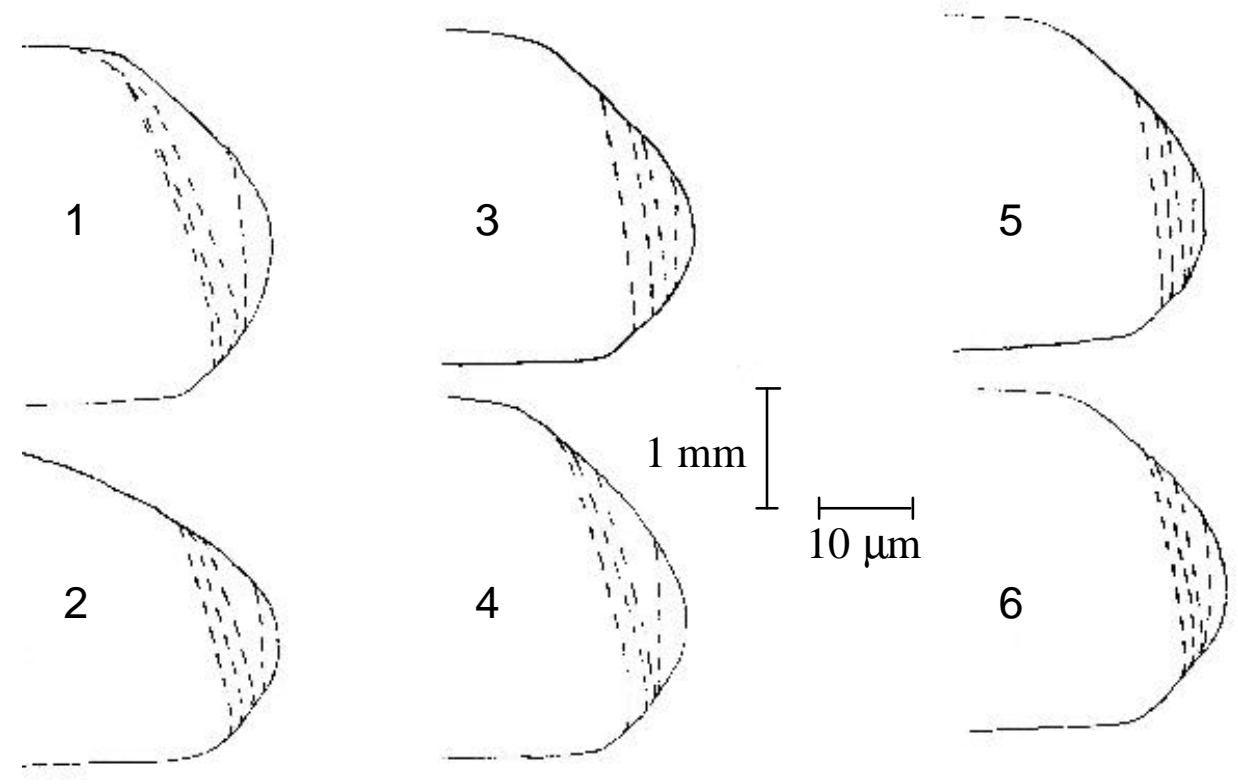

Fig.5.19- Perfil da face de contato dos anéis de $1^{\circ}$ canalete. A linha contínua é o perfil quando novo, as pontilhadas são após 100, 250, 500 e 750 horas de ensaio.

O desgaste radial ao longo da circunferência do anel foi semelhante ao mostrado na fig.5.19, exceto próximo às pontas, onde o desgaste foi maior, ultrapassando $10: \mathrm{m}$ e expondo o aço nitretado abaixo da camada de CrN. A figura 5.20 mostra a face de contato dos anéis após 
$750 \mathrm{~h}$ de ensaio. A cone claro nos anéis em GNS+CrN que se estreita ao se afastar da ponta é a região onde a camada de $\mathrm{CrN}$ já foi totalmente desgastada.

Fig.5.20- Face de contato dos anéis de $1^{\circ}$ canalete, região das pontas. $5 \mathrm{X}$.

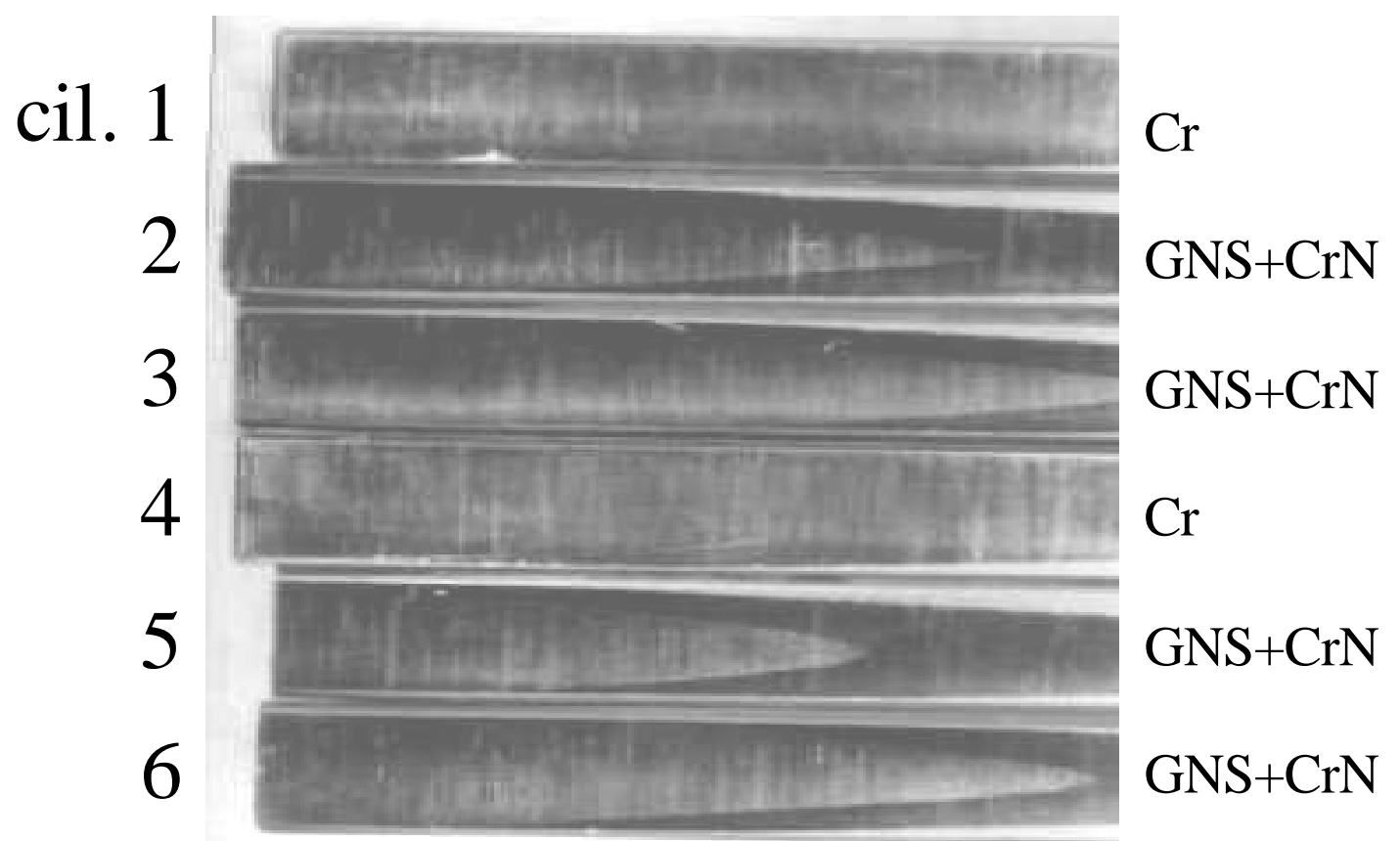

Vista sob maior aumento, a face de contato do anel apresenta um aspecto polido, com leves riscos situados preferencialmente na região inferior do anel, conforme mostrado nas figs.5.21 e 5.22. Na fig.5.21, as bordas inferior e superior do anel, em tom escuro na fotografia, ainda não se desgastaram e apresentam os riscos da operação de acabamento superficial de manufatura do anel. 


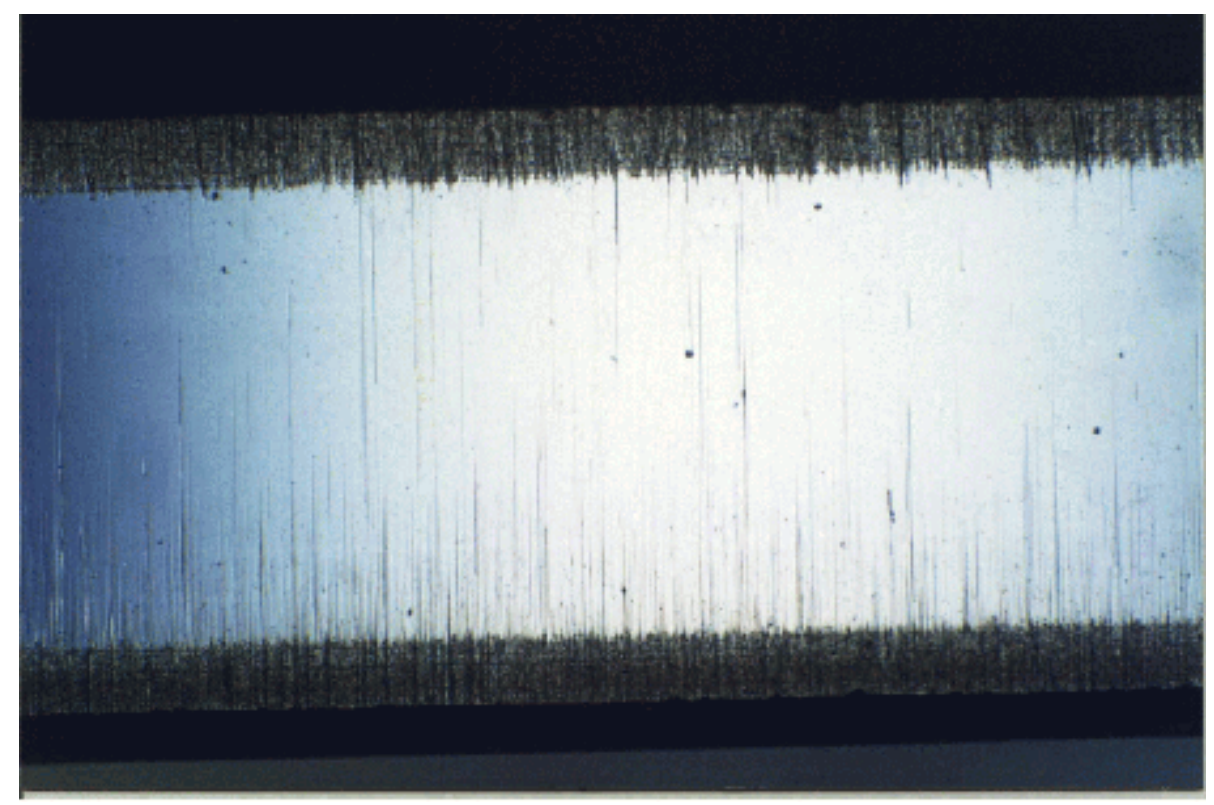

Fig.5.21- Detalhe da face de contato do $1^{\circ}$ anel, após 750 h de ensaio. Região a $90^{\circ}$ graus da ponta. Cilindro 3. $20 \mathrm{X}$.

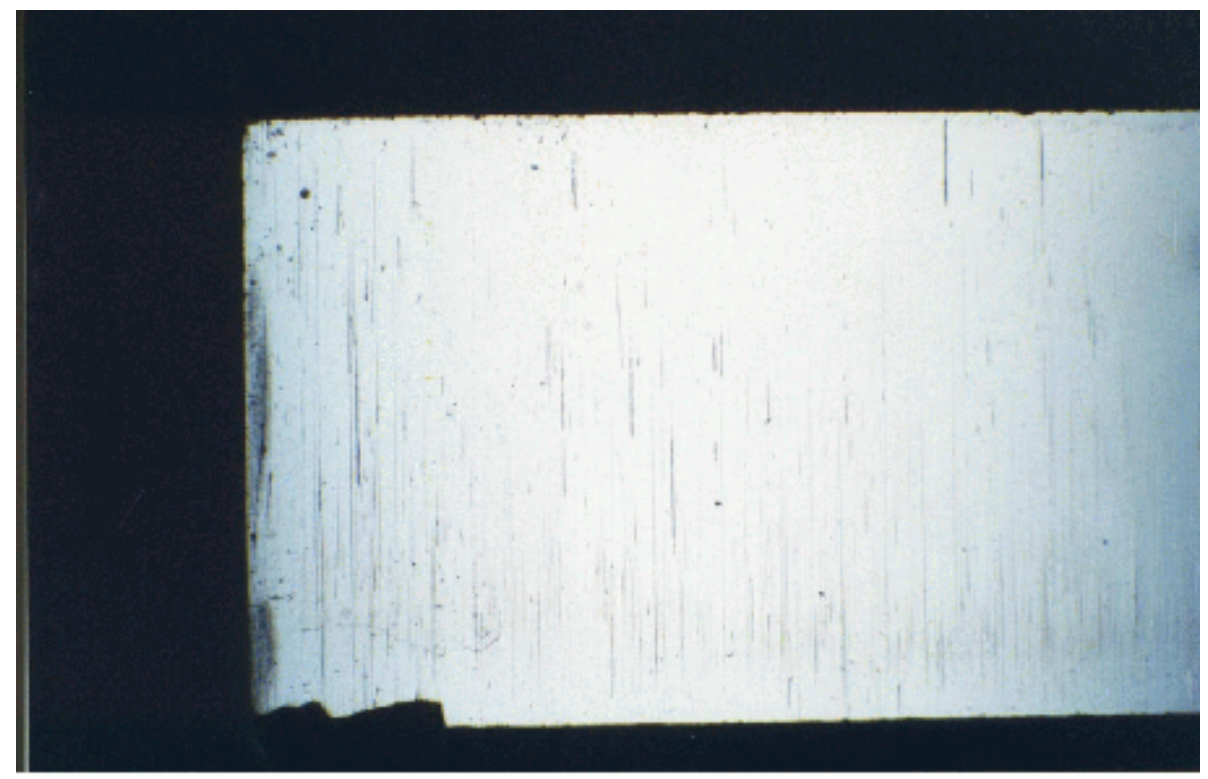

Fig.5.22- Detalhe da face de contato do $1^{\circ}$ anel, após 750 h de ensaio. Região da ponta.

\section{Cilindro 3. $20 \mathrm{X}$.}


Com valores tão baixos de desgaste radial, as medidas de aumento da folga entre pontas e da variação radial tem pouca precisão. A fig. 5.23 mostra o aumento medido da folga entre pontas dos anéis em GNS+CrN ao longo do ensaio; o gráfico mostra os valores médios e extremos do aumento de folga entre pontas nos quatro anéis em GNS+CrN. O aumento da folga entre pontas sugere que quase todo desgaste teria ocorrido apenas nas primeiras 100 horas, o que vimos pela fig. 5.19 não ter acontecido. Uma possível explicação para essa discrepância seria a falta de paralelismo na folga inicial entre pontas e ou a ocorrência de rebarbas que seriam interpretadas como menor folga inicial, uma vez que a medição é feita pela inserção de uma lâmina entre as pontas.

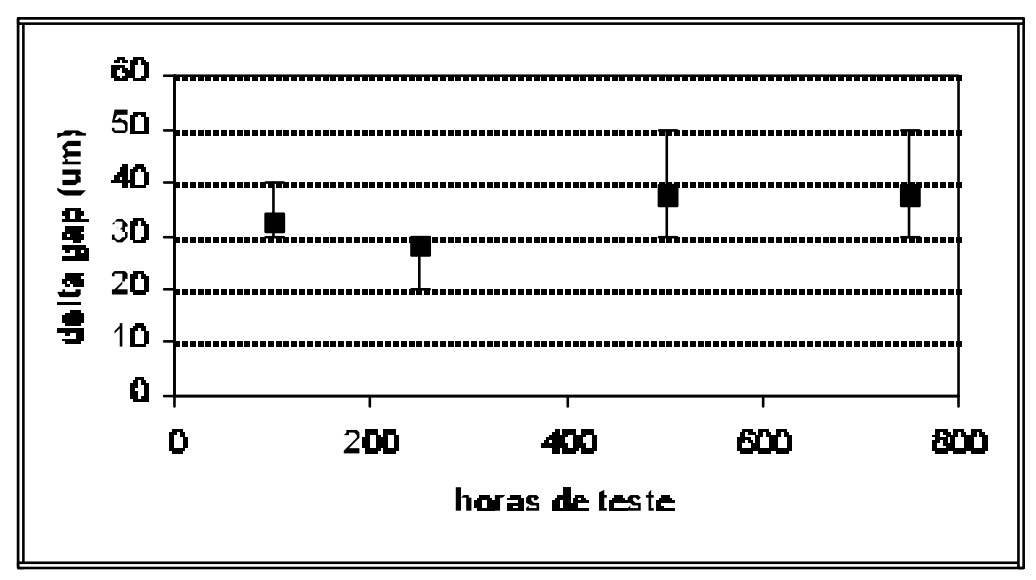

Fig.5.23- Valores medidos de aumento da folga entre pontas dos anéis de $1^{\circ}$ canalete em GNS+CrN. As barras indicam os valores máximos e mínimos (4 anéis em GNS+CrN).

A fig.5.24 mostra os valores de variação radial medidos com um micrômetro, medição também de pouca precisão para o baixo desgaste verificado. Parte dessa imprecisão advém do maior desgaste verificado nas pontas do anel, conforme mostrado na fig. 5.25. A falta do valor medido a 500 horas foi consequiência de desvio de procedimento: os anéis foram remontados antes de ter sido realizada a medição. 


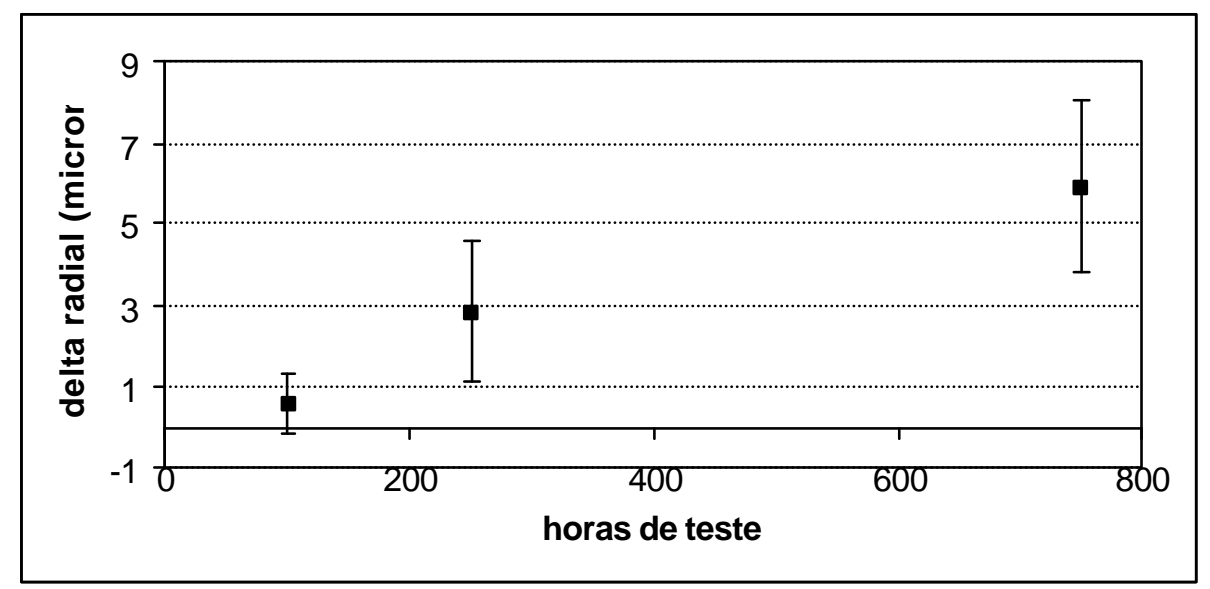

Fig.5.24- Valores medidos de variação radial dos anéis de $1^{\circ}$ canalete em GNS+CrN. A medição a 500 h não foi feita. As barras indicam 1 desvio padrão.

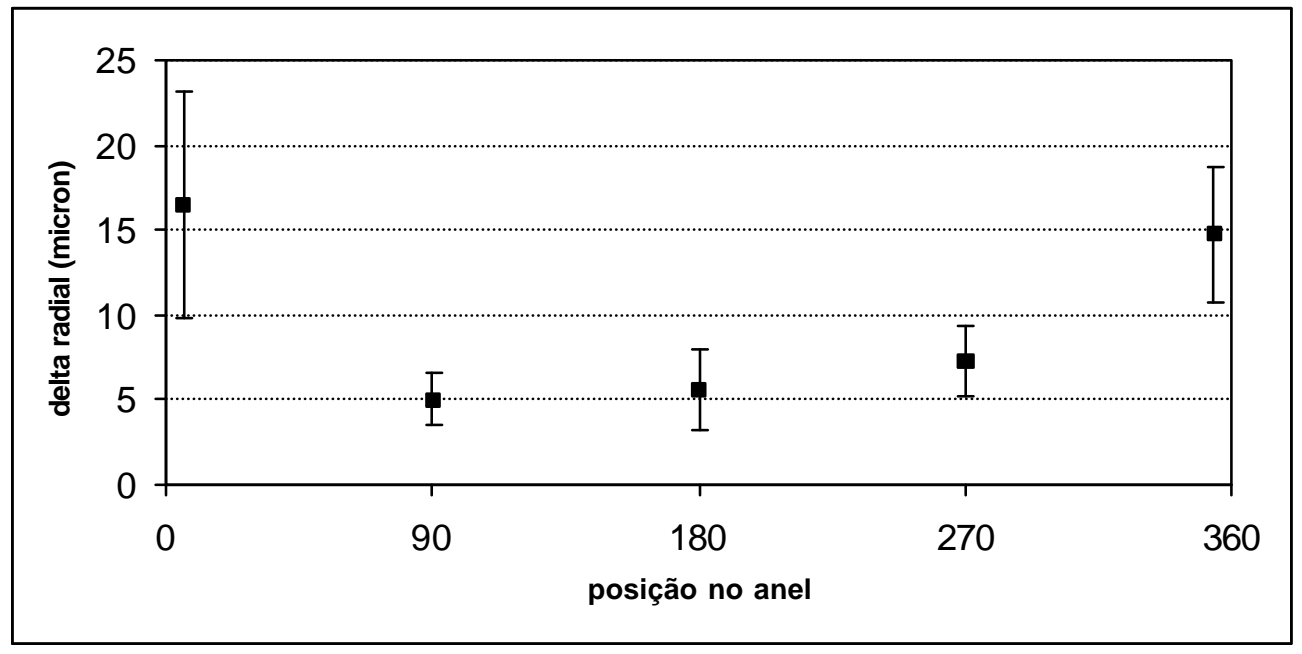

Fig.5.25- Valores medidos de variação radial, ao longo do perímetro, dos anéis de $1^{\circ}$ canalete em GNS+CrN, após 750 horas de ensaio.

Uma medida mais precisa, para esses baixos valores de desgaste, é calcular o desgaste diretamente do perfil da face de contato. Essa medida só é possível se parte do perfil inicial ainda tiver sido preservada para servir de referência, como mostrado na fig. 5.19. A variação radial medida com o auxílio destes perfis é mostrada na fig. 5.26. 


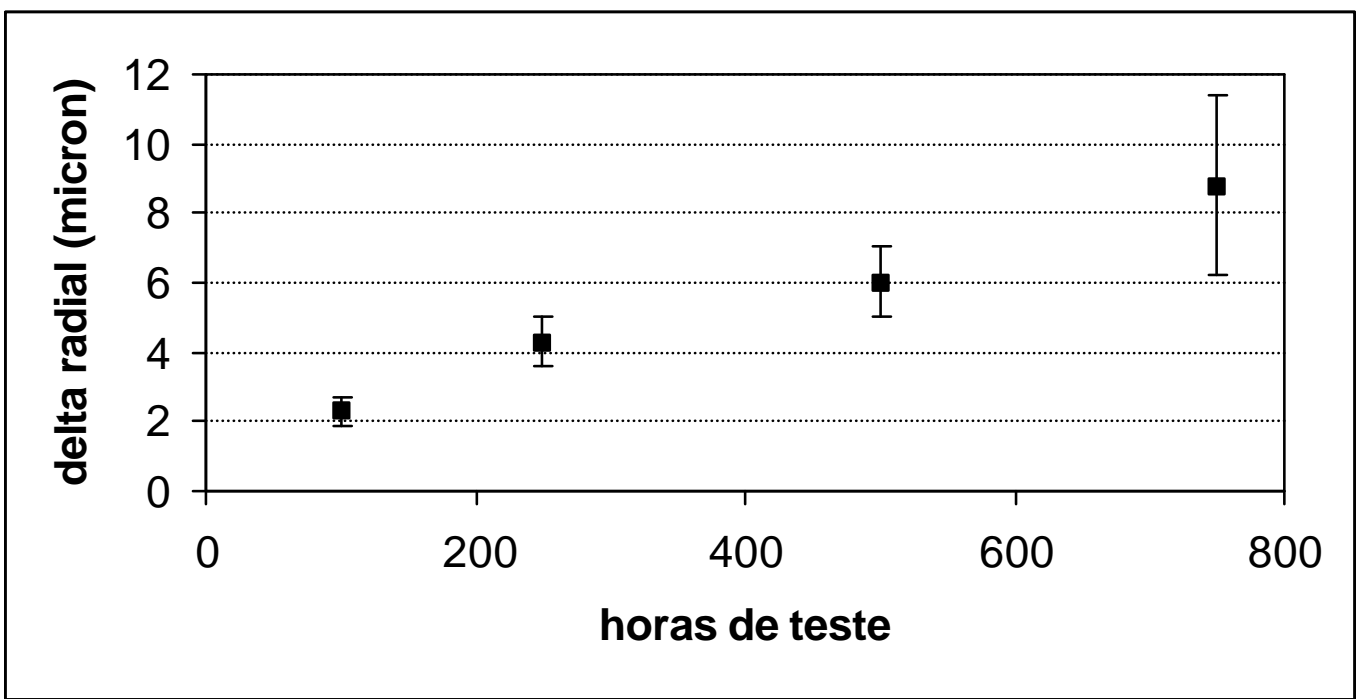

.26- Variação radial medida pela variação do perfil da face de contato, posição a $90^{\circ}$ da ponta.

Comparando-se os vários métodos, e considerando as incertezas envolvidas em cada processo de medição, utilizou-se os resultados da fig.5.26 como mais representativos do desgaste radial do $1^{\circ}$ anel. Também baseando-se nos perfis desgastados, como mostrados na fig.5.19, pode ser calculado o ângulo formado na face de contato do anel, conforme mostrado na tabela 5.4. Esse ângulo praticamente define o perfil resultante do desgaste.

\begin{tabular}{|l|c|c|c|c|}
\hline \multicolumn{5}{|c|}{ Tabela 5.4 - Ângulo formado na face de contato do $1^{\circ}$ anel } \\
(graus) \\
\hline Posição & $100 \mathrm{~h}$ & $250 \mathrm{~h}$ & $500 \mathrm{~h}$ & $750 \mathrm{~h}$ \\
\hline ponta & $0,06 \pm 0,06$ & $0,18 \pm 0,07$ & $0,18 \pm 0,13$ & $0,24 \pm 0,08$ \\
\hline $90^{\circ}$ & $0,04 \pm 0,02$ & $0,17 \pm 0,09$ & $0,18 \pm 0,09$ & $0,19 \pm 0,06$ \\
\hline $180^{\circ}$ & $0,09 \pm 0,05$ & $0,19 \pm 0,13$ & $0,20 \pm 0,10$ & $0,25 \pm 0,08$ \\
\hline
\end{tabular}

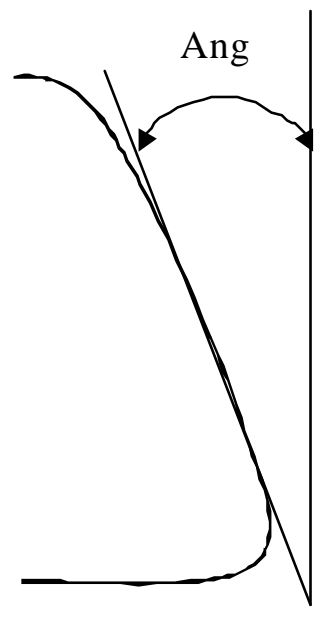




\section{Canalete do Pistão}

No canalete do $1^{\circ}$ anel não houve desgaste mensurável, conforme apresentado no gráfico de perfil dos flancos do canalete, fig. 5.26. A inclinação mostrada nos perfis é o afastamento em relação ao ângulo nominal $\left(3^{\circ}\right)$. Nota-se que as bordas externas ainda estão praticamente intactas, não suportando a hipótese de TIAN et al (1997a) que o perfil desgastado cônico do anel é decorrência do desgaste do flanco inferior do canalete.

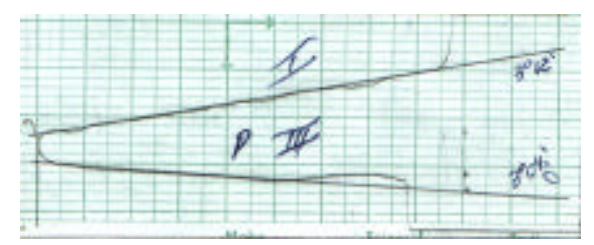

cil. 2 - TS

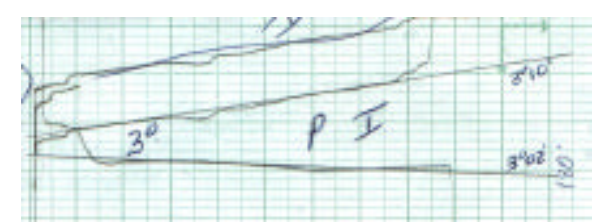

cil. 3 - TS

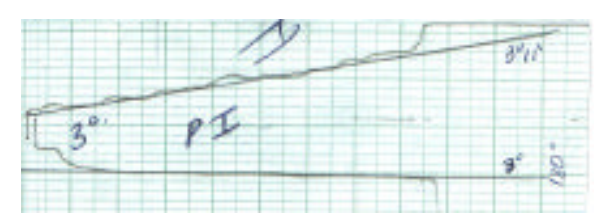

cil. 5 - TS

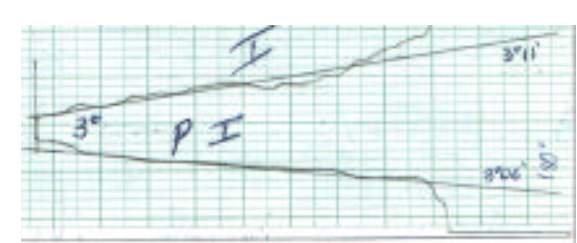

cil. 6 - TS

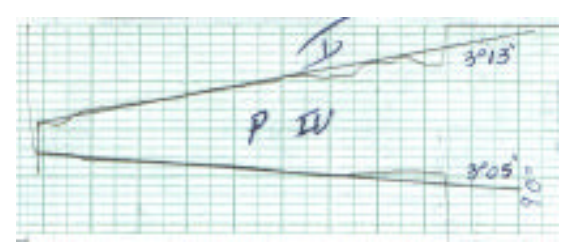

cil. 2 - ATS

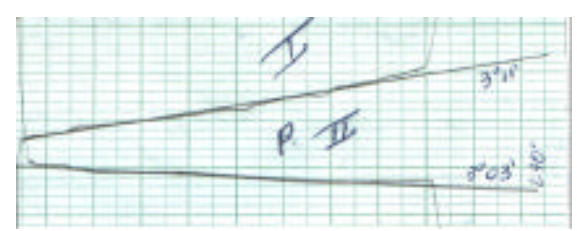

cil. 3 - ATS

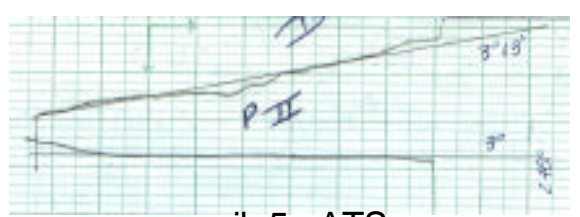

cil. 5 - ATS

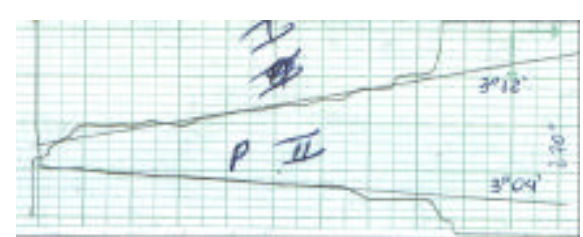

cil. 6 - ATS

Fig.5.26-Perfil dos flancos do $1^{\mathrm{o}}$ canalete, após $750 \mathrm{~h}$ de ensaio. 


\section{Cilindro}

O desgaste no cilindro foi bastante baixo. A porcentagem de área espelhada foi em torno de $2 \%$ após $750 \mathrm{~h}$ de ensaio, vide tabela 5.5. Pelo seu posicionamento, a região espelhada parece ser decorrente mais do contato do pistão do que dos anéis, conforme exemplificada na fig. 5.28.

\begin{tabular}{|c|c|c|c|c|}
\hline \multicolumn{5}{|c|}{ Tabela 5.5- Área espelhada no cilindro, após 750 h de ensaio. } \\
\hline & \multicolumn{3}{|c|}{ Área $\left(\mathrm{mm}^{2}\right)$} & \multirow{2}{*}{$\%$} \\
\hline cil $^{3}$ & TS & ATS & Total & 1,9 \\
\hline 1 & 402 & 541 & 943 & 1,7 \\
\hline 2 & 341 & 502 & 843 & 2,1 \\
\hline 3 & 465 & 547 & 1012 & 2,7 \\
\hline 4 & 345 & 984 & 1329 & 2,1 \\
\hline 5 & 466 & 587 & 1053 & 2,4 \\
\hline 6 & 593 & 570 & 1163 & \\
\hline
\end{tabular}

${ }^{3}$ cilindros 2, 3, 5 e 6 montados com anéis em GNS + PVD, cils 1 e 4 com anéis de série cromados 

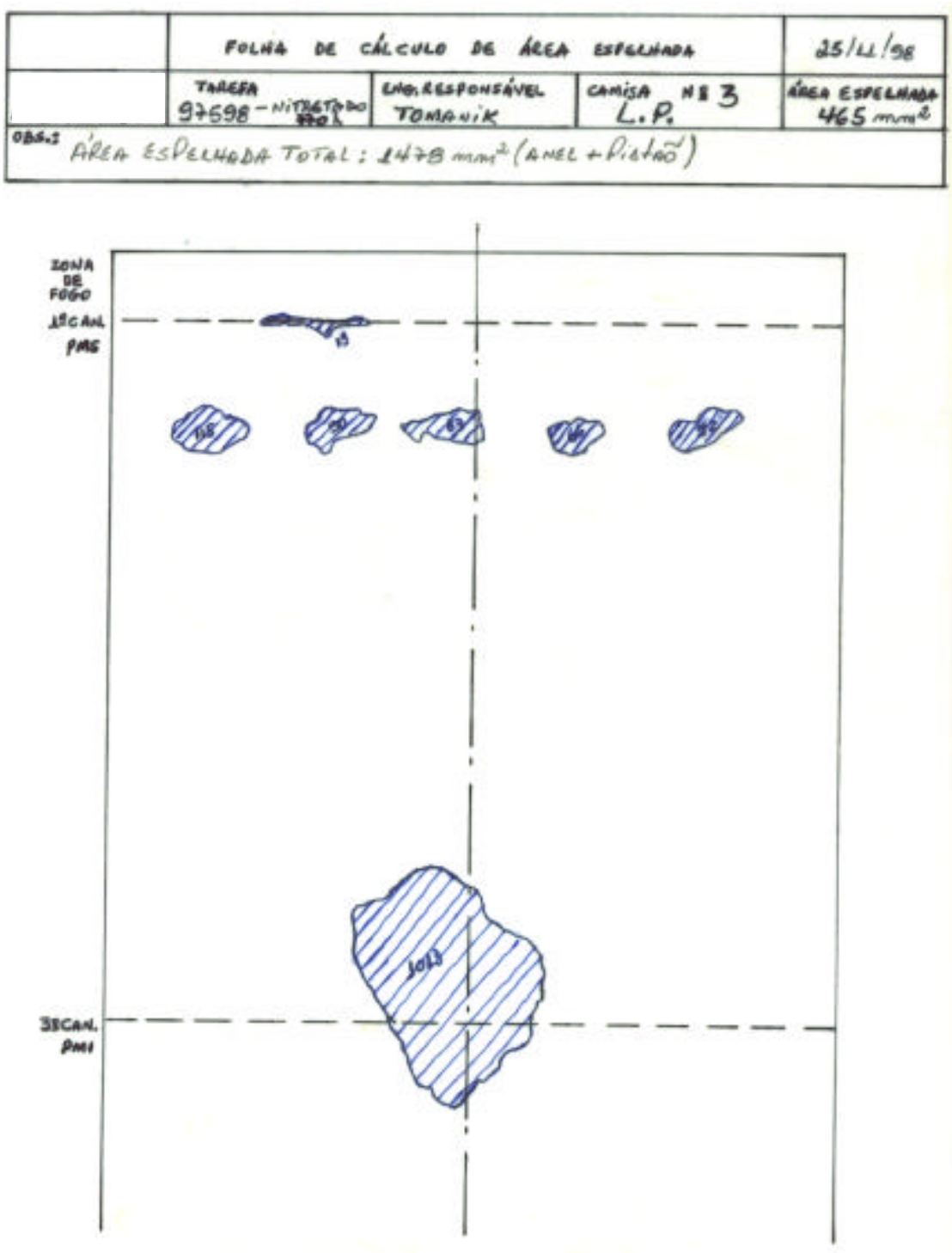

Fig.5.28- Exemplo de medição da área espelhada no cilindro, após 750 h de ensaio. Cilindro 3, TS.

A fig. 5.29 mostra o gráfico de perfil de rugosidade em duas posições: próximo ao PMS e aproximadamente no meio do curso. Os valores de rugosidade a $30 \mathrm{~mm}$ do topo são altos em virtude das marcas de desgaste localizadas na região de reversão do $1^{\circ}$ anel; na realidade a superfície apresenta-se mais lisa nessa região do que no meio do curso. 
$30 \mathrm{~mm}$ do Topo

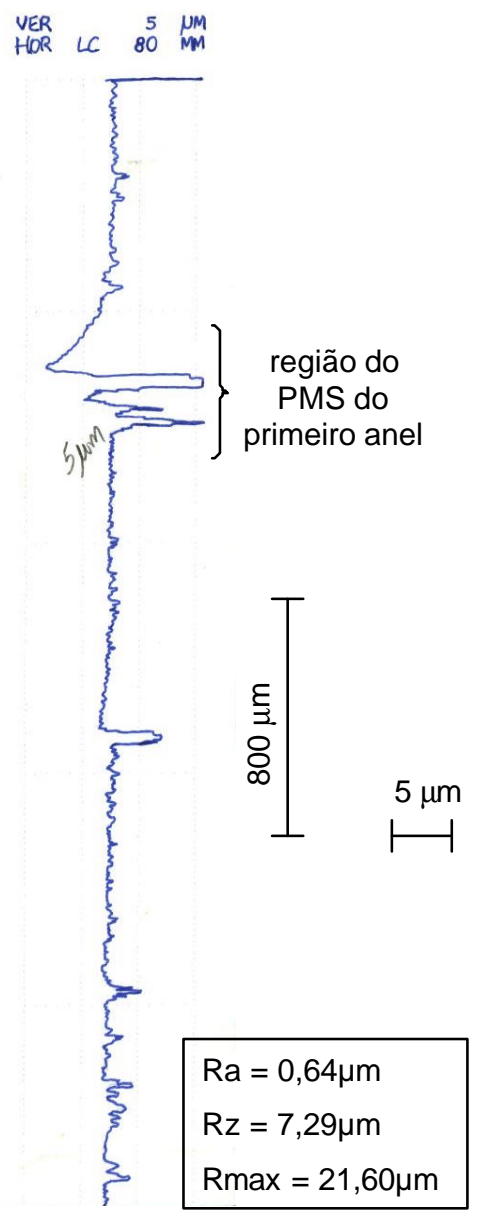

$60 \mathrm{~mm}$ do Topo

$\begin{array}{llll}\text { UER } & & 5 & \text { NM } \\ \text { HOR LC } & 80 & \text { MM }\end{array}$

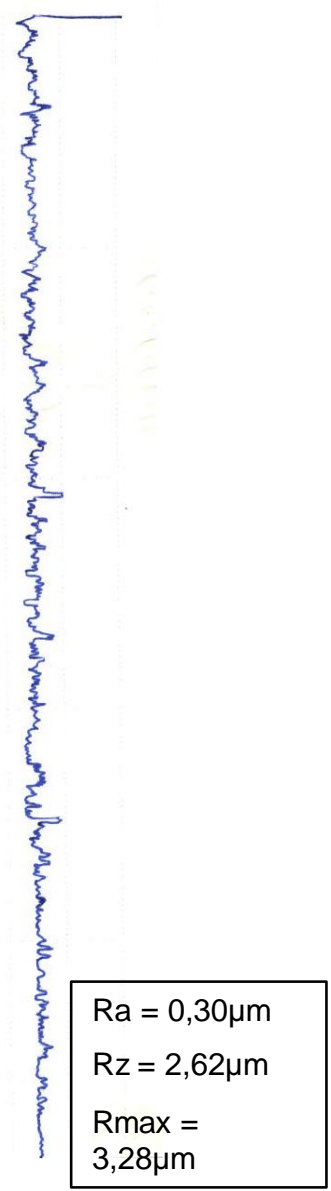

Fig.5.29- Exemplo de gráfico de perfil de rugosidade, após 750 h de ensaio.

\section{Demais anéis}

Tabela 5.6 - Desgaste medido no restante do pacote de anéis.

\begin{tabular}{|l|c|c|c|}
\hline Característica & $1^{\circ}$ can. Cromado & $2^{\circ}$ can. & Anel de óleo \\
\hline ) gap (mm) & $0,05 \pm 0,007$ & 0,05 & 0,20 \\
\hline ) radial (: $\mathrm{m})$ & $12,3 \pm 6$ & 18 & 43 \\
\hline ) $\mathrm{Ft}(\mathrm{N})$ & 1,2 & $-0,1$ & 4,6 \\
\hline
\end{tabular}




\section{7- Resultados calculados pelo modelo}

Com os dados de entrada descritos anteriormente, executou-se o código computacional para a condição de 2500 rpm, plena carga. Após cerca de 10 ciclos preparatórios para convergência das pressões intercanaletes e espessuras de filme de óleo, o código começa a calcular as interações de desgaste. A fig. 5.30 mostra as pressões dos gases agindo nos anéis, sendo que a pressão de combustão é um dado de entrada, enquanto as demais são calculadas pelo modelo. A fig. 5.31 mostra a espessura mínima do filme de óleo entre os anéis e a parede do cilindro.

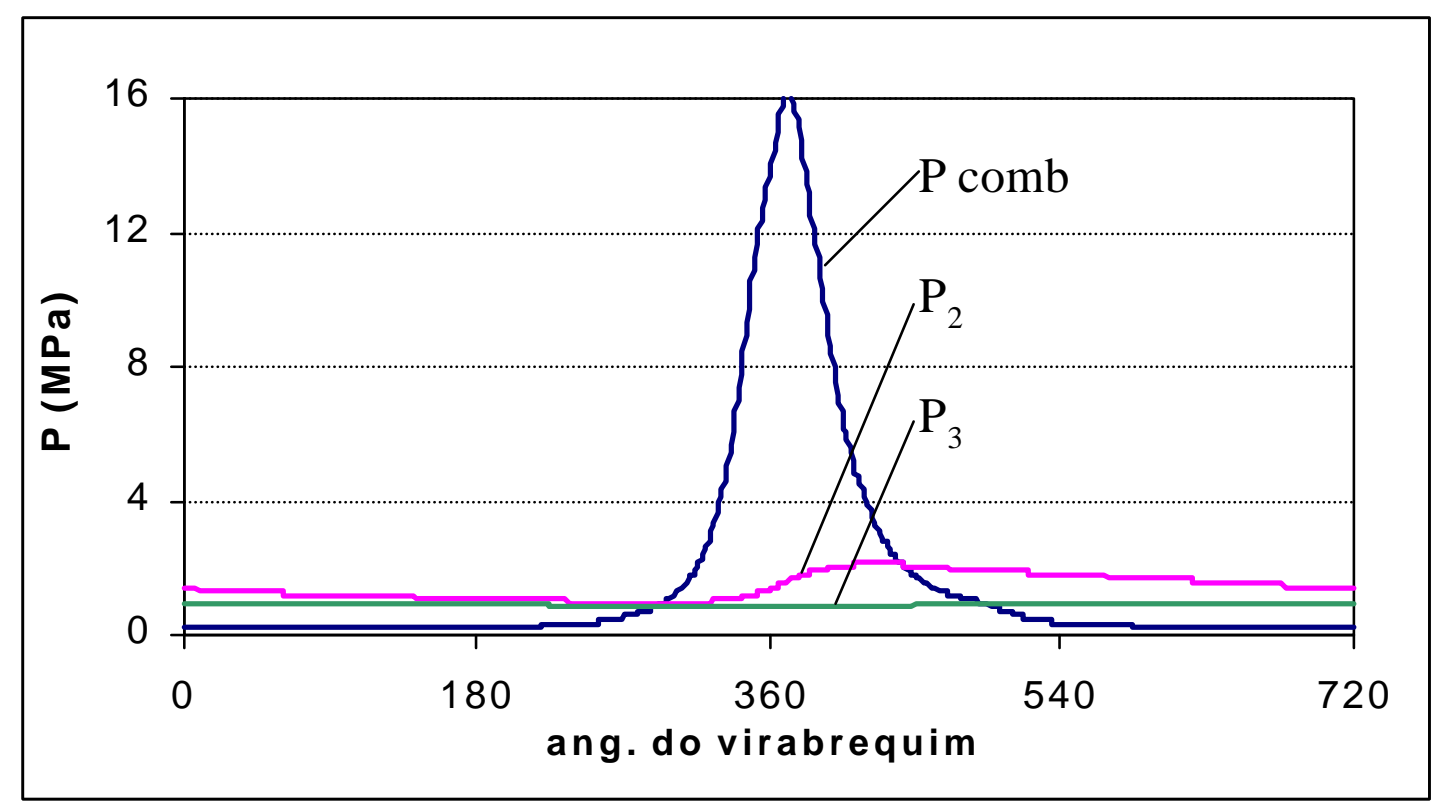

Fig.5.30 - Pressões dos gases, agindo nos anéis, no ínicio das interações de desgaste. 


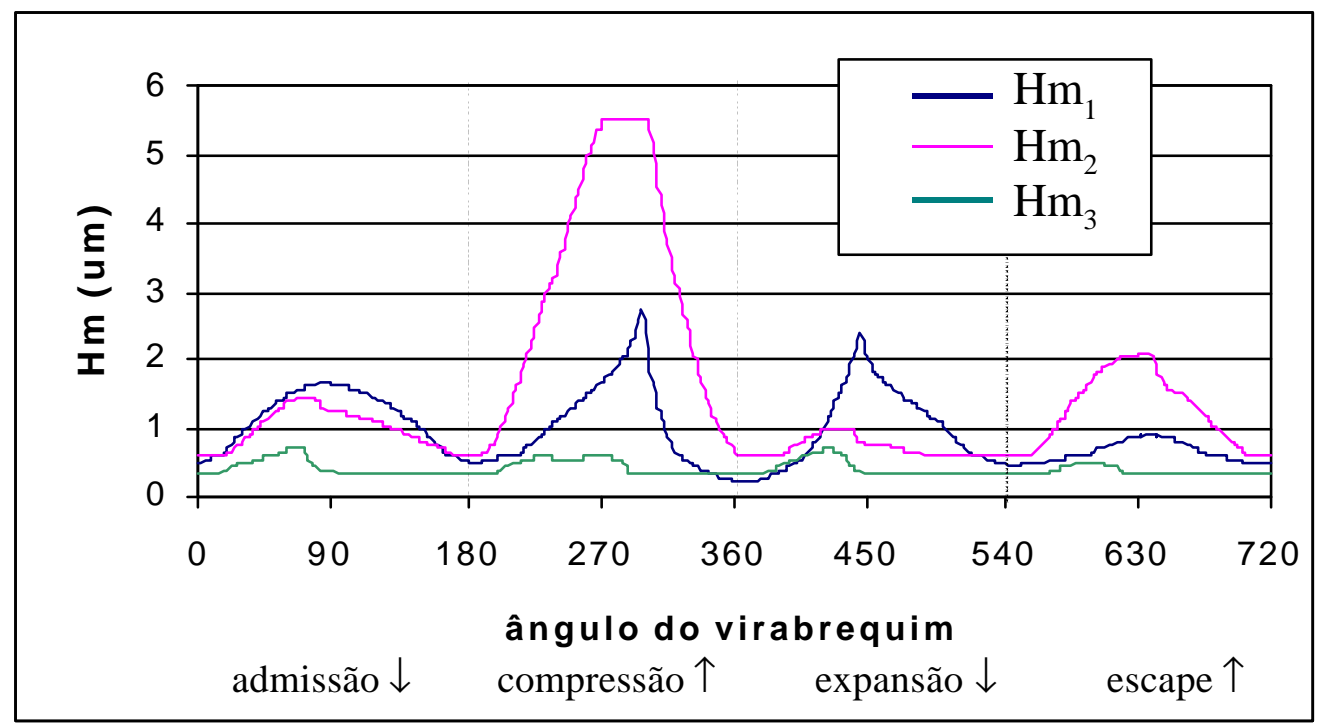

Fig. 5.31- Espessura mínima calculada do filme de óleo entre anéis e cilindro. Início das interações (anéis e cilindros novos).

\subsection{1- Anel de $1^{\circ}$ canalete}

A fig. 5.32 detalha a espessura do filme do $1^{\circ}$ anel, calculada para os lados de pressão (TS) e oposto ao de pressão (ATS). Observa-se que o perfil do anel é abaulado o suficiente para produzir a mesma espessura nesses 2 lados, ou seja, nessa situação o perfil do anel é hidrodinamicamente insensível ao movimento secundário do pistão. Na situação inicial, a rugosidade combinada do $1^{\circ}$ anel e do cilindro vale $0,224: \mathrm{m}$; pelo modelo de $\mathrm{G}-\mathrm{W}$, forças de contato rugoso surgem quando a espessura do filme de óleo for menor que 3 vezes a rugosidade combinada $(0,672: \mathrm{m})$. Portanto, nas regiões de reversão de movimento $\left(0^{\circ}\right.$, $180^{\circ}, 360^{\circ}$ e $\left.540^{\circ}\right)$ e em todo o curso de escape $\left(540\right.$ a $\left.720^{\circ}\right)$ alguma interação entre as asperezas estará ocorrendo. Entretanto, as forças de contato rugoso são pouco significativas, exceto durante a combustão. 


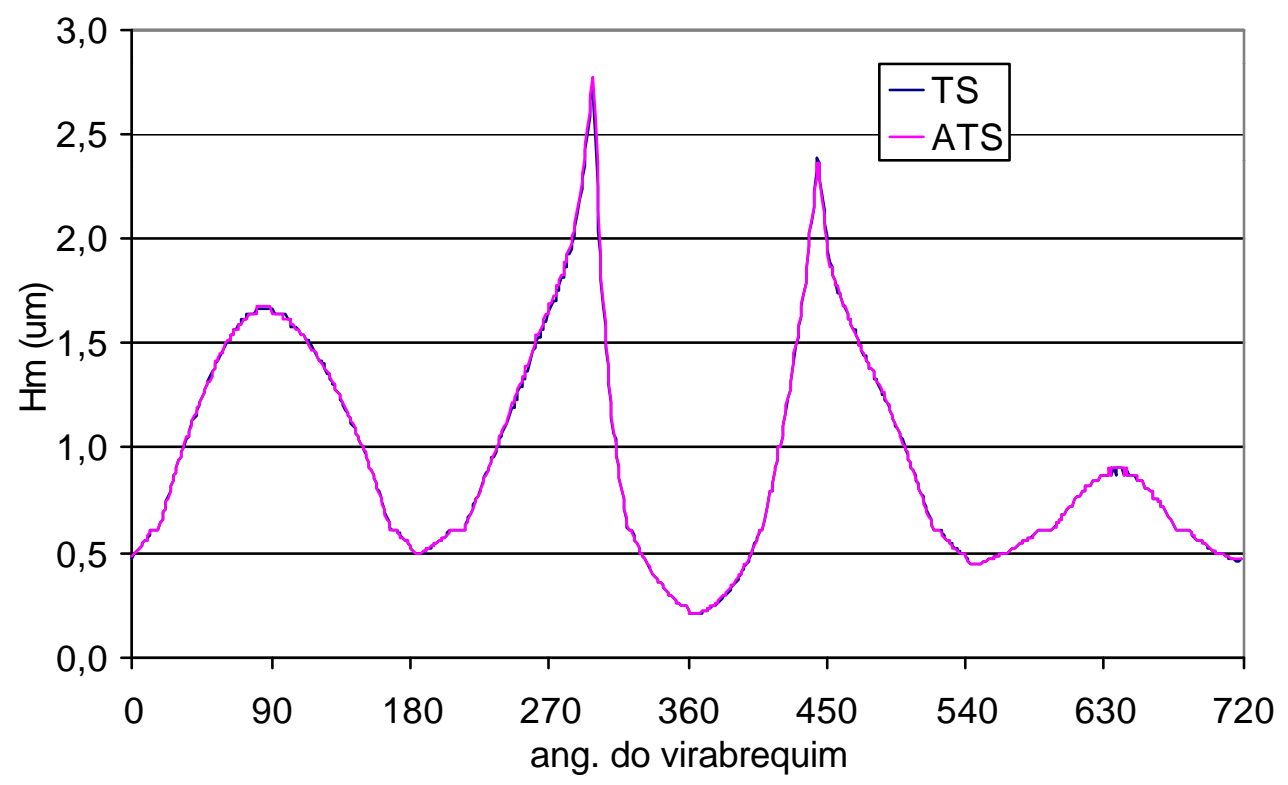

Fig.5.32- Espessura do filme de óleo, anel de $1^{\circ}$ canalete quando novo.

As figs. 5.33 e 5.34 mostram, respectivamente, as pressões hidrodinâmicas e as de contato rugoso ao longo dos 4 tempos do motor. Analisando a fig. 5.33, é possivel reconhecer a alteração da posição da distribuição das pressões com a direção de movimento do anel: de 0 a $180^{\circ}$ a cunha hidrodinâmica se forma na parte inferior da face do anel, as pressões hidrodinâmicas são relativamente baixas (menos de $10 \mathrm{MPa}$ ) fruto das baixas pressões atuantes no anel no curso de admissão do motor. No curso de compressão (180 a 360 ), a direção do movimento e a posição da cunha hidrodinâmica se invertem, pois enquanto o pistão e anel estão subindo, a cunha se forma na parte superior do anel.

A máxima pressão na câmara de combustão ocorre após o PMS $\left(360^{\circ}\right)$ provocando pressões hidrodinâmicas máximas de aproximadamente $45 \mathrm{MPa}$. 


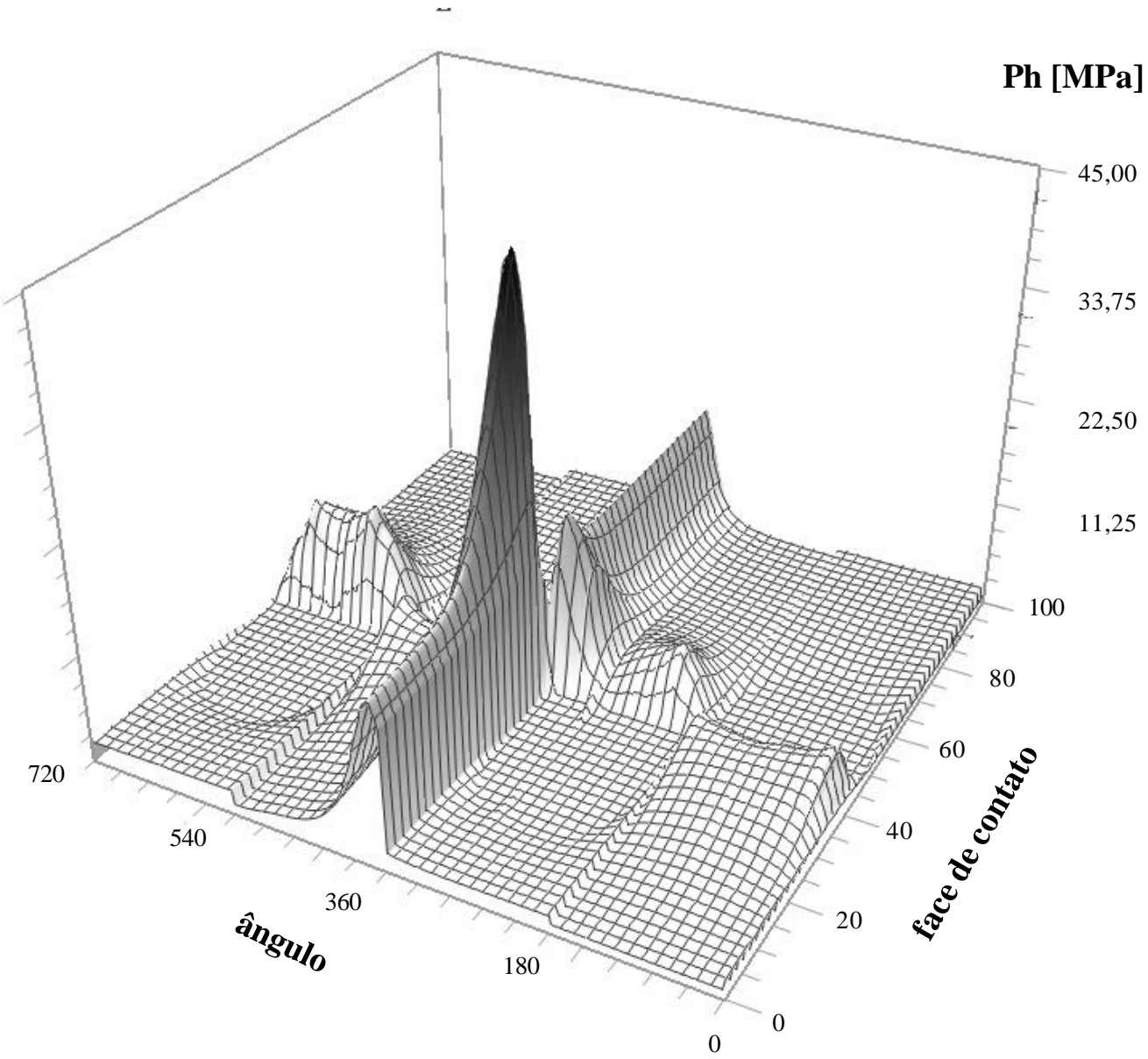

Fig.5.33- Pressões hidrodinâmicas, $1^{\circ}$ anel quando novo.

Já as pressões de contato rugoso (fig.5.34) têm comportamento bastante diferente: em decorrência do perfil inicial do anel, as pressões se concentram no meio da face de contato do anel, são relativamente baixas ao longo dos 4 tempos do motor, com pequenos picos nos pontos de reversão, mas atingem um máximo de aproximadamente 95 MPa no momento de máxima pressão de combustão. É importante ressaltar que essas pressões de contato são as pressões médias atuando numa determinada fatia do anel. Como a área real de contato é apenas uma pequena porcentagem da área nominal, as pressões agindo nos pontos de contato atingem magnitude de GPa. Essas pressões de contato rugoso provocam um dano 
ligeiramente deslocado para a região superior à posição mais proeminente do anel ( vide

fig.5.35); tal deslocamento é provocado pelas deformações de origem térmica do canalete.

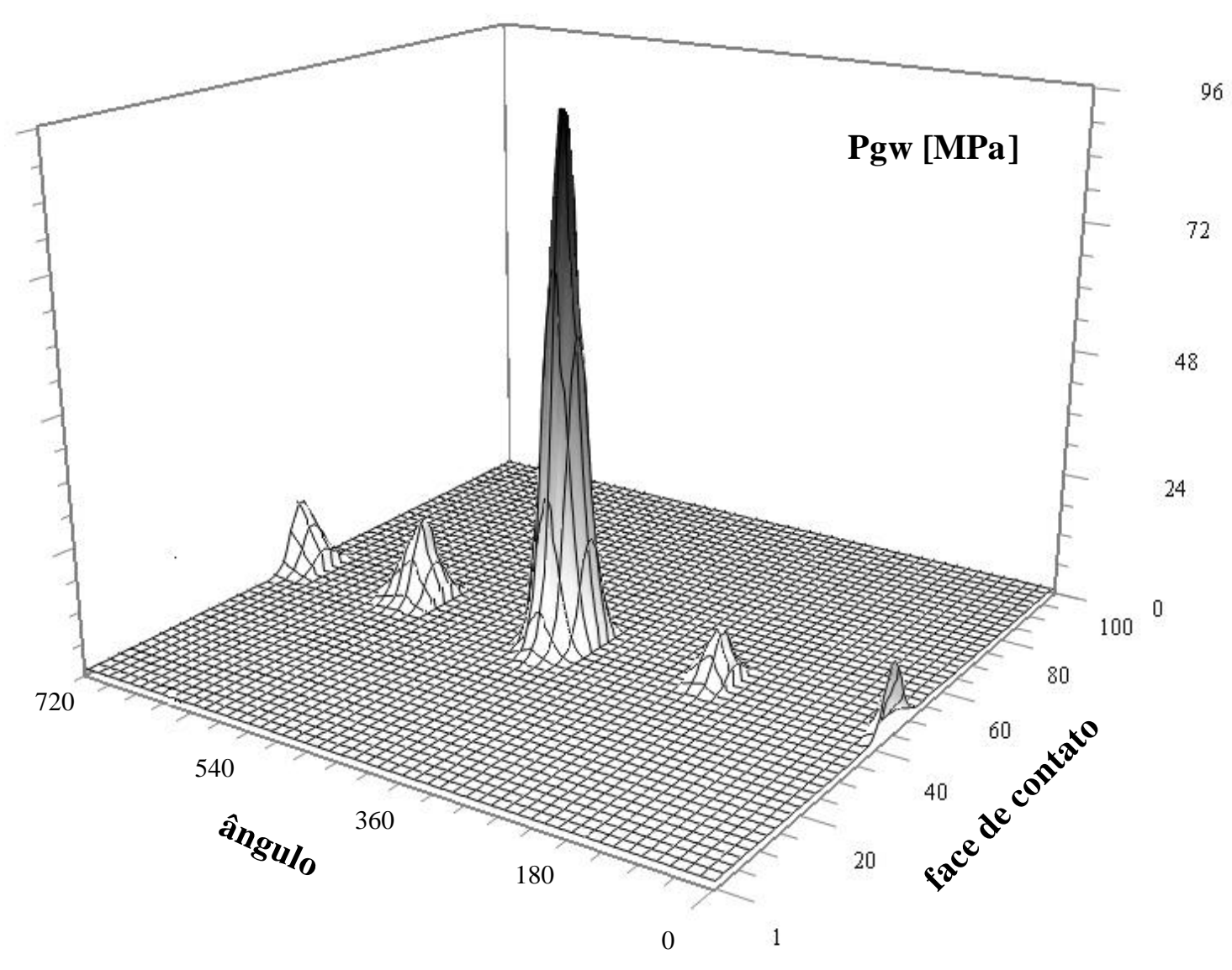

Fig.5.34- Pressões de contato rugoso, $1^{\mathrm{o}}$ anel quando novo.

Em decorrência do dano acumulado, ocorre desgaste e consequente modificação do perfil da face de contato. A fig.5.36 mostra o perfil e o dano acumulado na $10^{\mathrm{a}}$ interação de desgaste. Note-se que o dano máximo que ocorre numa interação reduziu de 2,5 na $1^{\mathrm{a}}$ para menos de 1,0 na $10^{\mathrm{a}}$ interação. Isso ocorre, mesmo sendo mínima a mudança do perfil, porque o pequeno desgaste já produziu uma área de apoio bem maior do que a existente no perfil 
inicial. A redução de rugosidade combinada, prevista pelo modelo, ainda é insignificante: de 0,22 para $0,21: \mathrm{m}$ nos pontos de contato. A curvatura do perfil ainda é bastante suave e o filme de óleo calculado (fig. 5.37) ainda é praticamente igual ao inicial e uniforme nas posições de TS e ATS.

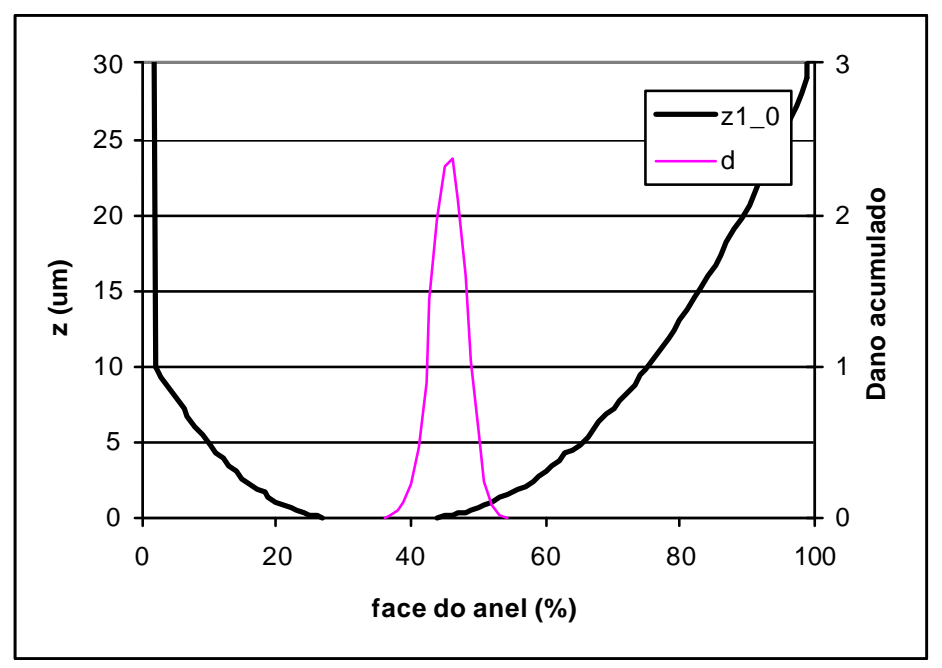

Fig.5.35- Perfil da face de contato e dano acumulado na $1^{\mathrm{a}}$ interação de desgaste. 


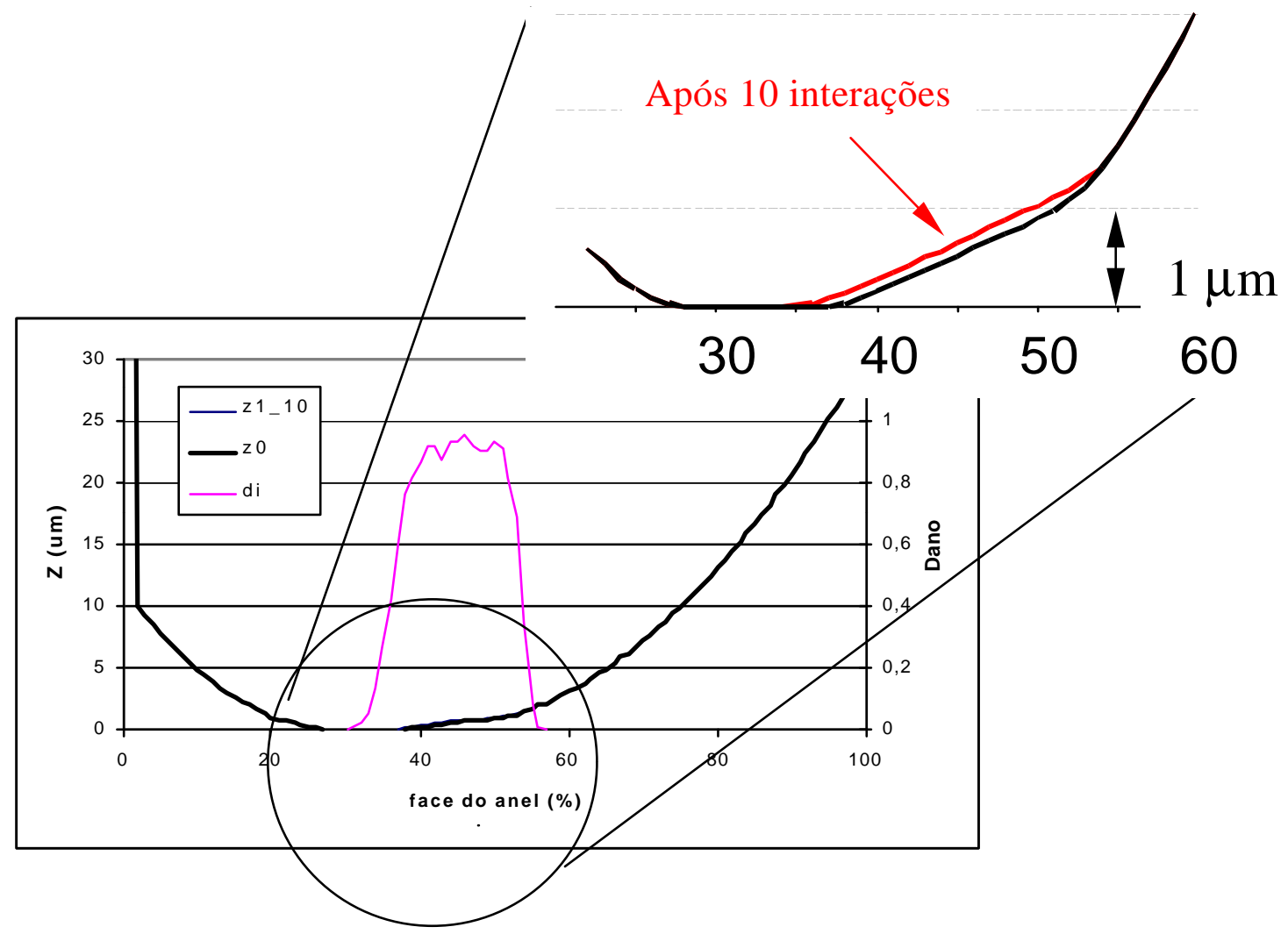

Fig.5.36- Perfil e dano acumulado durante a $10^{\mathrm{a}}$ interação.

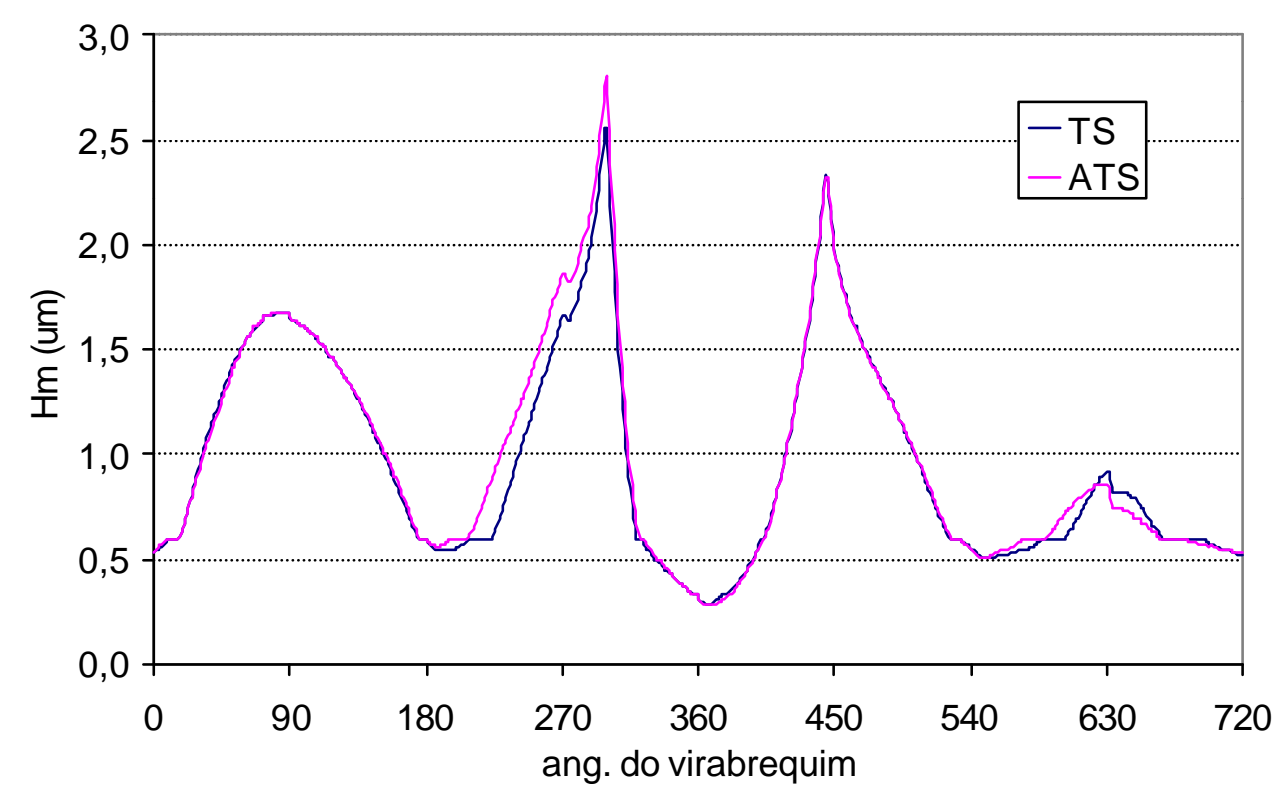

Fig.5.37- Espessura do filme de óleo após 10 interações. Posições TS e ATS. 
O processo se repete a cada interação, com as pressões hidrodinâmicas e de contato rugoso sendo calculadas a cada grau do virabrequim, bem como o dano decorrente em cada ponto do anel e do cilindro. No final de cada interação (4 tempos do motor) o modelo calcula se existe remoção de material e ajusta o perfil das faces de contato dos anéis e da parede do cilindro. A folga entre pontas do anel aumenta segundo a remoção de material na radial do anel, o que modifica o fluxo e as pressões dos gases. A fig. 5.38 mostra a evolução do perfil desgastado do $1^{\circ}$ anel até 500 interações. O desgaste radial total nesse instante é cerca de 10 : m na região inicialmente mais proeminente. Nessa região a camada de $\mathrm{CrN}$ já teria sido removida, como aconteceu na ponta dos anéis ensaiados (vide fig.5.19); as propriedades nesses pontos deveriam ser agora as do GNS e não mais do CrN, embora tal fato não tenha sido implementado na atual versão do modelo. Após 500 interações, o perfil cônico calculado para o $1^{\circ}$ anel já é bastante evidente, tornando a espessura do filme sensível ao movimento secundário do pistão, como mostra a fig.5.39 para as posições de TS e ATS. Vale ainda mencionar que essa diferença ocorre principalmente nas regiões onde o filme tem grande espessura, pouco afetando o desgaste. 


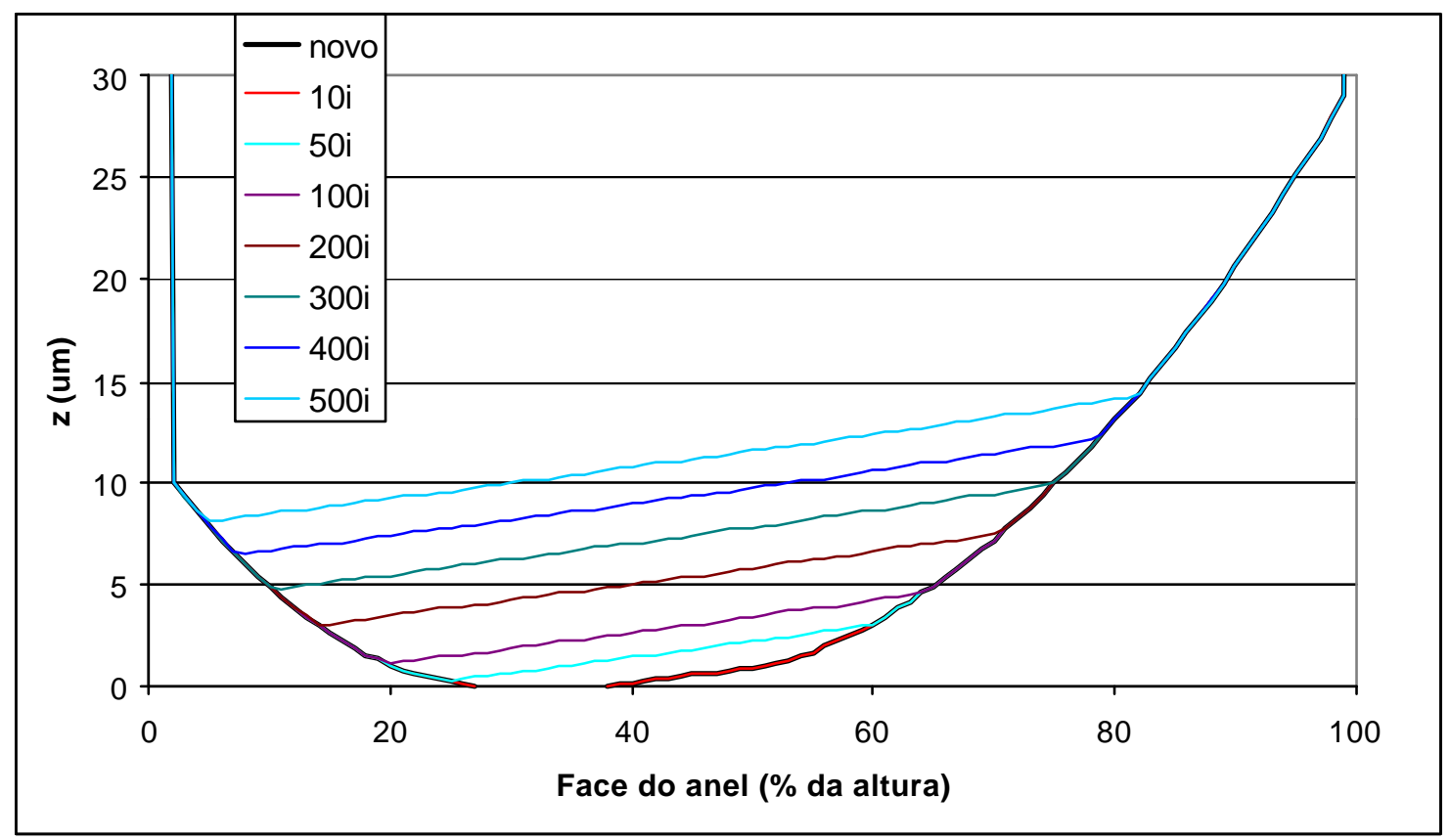

Fig. 5.38- Evolução do perfil desgastado do $1^{\circ}$ anel.

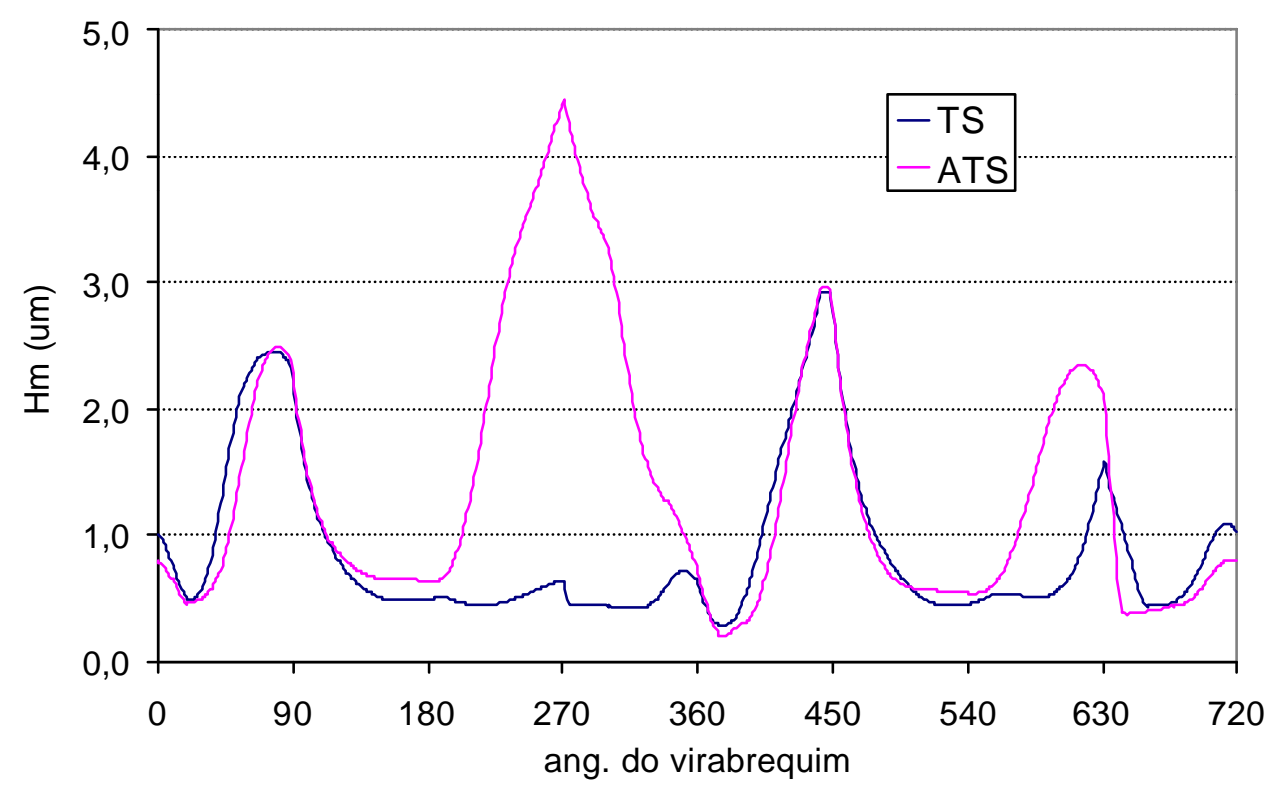

Fig. 5.39- Espessura do filme de óleo, $1^{\circ}$ anel, após 500 interações. 
Para efeito de ilustração vamos estudar em mais detalhe o comportamento calculado após 100 interações. O perfil resultante da remoção de material prevista pelo modelo é mostrada na fig. 5.40. Diferentemente da fig.5.38, aqui se preferiu representar o perfil contatando a parede do cilindro. O desgaste radial calculado é da ordem de $2: \mathrm{m}$, mas a parte cônica já ocupa perto de $40 \%$ da altura do anel, situação semelhante à verificada no anel ensaiado após 100 h (vide fig. 5.18). O máximo dano por interação (di) agora reduziu-se para cerca de 0,6 e é praticamente constante sobre o perfil cônico formado pelo desgaste.

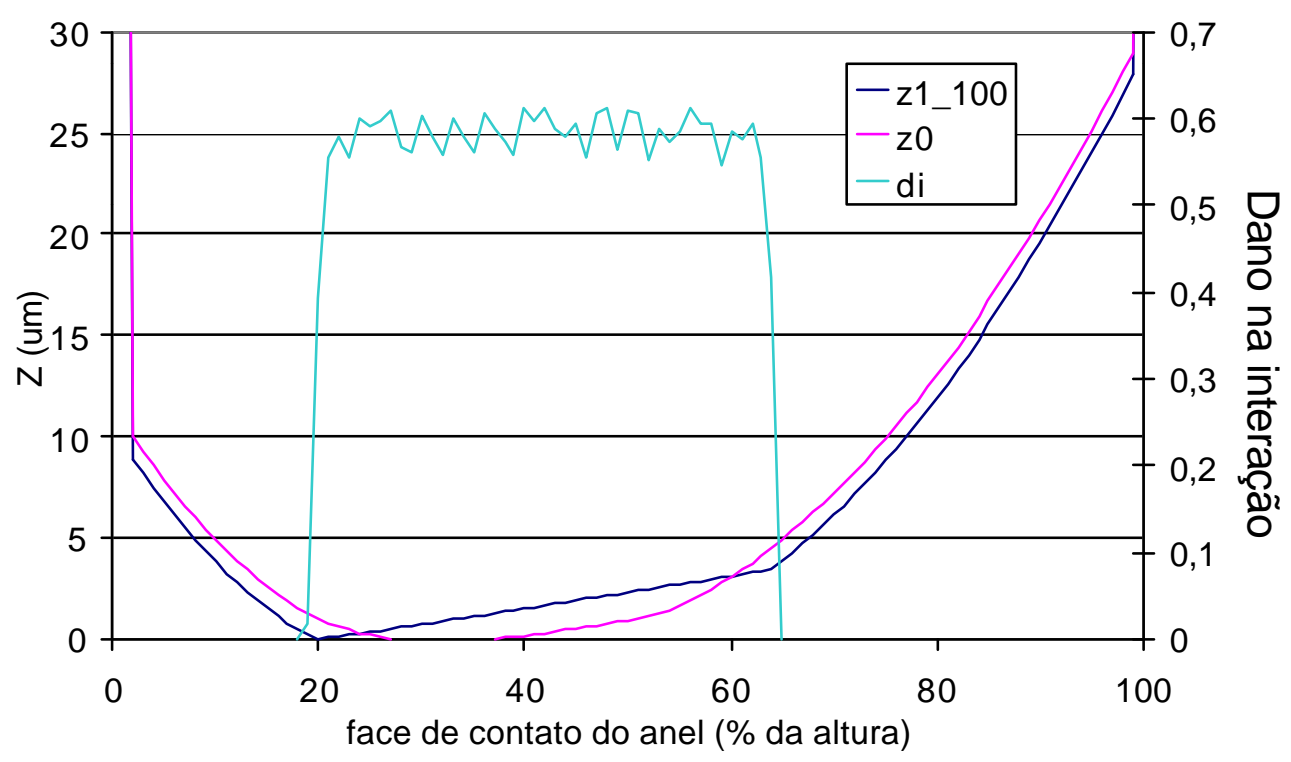

Fig.5.40- Perfil calculado da face de contato do anel após 100 interações.

$\mathrm{O}$ aumento de folga entre pontas, tanto do $1^{\circ}$ anel quanto dos demais é ainda muito pequeno e o fluxo e as pressões dos gases são praticamente idênticos aos iniciais (fig. 5.30). Entretanto, devido à mudança de perfil, o filme de óleo já é bastante diferenciado entre as posições TS e ATS (vide fig. 5.41). As figs. 5.42 e 5.43 mostram, respectivamente, as 
pressões hidrodinâmicas e de contato rugoso na face do anel, lado de maior pressão (TS).

Comparando as pressões de contato rugoso do anel quando novo (fig.5.43) com o do anel desgastado após 100 interações (fig.5.34) percebe-se que o valor máximo reduziu-se praticamente à metade (de 95 para $52 \mathrm{MPa}$ ) e o ponto de máximo deslocou-se em direção à borda inferior do anel; as pressões se distribuem por uma faixa maior do anel o que faz com que o dano total (que pode ser entendido como a taxa de remoção de material) não diminua na mesma proporção que o valor máximo de pressão de contato rugoso. Esse tópico será melhor discutido à frente. Note-se também que desapareceram as pressões de contato que existiam nos outros pontos de reversão $\left(0^{\circ}, 180^{\circ}\right.$ e $\left.720^{\circ}\right)$ no anel quando novo.

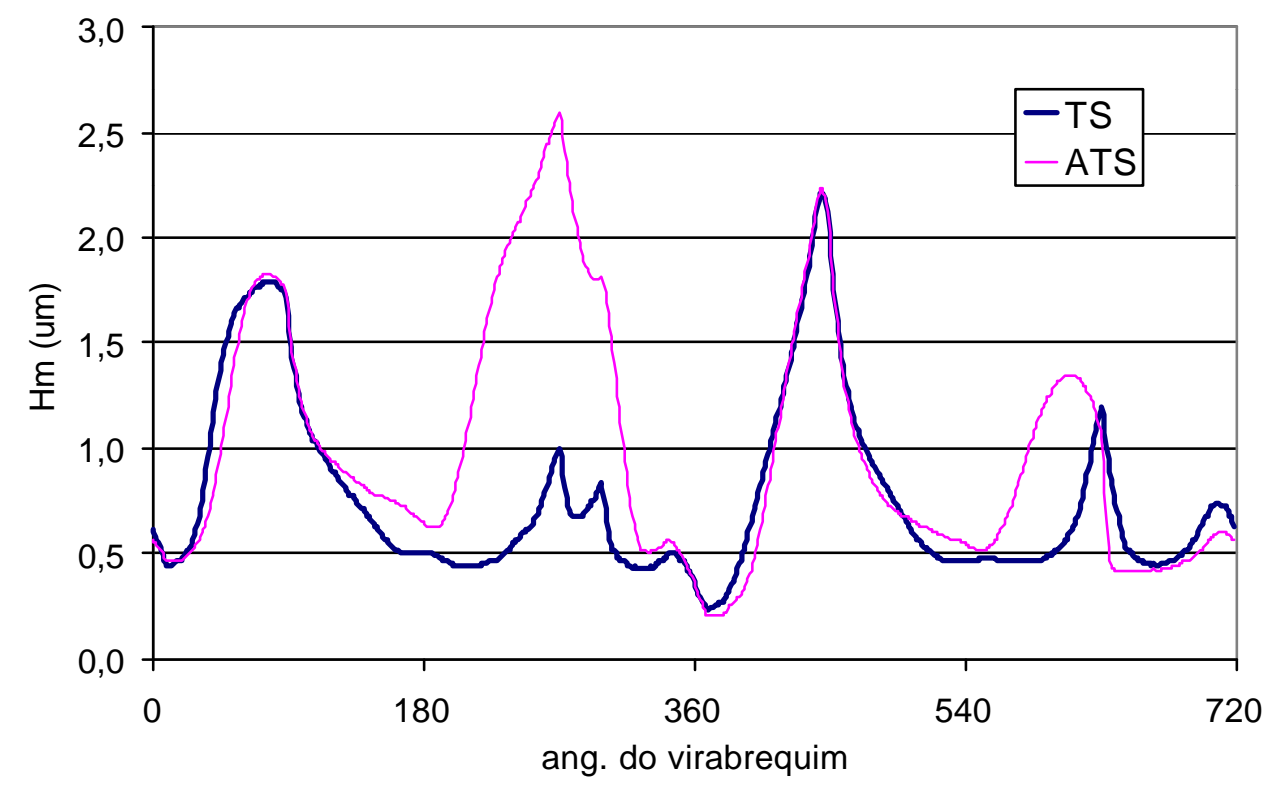

Fig.5.41- Filme de óleo calculado, perfil após 100 interações. 


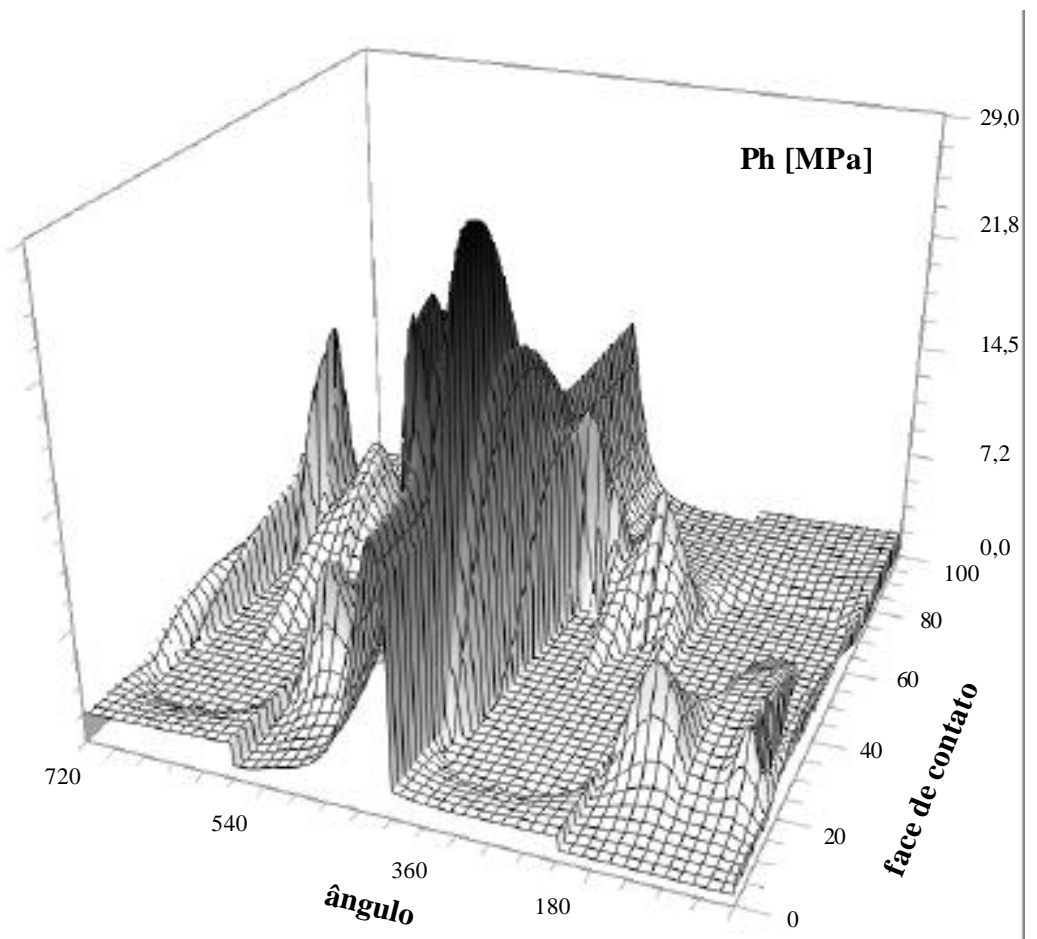

151

Fig.5.42- Pressões hidrodinâmicas, $1^{\circ}$ anel após 100 interações, posição TS.

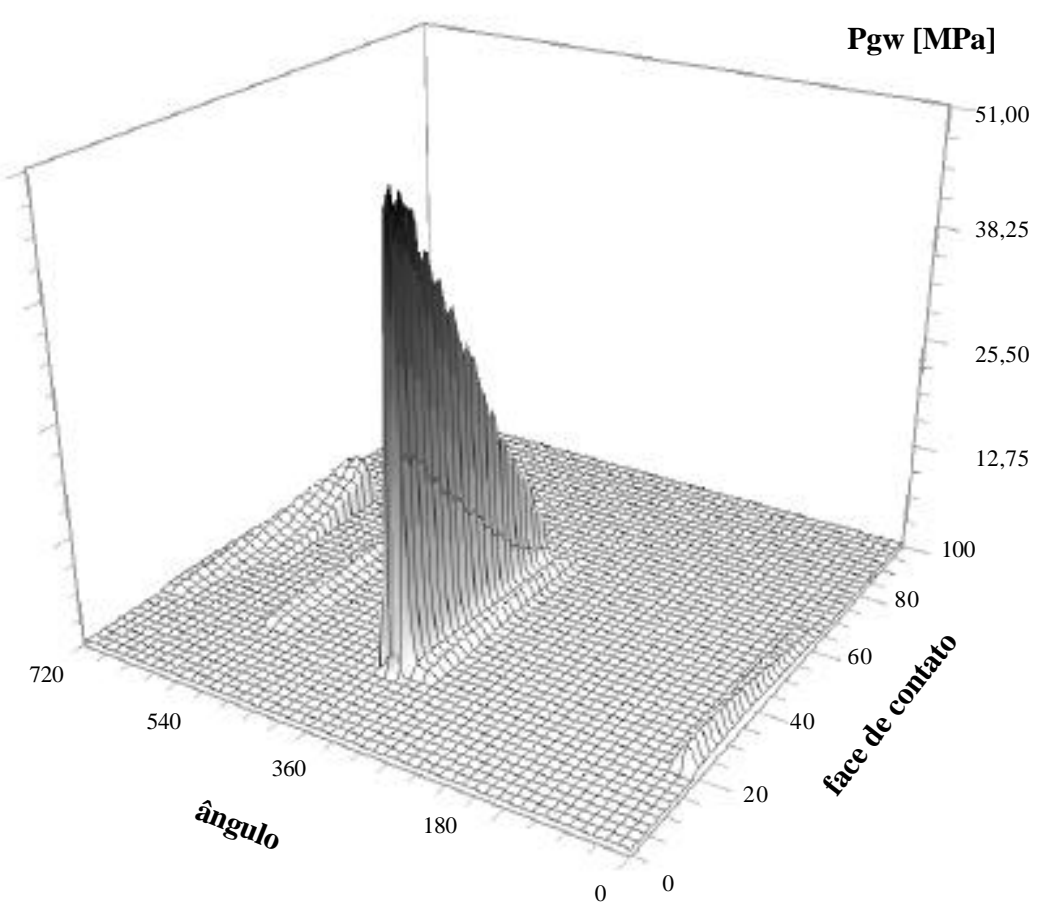

Fig.5.43- Pressões de contato rugoso, $1^{\circ}$ anel após 100 interações, posição TS. 


\subsection{2- Anel de $2^{\circ}$ canalete}

$\mathrm{O}$ anel de $2^{\circ}$ canalete tem perfil inicial mais cônico que o anel de $1^{\circ}$ canalete. Isso é feito para reforçar a ação raspadora de óleo e porque esse anel fica submetido a menores pressões gasosas, não necessitando, portanto, de um perfil tão hidrodinâmico quanto o $1^{\circ}$ anel. A fig.5.44 mostra as pressões hidrodinâmicas no anel quando novo.

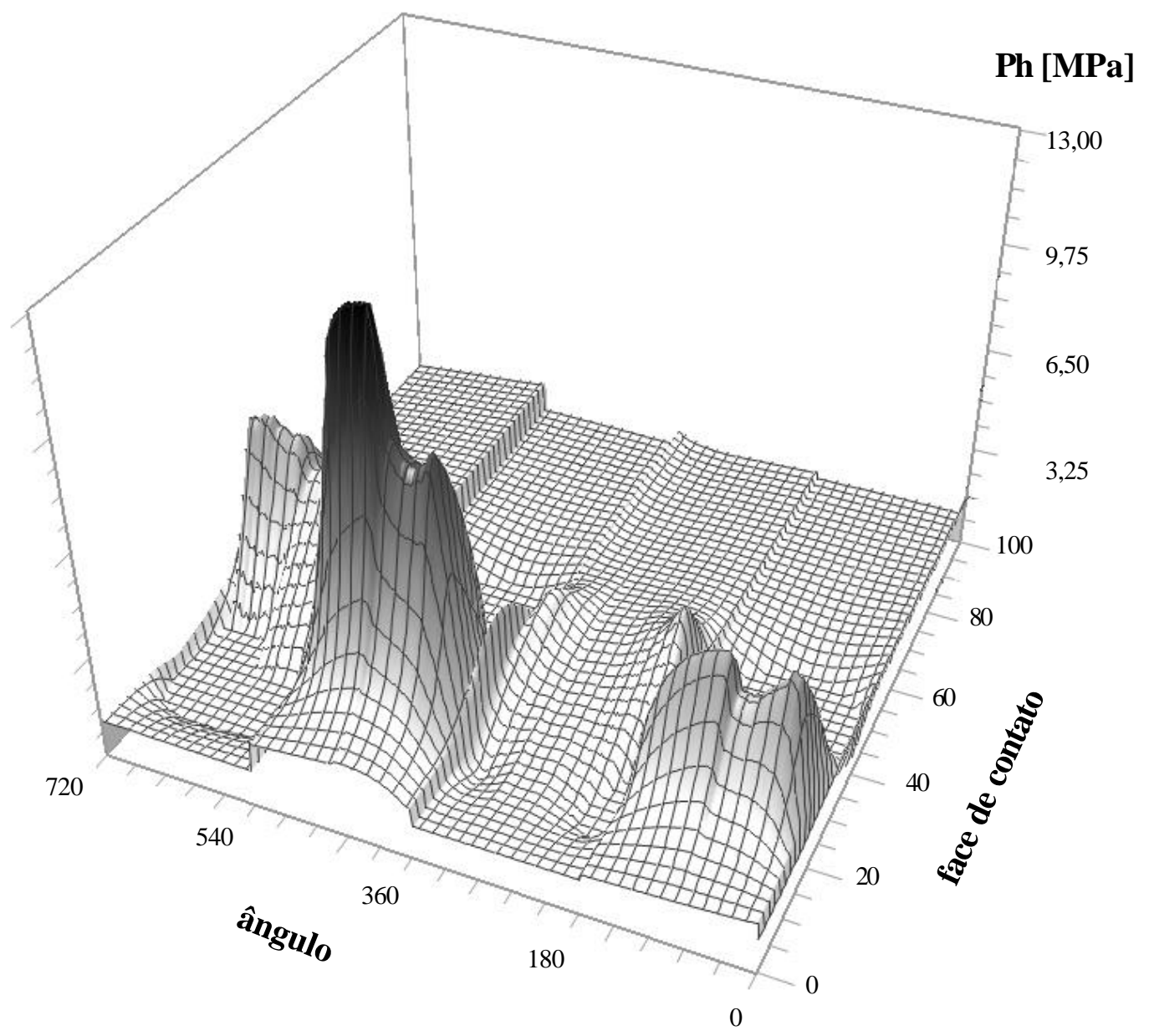

Fig.5.44- Pressões hidrodinâmicas, $2^{\circ}$ anel quando novo, lado TS. 
Devido ao perfil cônico inicial do $2^{\circ}$ anel e às maiores pressões gasosas ocorrendo nos tempos de expansão e escape, as pressões rugosas atingem um máximo de $4 \mathrm{MPa}$ aproximadamente a $540^{\circ}$ (vide fig.5.45). Essas pressões são bem menores que as que atuam no anel de $1^{\circ}$ canalete, mas o modelo prevê um maior desgaste em razão da menor dureza do $2^{\circ}$ anel mas principalmente devido as pressões de contato rugoso agirem durante uma maior distância percorrida pelo anel. A fig.5.46 mostra a evolução do perfil desgastado na face de contato do $2^{\circ}$ anel.

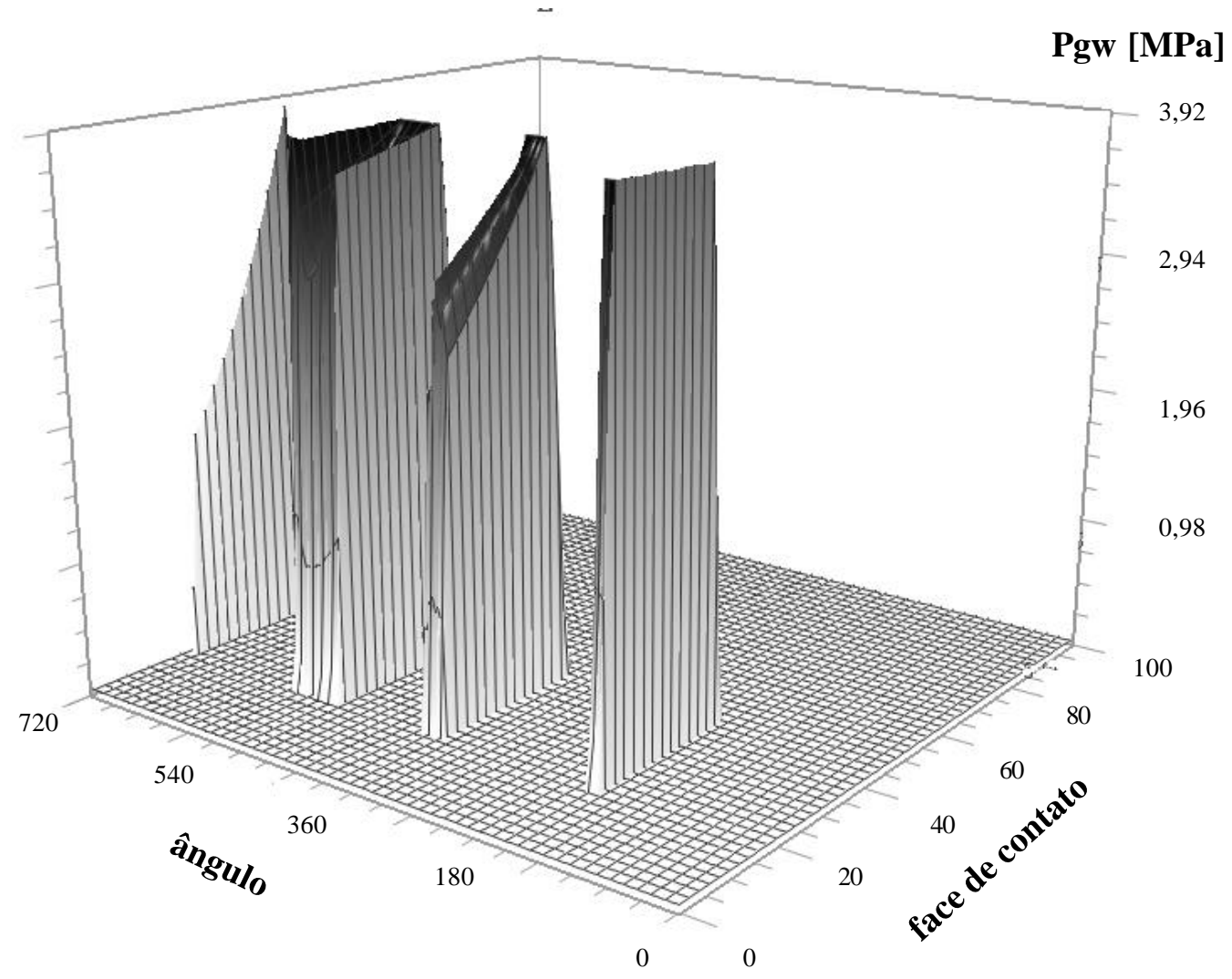

Fig.5.45- Pressões rugosas, anel de $2^{\circ}$ canalete quando novo, posição TS. 

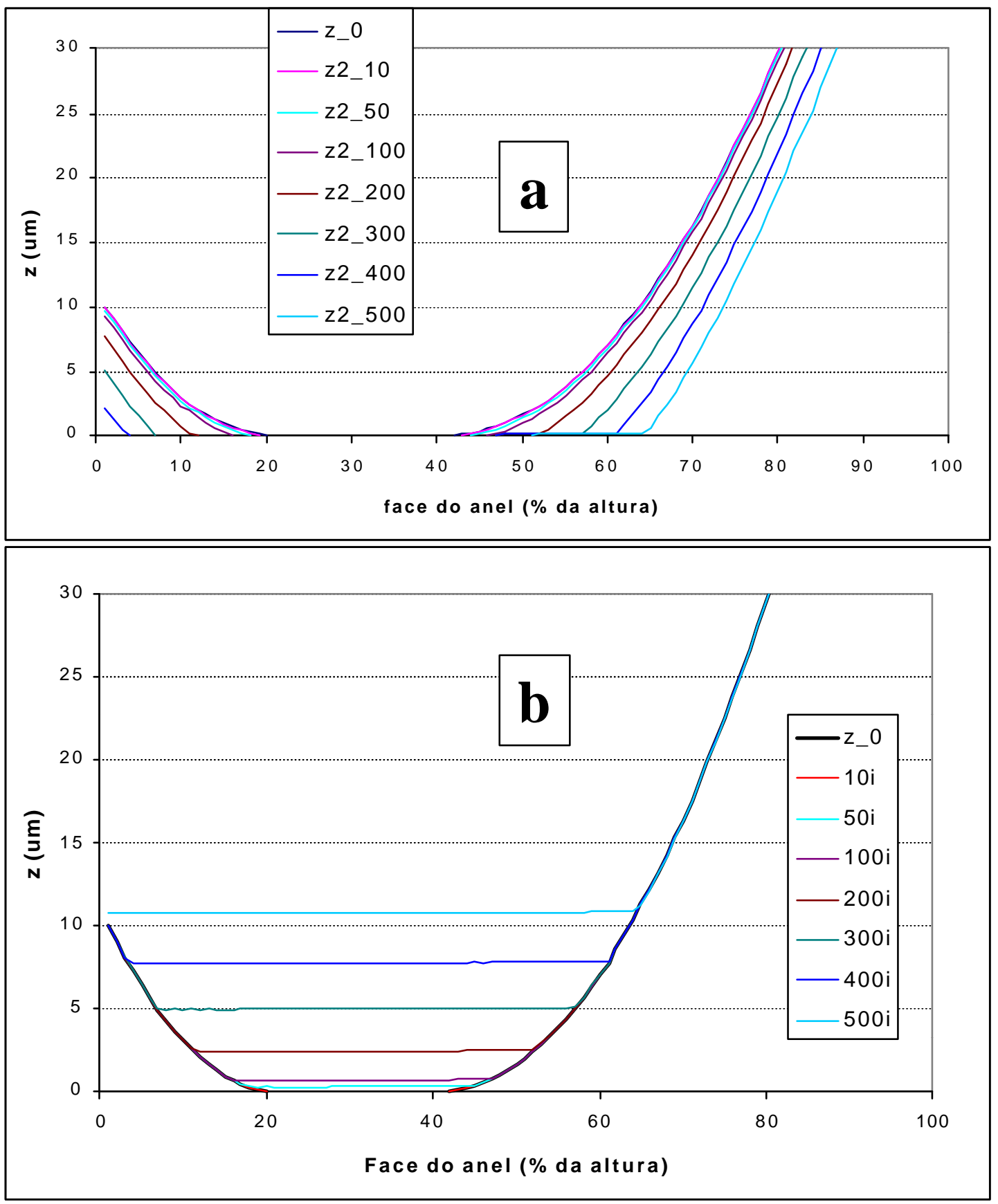

Fig.5.46- Evolução do perfil desgastado do $2^{\circ}$ anel.

a- Como percebido pelo modelo

b- Visualizando o desgaste radial

Após 100 interações, o modelo prevê um desgaste radial de aproximadamente $2:$ m para o

$2^{\circ}$ anel. As pressões hidrodinâmicas são muito semelhantes as do anel quando novo (fig.5.44) 
e não serão repetidas. Ao contrário do $1^{\circ}$ anel, o anel de $2^{\circ}$ canalete não tem seu desempenho hidrodinâmico melhorado com o desgaste, o que não deve ser entendido como um mau comportamento: desde que o desgaste e atrito não sejam excessivos, é desejável que o anel continue a ter uma boa ação de raspagem do filme de óleo. A fig. 5.47 mostra as pressões de contato rugoso no $2^{\circ}$ anel, após 100 interações. Observa-se a ampliação das faixas de ângulo de virabrequim nas quais ocorre contato rugoso.

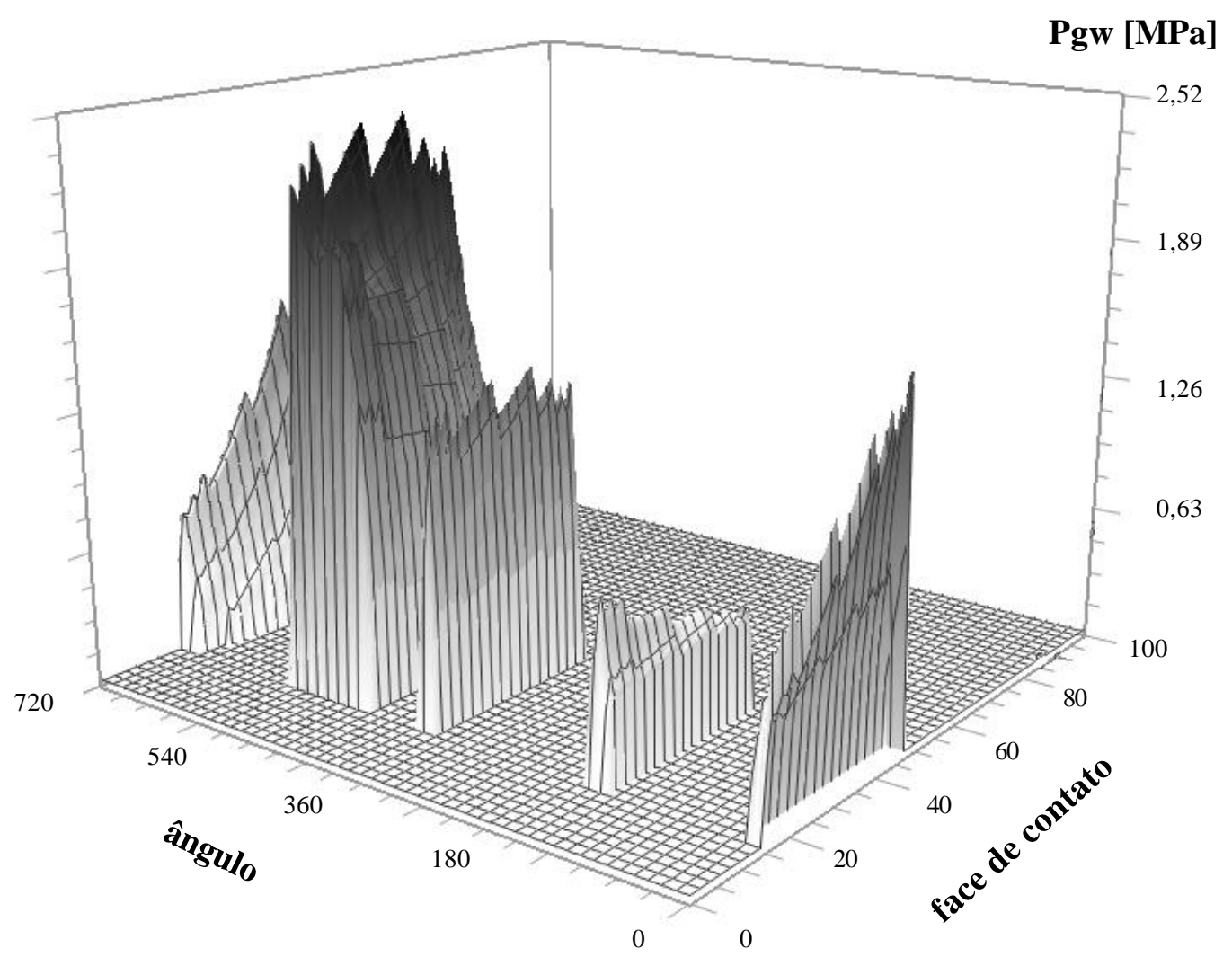

Fig.5.47- Pressões de contato rugoso, $2^{\circ}$ anel após 100 interações, posição TS. 


\subsection{3- Anel de óleo.}

A face de contato do anel de óleo é bem mais estreita que a dos anéis de compressão (0,30 versus 3,0 mm) e embora as pressões de gás sejam baixas (vide fig.5.30), a pressão própria do anel de óleo é cerca de 1,8 MPa. Essas duas características, aliadas à um perfil hidrodinâmicamente desfavorável, fazem com que surjam pressões de contato rugoso durante uma maior porção do curso. A fig. 5.48 e 5.49 mostram, respectivamente, as pressões hidrodinâmicas e de contato rugoso calculadas para o perfil novo.

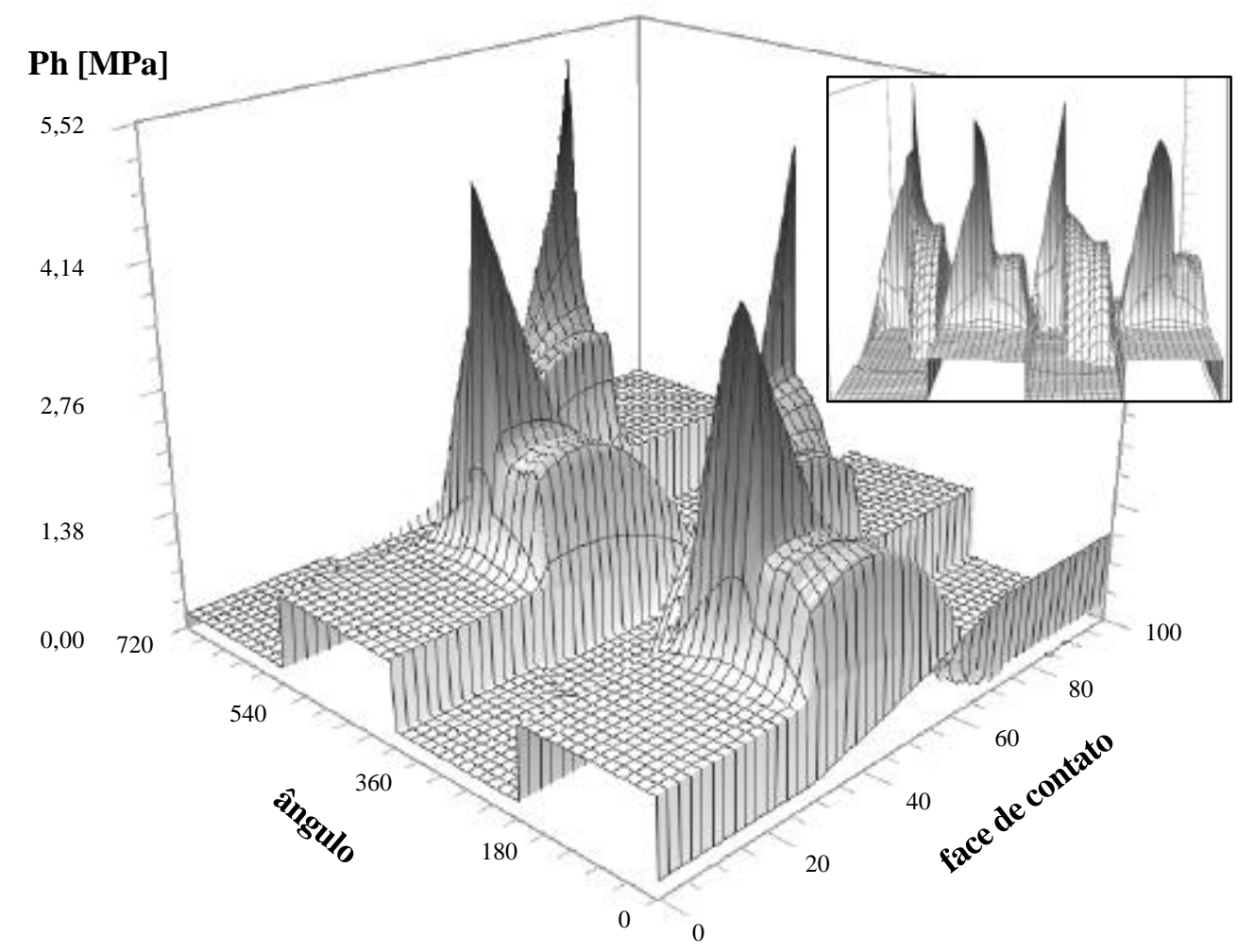

Fig.5.48- Pressões hidrodinâmicas, anel de óleo quando novo, posição TS. Em destaque, o mesmo gráfico visto de uma perspectiva diferente mostrando que as pressões máximas ocorrem no meio do curso, como esperado. 


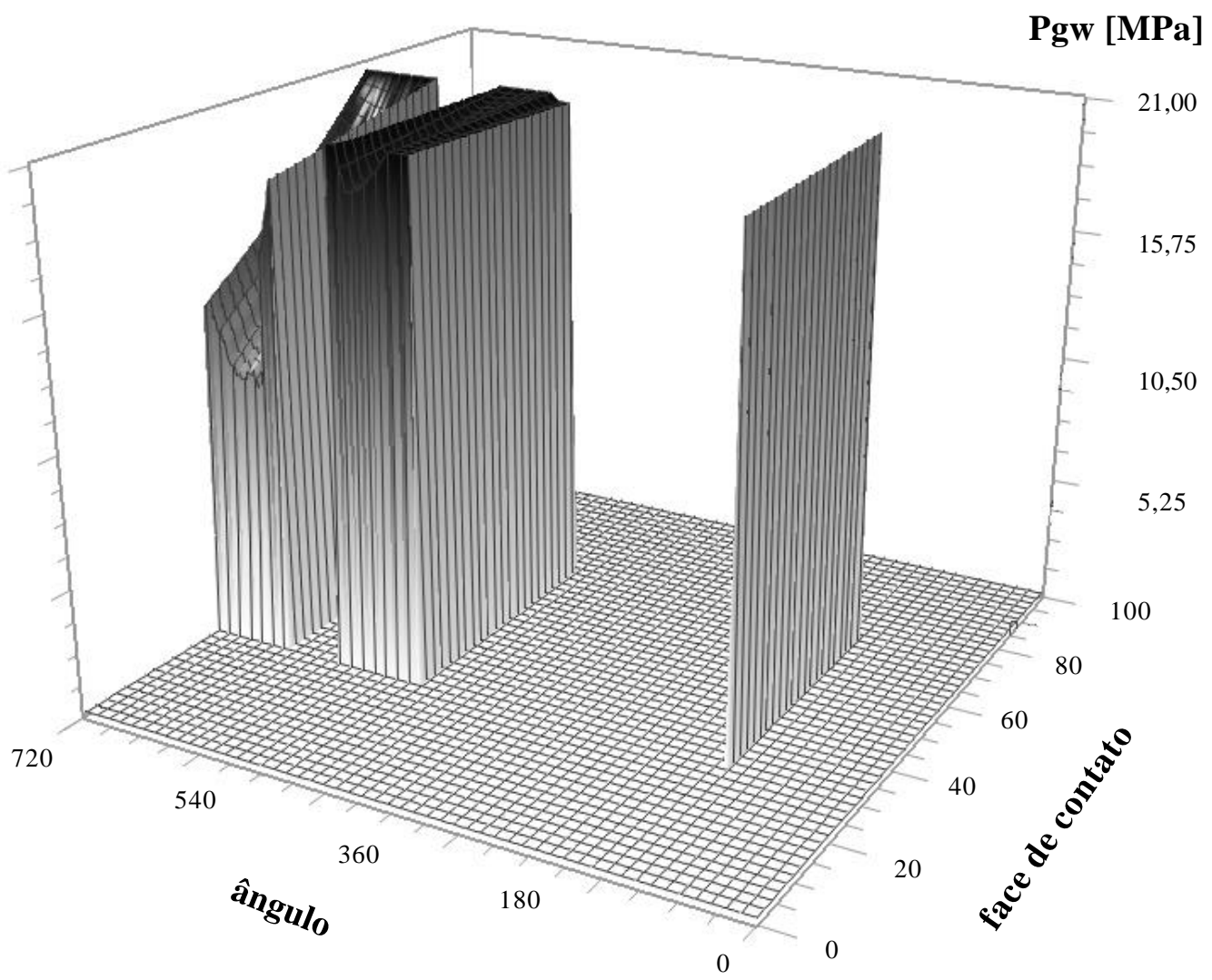

Fig.5.49- Pressões de contato rugoso, anel de óleo quando novo, posição TS.

Assim como $2^{\circ}$ anel, essas pressões de contato rugoso, agindo durante uma parcela considerável do curso, provocam um desgaste previsto sensivelmente maior que o do $1^{\circ}$ anel. A fig. 5.50 mostra a evolução do perfil desgastado do anel de óleo. 


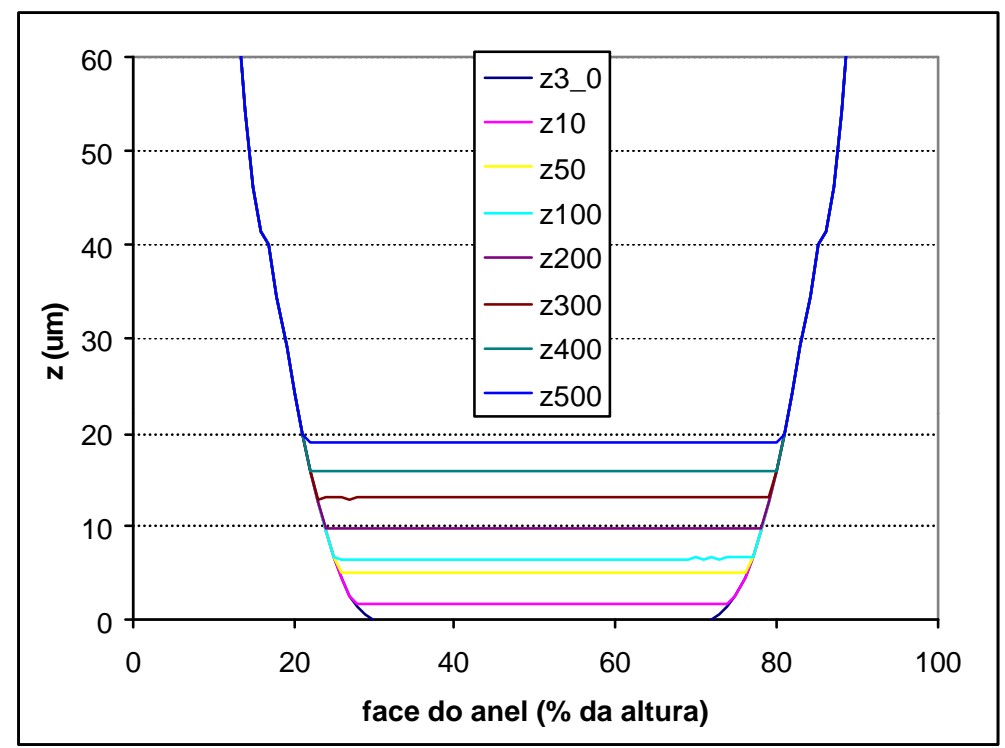

Fig.5.50- Evolução do perfil desgastado do anel de óleo.

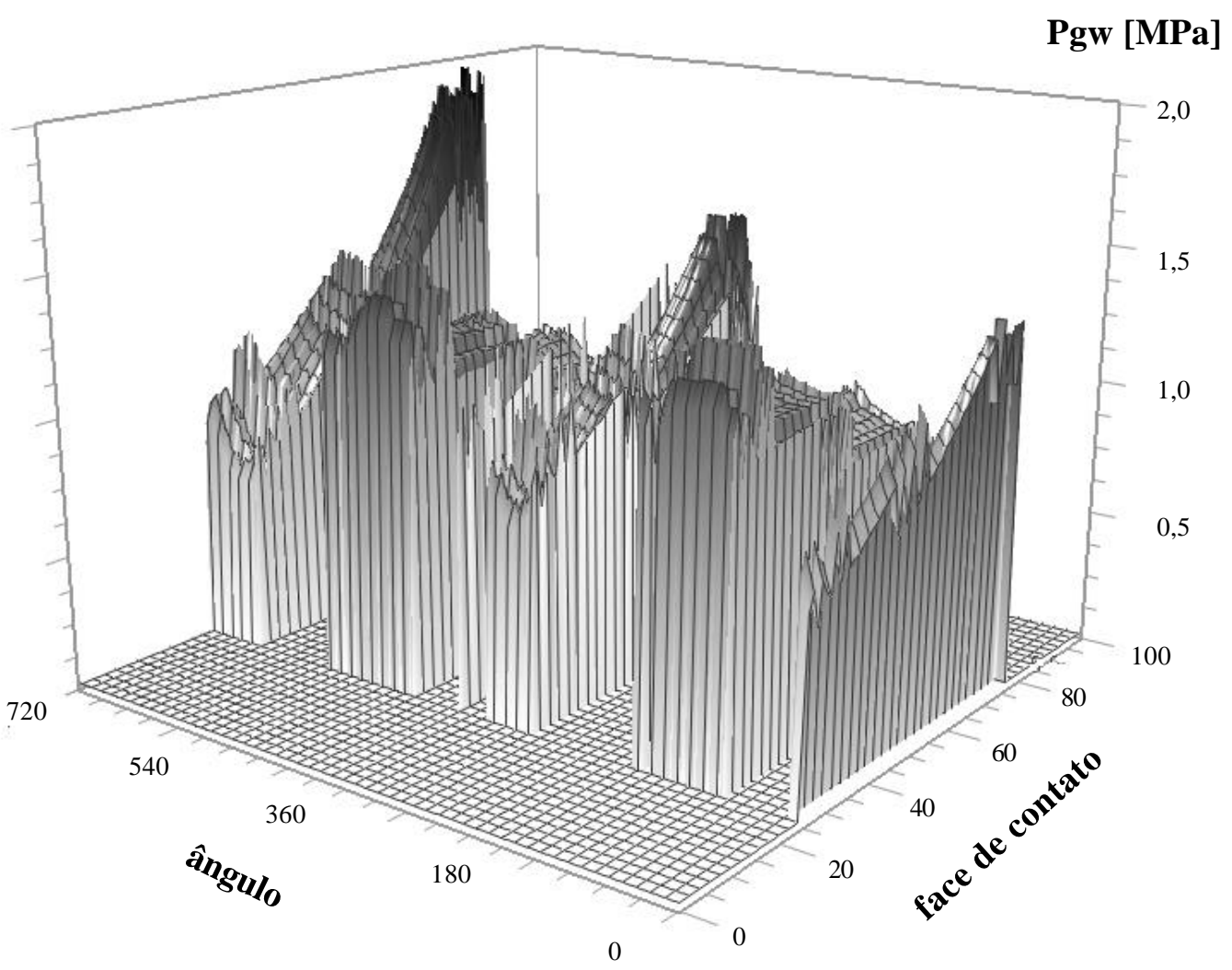

Fig.5.51- Pressões de contato rugoso, anel de óleo após 100 interações, posição TS. 


\subsection{4- Cilindro}

Em virtude de sua maior área, o desgaste radial do cilindro é significativamente menor que a dos anéis. A fig.5.2 mostra a evolução do desgaste previsto para o cilindro; o máximo desgaste radial é cerca de 2 : m e acontece próximo ao PMS do $1^{\circ}$ anel; no restante do cilindro o desgaste previsto é bem menor, praticamente zerando no meio do curso, voltando a aumentar na região de PMI dos anéis.

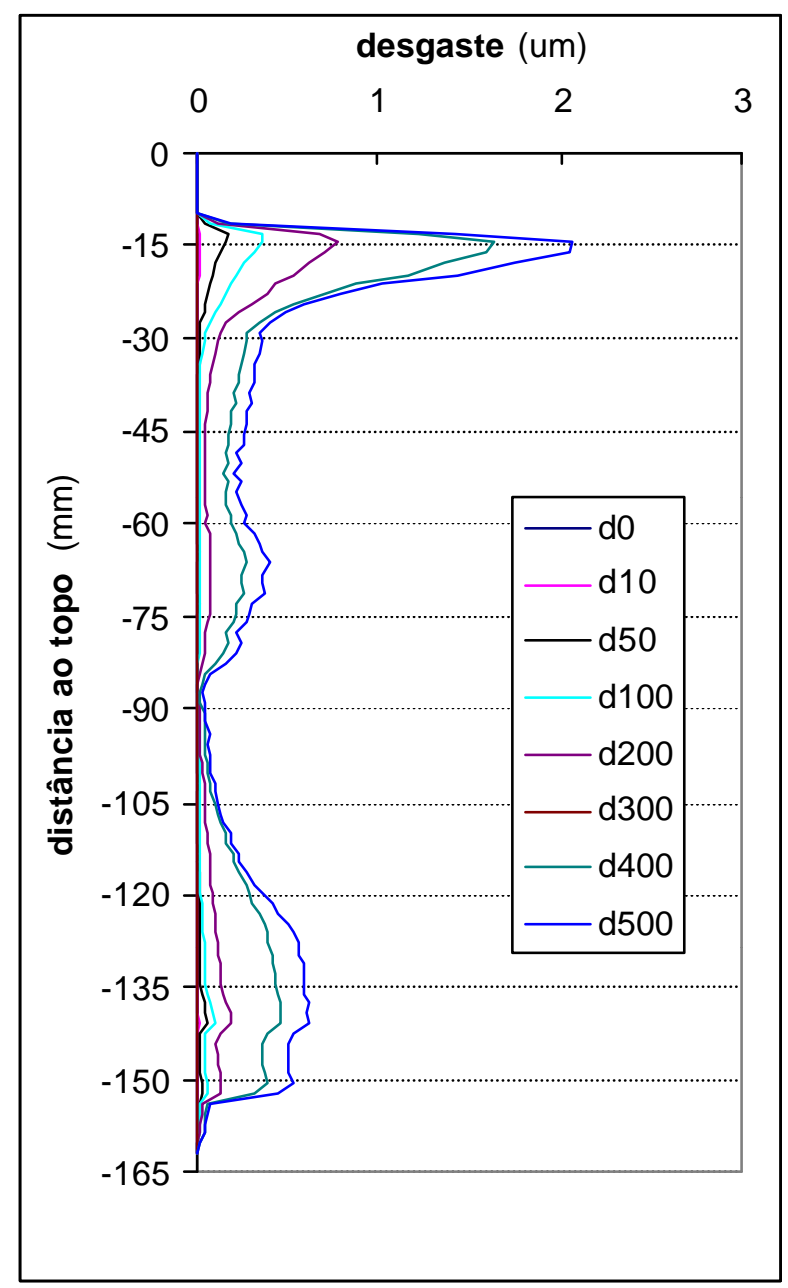

Fig.5.52- Evolução do desgaste radial previsto para o cilindro. 


\section{6- DISCUSSÃO DOS RESULTADOS}

A formação do perfil desgastado da face de contato do anel de $1^{\circ}$ canalete foi prevista com razoável precisão; a fig. 6.1 compara os valores previstos com os obtidos no ensaio. A inclinação prevista para o perfil cônico resultante foi de $0,14^{\circ}$, comparável ao valor experimental de $0,19^{\circ} \pm 0,06$ (vide tabela 5.4).
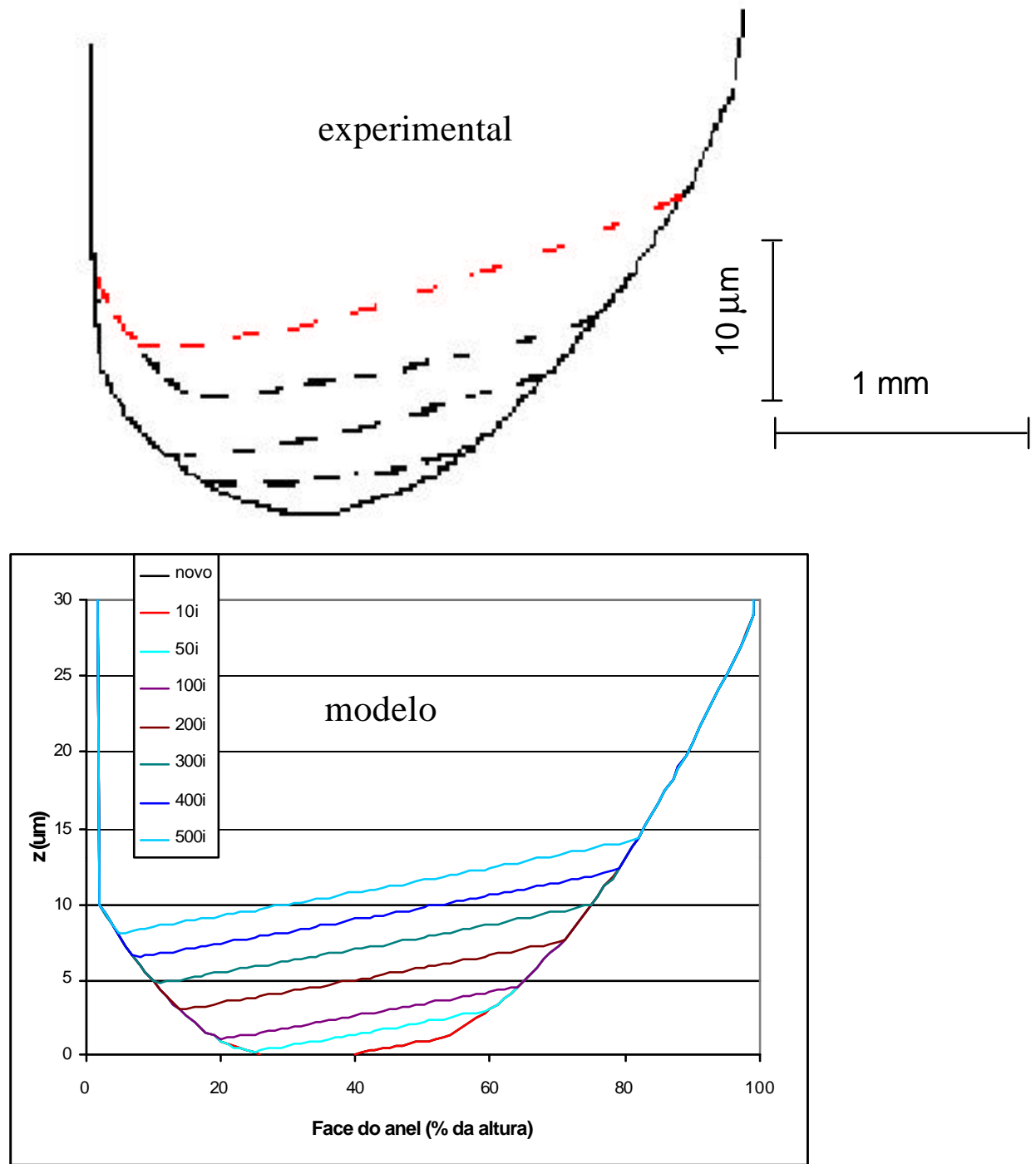

Fig.6.1- Evolução do perfil da face de contato do $1^{\circ}$ anel obtida experimentalmente e prevista pelo modelo. 
O deslocamento do contato para a região superior do anel também foi bem reproduzida pelo modelo. Tal deslocamento é provocado pelas deformações térmicas do pistão, que inclinam o canalete; no caso estudado (motor diesel, regime de plena carga) efeitos de desgaste do canalete e inclinação do anel foram insignificantes na determinação do perfil do $1^{\circ}$ anel. Mas, diferentemente do verificado experimentalmente, o ângulo previsto pelo modelo assume um valor constante desde as $1^{\text {as }}$ interações, enquanto que a parte desgastada do anel apresentava uma inclinação bem menor na $1^{\mathrm{a}}$ desmontagem do ensaio $(100 \mathrm{~h})$. Lembrando que nenhuma tentativa foi feita para prever-se o valor exato de remoção de material, vale a pena comparar a evolução da taxa de desgaste radial prevista com a real; para tanto foi arbitrado corresponder o valor de desgaste obtido após 500 interações com o verificado após 750 horas de ensaio, conforme mostrado na fig.6.2. Enquanto que a taxa prevista de desgaste radial é praticamente constante desde o início, a taxa real foi relativamente maior até 250 horas. A maior taxa relativa prevista pelo modelo para o final do processo, possivelmente está relacionada à menor sustentação hidrodinâmica, que o perfil desgastado calculado apresenta em relação ao experimental. Outro possível efeito é a modificação de rugosidade admitida no modelo, cujo valor limite (0,1 : m, após “amaciamento") permaneceu superior ao medido.

No caso estudado, o perfil de desgaste previsto pelo modelo foi pouco sensível a introdução de rotação no anel. Isso provavelmente é devido ao fato de que o pistão considerado tem pouca variação de inclinação no intervalo próximo aos $360^{\circ}$ do virabrequim (vide fig. 5.17), onde ocorre a maior parte do desgaste do $1^{\circ}$ anel e seu perfil é definido. Num pistão, ou condição de operação do motor, que apresentasse uma alteração de inclinação nessa região, a rotação do anel produziria um perfil mais arredondado. 
Outras causas, para o arredondamento do perfil, não abordadas pelo modelo, podem incluir algum desgaste abrasivo pelas próprias partículas de desgaste, e o fato de que as condições de funcionamento durante o ensaio sempre apresentam alguma variação aleatória em torno de valores médios, enquanto que o modelo considerado foi determinístico.

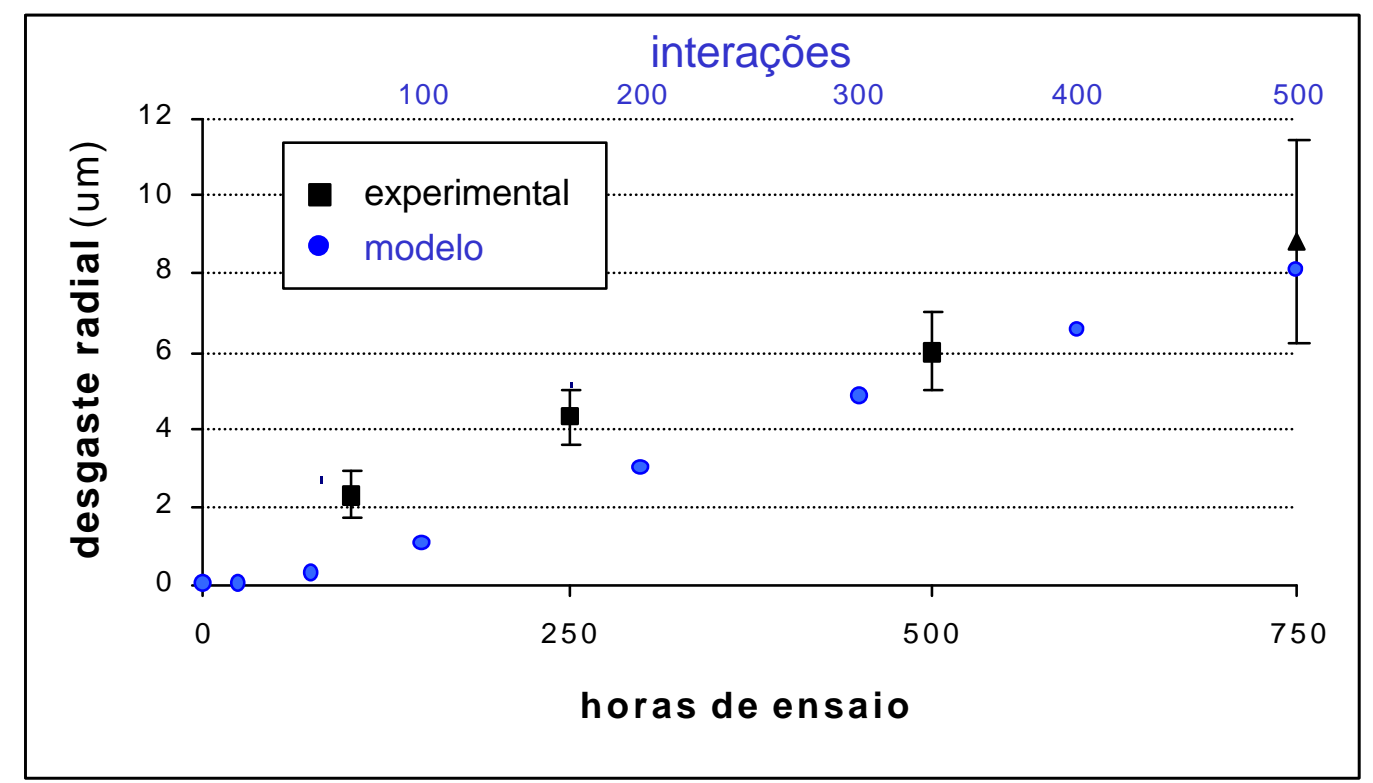

Fig.6.2- Comparação da taxa de desgaste radial prevista pelo modelo com a obtida experimentalmente. 
Mesmo sujeitos à cargas menores que o $1^{\circ}$ anel, o modelo previu um maior desgaste radial para os anéis de $2^{\circ}$ canalete e de óleo (vide fig.6.3). Esse maior desgaste foi também observado no ensaio, embora com razões maiores que as previstas (vide tabela 6.1).

\begin{tabular}{|c|c|c|c|c|}
\hline \multicolumn{4}{|c|}{ Tabela 6.1- Desgaste radial (: $\mathrm{m}$ ) dos anéis após 750 horas } \\
\hline & \multicolumn{2}{|c|}{ experimental } & \multicolumn{2}{c|}{ previsto } \\
\hline anel & ) radial & razão com \\
o $1^{\text {o }}$ anel & ) radial & $\begin{array}{c}\text { razão com } \\
\text { o } 1^{\text {o }} \text { anel }\end{array}$ \\
\hline $2^{\text {o }}$ anel & 18 & 2,0 & 10,7 & 1,3 \\
\hline anel de óleo & 43 & 4,8 & 19,1 & 2,4 \\
\hline
\end{tabular}

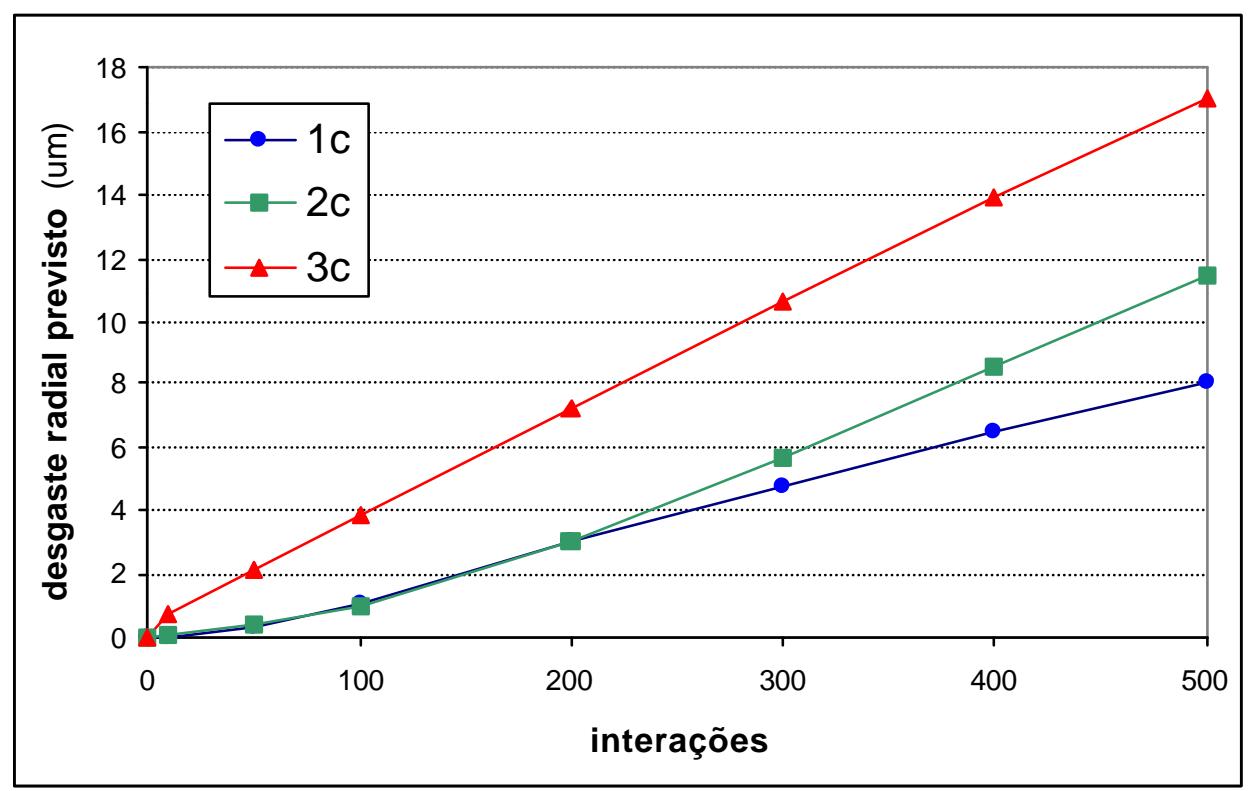

Fig.6.3- Desgaste radial previsto para o pacote de anéis. 
O desgaste previsto para o cilindro corresponde qualitativamente ao verificado no ensaio, embora os baixos valores não permitam uma determinaçào experimental precisa. No entanto, quando se avalia o perfil de rugosidade inicial do cilindro (fig.5.9) e os perfis após $750 \mathrm{~h}$ (fig.5.29) observa-se que os valores previstos de desgaste para o cilindro são bastante representativos. Vale lembrar também que o cilindro é desgastado pelo contato com o pistão, o que deve explicar as áreas espelhadas fora da região do PMS do $1^{\circ}$ anel (vide fig.5.28), o efeito do pistão não é considerado no modelo.

Para efeito desta discussão foi simulado um caso, idêntico ao do capítulo 5, mas sem endurecimento do cilindro na região de PMS. A fig. 6.4 compara o desgaste previsto para o cilindro nos 2 casos. O modelo previu que um cilindro não endurecido teria desgaste cerca de duas vezes maior na região do PMS, o que justifica a adoção desse tratamento térmico, pelo menos no caso estudado.

O desgaste reduz as pressões de contato rugoso, embora podendo gerar perfis hidrodinâmicamente inadequados; o modelo prevê que o anel de $2^{\circ}$ canalete tem sua taxa de desgaste aumentada após 200 interações, uma vez que o perfil desgastado cônico do anel afeta as pressões de contato rugoso. A previsão das pressões de contato rugoso durante a vida do motor podem ajudar muito no estudo do scuffing, embora isto não tenha sido tentado no presente trabalho. 


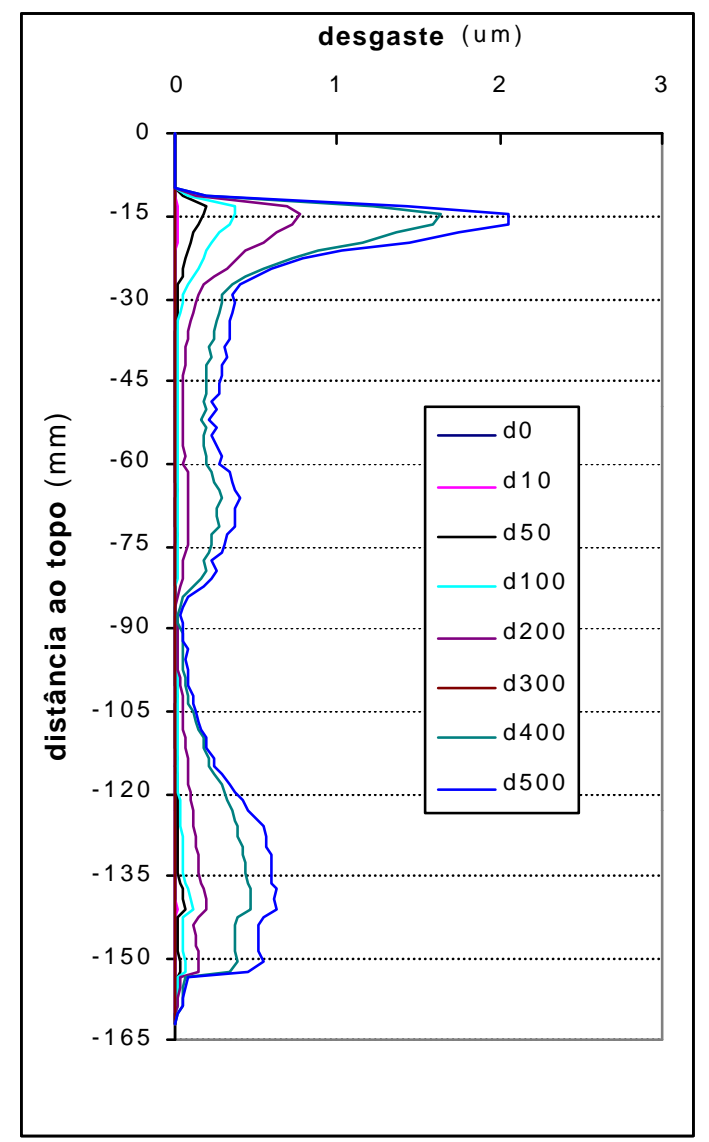

Cilindro endurecido no PMS

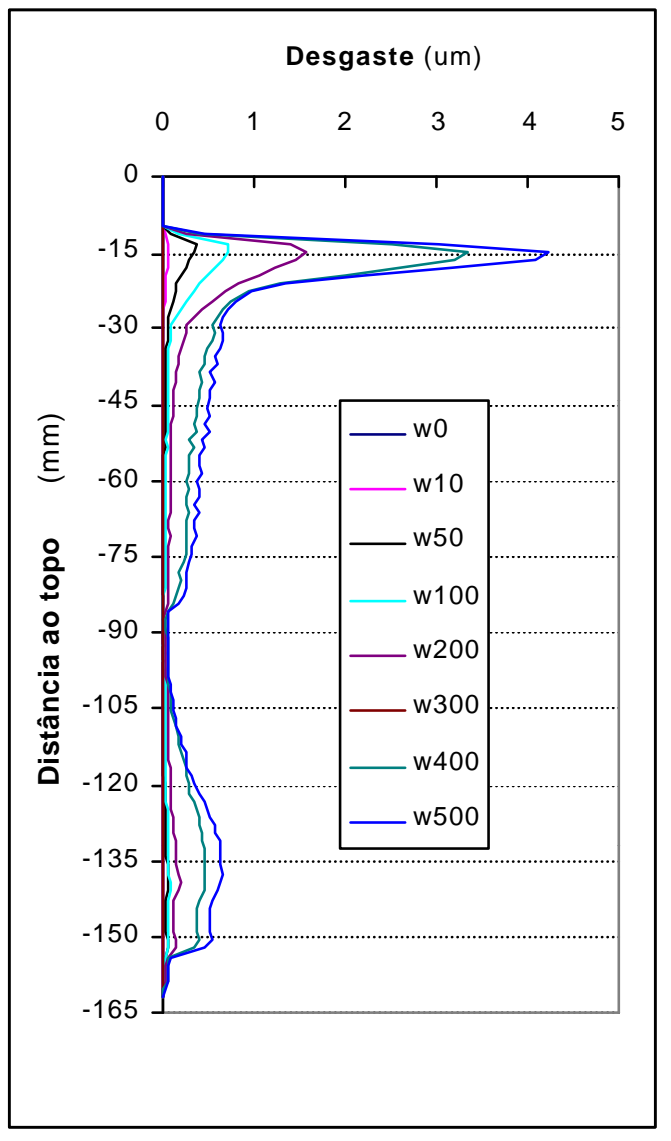

Dureza superficial constante

Fig.6.4- Valores previstos de desgaste radial, para o cilindro endurecido a região do PM versus um com dureza superficial constante.

Embora macroscópicamente reproduzindo de maneira geral a evolução do perfil desgastado do anel, pelo menos três grandes limitações são observadas no modelo desenvolvido: 1- sob ação das altas pressões de contato rugoso previstas, as propriedades microscópicas tanto das superfícies em contato, quanto do lubrificante devem ter importância considerável. O papel tribológico dos filmes de óxido superficiais, dos aditivos EP (Extrema Pressão) do lubrificante, das partículas duras presentes na matriz dos materiais etc., não são considerados pelo modelo.

2- é improvável que ocorram diferenças tão significativas de espessura de filme de óleo, entre 
as posições TS e ATS do anel, como as previstas pelo modelo. O maior desgaste no lado com menor espessura de filme de óleo e a rotação do anel tenderiam a produzir um sistema mais uniforme do que o previsto pelo modelo.

3- o modelo foi incapaz de prever bordas arredondadas na superfície deslizante, como as usualmente verificadas em anéis, mas também em outras peças deslizantes em geral.

Quanto à $1^{\mathrm{a}}$ limitação, parece ao autor que o Estado da Arte e os recursos computacionais disponíveis ainda não permitem o desenvolvimento de um modelo que considere tanto os aspectos macroscópicos quanto os que ocorrem a nível praticamente molecular para um sistema mecânico complexo quanto o de anéis de pistão em funcionamento, pelo menos não sem o trabalho de uma grande equipe multi-disciplinar. Quanto às outras duas limitações, ambas parecem ser oriundas de simplificações do modelo que serão discutidas a seguir: - o modelo considera que o motor funciona exclusivamente num determinado regime, o que na prática não acontece. O funcionamento do motor é interrompido e partido periodicamente; a maioria dos ensaios é cíclico, etc., de modo que a inclinação que o anel faz contra a parede do cilindro se altera com essas mudanças de regime o que levaria a formação de perfis diferentes. O perfil final é o resultado de diferentes inclinações, e portanto mais arredondado, com bordas menos pronunciadas que as previstas pelo modelo. Esse perfil mais “arredondado" é menos sensível às diferentes posições em relação ao plano do pino, como previsto por exemplo para o anel quando novo. Para investigar o funcionamento em condições variadas de operação, simulou-se um caso fictício e de certo modo artificial, onde a cada 10 interações, uma tinha o ângulo de inclinação do canalete zerado no momento da combustão, partindo e retornando suavemente ao seu valor original $\left(0,30^{\circ}\right)$ ao longo dos $720^{\circ}$ de virabrequim da interação. A fig. 6.5 compara o perfil desgastado do $1^{\circ}$ anel, após 500 interações para esse caso fictício com o previsto no capítulo 5. A variação da inclinação 
do canalete produziu um perfil mais parecido com o verificado no ensaio, com um patamar próximo à borda inferior. Esse novo perfil é menos sensível às posições de TS e ATS, produzindo espessuras de filme mais uniformes (vide fig.6.6) do que o perfil desgastado sob regime constante (vide fig.5.39). 


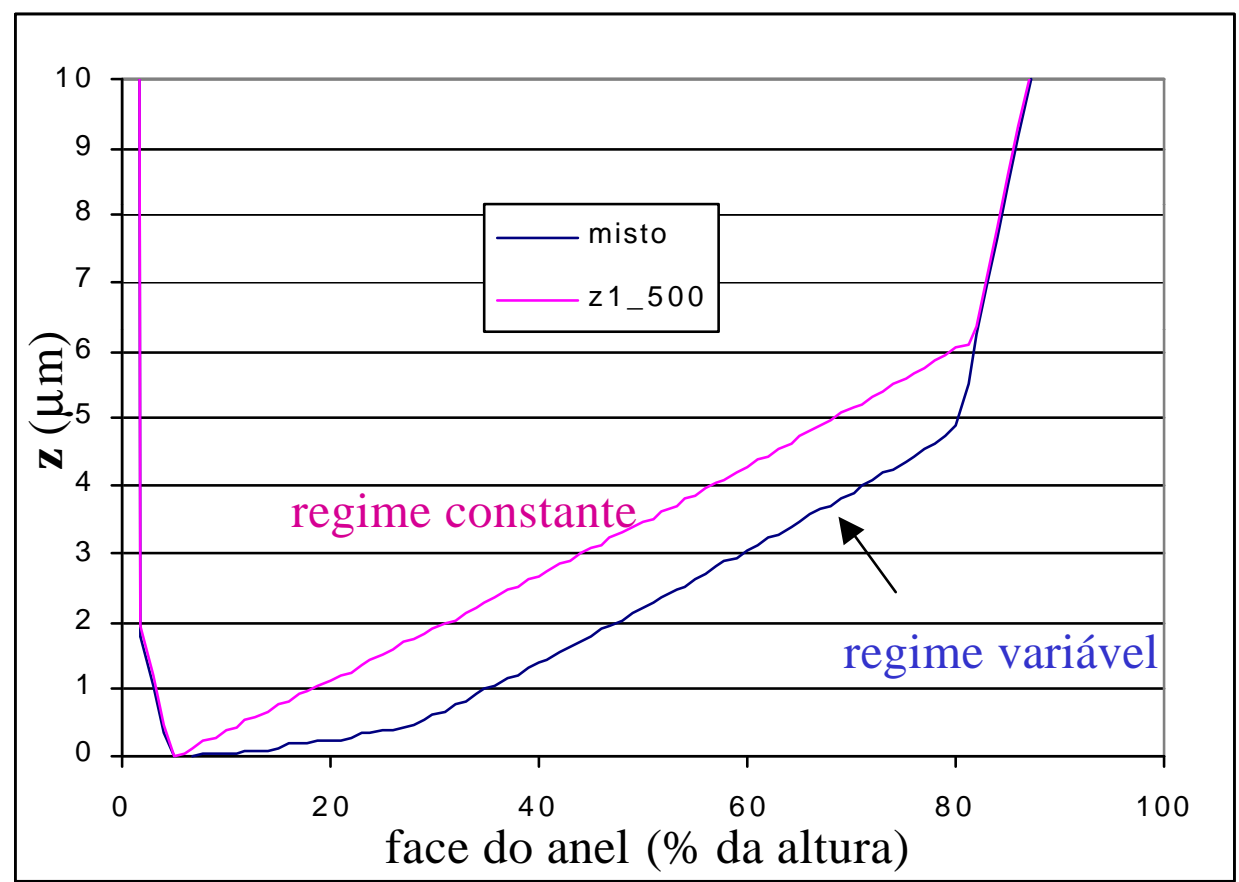

Fig.6.5- Comparação do perfil desgastado do $1^{\circ}$ anel, após 500 interações, regime constante e regime variável de operação.

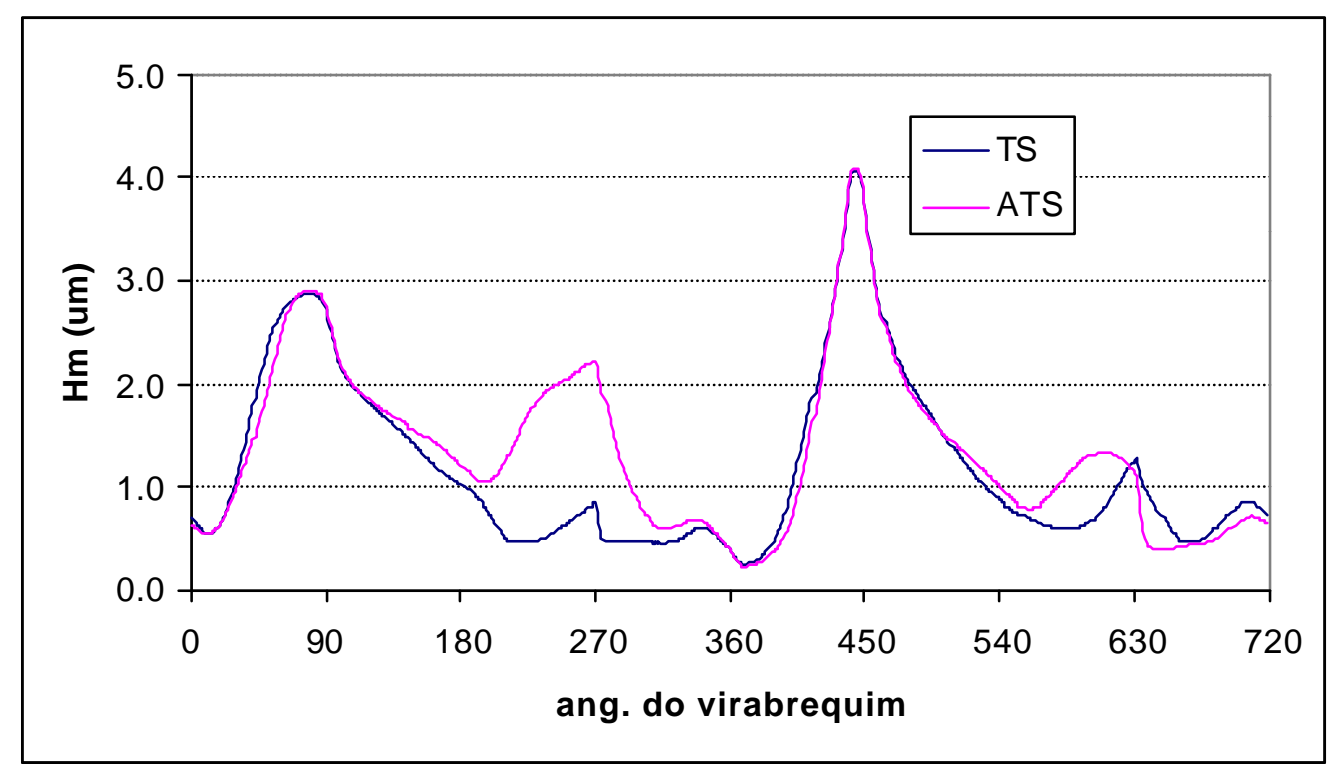

Fig.6.6- Espessura de filme de óleo, entre o $1^{\circ}$ anel e a parede do cilindro, perfil desgastado sob regime variável, após 500 interações. 


\section{7- CONCLUSÕES E SUGESTÕES PARA TRABALHOS FUTUROS}

1- O modelo desenvolvido contribui de maneira significativa para uma melhor compreensão do fenômeno de desgaste em anéis de pistão. Apesar da complexidade do fenômeno, foi possível modelar os aspectos fundamentais de carregamento, sustentação hidrodinâmica e contato rugoso, os quais permitem entender o desgaste tanto ao longo de um ciclo do motor, como ao longo da vida útil dos anéis. O modelo pode ser estendido, sem grandes dificuldades, para outras superfícies deslizantes.

2- O modelo de Greenwood-Williamson, acoplado à programa de simulação de anéis, foi capaz de prever com razoável precisão a evolução do perfil desgastado do anel de $1^{\circ}$ canalete. Os valores previstos de desgaste radial para os demais anéis do pacote e para o cilindro também corresponderam razoavelmente aos valores obtidos experimentalmente.

3- O perfil desgastado do $1^{\circ}$ anel é definido principalmente pela geometria instantânea do anel / cilindro. Essa geometria, por sua vez, é determinada fundamentalmente pela inclinação do canalete devido às deformações térmicas e mecânicas. No caso estudado, os efeitos de desgaste no canalete, inclinação do anel etc., não foram significativos.

4- A compreensão da distribuição de pressões de contato e distribuição de danos na face do anel ao longo do curso do pistão, abre a possibilidade para otimizações, via simulação numérica, do projeto do anel. Perfis visando uma maior durabilidade e menor suscetibilidade à falhas como scuffing podem ser investigados. 
Como sugestões de trabalhos futuros podemos mencionar:

1- A utilização do modelo desenvolvido em diferentes condições de operação de motores, não só para melhor avaliar o potencial do modelo como também para otimizar o projeto de anéis / pistão.

2- O equacionamento e inclusão no modelo de sustentação hidrodinâmica, do efeito de redução de densidade e viscosidade do óleo devido o aumento de temperatura ("thermal wedge"). Para filmes lubrificantes tão finos como os calculados e submetidos a altas razões de cisalhamento, esse efeito pode ser significativo. Sua inclusão poderia permitir uma predição mais realista das condições tribológicas dos anéis. Da mesma maneira, o efeito da redução de viscosidade devido altas razões de cisalhamento ("shear thinning") precisaria ser considerado, especialmente para o anel de óleo que opera com filmes de lubrificante muito finos, mesmo nos pontos de máxima velocidade.

3- Uma melhor caracterização da superfície rugosa, seja através da obtenção experimental dos dados de entrada do modelo de Greenwood, seja pelo desenvolvimento de metodologias que diferenciem os "picos" dos "vales" de uma superfície rugosa, utilizando parâmetros como Rpk e Rvk, de modo a eventualmente distinguir a espessura do filme para efeitos hidrodinâmicos, da espessura para efeitos de contato rugoso.

4- A obtenção de valores experimentais, através de ensaios em bancada, do coeficiente de desgaste da equação de Archard, para as diferentes condições tribológicas encontradas ao longo do curso do pistão, permitiria não só validar o modelo desenvolvido, mas também predizer as taxas de desgaste esperadas no motor. Isso possibilitaria, por exemplo, prever a 
variação esperada de desgaste com o aumento da potência do motor ou de sua temperatura de funcionamento.

5- A inclusão no modelo da distribuição dos valores calculados, através de abordagens estatísticas como as citadas em McCOOL (1988), por exemplo, possibilitaria a investigação das pressões de contato extremas, que são relevantes na ocorrência de falhas em operação.

6- A predição do aumento local de temperatura (“Flash temperature”) pelo deslizamento com contato rugoso e de sua influência no óleo lubrificante (redução/aumento da viscosidade, degradação devido oxidação etc.) e na superfície (dilatação térmica da aspereza, oxidação etc.), poderia ajudar a esclarecer a ocorrência de scuffing. 


\section{8- REFERÊNCIAS}

Arcoumanis, C.; Ostovar, P.; Mortier, R. "Mixed lubrication Modelling of Newtonian and Shear Thinning Liquids in a Piston-Ring Configuration”. paper SAE 972924, 1997

Aue, G.K. - "Piston Ring Scuffing - General Review". Piston Ring Scuffing Conference, ImechE, 1975

Barber,G.C.; Ludema,K.C. "The break-in stage of cylinder-ring wear: a correlation between fired engines and a laboratory simulator". Wear, v.118, p.57-75, 1987

Becker, Edward P. “An empirical Model of Cylinder Bore wear developed by Simulation”. PHD Thesis, Univ. of Michigan, 1998

Behrens, R. “Corrosion in Heavy Fuel Diesel Engines” MTZ v.49(1988) p.479-485

Bin, Feng “An experimental and Analytical study of scuffing in Al based metal matrix composites". PHD Dissertation, Wayne State University, Detroit, Michigan, 1998

Booser, E. R. "CRC Handbook of Lubrication - Vol. II - Theory \& Design" CRC Press, 1984

Bulatov, V. P.; Vedernikovo, D. “On The Influence Of Fatigue On Machine Part Wear”. Wear, v.170, p.167-72, 1993

Demarchi, V. "Estudo de Materiais, Geometria e Compatibilidade dos Tribossistemas em Anéis de Pistão para Motores de Combustão Interna”. Dissertação de Mestrado, Escola Politécnica da Universidade de São Paulo, 1994

Finkin, E.F. “An Explanation of the Wear of Metals" Wear, v.47, p.107-117, 1978

Fritz, S.G.; Cataldi, G.R. "In situ piston ring wear mesurements in a Medium-Speed Diesel Engine" J.S.T.L.E. Lubrication Engineering, June 1990, p.365-370, 1990

Frolund, K.; Schramm J. "Simulation of HC-Emissions from SI-Engines - A Parametric Study" paper SAE 972893, 1997

Furuhama, S.; Hiruma, M. "The relationship between piston ring scuffing and the formation of surface profile" s.ed. 1975.

Furuhama, S. et al "An Increase of Engine Oil Consumption at High Temperature of Piston and Cylinder" paper SAE 810976, 1981

Furuhama, S. et al. "Primary cause for abnormal wear in diesel engines with EGR systems". Tribol-Trans. v.34 n.1 Jan 1991, p.86-92, 1991. 
Gautam, M. et al. "Contribution of Soot contamined oils to wear". Paper SAE 981406, 1998

Greenwood, J.A.; Williamson, J. "Contact of nominally flat surfaces". Proc. R. Soc. London, Series A, v.295, p.300-319, 1966

Greenwood, J.A.; Tripp, J.H. "The Contact of Two Nominally Flat Rough Surfaces". Proc Inst Mech Engrs 1970-71 v.185, n.48, p.625-633 , 1970

Gulwadi, S.D. "Analysis of Lubrication, Friction, Blow-by and Oil Consumption in a Piston Ring Pack”. ASME-ICE Division, Spring Conference. Fort Collins, Colorado,E.U.A, 1997.

Halling, J. "A contribution to the Theory of Mechanical Wear" Wear v.34, p.239-249, 1975

Halling,J.; Arnell,R. “Ceramics Coatings in the War on Wear" Wear v.100, p.367-380, 1984

Hannoschock, N. - "On the Piston Ring Tribology" MTZ v.46, p.503-511, 1985

Hill, S. et al. "Bench Wear testing of common gasoline engine cylinder bore surface/piston ring combinations". STLE - Tribology Transations v.39, 4, p.929-935, 1996

$\mathrm{Hu}$, Y. et al. "Numerical Simulation of Piston Ring in Mixed Lubrication- A Nonaxisymetrical Analysis". Trans. of the ASME v.116, July 1994, p.470-478, 1994

Hutchings, I.M. “Tribology: Friction and Wear of Engineering Materials". Edward Arnold Londres, 1992

Ishiki, K. et al "A Study of Abnormal Wear in Power Cylinder of Diesel Engine with EGR - Wear Mechanism of Soot Contaminated in Lubricating Oil". paper SAE 2000-01-0925, 2000

Ishizuki et al. "Effects of Cylinder Liner Wear on Oil Consumption in Heavy Duty Diesel engines". paper SAE 810931, 1981

Johnson,K.L.; Greenwood,J.A.; Poon,S.Y. “A Simple Theory of Asperity Contact in Elastoydrodynamic Lubrication” Wear v.19 p.91-108, 1972

Karmakar, S.; Rao,U.; Sethuramiah,A. "An approach towards fatigue wear modelling”. Wear v.198, p.242-250, 1996

Keribar, R., Dursunkaya Z., Ganapathy, V. “An Integrated Predictive Design Analysis Methodology to Address Piston Tribological Issues”. paper SAE 930793, 1993

Kimura, Y.; Sugimura, J. - "Microgeometry of Sliding Surfaces and Wear Particles in Lubricated Contact". Wear v.100, p.33-45, 1984 
Kim,K.; Ludema,K. "A Correlation Between Low Cycle Fatigue Properties and Scuffing Properties of 4340 Steel”. ASME Trans., J. of Tribology, v.117, p.617-621, 1995

Koch, F. "A new technique for measuring the deformation of cylinder bores during engine operation" paper SAE 950540, 1995

Knopf, M. et al. "Calculation of Unsteady Hydrodynamic Lubrication and Surface Contact at the Piston-ring/cylinder-liner Interface”. Paper SAE 981402, 1998

Knowland, C.; Russel, C. "Predictive Optimization of Piston and Ring Stability". paper SAE 960873, 1996

Kodali, P.; How, P.; D McNulty, W. "Methods of Improving Cylinder Liner Wear"- paper SAE 2000-01-0926 2000

Kornprobst; Woschni \& Zeilinger "Simulation des Kolbenring-Verhaltens im Motorbetrieb-Teil 1". MTZ, Nov.1989, 1989

Ludema, K. "A Review of Scuffing and Running-in of Lubricated Surfaces, with Asperities and Oxides in Perspective". Wear v.100, p.315-331, 1984

Ludema, K. "Friction, Wear, Lubrication - A Textbook in Tribology". CRC Press. Boca Raton, 1996

McCool, J.I. "Comparison of models for the contact of rough surfaces". Wear, v.107, 1986

McCool, J.I. "The Distribution of Microcontact Area, Load, Pressure, and Flash Temperature under the Greenwood-Williamson Model”. Trans. of the ASME, v.110, p.106-111, 1988

Meng, H.C.; Ludema, K.C. - "Wear models and predictive equations: their form and content" Wear v.181-183 (1995), p.443-457, 1995

Michalski, J.; Pawlus, P. "Effects of Metallurgical structure and cylinder surface topography on the wear of piston ring-cylinder assemblies under artificially increased dustiness conditions" Wear v.179 (1994), p.109-115, 1994

Mihara, K.; Inoue, H. "Effect of Piston Top Ring Design on Oil Consumption". paper SAE 950937, 1995

Nigro, E.B. "Metodologia de aplicação de forças para análise dinâmica estrutural de motores de combustão interna” Dissertação de Mestrado, Escola Politécnica da Universidade de São Paulo, 1999

Pawlus, Pawel "Method of measuring 'zero-wear' of the cylinder liner". TriboTest. v.5, n.1 Sep.1998, p.53-70, 1998 
Pint, S.; Schock, H. "Design and Development of a Software Module for Analysis of Three Dimensional Piston Ring Wear". paper SAE 2000-01-0920

Priest, M. et al. "Predictive wear modelling of lubricated piston rings in a diesel engine" Wear v.231, p.89-101, 1999

Rabinowicz,E. “The Least Wear”. Wear v.100, p.533-541, 1984

Richardson, D.; Krause, S. "Predicted Effects of Cylinder Kit Wear on Blow-by and Oil Consumption for two Diesel Engines". Proc. of the 3rd Ricardo Software International Conference, Detroit, E.U.A., 1998

Rosen,B.-G,; Ohlsson,R.; Thomas,T.R. "Wear of cylinder bore microtopography". Wear v. 198 (1996), p.271-279, 1996

Ruddy, B. Et al. "Piston Ring Lubrication - Part III -The Influence of Ring Dynamics and Ring Twist" - 'Energy Conservation' through fluid film lubrication Technology: Frontiers in Research and Design, 1979, p.91-217 (ASME, New York)

Ruddy, B. et al. "The influence of running-in of the twin-land type of oil control Piston Ring". Leeds/Lyon Symposium on Tribology, p.162-169, 1982

Schneider, E. et al. "Effect of Speed and Power Output on Piston Ring Wear in a Diesel Engine" paper SAE 880672, 1988

Shuster M. et al. "Piston Ring Cylinder Liner Scuffing Phenomenom: Investigation, Simulation and Prevention" paper SAE 1999-01-1219, 1999a

Shuster, M. et al. "Metallurgical and Metrological Examinations of the Cylinder Liner-Piston Ring Surfaces After Heavy Duty Diesel Engine Testing”Tribology Transactions v.42 (1999), 1, p.116-125. 1999 b

Stecher, F. "Survey and State of the Art of Friction and Wear in Regard to Piston Rings" Publicação da firma GOETZE AG, década de 80, (s.d.)

Suh, N. "The delamination theory of wear" Wear v.25, p.111-124. 1973

Taylor, R. et al. "The Influence of Lubricant Rheology on Friction in the Piston Ring-Pack" paper SAE 941981,1994

Thom, R. et al. "Extended Oil Drain Intervals: Conservation of Resources or Reduction of Engine Life". paper SAE 951035,1995

Tian, T. et al. "Effects of Piston-Ring Dynamics on Ring/groove Wear and Oil Consumption in a Diesel Engine”. paper SAE 970835, 1997a 
Tian T. "Modeling the Performance of the Piston Ring-Pack in Internal Combustion Engines". PHD dissertation. MIT, 1997b

Ting, L.L. “Lubricated Piston Ring \& Cylinder Bore Wear”. Wear Control Handbook. M.B. Peterson; W.O. Winer. ASME. p.609-665, 1980

Tomanik, E. "Simulação do Movimento Axial dos Anéis de Pistão". Dissertação de mestrado, 80 p. Escola Politécnica, Universidade de São Paulo, 1993

Tomanik, E.; Galvano, M. "PVD Duplex Coatings - Summary of Activities”. I Workshop "Desafios e Experiências em Tratamentos de Superfície Visando Resistência ao Desgaste Uma Abordagem Cooperativa”. Escola Politécnica, Univ. de São Paulo, 1998

Truhan-J.; Covington, C.B. "The use of Direct Method Surface Layer Activation to measure ring wear in Diesel engine". paper SAE 931627, 1993

Urabe, M. et al. "Variation of Piston Friction Force and Ring Lubricating Condition in a Diesel Engine with EGR”. paper SAE 982660, 1998

Ushijima, K. et al. "A Study on Engine Bearing Wear and Fatigue Using EHL Analysis And Experimental Analysis". paper SAE 1999-01-1514, 1999

Vatavuk, J. "Mecanismos de desgaste em anéis de pistão e cilindros de motores de combustão interna". Tese (Doutorado), Escola Politécnica - Universidade de São Paulo, 1994

Whitehouse, David J. "Handbook of Surface Metrology” Institute of of Physics Publishing 1994

Williams, J.A. "Engineering Tribology” Oxford University Press, 1994

Yoshida, H. "Effects of surface treatments on Piston Ring friction force and wear". paper SAE 900589, 1990

Yoshida, H. et al. "Diesel Engine Oil Consumption Depending on Piston Ring Design”. paper SAE 911699, 1991

Yoshida, H. et al. "Method to improve scuffing resistance of nitrided rings". paper SAE 973103, 1997

Zottin, W. "Simulação da Dinâmica de Anéis de um Pistão Utilizado em Motores de Combustão Interna”. Dissertação de mestrado, Escola Politécnica - Universidade de São Paulo ,1992 


\section{ANEXO I - COEFICIENTE DE DESGASTE}

Quando duas superfícies em contato deslizam uma sobre a outra, uma delas ou ambas sofrem desgaste. Este tipo de desgaste é usualmente modelado pela chamada equação de Archard. Pela sua importância e pela definição do coeficiente de desgaste $K$, uma explicação mais detalhada é dada neste anexo. A explicação segue em linhas gerais o capítulo 5 do livro texto de HUTCHINGS (1992). O modelo de Archard parte do princípio que o contato entre corpos ocorre onde as asperezas se tocam e que a área real de contato é a soma das áreas individuais de contato entre as asperezas. Esta área é praticamente proporcional à carga aplicada e pode ser admitido que para a maioria dos contatos entre metais a deformação das asperezas é plástica. Admite-se que as asperezas tem formato esférico quando vistas de cima. Assim, quando duas asperezas estão em contato e alinhadas, a carga normal $(\delta W)$ suportada por este contato é:

$$
\delta W=P \cdot \pi \cdot a^{2}
$$

onde $P$ : tensão de escoamento para a aspereza deformada plasticamente $a$ : raio da área de contato

Com o deslizamento entre as duas superfícies, a carga suportada por este contato é transferida progressivamente para o contato entre duas outras asperezas que estão em processo de contato em algum outro lugar da superfície. Com a continuidade do deslizamento, novos contatos são continuamente formados e desfeitos. O desgaste por deslizamento é devido ao destacamento de material destas asperezas. O volume de cada um 
destes destacamentos depende do tamanho da junção entre asperezas da qual este material se originou. Admite-se que o volume de material removido, $\delta V$, em cada arrancamento é proporcional ao cubo do raio de contato $a$, e se admite arbitrariamente que este volume pode ser considerado igual ao de uma semi-esfera de raio $a$. Embora esta última hipótese não implique que as partículas de material removido sejam esféricas.

$$
\delta V=2 \cdot \pi \cdot a^{3} / 3
$$

Nem todos os contatos entre asperezas geram remoção de material. Vamos denominar de $K$ a fração de contatos que geram remoção. Deste modo, a taxa de volume de material removido por unidade de distância, $\delta Q$, entre duas asperezas é dada por:

$$
\delta Q=K . \delta V /(2 . a)=K . \pi \cdot a^{2} / 3
$$

e o volume total é a soma das contribuições sobre toda área real de contato:

$$
Q=\sum \delta Q=K / 3 \sum \pi \cdot a^{2}
$$

a carga total de contato é dada por

$$
W=\sum \delta W=P \sum \pi \cdot a^{2}
$$

Portanto: $Q=K . W /(3 . P)$

Considerando que a pressão $P$ de contato plástico é igual á dureza do material mais mole dividido por aproximadamente 3 temos $^{1}$ :

$$
Q=K \cdot W / H
$$

\footnotetext{
${ }^{1}$ Hutchings considera que $P=H$ e um fator de proporcionalidade $1 / 3$ para chegar na
} mesma equação. 
O coeficiente de desgaste, $K$, é adimensional e sempre menor que 1 . Ele é muito usado por ser simples e por dar uma indicação da severidade do desgaste. Embora no modelo de Archard este coeficiente tenha o significado de ser a fração (ou probabilidade) de contatos entre asperezas removendo material, o coeficiente $K$ pode, e é também entendido com outros significados, por exemplo, o inverso do número de ciclos de deformação necessários para uma partícula ser removida por fadiga. A tabela I.1 fornece os valores típicos do coeficiente de desgaste $K$ para diversos sistemas tribológicos. RABINOWICZ (1984).

\section{Tabela I.1- Valores Típicos do coeficiente de desgaste}

RABINOWICZ, 1984

\begin{tabular}{|c|c|c|c|c|c|c|c|c|}
\hline \multicolumn{3}{|c|}{ adesivo $^{2}$} & \multicolumn{2}{|c|}{ abrasivo } & \multicolumn{2}{|c|}{ corrosivo } & \multicolumn{2}{|c|}{$\begin{array}{l}\text { por fratura de } \\
\text { superfície }\end{array}$} \\
\hline \multicolumn{3}{|c|}{$10^{-3}$ a $10^{-7}$} & \multicolumn{2}{|c|}{$10^{-2}$ a $10^{-5}$} & \multicolumn{2}{|c|}{$10^{-2}$ a $10^{-5}$} & \multicolumn{2}{|c|}{$10^{-4}$ a $10^{-8}$} \\
\hline $\begin{array}{c}\text { Sever } \\
0\end{array}$ & $\begin{array}{c}\text { Moderad } \\
\text { o }\end{array}$ & $\begin{array}{c}\text { Ultra } \\
\text { Moderad } \\
\text { o }\end{array}$ & Severo & $\begin{array}{l}\text { Moderado } \\
\text { (polimento) }\end{array}$ & severo & $\begin{array}{l}\text { lubrif. } \\
\text { sólida }\end{array}$ & $\begin{array}{l}\text { fratura } \\
\text { frágil }\end{array}$ & $\begin{array}{l}\text { fadiga de } \\
\text { contato }\end{array}$ \\
\hline $10^{-3}$ & $10^{-5}$ & $10^{-7}$ & $10^{-2}$ & $10^{-5}$ & $10^{-2}$ & $10^{-5}$ & $10^{-4}$ & $10^{-8}$ \\
\hline
\end{tabular}

${ }^{2}$ Neste caso preferiu-se manter a nomenclatura adotada pelo autor. Ao longo da tese, este tipo de desgaste é denominado "por deslizamento". Rabinowicz denomina o desgaste adesivo ultra moderado de "burnishing" e o caracteriza pela remoção de material em escala molecular. 


\section{ANEXO II - DADOS DE ENTRADA PARA O MODELO DE GREENWOOD}

Tanto o modelo de Greenwood-Williamson (G-W) quanto o de Greenwood-Tripp (G-T) consideram 3 parâmetros para caracterização da superfície rugosa:

F: desvio padrão da distribuição da altura do pico das asperezas [m]

\$: raio médio do pico das asperezas [m]

0: densidade dos picos $\left[\mathrm{m}^{-2}\right]$

Desses, apenas $\mathrm{F}$ pode ser obtido diretamente com rugosímetros comerciais, já que essa é a definição de $\mathrm{Rq}^{3}$. Os outros dois parâmetros são, em geral, admitidos a partir da regra obtida experimentalmente por GREENWOOD \& TRIPP (1971):

$$
0,03<\mathrm{F} . \$ .0<0,05
$$

A tabela II.1 resume os valores de entrada do modelo de G-W ou de G-T encontrados na literatura.

${ }^{3}$ desde que se considere que a linha referência dos picos é a mesma que da superfície como um todo. 


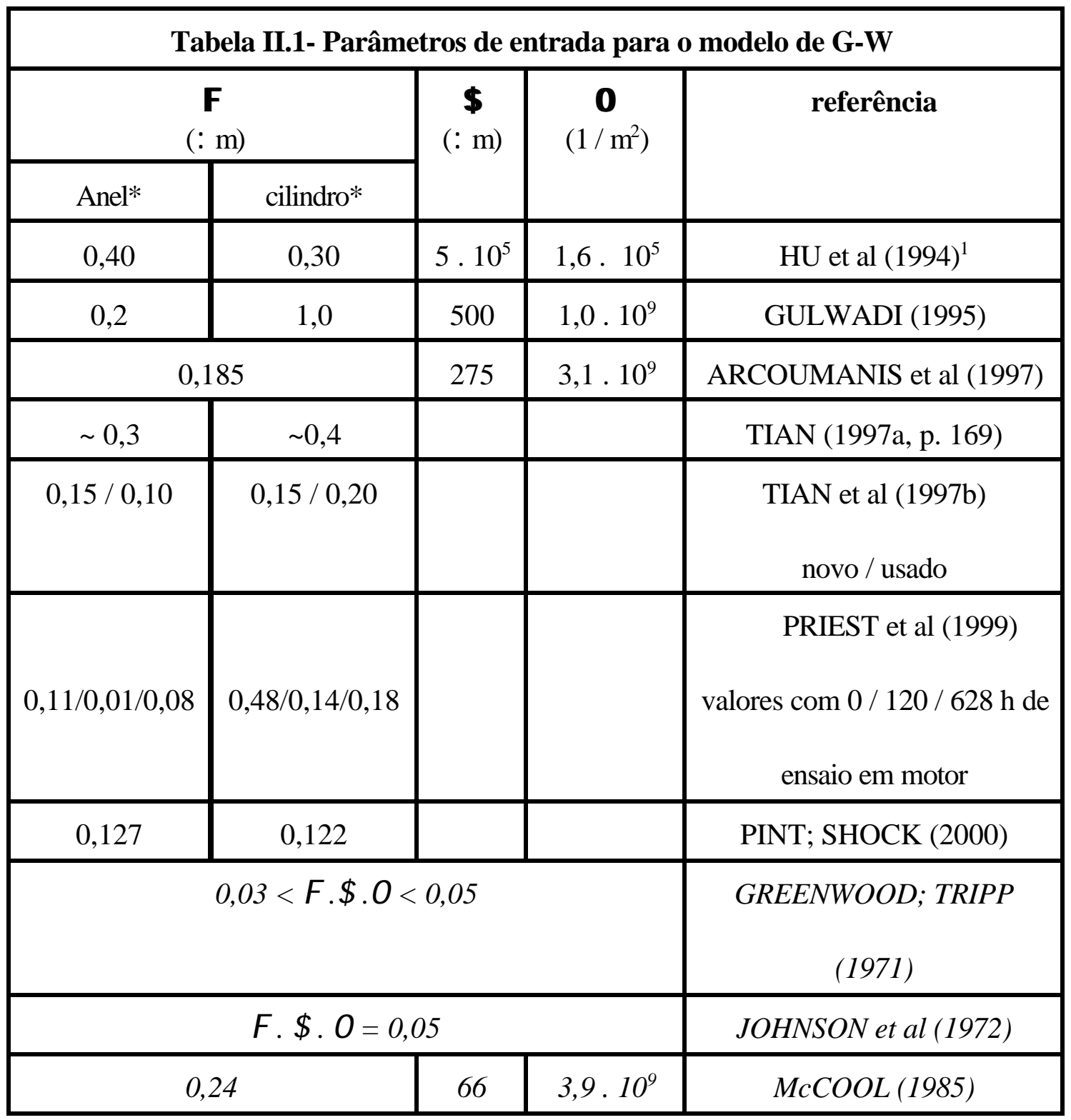

* em itálico, trabalhos não relacionados com anéis.

${ }^{1} \mathrm{HU}$ não explicita os valores de $\$$ e 0 , mas diz que $(F . \$$. 0$)=0,04$ e que $(F / \$)^{1 / 2}=0,001$. Reconhece que obteve valores muito baixos de pressão rugosa. 
A partir das alturas $y$ do perfil de rugosidade, os dados de entrada de G-W podem ser calculados pelas seguintes equações: (McCOOL, 1986):

$$
\begin{gathered}
\sigma_{s}=\sqrt{\left(1-\frac{0,8968}{\alpha}\right) m_{0}} \quad[\mathrm{~m}] \\
\beta=\frac{3 \cdot \sqrt{\pi}}{8 \cdot \sqrt{m_{4}}}
\end{gathered}
$$

onde $m_{0}, m_{2}$ e $m_{4}$ são os chamados momentos espectrais:

$$
\begin{array}{cc}
m_{0}=\text { Média dos }\left(y^{2}\right) \text { do perfil de rugosidade } & {\left[\mathrm{m}^{2}\right]} \\
m_{2}=\text { Média } \operatorname{dos}\left\{(\mathrm{d} y / \mathrm{d} x)^{2}\right\} & {[]} \\
m_{4}=\text { Média } \operatorname{dos}\left\{\left(\mathrm{d}^{2} y / \mathrm{d} x^{2}\right)^{2}\right\} & {\left[\mathrm{m}^{-2}\right]} \\
\mathbf{a}=\frac{\boldsymbol{m}_{\mathbf{a}} \cdot \boldsymbol{m}_{\mathbf{4}}}{\mathbf{m}_{\mathbf{2}}^{\mathbf{2}}} &
\end{array}
$$

O problema é calcular $\mathrm{d} y / \mathrm{d} x$ e principalmente $\left(\mathrm{d}^{2} y / \mathrm{d} x^{2}\right)$, pois como veremos $\mathrm{d} y$ é muito pequeno em relação a dx. Mesmo assim tentativamente se calculou os parâmetros de GW utilizando a metodologia que será descrita mais a frente. 
Anéis e cilindros foram medidos num rugosímetro Perthometer PGK Concept da firma Mahr; o apalpador era do modelo "sem patim" e tinha raio da ponta de $2:$ m. Este equipamento além dos valores de rugosidade, disponibiliza um arquivo com os valores, não filtrados de (x, y). Esse equipamento só foi adquirido após o encerramento do ensaio, assim foram usados peças do mesmo lote de produção como representativos do acabamento superficial quando novo. A tabela II.2 mostra os valores de rugosidade medidos pelo equipamento, a definição ${ }^{1}$ dos parâmetros antecede a tabela.

$-R x=\frac{1}{L} \int_{0}^{I}|z(x)| d x$

$-R q=\sqrt{\frac{1}{L} \int_{0}^{I}\left|z^{2}(x)\right| d x}$

- Rti são os maiores alturas pico-vale dentro de cada comprimento de cut-off analisado

$-R t m=R(D N)=\frac{\left(R t_{1}+R t_{2}+R t_{9}+. . R t_{n}\right)}{n}=\frac{1}{n} \sum_{t=1}^{n} R t_{i}$

- Rz (ISO) é a altura média entre os 5 maiores picos e o 5 mais baixos vales no comprimento medido ("sampling length").

- Densidade é a densidade de picos do perfil na linha média. Um pico de perfil é a maior parte do perfil entre um cruzamento ascendente e descendente do perfil pela linha média.

${ }^{1}$ Anexo "INSTRUMENT THEORY, PARAMETERS AND DEFINITIONS” do equipamento Form Talysurf. 
Rpk, Rk, Rvk é uma família de parâmetros criada ${ }^{1}$ especificamente para caracterização de cilindros de MCI. Os parâmetros são obtidos pela divisão da curva de material em função da profundidade (“Curva tp ou de Abbot”) em três partes. A parte central (Rk) representa 40\% da porcentagem total de distribuição de material( vide fig.II.1) e é considerada a porção que define a durabilidade do cilindro. Essa linha central define o parâmetro Rk ("kernal Roughness Depth"), em micrometros (assim como Rpk e Rvk). A porção superior da curva define Rpk (“Reduced Peak Height”) e a inferior define Rvk (“Reduced Valley Depth”).

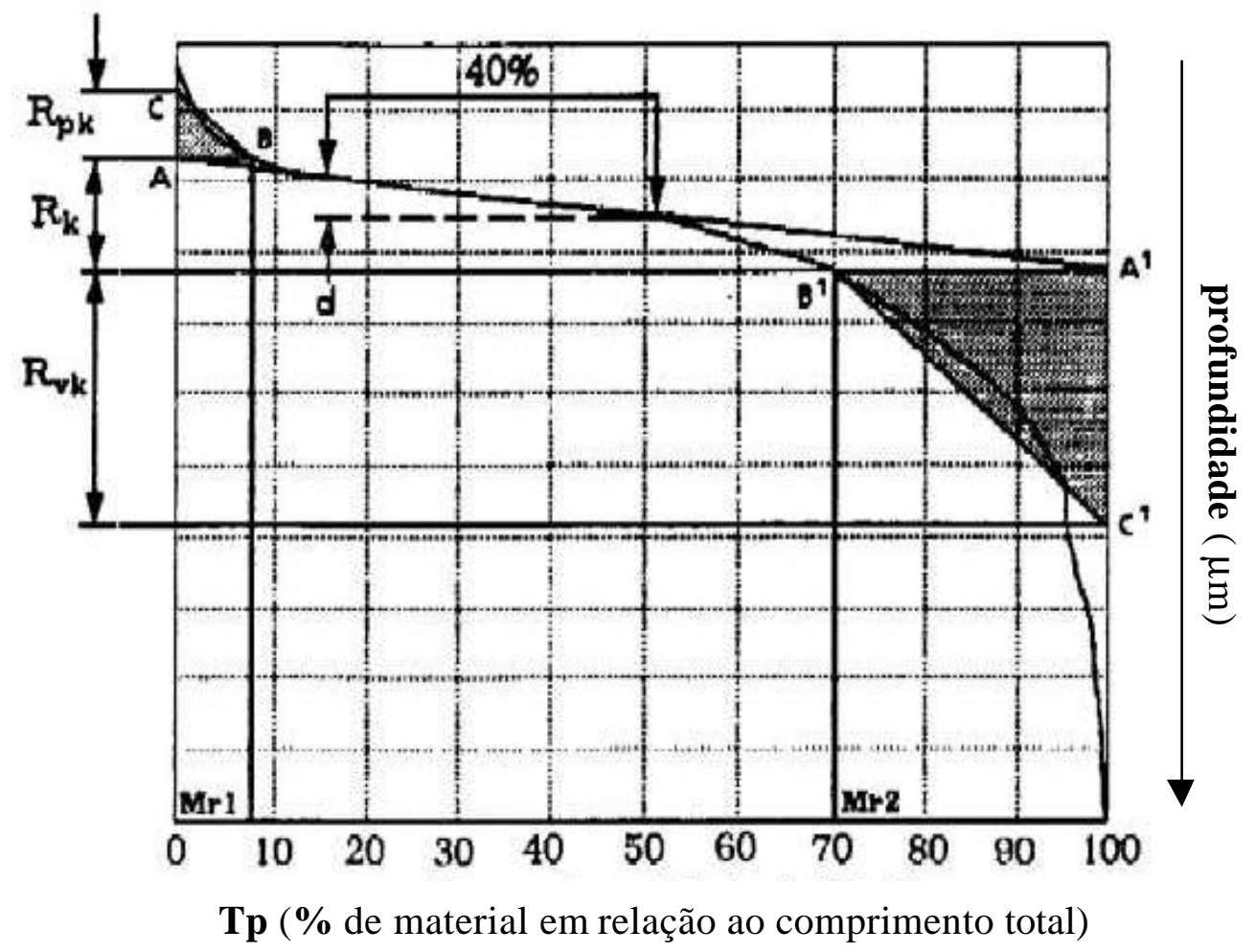

Fig.II.1- Curva de porcentagem de material em função da profundidade (“Curva Tp”) e parâmetros Rpk, Rk e Rvk de rugosidade. 
- R) q ou ) q é a inclinação do perfil

$R \Delta q=\sqrt{\frac{1}{L} \int_{a}^{1}(\theta(x)-\theta)^{2} d x}$

onde

$\theta=\frac{1}{L} \int_{0}^{L} \theta(x) d x$ e $2(x)$ é a inclinação do perfil na posição $x, 2(x)=* y /{ }^{*} x$

\begin{tabular}{|l|c|c|c|c|c|c|c|}
\hline \multicolumn{7}{|c|}{ Tabela II.2- Rugosidade medida no cilindro } \\
\hline & dir & $\begin{array}{c}\mathrm{Rq} \\
(: \mathrm{m})\end{array}$ & $\begin{array}{c}) \mathrm{q} \\
(1 /: \mathrm{m})\end{array}$ & $\begin{array}{c}\text { Dens. } \\
10^{9} / \mathrm{m}^{2}\end{array}$ & $\begin{array}{c}\text { Rpk } \\
(: \mathrm{m})\end{array}$ & $\begin{array}{c}\text { Rk } \\
(: \mathrm{m})\end{array}$ & $\begin{array}{c}\text { Rvk } \\
(: \mathrm{m})\end{array}$ \\
\hline \multirow{2}{*}{ novo } & $\mathrm{L}$ & 0,81 & 0,137 & 0,428 & 0,28 & 1,67 & 1,28 \\
\cline { 2 - 9 } & $\mathrm{T}$ & 0,67 & 0,078 & 0,144 & 0,17 & 1,41 & 1,02 \\
\hline \multirow{2}{*}{$1 / 2$} & $\mathrm{~L}$ & 0,67 & 0,126 & 0,380 & 0,15 & 1,18 & 1,26 \\
\cline { 2 - 9 } curso & $\mathrm{T}$ & 0,64 & 0,087 & 0,144 & 0,22 & 1,03 & 1,20 \\
\hline \multirow{2}{*}{ próx. } & $\mathrm{L}$ & 0,70 & 0,101 & 0,240 & 0,26 & 0,74 & 1,45 \\
\cline { 2 - 9 } topo & $\mathrm{T}$ & 0,68 & 0,097 & 0,149 & 0,90 & 0,93 & 1,23 \\
\hline \multirow{2}{*}{ PMS } & $\mathrm{L}$ & 2,58 & 0,151 & 0,104 & $*$ & $*$ & $*$ \\
\cline { 2 - 9 } & $\mathrm{T}$ & 1,37 & 0,112 & 0,045 & $*$ & $*$ & $*$ \\
\hline
\end{tabular}

* indica grandezas para as quais o equipamento não apresentou resultados.

Nota-se pelos valores de Rvk e Rpk que o cilindro apresenta vales mais profundos que a altura dos picos. Grosseiramente, enquanto os vales apresentam profundidades da ordem de 
mais de $1: \mathrm{m}$, os picos são da ordem de $0,2: \mathrm{m}$. Em virtude do acabamento original ter sido preservado, a rugosidade praticamente é a mesma nas várias posições e ainda próxima de quando novo. Entretanto, quando se observa os valores de Rpk, os valores parecem indicar uma diminuição da altura dos picos no sentido longitudinal e um aumento no sentido transversal. Na região de PMS, o cilindro apresenta uma pequena faixa espelhada, bem como um desgaste localizado como exemplificado na fig.5.29, o que produziu um alto valor de Rq.

Já o anel de $1^{\circ}$ canalete, apresenta nítida diferença entre o acabamento quando novo e após o ensaio, já que como vimos, o desgaste removeu completamente o acabamento original da face de contato. A superfície após ensaio é mais lisa que quando nova.

Tabela II.3- Rugosidade medida no $1^{\circ}$ anel em GNS + CrN

\begin{tabular}{|l|c|c|c|c|c|c|c|}
\hline & dir & $\begin{array}{c}\mathrm{Rq} \\
(: \mathrm{m})\end{array}$ & $\begin{array}{c}) \mathrm{q} \\
(1 /: \mathrm{m})\end{array}$ & $\begin{array}{c}\text { Dens. } \\
10^{9} / \mathrm{m}^{2}\end{array}$ & $\begin{array}{c}\text { Rpk } \\
(: \mathrm{m})\end{array}$ & $\begin{array}{c}\text { Rk } \\
(: \mathrm{m})\end{array}$ & $\begin{array}{c}\text { Rvk } \\
(: \mathrm{m})\end{array}$ \\
\hline \multirow{2}{*}{ novo } & $\mathrm{L}$ & 0,45 & 0,172 & 0,076 & 0,54 & 0,45 & 0,59 \\
\cline { 2 - 8 } & $\mathrm{T}$ & 0,39 & 0,165 & 0,361 & 0,67 & 0,52 & 0,43 \\
\hline \multirow{2}{*}{$750 \mathrm{~h}$} & $\mathrm{~L}$ & 0,04 & 0,008 & - & 0,03 & 0,09 & 0,03 \\
\cline { 2 - 8 } & $\mathrm{T}$ & 0,22 & 0,010 & - & 0,04 & 0,08 & 0,03 \\
\hline
\end{tabular}

Foi feita uma tentativa de cálculo dos parâmetros $F, 0$, \$ utilizando o arquivo texto com o perfil de rugosidade, não filtrado, que o equipamento disponibiliza, através da seguinte metodologia:

- Para excluir os desvios de forma e fixação, a linha média foi calculada subtraindo-se a regressão, linear ou polinomial, do próprio sinal. A linha média adotada para cálculo dos 
momentos espectrais foi colocada na posição de deslocamento (y) nulo. A fig. II.2 mostra os valores de (x,y) do cilindro quando novo. A fig. II.3 mostra o mesmo perfil após filtragem, conforme descrito. A fig. II.4 mostra um trecho da fig. II.3, mas agora usando a mesma ampliação nos dois eixos, visualizando quão "suaves" são as asperezas na realidade.

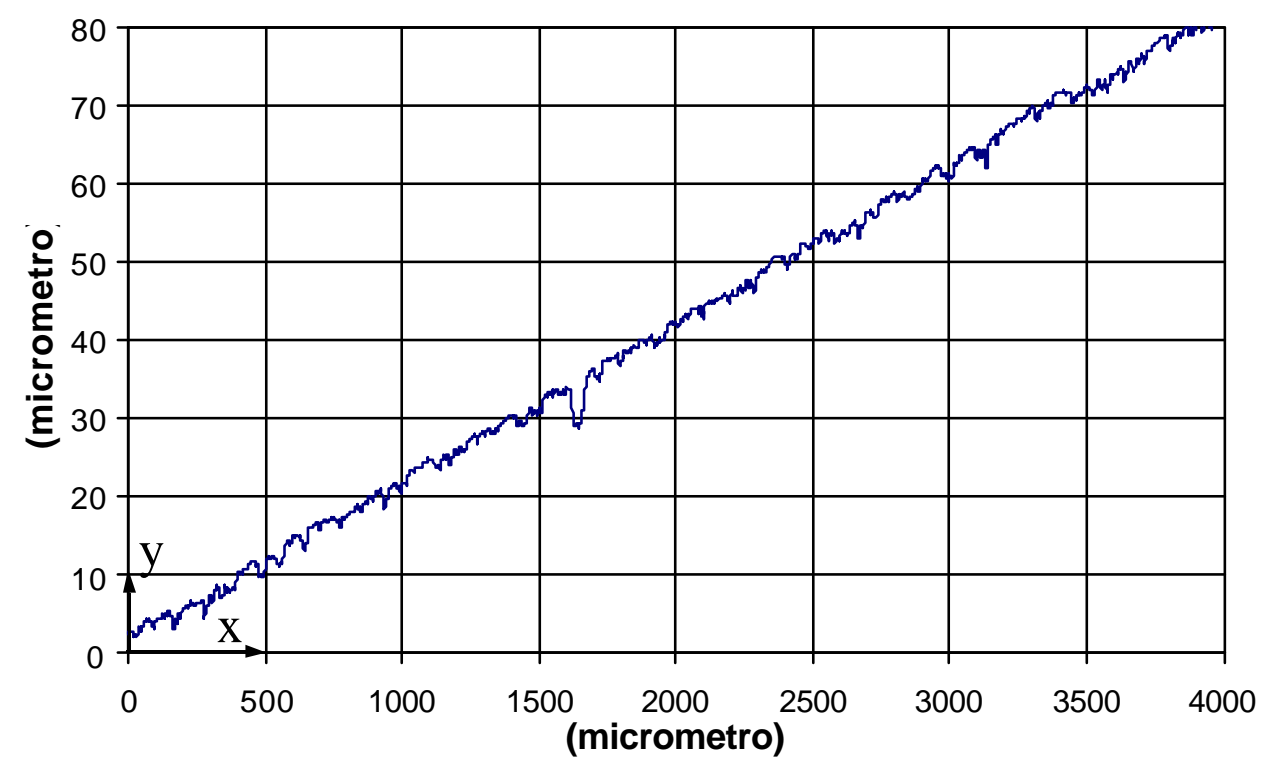

Fig.II.2- Perfil de rugosidade, não filtrado, cilindro quando novo, direção longitudinal.

- dy/dx e $\left(d^{2} y / d x^{2}\right)$ foram calculados pela regra de "derivada por 3 pontos":

$$
\begin{gathered}
\left(\frac{d y}{d x}\right)_{i}=\frac{1}{3} \sum_{j+1}^{i+1}\left(\frac{y_{j}-y_{j-1}}{x_{j}-x_{j+1}}\right) \\
\left(\frac{d^{2} y}{d x^{2}}\right)_{i}=\frac{1}{3} \sum_{j+1}^{i+1}\left(\frac{\left(\frac{d y}{d x}\right)_{j}-\left(\frac{d y}{d x}\right)_{j+1}}{x_{j}-x_{j-1}}\right)
\end{gathered}
$$




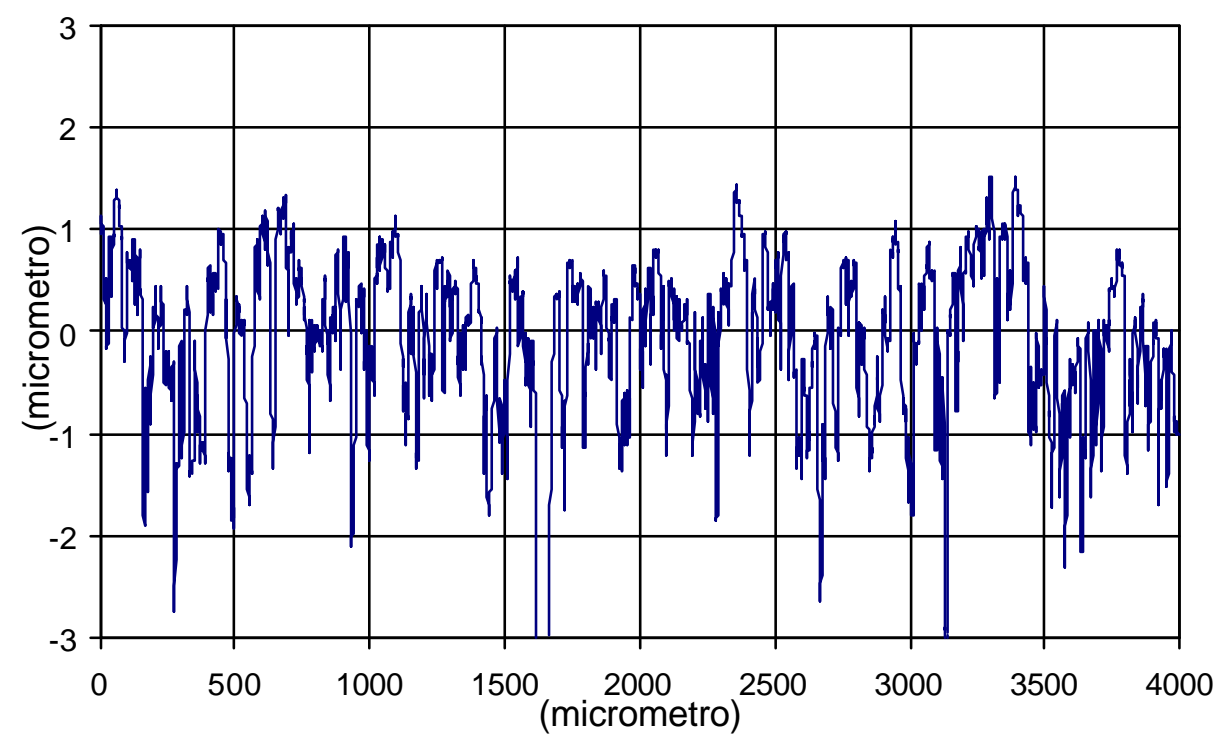

Fig.II.3- Perfil de rugosidade, após filtragem numérica, cilindro quando novo, direção longitudinal.

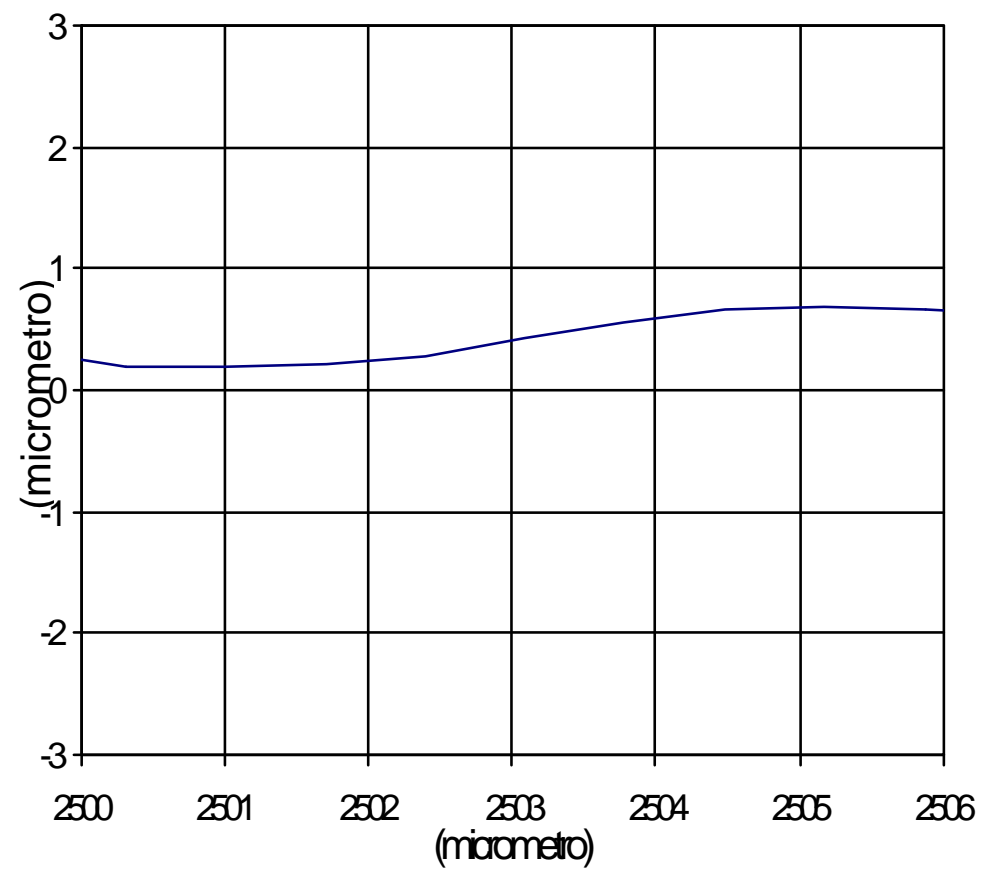

Fig.II.4- Trecho do perfil anterior (fig. II.3), trazido agora para uma mesma ampliação nos dois eixos. 
A tabela II.4 mostra alguns valores calculados pela regra acima, bem como a diferença de $\mathrm{F}$ com os valores de $\mathrm{Rq}$ medidos pelo equipamento. Embora os valores de $\mathrm{F}$ tenham concordado razoavelmente com os medidos, os de 0 diferem em uma ordem de grandeza dos medidos. Tentou-se também o cálculo das derivadas por 5 pontos, mas os valores obtidos não foram muito diferentes dos apresentados com 3 pontos e essa tentativa de se calcular os parâmetros de GW foi abandonada, optando-se por adotar no modelo os valores de ARCOUMANIS et al (1997).

\begin{tabular}{|c|c|c|c|c|c|c|c|c|c|}
\hline \multicolumn{7}{|c|}{ Tabela II.4- Valores Calculados a partir do perfil de rugosidade } \\
\hline \multirow{2}{*}{ cilindro } & \multirow{2}{*}{ dir } & $\mathrm{m}_{0}$ & $\mathrm{~m}_{2}$ & $\mathrm{~m}_{4}$ & \multicolumn{2}{|c|}{$(: \mathrm{m})$} & $10^{9} \mathrm{~m}^{-2}$ & $(: \mathrm{m})$ & \\
\cline { 5 - 11 } & & & & & calc & $\begin{array}{c}\text { calc/ } \\
\text { med }\end{array}$ & calc & calc & calc \\
\hline \multirow{2}{*}{ novo } & $\mathrm{L}$ & 0,7854 & 0,0150 & 0,00370 & 0,89 & 1,10 & 7,57 & 10,93 & 0,07 \\
\cline { 2 - 11 } & $\mathrm{T}$ & 0,7208 & 0,0050 & 0,00098 & 0,85 & 1,27 & 6,07 & 21,21 & 0,11 \\
\hline \multirow{2}{*}{$1 / 2$} & $\mathrm{~L}$ & 0,5129 & 0,0125 & 0,00308 & 0,72 & 1,08 & 7,55 & 11,98 & 0,07 \\
\cline { 3 - 10 } & $\mathrm{T}$ & 0,5346 & 0,0050 & 0,00190 & 0,73 & 1,14 & 8,46 & 17,91 & 0,11 \\
\hline
\end{tabular}

Pela sua importância na caracterização de superfícies rugosas, sugere-se como trabalho futuro o desenvolvimento de técnicas para obtenção dos parâmetros de G-W, o que parece envolver principalmente a aquisição do perfil de rugosidade com maior resolução. 


\section{ANEXO III - Programa fonte para cálculo das pressões rugosas e subrotinas de acumulo de dano e remoção de material.}

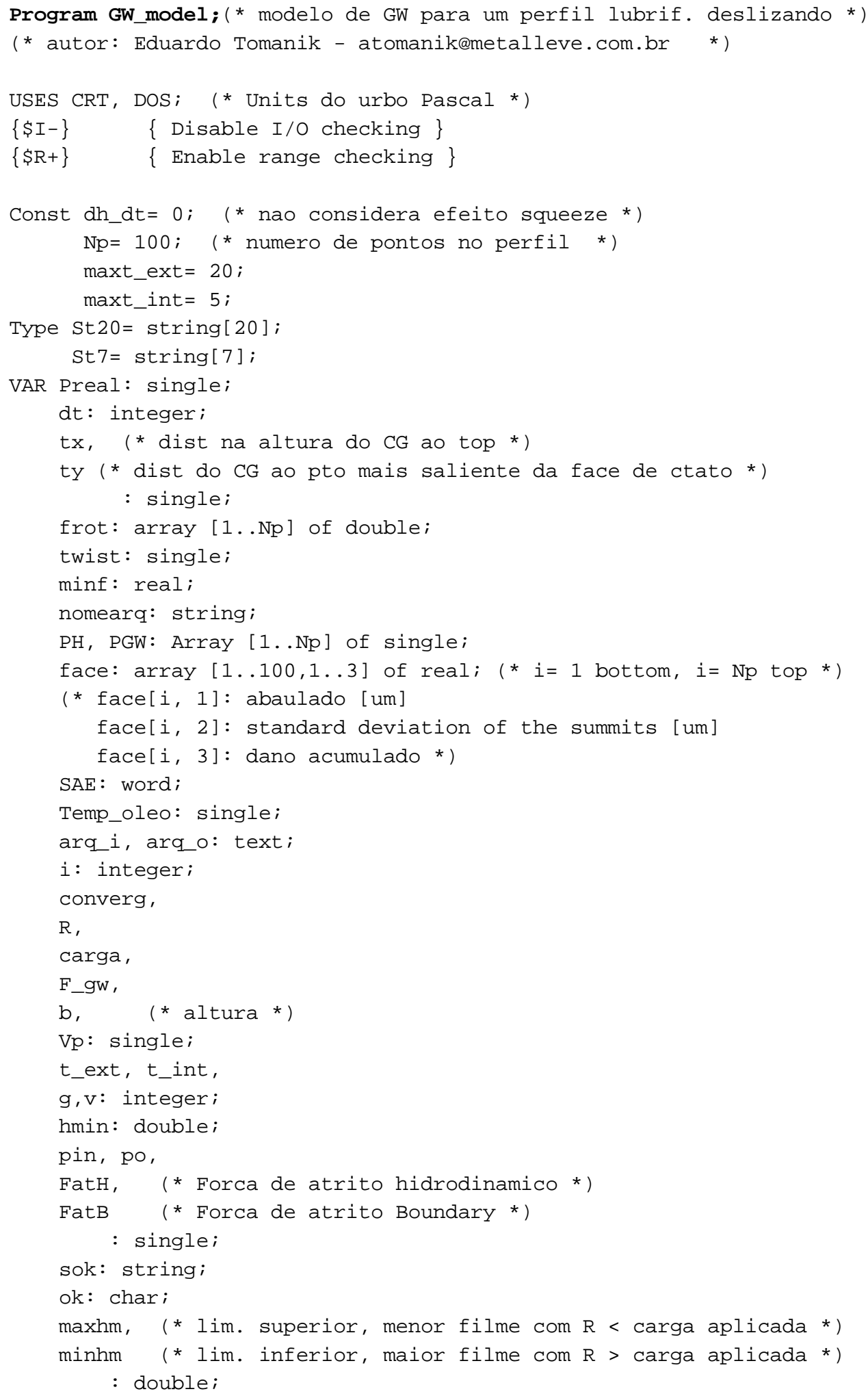




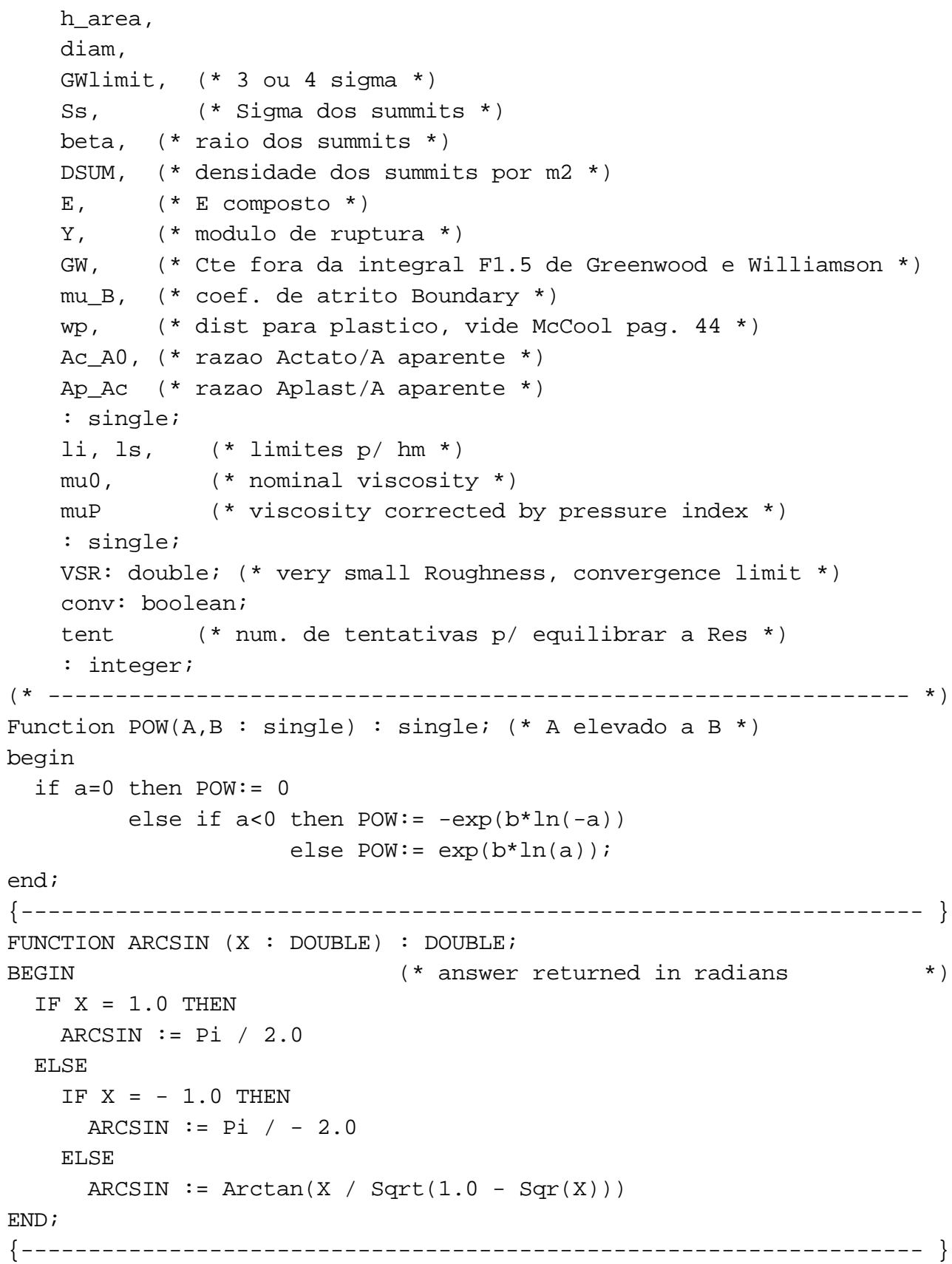

Function Viscosidade (grade: shortint; $\mathrm{T}$ : single): single;

(* Vogel equation, $\mathrm{T}$ em C, visc. em Pas.s *)

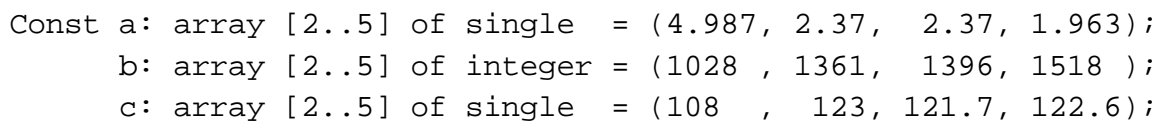




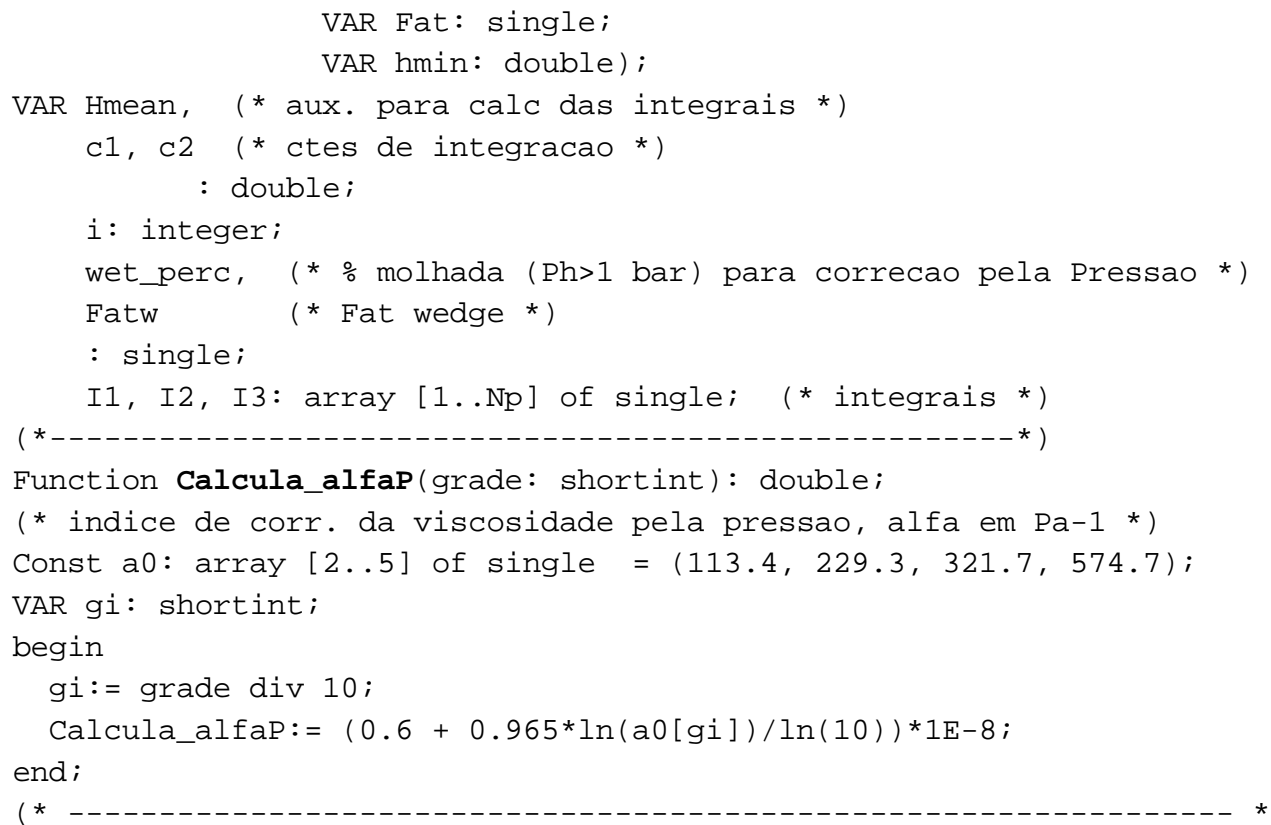

Function Pres_ef (P: single): single;

VAR aux: single;

begin

Pres_Ef $:=\exp ($ Calcula_alfaP $(\mathrm{SAE}) * \mathrm{P})$;

end;

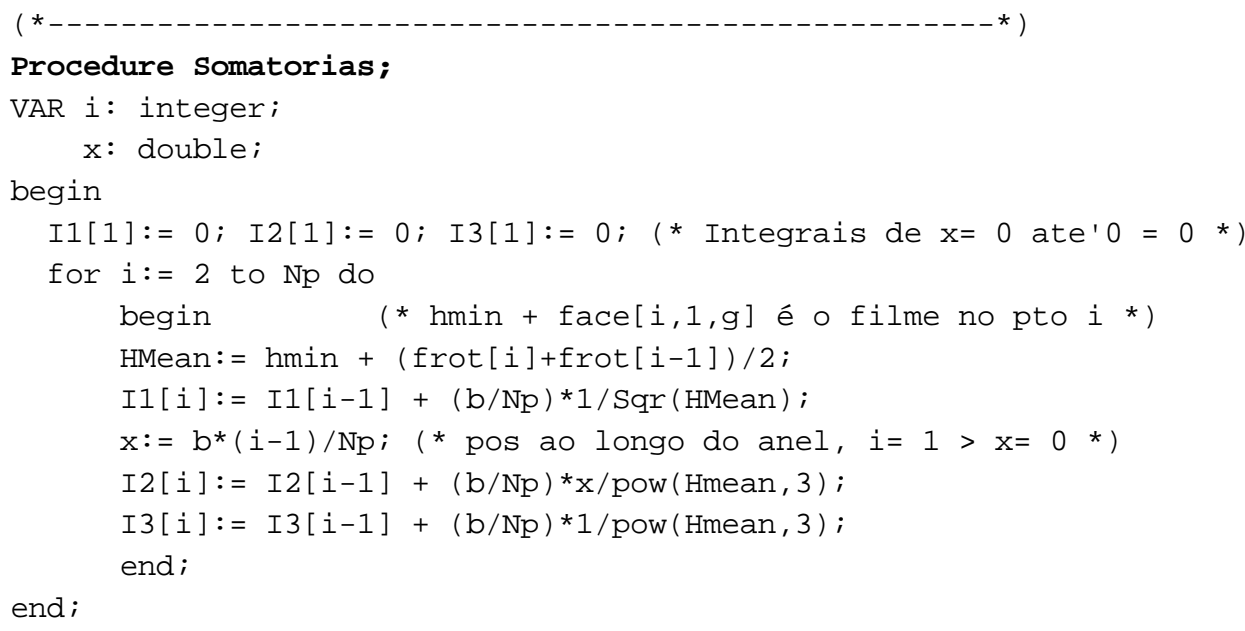

Function Px (k: byte) : single; (* $\mathrm{PH}=f(\mathrm{x})$ segundo Reynolds *)

VAR aux: single;

begin

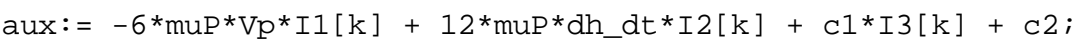

if aux $<=0$ then $\mathrm{Px}:=0 \quad(* \mathrm{dPx} / \mathrm{dx}$ tambem *)

else Px:= aux

end;

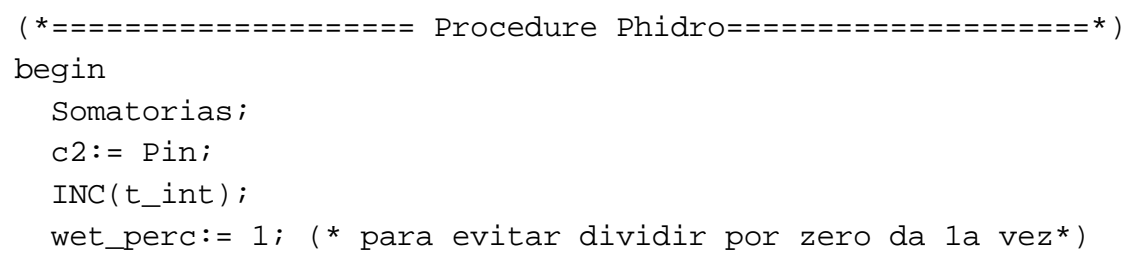




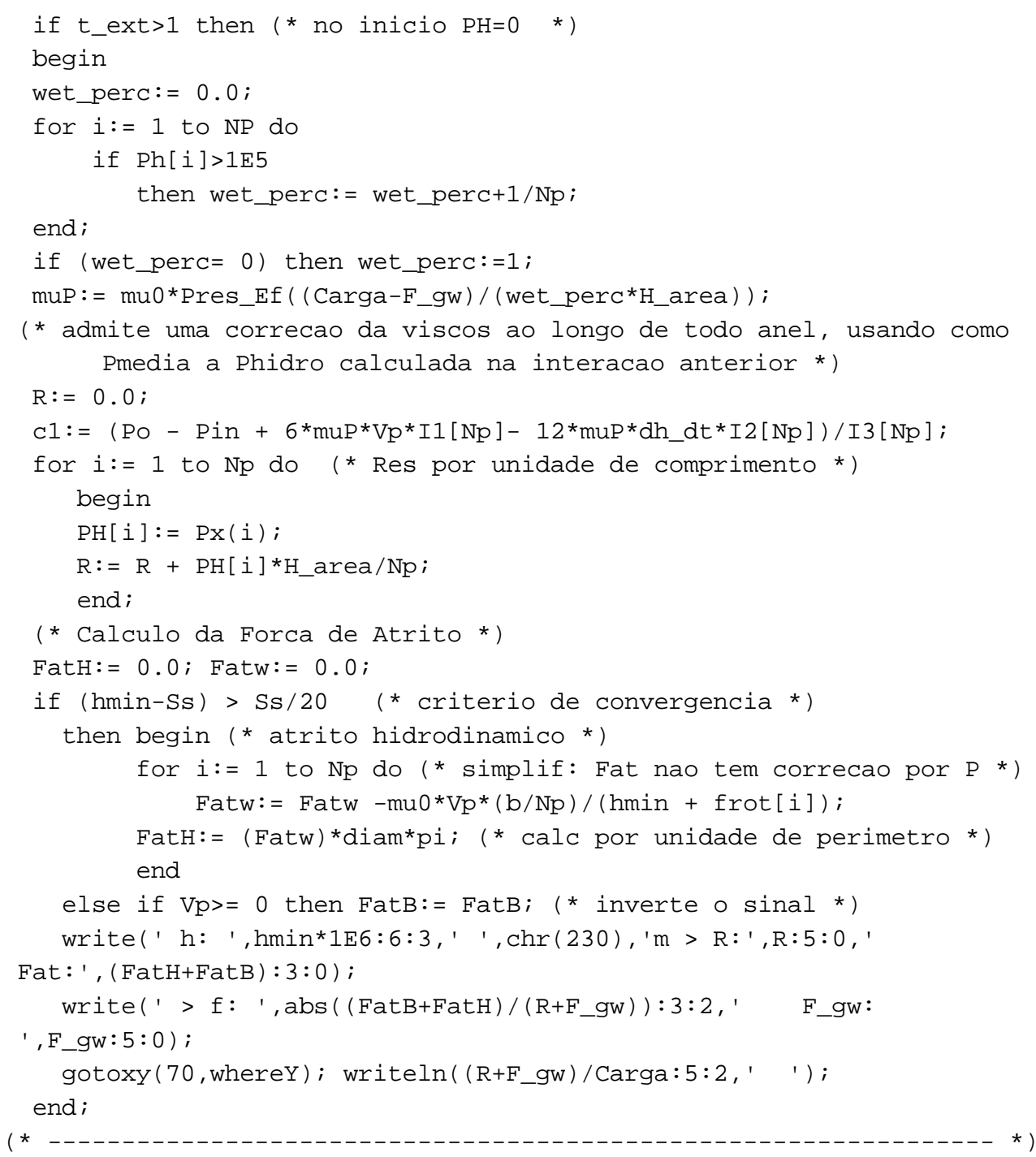

Function Fo(t: double): double;

begin

if $t<3$

then $\mathrm{F} 0:=-7.97644 \mathrm{E}-5 *$ pow $(t, 6)+4.70151 \mathrm{E}-3 *$ pow $(t, 5)-3.93940 \mathrm{E}-2 *$ pow $(t, 4)$ $+1.10974 \mathrm{E}-1 * \operatorname{pow}(t, 3)-2.26998 \mathrm{E}-2 * \operatorname{pow}(t, 2)-3.94608 \mathrm{E}-1 * t+4.99873 \mathrm{E}-1$ else $F 0:=111.24 * \exp (-3.7522 * t)$; end; (*

Function F1(t: double): double;

begin

if $t<3$

then $F 1:=-7.163 e-4 *$ pow $(t, 6)+7.86431 e-3{ }^{*}$ pow $(t, 5)-2.83941 e-2 *$ pow $(t, 4)$ $+9.21055 e-3 *$ pow $(t, 3)+1.95747 e-1 *$ pow $(t, 2)-4.99283 e-1 * t+3.98891 e-1$ else $F 1:=62.041 * \exp (-3.9792 * t)$; end;

(*

Function F3_2(t: double): double; (*F3/2*)

begin

if $t<3$

then F3_2:= $-6.85507 \mathrm{E}-4{ }^{*}$ pow $(t, 6)+6.22034 \mathrm{E}-3 *$ pow $(t, 5)-1.25047 \mathrm{E}-2 *$ pow $(t, 4)$ 
$-5.59306 \mathrm{E}-2 *$ pow $(t, 3)+3.2596 \mathrm{E}-1 *$ pow $(t, 2)-6.17398 \mathrm{E}-1 * t+4.29964 \mathrm{E}-1$ else F3_2:=58.788*exp $\left(-4.085^{*} t\right)$;

end;

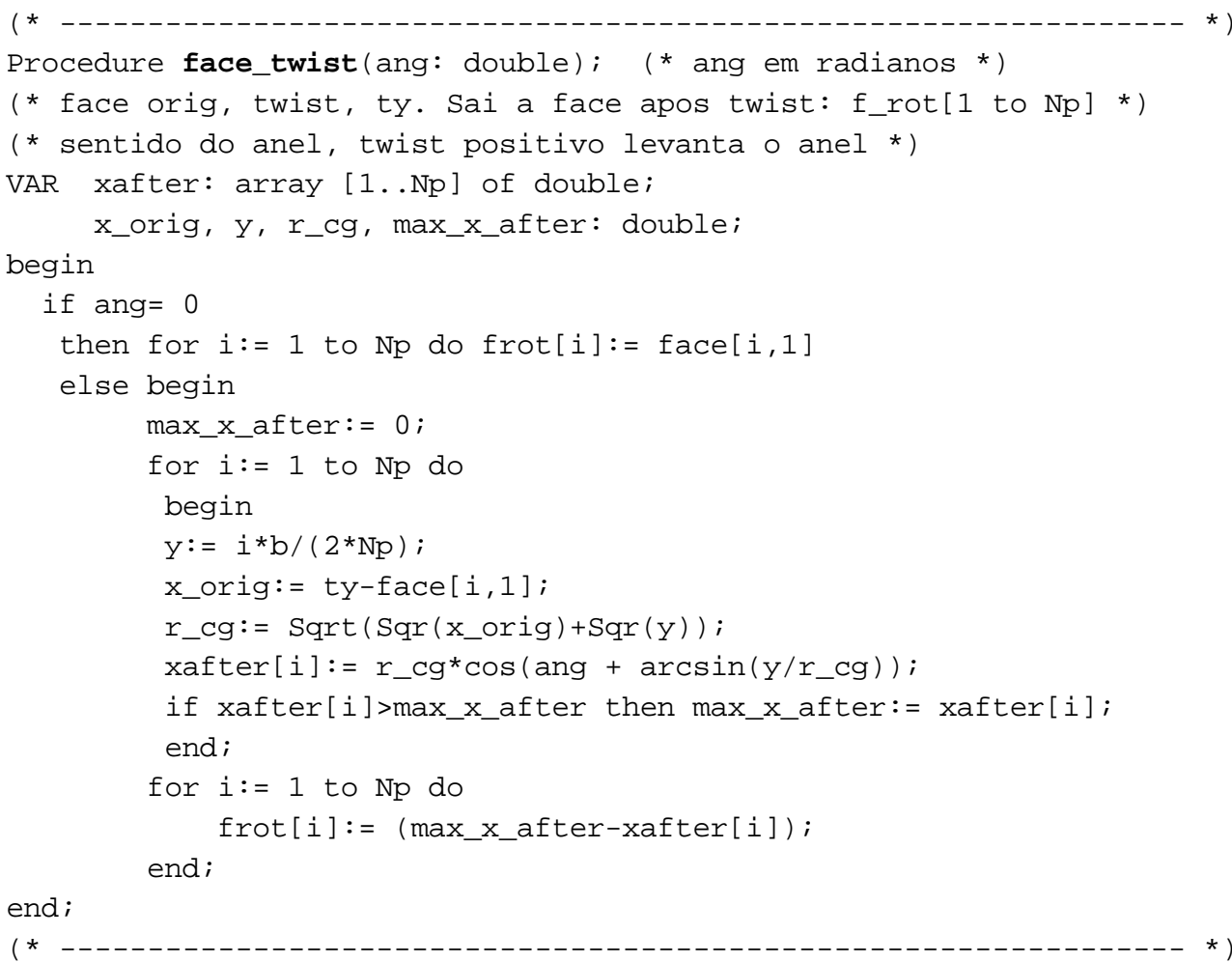

\section{Procedure Entra_Dados;}

VAR lixo: integer;

alt: array [1..Np] of single; (* tem no arq mas nao e'usado *) begin

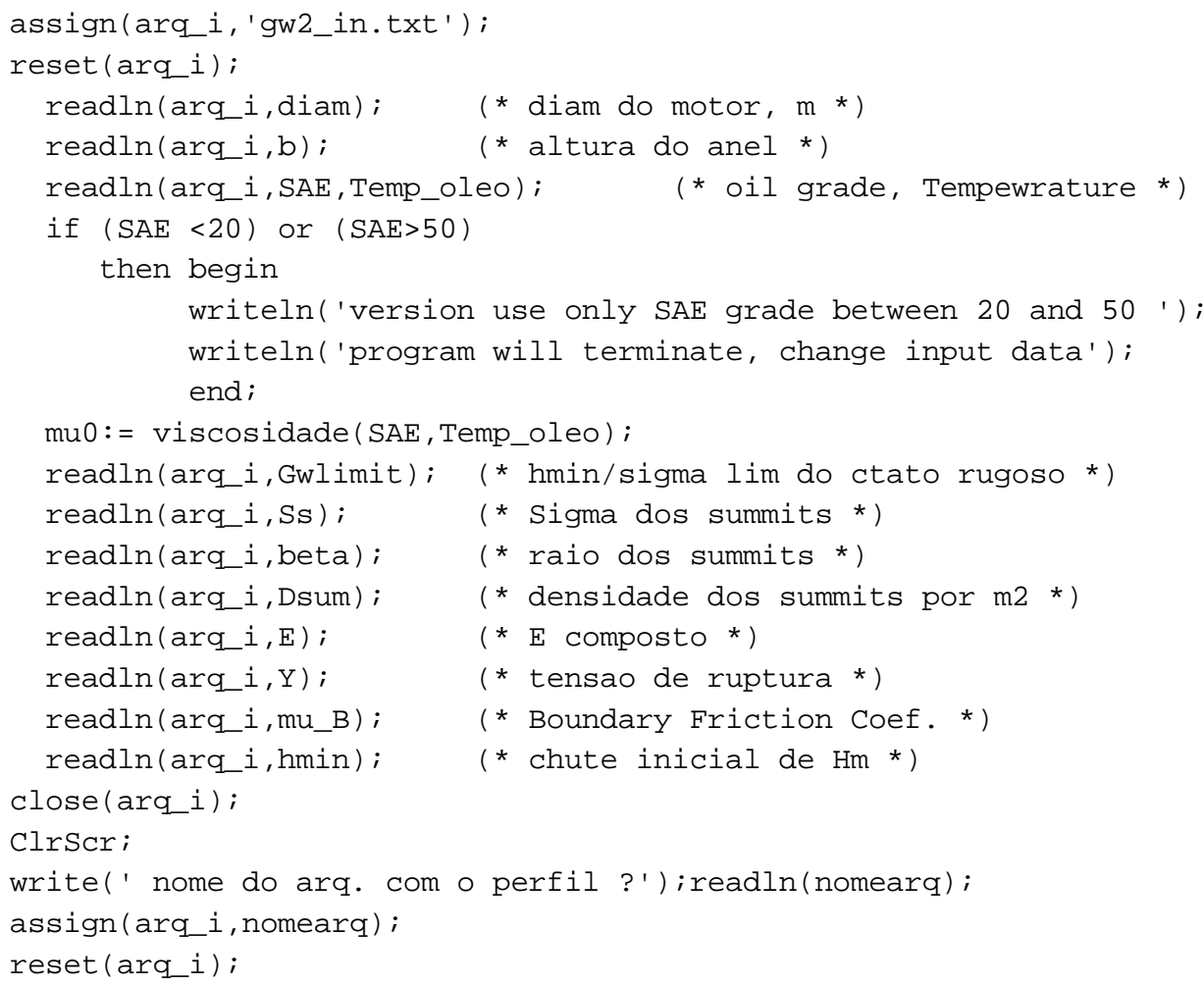




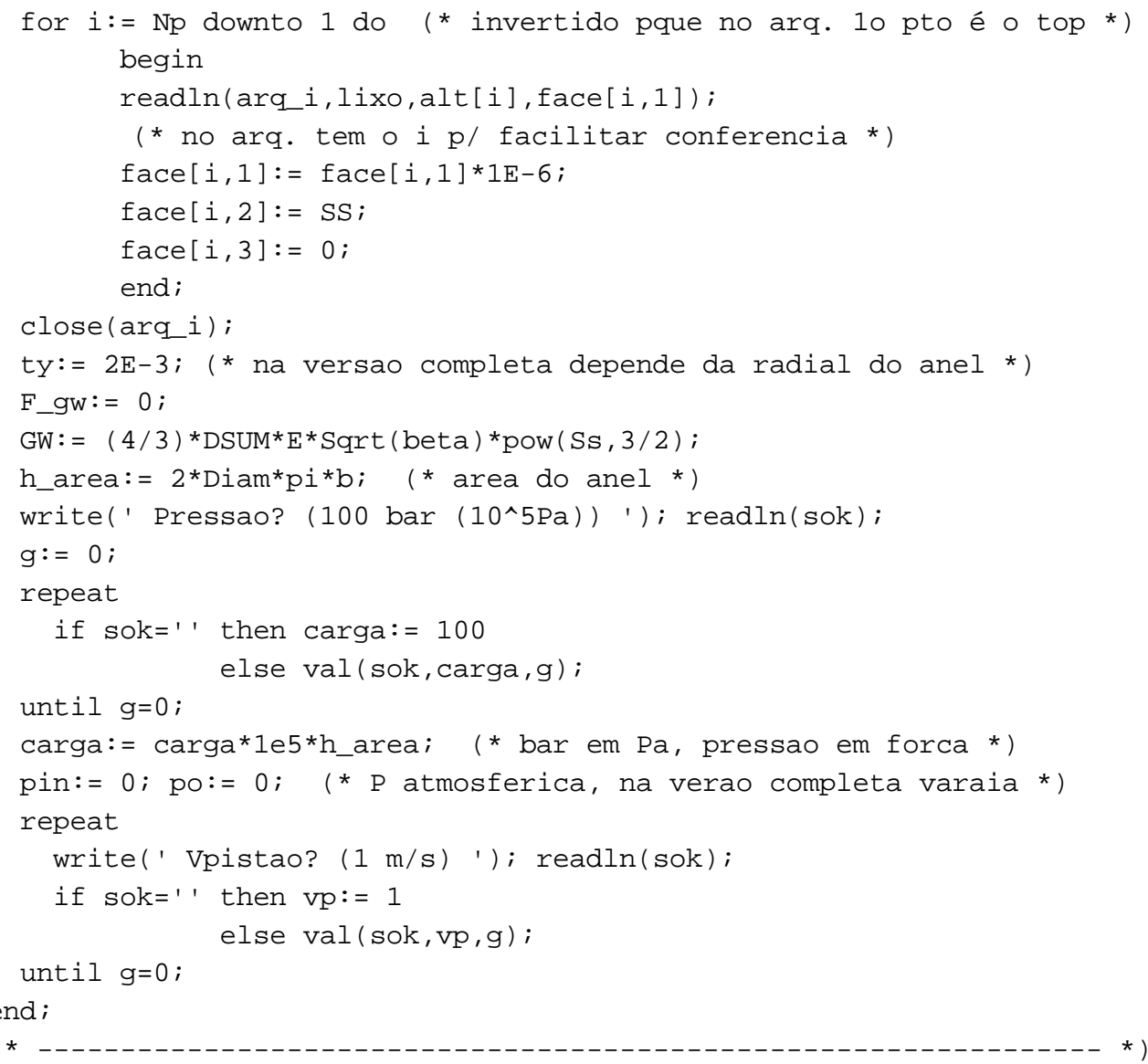

Procedure Calc_GW (hmin,Ss: double; carga: single; Var F_gw, Fat_gw:single);

VAR i, (* contador do indice da face, 1 a Np pontos *)

kt (* contador de fatias com contato para calc. do Ac_A0 *) : shortint;

Hx, (* dist. do perfil no pto $x$ ao plano *)

t (* razao H_x/Ss *)

: double;

begin

F_gw: $=0$;

FatB: $:=0$;

$k t:=0 ;$ AC_A0 $:=0 ;$ Ap_AC: $=0$;

for $i:=1$ to $\mathrm{Np}$ do

begin

$\mathrm{Hx}:=$ hmin + frot $[i] ;$

$t:=\mathrm{Hx} /$ face $[i, 2] ;$ (* face $[i, 2]$ é o Ss combinado *)

if $t<G W l i m i t$ then

begin

$\mathrm{kt}:=\mathrm{kt}+1$;

PGW $[i]:=G W^{\star} F 3 \_2(t)$;

if $\mathrm{PGW}[i]>3 * \mathrm{Y}$ then $\mathrm{PGW}[i]:=3 * \mathrm{Y}$; (* plastic limit *)

Ap_Ac: $=$ Ap_AC $+(F 1(t+w p) / F 1(t)) / N p ;$

F_gw: $: F \_g w+P G W[i]$;

if $V p<>0$ then FatB:= FatB + mu_B*PGW[i];

$A C \_A 0:=A C \_A 0+p i *$ Beta*face $[i, 2] * D S u m * F 1(t) ;$

end;

end; 


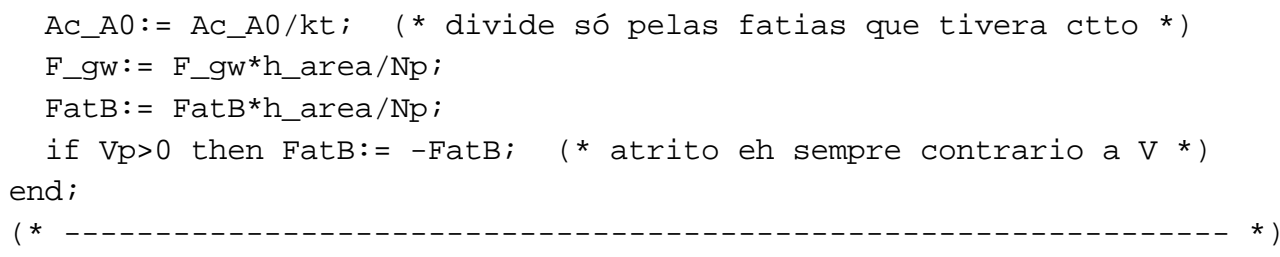

\section{PROCEDURE INICIO;}

VAR i: integer;

begin

VSR:= Ss/100; (* minimo p/ conv., aliviado se nao tiver ctato *)

if carga/100<= 1 then converg:= 1

else converg:= carga/100;

$g:=1$

conv: $=$ false

$l i:=0.75 * \mathrm{hmin} ;$

ls: $=1.25 * \mathrm{hmin} ;$

$\operatorname{minhm}:=0$;

$\operatorname{maxhm}:=50 * 1 \mathrm{E}-6$

$\mathrm{wp}:=6.4 *($ Beta/Ss $) *$ pow $(\mathrm{Y} / \mathrm{E}, 2) ;$ (* plastic compliance *)

end;

(*

begin

Entra_Dados;

Inicio;

write(' ang. de twist (em graus )? '); readln(twist);

twist: $=$ pi*twist $/ 180 ; \quad$ (* converte para radianos ${ }^{*}$ )

conv: = false;

t_ext:=0;

face_twist(twist); (* calc. o abaulado rotacionado *)

repeat (* tent. ext *)

INC (t_ext);

t_int: $=0$;

repeat (* tent. int *)

if $(\mathrm{hmin} / \mathrm{Ss})<$ GWlimit

then Calc_GW (hmin, Ss, carga, F_gw, FatB);

if (Vp $<>0)$ AND $(\mathrm{mu} 0<>0)$

(* Phidro(anel, ang, Vpistao, Pi, Po, Carga, VAR: Fat,hmin) *)

then Phidro(1, 2, Vp, Pin, Po, Carga, FatH, hmin)

else $\mathrm{R}:=0$;

if abs (R-(carga-F_gw)) <converg

then conv: $=$ true

else begin

if $R>$ (carga-F_gw)

then begin

$l i:=$ hmin

$\operatorname{minhm}:=1 i$

end

else begin

ls: $=$ hmin

$\operatorname{maxhm}:=1 \mathrm{~s} ;$

end;

$h \min :=(1 s+l i) / 2$

end;

until (t_int>maxt_int) or (ls-li<=VSR) or (conv=true);

if $(R>($ carga-f_gw) $)$ 


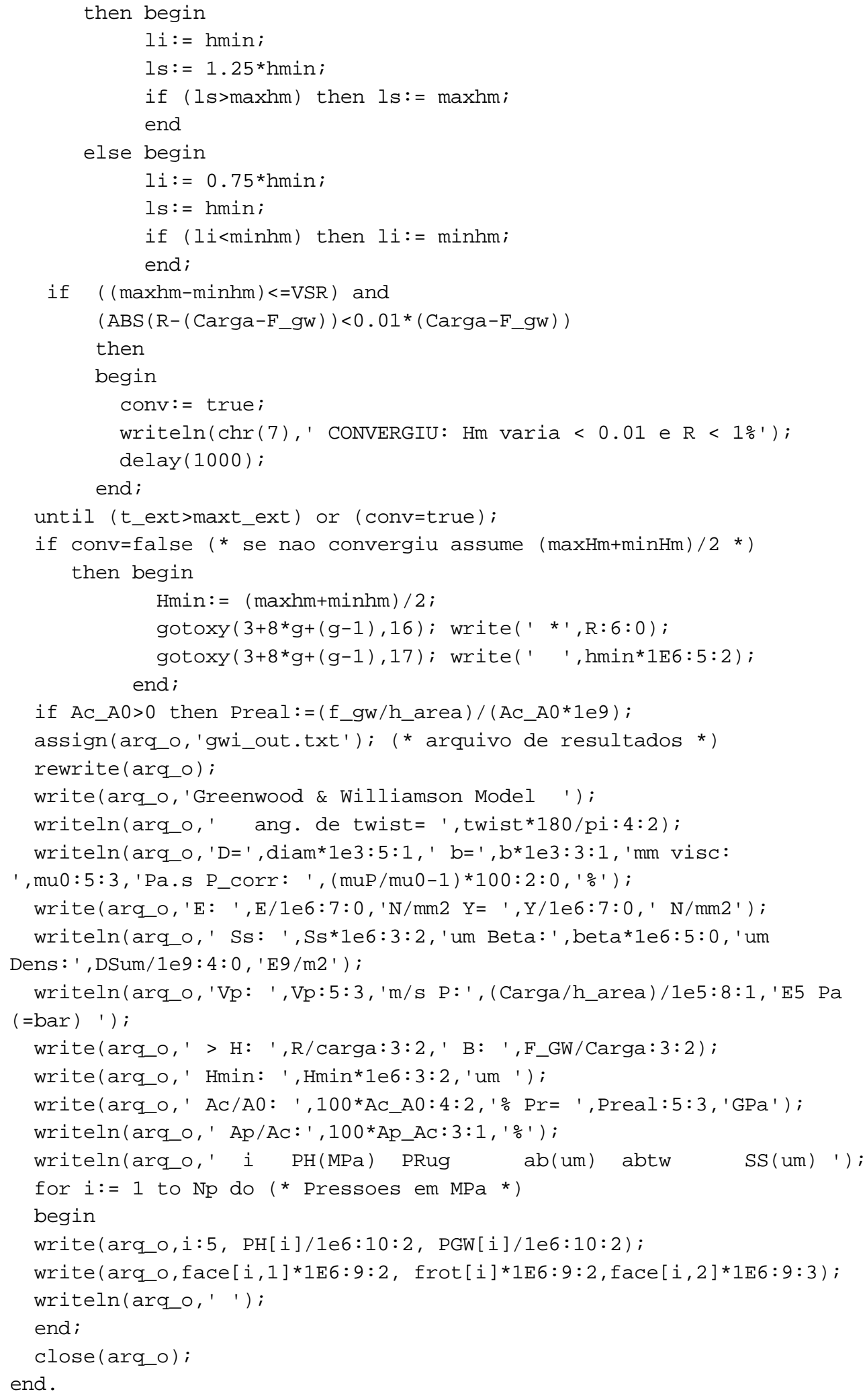




\section{Procedure Acumula_dano;}

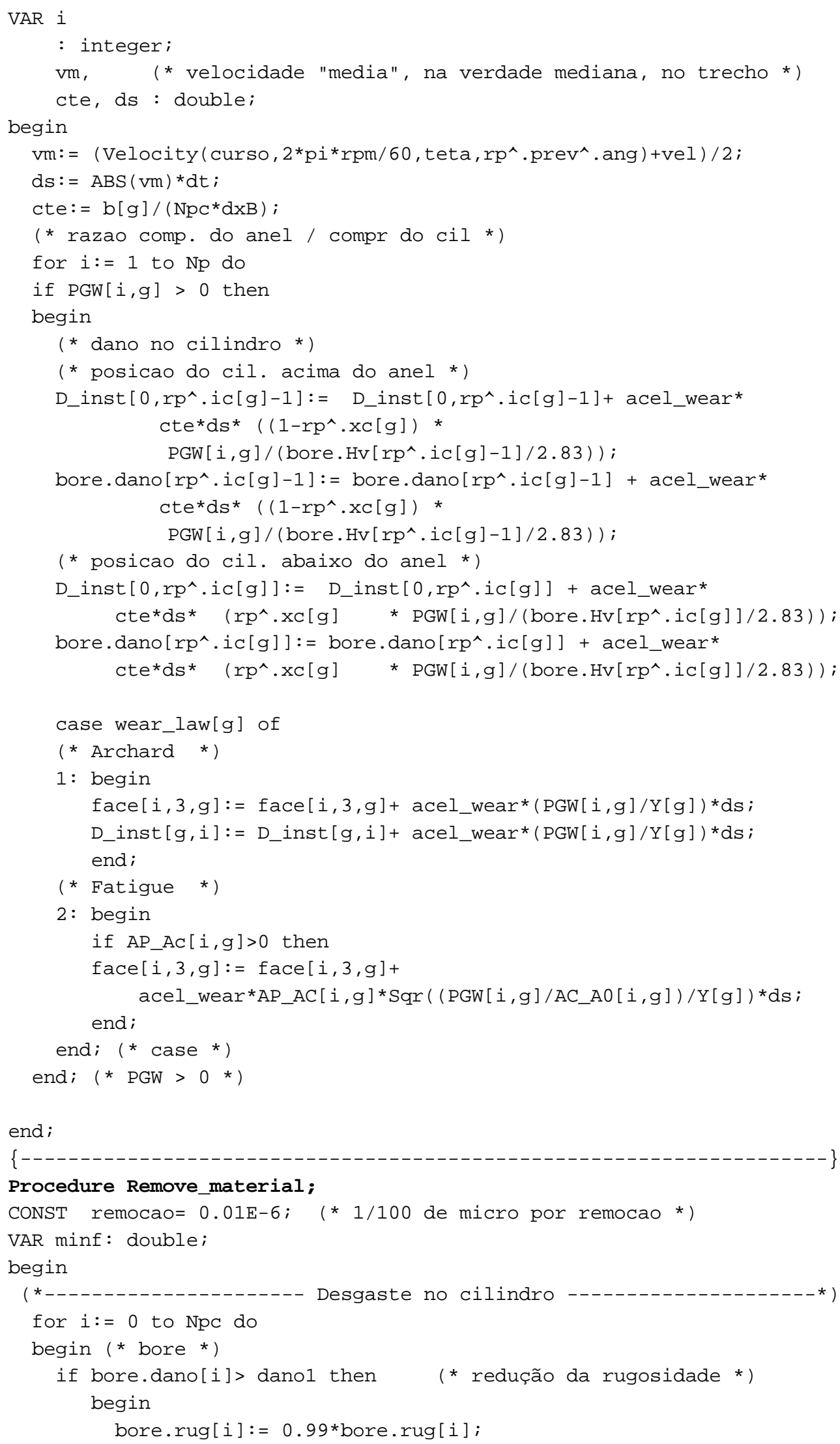




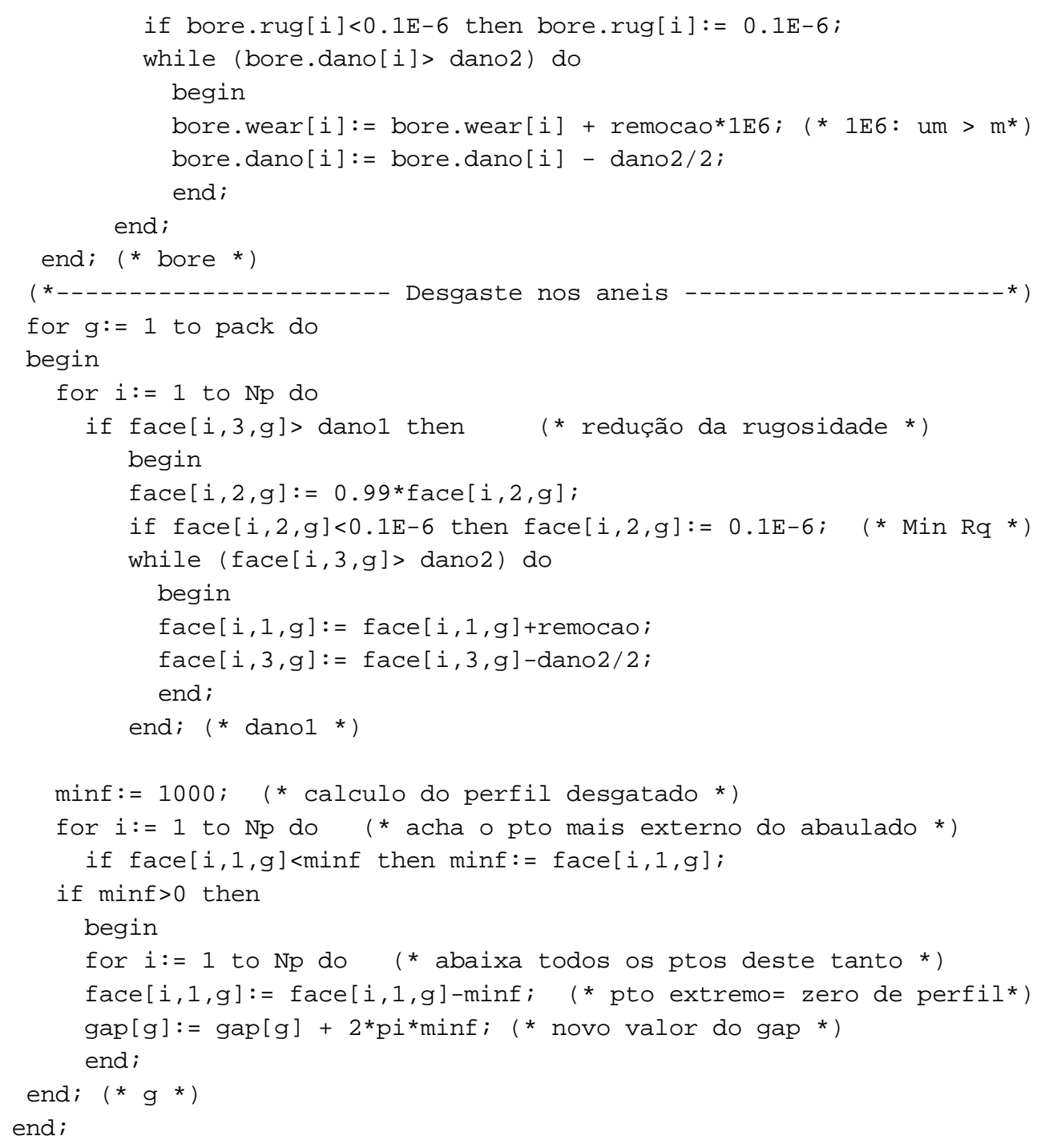

